VICTOR BARBOSA FELIX

ANÁLISE EXPERIMENTAL DA INFLUÊNCIA DE SISTEMA DE VENTILAÇÃO PERSONALIZADA NA CONCENTRAÇÃO, DISPERSÃO E REMOÇÃO DE PARTÍCULAS EXPIRATÓRIAS EM CABINE DE AERONAVE COM SISTEMA DE VENTILAÇÃO POR MISTURA E POR DESLOCAMENTO 
VICTOR BARBOSA FELIX

\section{ANÁLISE EXPERIMENTAL DA INFLUÊNCIA DE SISTEMA DE VENTILAÇÃO PERSONALIZADA NA CONCENTRAÇÃO, DISPERSÃO E REMOÇÃO DE PARTÍCULAS EXPIRATÓRIAS EM CABINE DE AERONAVE COM SISTEMA DE VENTILAÇÃO POR MISTURA E POR DESLOCAMENTO}

Tese de Doutorado apresentada à Escola Politécnica da Universidade de São Paulo para obtenção do título de Doutor em Ciências

Área de concentração:

Engenharia Mecânica

Orientador:

Prof. Dr. Arlindo Tribess 
Autorizo a reprodução e divulgação total ou parcial deste trabalho, por qualquer meio convencional ou eletrônico, para fins de estudo e pesquisa, desde que citada a fonte.

Este exemplar foi revisado e alterado em relação à versão original, sob responsabilidade única do autor e com anuência de seu orientador. São Paulo, 20 de maio de 2019

Assinatura do autor

Assinatura do orientador

Catalogação-na-publicação

Felix, Victor Barbosa

Análise experimental da influência de sistema de ventilação personalizada na concentração, dispersão e remoção de partículas expiratórias em cabine de aeronave com sistema de ventilação por mistura e por deslocamento/ V. B. Felix, ed. rev., São Paulo, 2019.

$135 \mathrm{p}$.

Tese (Doutorado) - Escola Politécnica da Universidade de São Paulo. Departamento de Engenharia Mecânica.

1. Qualidade do ar 2. Ventilação 3. Sistema de ventilação personalizada 4. Dispersão de partículas 5. Cabine de aeronave I. Universidade de São Paulo. Escola Politécnica. Departamento de Engenharia Mecânica II. $\mathrm{t}$ 
À minha amada esposa Katarina e aos meus amados filhos Arthur e Vitória Helena, por todo amor e carinho que são tão essenciais para minha vida.

Aos meus pais, José de Souza Felix Neto e Maria Aparecida Barbosa Felix, com todo meu amor e gratidão.

À minha irmã Valéria (in memorian) que sempre estará comigo. 


\section{AGRADECIMENTOS}

Ao meu orientador, Prof. Dr. Arlindo Tribess, pelo companheirismo e paciência, que ao longo desses anos muito me ensinou, contribuindo para meu crescimento intelectual, profissional e pessoal.

À Prof. Dra. Brenda Chaves Coelho Leite e ao Prof. Dr. Flávio Augusto Sanzovo Fiorelli pelas relevantes contribuições para o aprimoramento deste trabalho.

Ao amigo Eng. Douglas Fabichack Jr. pela ajuda prestada nos ensaios experimentais e na elaboração da Tese e pela amizade e companheirismo ao longo desses anos.

Aos colegas do laboratório de Conforto Térmico e Qualidade do Ar do Departamento de Engenharia Mecânica da Escola Politécnica da USP, que me ajudaram na realização deste trabalho, dentre eles, agradeço ao Eng. Paulo Celline, o Físico José Carlos Orsi Morel, ao Técnico Sidney Castilho Alves, ao Eng. Sandro Tavares Conceição e ao Eng. Rogério Vilain.

Aos colegas do programa de Pós-Graduação em Engenharia Mecânica da EPUSP

Aos colegas docentes e funcionários da Universidade Cruzeiro do Sul, dentre eles os amigos Prof. Mestre Robmilson Simões Gundim, Prof. Ms. Adriano Mendanha, Prof. Ms. Uerley Magalhães Franchi, a Enga ${ }^{a}$ Luciana Cristiane Cassolin da Silva, a Secretária Mariana Oliveira da Silva e a Secretária Débora Balista Souza pelas contribuições para a realização desse trabalho.

Ao Insper - Instituto de Educação e Pesquisa pelo apoio enquanto Docente.

Ao Prof. Ms. Israel Ferreira Alves por toda ajuda, apoio e amizade que foram essenciais para a realização desse trabalho.

A todos que colaboraram na realização deste trabalho. 


\section{RESUMO}

As pessoas estão cada vez mais viajando de avião e, muitas vezes, em viagens longas. A qualidade do ar torna-se uma questão crucial. Uma forma de melhorar a qualidade do ar e as condições de conforto térmico dentro de uma cabine de aeronave está na utilização de novos sistemas de ventilação personalizada. O objetivo do presente trabalho consiste na análise experimental da influência de um sistema de ventilação personalizada (PV) na concentração, dispersão e remoção de partículas expiratórias em cabine de aeronave com sistema por mistura (MV) e por deslocamento (DV). Os ensaios foram realizados em um mock-up de cabine de aeronave comercial de 12 assentos, com 4 assentos por fileira. $\mathrm{O}$ ar foi insuflado na cabine a $18^{\circ} \mathrm{C}$ pelo sistema MV ou DV, correspondendo a uma leve sensação de frio, e a $24^{\circ} \mathrm{C}$ pelo sistema personalizado (PV), com vazão de 3,0 1/s, operando no assento próximo à fuselagem e ao corredor, alternadamente. As partículas simulando uma pessoa espirrando foram injetadas em dois pontos no fundo da cabine, respectivamente, no assento próximo à fuselagem e naquele junto do corredor, a 1,10m do piso, que corresponde à região de respiração. Foram medidas velocidades e temperaturas do ar e de partículas ao longo de toda a cabine. Os resultados mostraram que no sistema MV o sistema PV somente influenciou o escoamento do ar e a concentração de partículas no assento onde o sistema PV estava operando, com uma eficiência na remoção de partículas de até 30\%. No sistema DV, por sua vez, o sistema PV apresentou eficiência de remoção de até $49 \%$ nos assentos em que estava operando. Contudo, o sistema PV pode aumentar em até $32 \%$ a concentração de partículas no assento próximo da janela quando o sistema PV estava operando no assento próximo do corredor, no sistema DV. Finalmente, os resultados mostraram resultados mais promissores do sistema PV no sistema MV, com melhoria significativa na remoção de partículas nos assentos onde está operando, sem influenciar negativamente no assento ao lado. 


\begin{abstract}
People are increasingly traveling by plane and often on long journeys. Air quality becomes a crucial issue. One way to improve air quality and thermal comfort conditions within an aircraft cabin is to use new personalized ventilation systems. The objective of the present work is the experimental analysis of the influence of a personalized ventilation system (PV) on the concentration, dispersion and removal of expiratory particles in aircraft cabin with mixed system (MV) and displacement (DV). The tests were performed in a 12 seat commercial aircraft cabin mock-up, with 4 seats per row. The air was inflated in the cabin at $18^{\circ} \mathrm{C}$ by the MV or DV system, corresponding to a slight cold sensation, and at $24^{\circ} \mathrm{C}$ by the custom system (PV), with a flow rate of $3.01 / \mathrm{s}$, operating in the nearby seat the fuselage and the aisle, alternately. Particles simulating a person sneezing were injected at two points in the bottom of the cockpit, respectively, in the seat near the fuselage and next to the corridor, $1.10 \mathrm{~m}$ from the floor, which corresponds to the breathing region. Air and particle velocities and temperatures were measured throughout the cabin. The results showed that in the MV system the PV system only influenced the air flow and the concentration of particles in the seat where the PV system was operating, with a particle removal efficiency of up to $30 \%$. The DV system together with PV system showed removal efficiency of up to $49 \%$ in the seats in which it was operating. However, the PV system can increase particle concentration in the near-window seat by up to $32 \%$ when the PV system was operating on the seat next to the aisle in the DV system. Finally, the results showed more promising results of the PV system in the MV system, with significant improvement in particle removal in the seats where it is operating, without negatively influencing the next seat
\end{abstract}




\section{LISTA DE ILUSTRAÇÕES}

Figura 2.1 Sistema de distribuição por mistura de ar na cabine, MV (adaptado de Hunt e Space, 1994) 9

Figura 2.2 Sistema de distribuição de ar por deslocamento na cabine 10

Figura 2.3 Sistema de distribuição por insuflamento de ar pelo piso. 11

Figura 2.4 Saídas de ar personalizadas tipo válvula gasper

(Walkinshaw, 2011; Conceição, 2012)

Figura 2.5 Insuflamento de ar personalizado próximo a cabeça

(Jacobs e Gibs, 2005)

Figura 2.6 Geometria do mock-up com e o padrão de escoamento do ar (Jacobs e Gibs, 2005)

Figura 2.7 Sistema personalizado com insuflamento de ar por bocal instalado na poltrona (figura adaptada de Gao e Niu, 2007a)

Figura 2.8 Vetores velocidade em sistema personalizado com insuflamento de ar pela poltrona à frente (figura adaptada de Zhang e Chen, 2007)

Figura 2.9 Estudos de ventilação personalizada em bancos de aeronaves.

(a) solução integrada ao suporte de pescoço;

(b) solução integrada à espuma do assento (Nielsen et al., 2007)

Figura 2.10 Sistema personalizado com insuflamento de ar tipo travesseiro de pescoço (Nielsen et al., 2008)

Figura 2.11 Mock-up de cabine de aeronave e planos de medição

(Zhang et al., 2008)

Figura 2.12 Linhas de corrente: (a) sistema MV, (b) sistema UFAD e (c) sistema UFAD com ventilação personalizada (Zhang e Chen, 2008)

Figura 2.13 Sistema personalizado com insuflamento de ar pela lateral da poltrona (Zhang et al, 2011)

Figura 2.14 Sistema com isuflamento debaixo dos assentos (adaptado de You et al., 2018)

Figura 3.1 Efeito da forma da partícula para sua classificação 
Figura 3.2 Gotículas expiratórias, baseado nas medições de Duguid, 1946.

a) quantidade absoluta de partículas. b) distribuição do tamanho de partículas normalizada pelo intervalo de medição.

b) distribuição acumulada (adaptado por Conceição, 2012)

Figura 3.3 Pontos de injeção e de medição de partículas para diferentes vazões de ar em mock-up de cabine (Wan et al., 2005)

Figura 3.4 Distribuição do tamanho de gotículas produzidas por um gerador polidisperso próprio, medida a $10 \mathrm{~cm}$ do bico de saída do mesmo (Wan et al., 2005)

Figura 3.5 Mock-up de cabine de avião para estudar dispersão de partículas expiratórias (Zhang et al., 2008)

Figura 3.6 Mock-up de 20 lugares utilizado na avaliação da dispersão de partículas (Conceição, 2012)

Figura 3.7 Mock-up de 12 lugares: (a) Esquema interno e (b) Acesso e vista externa (Fabichak Jr., 2013)

Figura 3.8 Simulação de partículas expiratórias: (a) exaladas por passageiro infectado e (b) caminho percorrido pelas partículas (Li et al., 2014)

Figura 4.1 Representação esquemática do sistema de cabine (em azul claro) e personalizada (em amarelo) do mock-up (Fabichak Jr., 2013)

Figura 4.2 Configuração do mock-up

Figura 4.3 Vista interna do mock-up com os manequins aquecidos 42

Figura 4.4 Sistema Personalizado (PV) 42

Figura 4.5 Detalhe do sistema da poltrona PV (medidas em mm) 43

Figura 4.6 Arquitetura 1: Sistema de ventilação por mistura (MV) 44

Figura 4.7 Arquitetura 2: Sistema por deslocamento (DV) 44

Figura 4.8 Gerador de aerossol TSI modelo 3475 (TSI, 2010) - imagem de catálogo 46

Figura 4.9 Concentração de partículas em função do tamanho da gotícula produzida pelo gerador TSI modelo 3475 (TSI, 2010) - imagem de catálogo 46

Figura 4.10 Gerador de aerossol TSI modelo 3475 associado ao indicador de monitoramento de partículas PAM 3375 (TSI, 2010)

Figura 4.11 Contador de partículas da Met One, modelo HHPC6 (Met One HHPC6, 2010) 
Figura 4.12 Sensor de anemômetro omnidirecional (elemento sensor livre)

(Fabichak Jr., 2013)

Figura 4.13 Distribuição dos pontos de medição de velocidade e de temperatura do ar (Fabichak Jr., 2013)

Figura 4.14 Pedestal para posicionamento da sondas do Comfort Sense

Figura 4.15 Vistas do tubo de Pitot antes e após a instalação (Fabichak Jr., 2013)

Figura 4.16 Manômetro diferencial para a determinação e monitoramento da vazão de ar (Fabichak Jr., 2013)

Figura 4.17 Configuração para instalação do medidor de vazão

Figura 4.18 Instalação do medidor de vazão - em detalhe, valor da vazão no sistema personalizado

Figura 4.19 (a) Gerador de aerossol TSI modelo 3475 e monitor PAM 3475 posicionados externamente ao mock-up e (b) Detalhe dos tubos e mangueiras de conexão (Fabichak Jr., 2013)

Figura 4.20 Pontos de injeção e medição de partículas no mock-up: (a) injeção de partículas na poltrona 3A e (b) injeção de partículas na poltrona 3B

Figura 4.21 Posição dos contadores de partículas 58

Figura 5.1 Identificação dos assentos

Figura 5.2 Perfis de velocidades do ar nos sistemas MV e DV com o sistema PV no assento 2A (PV2A) ligado e desligado

Figura 5.3 Perfis de velocidades do ar nos sistemas MV e DV com o sistema PV no assento 2B (PV2B) ligado e desligado

Figura 5.4 Diferenças de velocidades do ar entre os ensaios com o sistema PV ligado e desligado, sistemas MV e DV

Figura 5.5 Comparação entre as incertezas de medição e as diferenças de velocidades do ar entre os ensaios com o sistema PV ligado e desligado, $\Delta \mathrm{V}$, nos sistemas MV e DV

Figura 5.6 Perfis de temperaturas do ar nos sistemas MV e DV com o sistema PV2A ligado e desligado

Figura 5.7 Perfis de temperaturas do ar nos sistemas MV e DV com o sistema PV2B ligado e desligado

Figura 5.8 Diferenças de temperaturas do ar entre ensaios com o sistema PV ligado e desligado, sistemas MV e DV 
Figura 5.9 Comparação entre as incertezas de medição e as diferenças de temperaturas do ar entre os ensaios com o sistema PV ligado e desligado, $\Delta \mathrm{T}$, sistemas MV e DV

Figura 5.10 Concentração de partículas com o sistema PV ligado e desligado, operando alternadamente nas poltronas $2 \mathrm{~A}$ e $2 \mathrm{~B}$, com injeção de partículas no assento 3A e sistema MV

Figura 5.11 Concentração de partículas com o sistema PV ligado e desligado, operando alternadamente nas poltronas $2 \mathrm{~A}$ e $2 \mathrm{~B}$, com injeção de partículas no assento 3B e sistema MV

Figura 5.12 Concentração de partículas com o sistema PV ligado e desligado, operando alternadamente nas poltronas $2 \mathrm{~A}$ e $2 \mathrm{~B}$, com injeção de partículas no assento 3 e sistema DV

Figura 5.13 Concentração de partículas com o sistema PV ligado e desligado, operando alternadamente nas poltronas $2 \mathrm{~A}$ e $2 \mathrm{~B}$, com injeção de partículas no assento 3B e sistema DV

Figura 5.14 Diferenças entre as concentrações de partículas com e sem o sistema PV em operação no sistemas MV nos assentos 2A e 2B

Figura 5.15 Diferenças entre as concentrações de partículas com e sem o sistema PV em operação nos sistemas DV nos assentos 2A e 2B

Figura 5.16 Concentração de partículas nos assentos 2A e 2B no sistema MV

Figura 5.17 Concentração de partículas nos assentos 2A e 2B no sistema DV

Figura 5.18 Eficiência na remoção de partículas com o sistema PV operando no assento 2A (PV2A), sistemas MV e DV

Figura 5.19 Eficiência na remoção de partículas com o sistema PV operando no assento 2B (PV2B), sistemas MV e DV 


\section{LISTA DE TABELAS}

Tabela 5.1 Caracterização das situações de ensaio

Tabela D.1 Médias dos valores de Velocidade do Ar em m/s para o sistema MV

Tabela D.2 Médias dos valores de Velocidade do Ar em m/s para o sistema $\mathrm{MV}+\mathrm{PV} 2 \mathrm{~A}$

Tabela D.3 Médias dos valores de Velocidade do Ar em m/s para o sistema $\mathrm{MV}+\mathrm{PV} 2 \mathrm{~B}$

Tabela D.4 Incertezas dos valores Velocidade do Ar calculadas em m/s para o sistema MV

Tabela D.5 Incertezas dos valores Velocidade do Ar calculadas em m/s para o sistema $\mathrm{MV}+\mathrm{PV} 2 \mathrm{~A}$

Tabela D.6 Incertezas dos valores Velocidade do Ar calculadas em m/s para o sistema $\mathrm{MV}+\mathrm{PV} 2 \mathrm{~A}$

Tabela D.7 Médias dos valores de Velocidade do Ar em m/s para o sistema DV

Tabela D.8 Médias dos valores de Velocidade do Ar em m/s para o sistema $\mathrm{DV}+\mathrm{PV} 2 \mathrm{~A}$

Tabela D.9 Médias dos valores de Velocidade do Ar em m/s para o sistema $\mathrm{DV}+\mathrm{PV} 2 \mathrm{~B}$

Tabela D.10 Incertezas dos valores velocidade do Ar calculadas em m/s para o sistema DV

Tabela D.11 Incertezas dos valores velocidade do Ar calculadas em m/s para o sistema DV+PV2A

Tabela D.12 Incertezas dos valores velocidade do Ar calculadas em m/s para o sistema DV+PV2A

Tabela D.13 Valores médios de Temperatura do Ar calculadas em ${ }^{\circ} \mathrm{C}$ para o sistema MV

Tabela D.14 Valores médios de Temperatura do Ar calculadas em ${ }^{\circ} \mathrm{C}$ para o sistema $\mathrm{MV}+\mathrm{PV} 2 \mathrm{~A}$

Tabela D.15 Valores médios de Temperatura do Ar calculadas em ${ }^{\circ} \mathrm{C}$ 
Para o sistema MV+PV2B

Tabela D.16 Incertezas dos valores de temperatura do Ar calculadas em ${ }^{\circ} \mathrm{C}$ para o sistema MV

Tabela D.17 Incertezas dos valores de temperatura do Ar calculadas em ${ }^{\circ} \mathrm{C}$ para o sistema MV+PV2A

Tabela D.18 Incertezas dos valores de temperatura do $\mathrm{Ar}$ calculadas em ${ }^{\circ} \mathrm{C}$ para o sistema MV+PV2B

Tabela D.19 Valores médios de Temperatura do Ar calculadas em ${ }^{\circ} \mathrm{C}$ para o sistema DV

Tabela D.20 Valores médios de Temperatura do Ar calculadas em ${ }^{\circ} \mathrm{C}$ para o sistema DV+PV2A

Tabela D.21 Valores médios de Temperatura do Ar calculadas em ${ }^{\circ} \mathrm{C}$ para o sistema DV+PV2A

Tabela D.22 Incertezas dos valores de temperatura do Ar calculadas em ${ }^{\circ} \mathrm{C}$ para o sistema DV

Tabela D.23 Incertezas dos valores de temperatura do Ar calculadas em ${ }^{\circ} \mathrm{C}$ para o sistema DV+PV2A

Tabela D.24 Incertezas dos valores de temperatura do Ar calculadas em ${ }^{\circ} \mathrm{C}$ para o sistema DV+PV2A

Tabela E.1 Valores de concentração de partículas para o sistema MV em Partículas $/ \mathrm{m}^{3}$

Tabela E.2 Valores das incertezas calculadas das concentrações de partículas para o sistema MV em Partículas $/ \mathrm{m}^{3}$

Tabela E.3 Valores de concentração de partículas para o sistema MV+PV2A em Partículas/m

Tabela E.4 Valores das incertezas calculadas das concentrações de partículas para o sistema MV+PV2A em Partículas $/ \mathrm{m}^{3}$

Tabela E.5 Valores de concentração de partículas para o sistema MV+PV2B em Partículas $/ \mathrm{m}^{3}$

Tabela E.6 Valores das incertezas calculadas das concentrações de partículas para o sistema MV+PV2B em Partículas $/ \mathrm{m}^{3}$

Tabela E.7 Valores de concentração de partículas para o sistema DV em Partículas $/ \mathrm{m}^{3}$

Tabela E.8 Valores das incertezas calculadas das concentrações de partículas 
para o sistema DV em Partículas $/ \mathrm{m}^{3}$

Tabela E.9 Valores de concentração de partículas para o sistema DV+PV2A em Partículas $/ \mathrm{m}^{3}$

Tabela E.10 Valores das incertezas calculadas das concentrações de partículas para o sistema DV+PV2A em Partículas/m

Tabela E.11 Valores de concentração de partículas para o sistema DV+PV2B em Partículas $/ \mathrm{m}^{3}$

Tabela E.12 Valores das incertezas calculadas das concentrações de partículas para o sistema DV+PV2B em Partículas $/ \mathrm{m}^{3}$ 


\section{LISTA DE SIGLAS}

\begin{tabular}{|c|c|}
\hline ASHRAE & $\begin{array}{l}\text { American Society of Heating, Refrigerating and Air-Conditioning } \\
\text { Engineers }\end{array}$ \\
\hline CFD & Computational Fluid Dynamics - Dinâmica dos fluidos computacional \\
\hline $\mathrm{cfm}$ & Cubic feet per minute - pés cúbicos por minuto $\left(\mathrm{ft}^{3} / \mathrm{min}\right.$.) \\
\hline CLP & Controlador Lógico Programável \\
\hline $\mathrm{CO}_{2}$ & Gás carbônico \\
\hline DEHS & Di-Etil-Hexil-Sebacato \\
\hline DV & Displacement Ventilation - Ventilação por deslocamento \\
\hline EMBRAER & Empresa Brasileira de Aeronáutica S.A. \\
\hline FAPESP & Fundação de Amparo à Pesquisa do Estado de São Paulo \\
\hline FINEP & Financiadora de Estudos e Projetos \\
\hline H1N1 & Subtipo do vírus Influenza A \\
\hline HEPA & High Efficiency Particulate Air \\
\hline ISO & International Organization for Standardization \\
\hline MV & Mixing Ventilation - Ventilação por mistura \\
\hline $\mathrm{N}_{2}$ & Nitrogênio \\
\hline PIV & Particle Image Velocimetry - Velocidade de partícula por imagem \\
\hline psi & Pound Square Inch - libra por polegada quadrada $\left(\mathrm{lb} / \mathrm{in}^{2}\right)$ \\
\hline PV & Personalized Ventilation - Ventilação personalizada \\
\hline SARS & Severe Acute Respiratory Syndrome \\
\hline $\mathrm{SF}_{6}$ & Gás Hexafluoreto de Enxofre \\
\hline UFAD & Under Floor Air Distribution - Insuflamento de ar pelo piso \\
\hline UR & Umidade relativa do ar \\
\hline
\end{tabular}




\section{SUMÁRIO}

\section{RESUMO}

LISTA DE ILUSTRAÇÕES

LISTA DE TABELAS

LISTA DE SIGLAS

1 INTRODUÇÃO 1

1.1 Motivação do Trabalho 4

1.2 Objetivo 6

1.2.1 Objetivos Específicos 6

1.3 Estrutura do Trabalho

2 DISTRIBUIÇÃO DE AR E VENTILAÇÃO PERSONALIZADA EM CABINES DE $\begin{array}{lr}\text { AERONAVES } & 8\end{array}$

2.1 Sistemas de Ventilação e Distribuição de Ar em Cabines de Aeronaves 8

2.2 Sistemas de Ventilação Personalizada em Cabines de Aeronaves 12

3 DISPERSÃO DE PARTÍCULAS EM CABINES DE AERONAVES 24

3.1 Qualidade do ar 24

3.2 Tamanho das partículas 26

3.3 Qualidade do ar em ambientes de aeronaves $\quad 27$

3.4 Contaminantes aéreos e a contaminação cruzada 28

3.5 Estudos de dispersão de partículas em cabines de aeronaves usando geradores de partículas $\quad 32$

4 MÉTODO DE TRABALHO 39

4.1 Introdução 39

4.2 O Laboratório 39

4.3 Sistema de ventilação personalizada proposto 42

4.4 Arquiteturas de distribuição de ar analisadas 43

4.5 Geração de partículas $\quad 45$

4.6 Quantificações das partículas $\quad 47$

4.7 Variáveis ambientais e condições dos ensaios 49

4.8 Procedimentos de medição e instrumentação 51 
4.9 Processo de geração e de medição da concentração de partículas

4.9.1 Intervalo entre medições e tempo de medição das partículas 58

4.10 Repetitividade dos ensaios $\quad 58$

4.11 Sequência experimental $\quad 59$

5 RESULTADOS EXPERIMENTAIS

5.1 Perfis de Velocidades e Temperaturas do Ar $\quad 62$

5.1.1 Perfis de Velocidades do Ar 63

5.1.2 Perfis de Temperaturas do Ar 68

5.2 Concentração, Dispersão e Remoção de Partículas na Região de Respiração 72

5.2.1 Análise da influência do sistema PV na concentração e dispersão de $\begin{array}{ll}\text { partículas } & 75\end{array}$

5.2.1.1 Análise da influência do sistema PV na concentração e dispersão de partículas no sistema MV e DV 76

5.2.1.2 Análise da influência do sistema PV em função do ponto de injeção de partículas no assento 3A e 3B 79

\section{CONCLUSÕES}

6.1 Influência do sistema personalizado na dispersão de partículas e características do ambiente 86

6.2 Eficiência de remoção de partículas $\quad 88$

6.3 Sugestões para trabalhos futuros $\quad 89$

7 REFERÊNCIAS BIBLIOGRÁFICAS

APÊNDICE A - MANEQUINS AQUECIDOS $\quad 102$

APÊNDICE B - MANÔMETRO DIFRENCIAL 103

$\begin{array}{ll}\text { APÊNDICE C - VAZÃO DO SISTEMA PV } & 105\end{array}$

APÊNDICE D- RESULTADOS DAS MEDIÇÕES E RESPECTIVAS

INCERTEZAS DAS VELOCIDADES E DAS TEMPERATURAS DO AR 109

APÊNDICE E - RESULTADOS DAS MEDIÇÕES E RESPECTIVAS

INCERTEZAS DAS CONCENTRAÇÕES DE PARTÍCULAS 120 


\section{Capítulo 1}

INTRODUÇÃO

As pessoas hoje em dia passam cada vez mais tempo de suas vidas, por diversas circunstâncias, em ambientes fechados. Com isso a pessoa fica sujeita às condições destes ambientes e caso eles não apresentem características adequadas ao uso podem muitas vezes gerar uma má qualidade do ar interior, ocasionando desconforto e problemas de saúde. A preocupação com a questão da qualidade do ar em ambientes interiores remonta ao início do século XIV, e um dos principais enfoques na sua solução está na ventilação adequada dos ambientes (HAINES; WILSON, 1998, SPLENGER; SAMET; MCCARTHY, 2004, QUADROS, 2008).

Como consequência, houve ao longo dos anos um aumento no número de estudos voltados ao tema da qualidade do ar interior, principalmente sobre a contaminação aérea em diversos ambientes como residências, hospitais, cabines de avião, dentre outros (BEGGS, 2003, YU et al., 2004, GAO et al., 2008, CHEN; DENG, 2008, CHO et al., 2008, PARRA et al., 2008, ONGWANDEE, 2008, WAGNER; COBURN; BLOWER; 2009, NIELSEN, 2009, CONCEIÇÃO; PEREIRA; TRIBESS, 2011, GUAN et al., 2014a, GUAN et al., 2014b, LI et al., 2014, GAO; XIE; YANG, 2015, LI et al., 2016, YOU et al. 2018a, YOU et al. 2018b). Porém, mesmo com esse aumento no número de estudos voltados a essa área, ainda se pode perceber que existe muito a ser estudado, principalmente sobre o controle e a prevenção da disseminação de agentes infecciosos em função do sistema de ventilação.

As cabines de aviões são diferentes de outros ambientes, pois nesses ambientes os ocupantes encontram uma combinação de fatores como baixa umidade, baixa pressão do ar, e potencial exposição a contaminantes aéreos, tais como Ozônio $\left(0_{3}\right)$, material particulado, compostos orgânicos voláteis (VOC) e agentes biológicos (LEE et al., 1999, SPLENGER; SAMET; MCCARTHY, 2004, CHESTER et al., 2004, WANG et al., 2014, GAO; XIE; YANG, 2015). Durante o voo, uma vez que os passageiros estão todos diretamente expostos ao mesmo ambiente durante muito tempo, a qualidade do ar e a transmissão de doenças estão intimamente relacionados com os contaminantes locais suspensos no ar (YAN, 2017). Também a característica do ambiente externo, função das variações das condições térmicas, faz com que o ambiente de cabine de aviões seja complexo e assimétrico. 
Segundo Stancato (2009), mudanças bruscas das condições térmicas fazem com que o sistema de climatização da aeronave tenha que mudar de uma situação de elevado resfriamento a uma situação de aquecimento, levando em conta, por exemplo, que a temperatura externa da fuselagem pode variar de $80{ }^{\circ} \mathrm{C}$ no solo a $-40{ }^{\circ} \mathrm{C}$ no ar em um curto período de tempo. Somado a isso, nota-se que em função da baixa umidade do ar exterior, em condições de voo são verificadas umidades relativas bastante baixas por períodos longos de exposição, podendo chegar a 5\% de umidade relativa, amplificando o desconforto térmico e comprometendo a salubridade a bordo (STROM-TEJSEN et al., 2005, GRUN et al., 2008, STANCATO, 2009).

Assim, com relação à qualidade do ar, devido à proximidade entre os passageiros e à duração dos voos que vem aumentando, a dispersão de doenças tem sido tema de diversos estudos, principalmente, os efeitos da contaminação do ar, seja por agentes transmissores de doenças ou pela dinâmica das partículas expiratórias (DRIVER et al., 1994, KENYON et al., 1996, OLSENet al., 2003, MANGILI; GEANDREAU, 2005, WAN et al., 2009, SZE TO et al., 2009, WALKINSHAW, 2010, FISER; MIROSLAV, 2013, VOLAVÝ et al., 2013, LI et al., 2014, LI et al., 2016, YAN, 2017).

A doença viral SARS (Severe Acute Respiratory Syndrome), que teve sua eclosão mundial em 2003, demonstrou que a disseminação de contaminantes aéreos é um evento não controlável, uma vez que foi rapidamente difundido, principalmente porque pessoas infectadas viajaram de avião para cidades distantes (OLSEN et al., 2003). Autores como Driver et al. (1994), Kennyon et al. (1996), WHO (1998), Wang (2000) também citam a transmissão de tuberculose em meados dos anos 1990 e apresentam uma provável ligação com a disseminação do vírus em ambientes de aeronaves.

Para diminuir os riscos de contaminação faz-se necessário que ocorra funcionamento adequado do sistema de climatização e de ventilação e distribuição de ar. Para se avaliar a influência do sistema de ventilação e distribuição de ar e da dinâmica das partículas na qualidade do ar interior em cabines de aeronaves é necessário que haja um conhecimento dos métodos utilizados para reproduzir e quantificar esse fenômeno, e por outro lado também é necessário conhecer a fundo as limitações desse processo.

Alguns estudos experimentais realizados com o objetivo de se entender a dinâmica de partículas e a qualidade do ar interior em aeronaves foram conduzidos por meio de monitoramento em situações reais de voos (NAGDA et al., 2000, HOCKING, 1998; UVA, 2000, HOCKING, 2000, UVA, 2002, OSMAN et al., 2008). Porém, devido aos altos custos e dificuldades para a realização de ensaios em voos, função, principalmente, do 
procedimento de certificação, as análises experimentais têm sido realizadas em mock-ups (WAN; CHAO; FANG, 2005, ZHANG et al., 2007, YAN et al., 2009, SZE TO et al., 2009, GUPTA; LIN; CHEN, 2011, CHEN et al., 2012, CONCEIÇÃO, 2012, FABICHAK JR., 2018, LI et al., 2016, YOU et al., 2018a, YOU et al., 2018b). Por se tratar de seção de cabine de aeronave, o mock-up permite que sejam desenvolvidas as mesmas condições de troca de calor e do escoamento do ar daquelas de aeronave em solo ou durante o voo.

É importante ressaltar que o entendimento sobre a contaminação aérea em aeronaves e em outros tipos de ambientes evoluiu bastante. Porém, pouco ainda se conhece sobre a dinâmica das partículas e a influência do sistema de ventilação na dispersão de partículas para controlar e prevenir a sua disseminação (MORAWSKA, 2005, LI et al., 2007, YANG et al., 2007, NIELSEN et al., 2007, NIELSEN et al., 2008, MÜLLER; SCHMIDT; MÜLLER., 2011, BOSBACH et al., 2012, LIU; CHEN, 2013, ZHANG; LI; WANG, 2012, LI et al., 2014, LI et al., 2016).

Os sistemas de ventilação e distribuição de ar em aeronaves desempenham papel crítico em criar um ambiente dentro da cabine que seja seguro, saudável e confortável. O sistema de ventilação e distribuição de ar comumente utilizado em cabines de avião tem como característica o insuflamento do ar em alta velocidade pelo teto e retorno do ar pelos níveis inferiores. Estudos mostram que o insuflamento de ar em altas velocidades faz com que o ar dentro da cabine seja bem misturado, diminuindo a eficiência da ventilação na remoção de contaminantes da cabine da aeronave (GAO; NIU, 2007a, ZHANG et al., 2007, LIU et al., 2013, ZHANG; LI; WANG, 2012, LI et al., 2014). Porém, este conceito de mistura não só induz insatisfação com relação à qualidade do ar (NAGDA; HODGSON, 2001, SPLENGER; WILSON, 2003) e conforto térmico (HINNINGHOFEN; ENCK, 2006), como também impõe ameaça à saúde (LINDGREN; NORBACK, 2005).

Alguns autores apresentam estudos numéricos de novos sistemas de ventilação e de distribuição de ar em aeronaves com o objetivo de melhorar o conforto térmico e a qualidade do ar (ZHANG; CHEN, 2007, GAO; NIU, 2007a, ZHANG et al., 2008, ZHANG et al., 2011, BOSBACH et al., 2012, BOSBACH et al., 2013, WINZEN et al., 2013, DEHNE et al., 2018, YOU et al., 2017). Estes novos sistemas são baseados em sistemas já aplicados em edificações como, por exemplo, o sistema de ventilação por deslocamento (CHEN; GLICKSMAN, 2003) e o sistema de distribuição de ar pelo piso (BAUMAN; DAILY, 2003, LEITE, 2003, LEITE; TRIBESS, 2004).

Outros autores apresentam que, uma das soluções para melhorar a qualidade do ar e o conforto dos ocupantes em ambientes interiores, são os sistemas com suprimento de ar 
personalizados (MELIKOV, 2004, SEKHAR et al., 2005, KACZMARCZYK et al, 2006, LI et al., 2010, ZHANG; LI; WANG, 2011, CONCEIÇÃO, 2012, FANG et al., 2015, YOU et al., 2017, YOU et al., 2018a, YOU et al., 2018b). Esses sistemas têm boa aplicação em edificações (MELIKOV, 2004, LEITE; TRIBESS, 2004, KACZMARCZYK et al., 2006, LI et al., 2010), mas ainda não têm sido efetivamente utilizados em cabines de aeronaves, com exceção das saídas de ar individualizadas posicionadas nas proximidades da cabeça dos passageiros, denominadas de válvulas gasper, amplamente utilizados em aeronaves comerciais.

Os sistemas personalizados têm o objetivo de melhorar as condições de conforto térmico e de qualidade do ar de forma individualizada, pois tais sistemas fornecem ao usuário opções para o controle e ajuste de condições térmicas de forma a oferecer conforto térmico individual, além de fornecer ar mais limpo na zona de respiração, diminuindo a possibilidade de contaminação cruzada por meio dos contaminantes dispersos no ambiente. (MELIKOV, 2004, KACZMARCZYK et al., 2004, LEITE; TRIBESS, 2004, KACZMARCZYK et al., 2006, GAO; NIU, 2007b, LI et al., 2010, ZHANG; LI; WANG, 2011, CONCEIÇÃO, 2012, ZHANG et al., 2012, FANG et al. 2015, YOU et al., 2017, YOU et al., 2018a, YOU et al.,2018b). O sistema personalizado de válvula gasper, contudo, não tem cumprido satisfatoriamente esta função, apresentando problemas de desconforto térmico devido a correntes de ar (NIELSEN et al., 2007, ZHANG; LI; WANG, 2012, FANG et al., 2015).

É importante ressaltar que a utilização de sistemas personalizados pode melhorar as condições térmicas e a qualidade do ar na zona de respiração do usuário. Porém, eles também podem aumentar a possibilidade de contaminação de outros passageiros em função da dispersão das partículas na cabine, sendo este o tema principal de estudo no presente trabalho.

O trabalho tem enfoque na dinâmica da dispersão de partículas expiratórias, pois este tema, junto com a influência do sistema de ventilação da aeronave, embora bastante estudados, ainda requerem muita atenção, pois em muitos casos, ainda são desconhecidos os mecanismos de propagação de partículas expiratórias nesse tipo de ambiente. (MORAWSKA, 2005, LI et al., 2007, YANG et al., 2007, NIELSEN et al., 2007, NIELSEN et al., 2008, MÜLLER; SCHMIDT; MÜLLER., 2011, BOSBACH et al., 2012, YAN, 2017). 


\subsection{Motivação do Trabalho}

O significativo aumento da demanda de passageiros preocupa tanto fabricantes quanto companhias aéreas no que diz respeito à dispersão de partículas no ambiente interno. De acordo com a International Air Transport Association (IATA) 3,6 bilhões de passageiros utilizaram as linhas aéreas pelo mundo em 2016. Fato este que mostra um aumento de 800 milhões de passageiros em 5 anos, levando em consideração os 2,8 bilhões de passageiros que voaram em aviões em 2011. Segundo Tyler (2015) o número de passageiros que utilizarão aviões dobrará (7,4 bilhões) em 20 anos.

Estas informações somadas ao fato de que a dispersão de partículas em ambientes de aeronaves tem influência direta na qualidade do ar interior, principalmente no que diz respeito à dispersão de agentes que comprometam a saúde dos ocupantes, demonstram a necessidade da realização de estudos aprofundados que relacionem a influência do sistema de ventilação de cabine e de sistemas de ventilação personalizada no escoamento do ar e da dinâmica das partículas na dispersão de contaminantes aéreos em cabines de aeronaves.

Como descrito anteriormente, o sistema convencional de ventilação e distribuição de ar pelo teto, denominado sistema de ventilação por mistura, juntamente com o sistema personalizado da válvula gasper, não tem sido eficientes no que diz respeito ao controle da dispersão de contaminantes aéreos e na manutenção das condições de conforto térmico em cabines de aeronaves. Uma forma de melhorar a qualidade do ar e as condições de conforto térmico dentro da cabine está na utilização de novos sistemas de ventilação e distribuição de ar e de ventilação personalizada.

Os sistemas de ventilação personalizada têm como característica fornecer ao usuário opções para o controle e ajuste de condições térmicas de forma a oferecer conforto térmico individual, além de fornecer ar mais limpo na zona de respiração, diminuindo a possibilidade de contaminação cruzada por meio dos contaminantes dispersos no ambiente. (MELIKOV, 2004, KACZMARCZYK et al., 2004, LEITE; TRIBESS, 2004, KACZMARCZYK et al., 2006, GAO; NIU, 2007b, LI et al., 2010, ZHANG; LI; WANG, 2011, CONCEIÇÃO, 2012, FANG et al. 2015, YOU et al., 2017, YOU et al., 2018a, YOU et al., 2018b).

A maioria destes estudos somente considera a influência de novos sistemas de ventilação personalizada na qualidade do ar utilizando simulação numérica e em ambientes de edificações. E somente alguns poucos estudos incluem investigação experimental. A 
desvantagem das simulações numéricas é que os resultados requerem validações futuras devido às simplificações dos modelos e das condições de contorno (FANG et al., 2015).

Assim, existe a necessidade de estudos aprofundados que relacionem a influência da dinâmica do escoamento do ar nas cabines de aeronaves, função dos sistemas de ventilação da cabine e também de sistemas de ventilação personalizada, na dispersão de partículas. Verifica-se na literatura que não existem muitos estudos que apresentem propostas de modelos de sistemas personalizados mais eficientes que as válvulas gasper, e que analisem o impacto do escoamento do ar causado por tais sistemas na dispersão de partículas ao longo da cabine, principalmente na contaminação de outros ocupantes que não estejam utilizando o sistema personalizado.

Uma vez que novos sistemas de ventilação e de distribuição de ar em aeronaves também estão sendo desenvolvidos, como, por exemplo, na Escola de Engenharia Mecânica da Universidade de Purdue, EUA, em parceria com a Escola de Ciências Ambientais e Engenharia da Universidade Tianjin, China, onde estão sendo desenvolvidos estudos experimentais e numéricos relacionados à distribuição de ar em cabines de aeronaves, nota-se a necessidade de se fazer análise do impacto do sistema personalizado em diferentes sistemas de ventilação, como por exemplo o sistema por deslocamento (ZHANG et al., 2007, ZHANG; CHEN, 2007, YAN et al., 2009, LIU; CHEN, 2013, LIU et al., 2013, LI et al., 2014, CUI et al.,2014, GAO; XIE; YANG, 2015, LIU et al., 2015, DUAN et al., 2015, CAO et al., 2016, WEI; ZHANG; WANG, 2016, YOU et al., 2016, ZHENG et al., 2016, LI et al., 2016, YOU et al., 2018a, YOU et al., 2018b). Para isso, deve ser analisada a influência que o sistema personalizado tem nas variáveis que caracterizam a movimentação do ar, juntamente com a dispersão de partículas para os diferentes padrões de escoamento do ar dentro das cabines de aeronaves, objetivando determinar padrões de escoamento que possam priorizar o controle da dispersão de partículas expiratórias nestes ambientes.

\subsection{Objetivo}

O objetivo do presente trabalho consiste na análise experimental da influência de um sistema de ventilação personalizada proposto na concentração, dispersão e remoção de partículas expiratórias em cabine de aeronave com sistema de ventilação por mistura e por deslocamento. 


\subsubsection{Objetivos específicos}

Para atingir o objetivo do trabalho têm-se os seguintes objetivos específicos:

$\checkmark$ Analisar a influência do sistema de ventilação personalizada na velocidade e na temperatura do ar na cabine nos sistemas de ventilação por mistura e por deslocamento

$\checkmark$ Analisar a influência do sistema personalizado na concentração e difusão de partículas em função da localização do sistema de ventilação personalizada em operação na cabine.

$\checkmark$ Analisar a influência do sistema de ventilação personalizada na concentração e difusão de partículas em função do ponto de geração/injeção de partículas na cabine.

$\checkmark$ Analisar a influência do sistema de ventilação personalizada na remoção de partículas nos sistemas de ventilação por mistura e por deslocamento.

\subsection{Estrutura do Trabalho}

Inicialmente, no capítulo 2 são apresentadas as características dos sistemas de ventilação e distribuição de ar e de ventilação personalizada em cabines de aeronaves, com ênfase nos estudos relativos ao uso e propostas de sistemas de ventilação personalizada.

No capítulo 3 é feita uma revisão da literatura com enfoque na dispersão de partículas em ambientes de cabines de aeronaves.

No capítulo 4 é descrito o método experimental utilizado, apresentando as características do mock-up onde o estudo foi realizado e também as etapas que foram realizadas para a injeção de partículas na cabine e a medição das variáveis que influenciam na concentração, dispersão e remoção de partículas no ambiente de cabine de aeronaves.

No capítulo 5 são apresentados os resultados, bem como a análise e discussão dos resultados. No capítulo 6 é apresentada a conclusão da tese e propostas de trabalhos futuros. Finalmente, no Capítulo 7 são apresentadas as referências bibliográficas. 
Capítulo 2

\section{DISTRIBUIÇÃO DE AR E VENTILAÇÃO PERSONALIZADA EM CABINES DE AERONAVES}

Neste capítulo são apresentadas as principais características dos sistemas de ventilação e distribuição de ar de cabine e de ventilação personalizada em cabines de aeronaves, bem como resultados de estudos no uso e propostas de sistemas de ventilação personalizada.

\subsection{Sistemas de Ventilação e Distribuição de Ar em Cabines de Aeronaves}

Em cabines de aeronaves o sistema de ventilação e distribuição de ar é responsável por manter a pressão, a temperatura, a ventilação e a filtração do ar. Segundo a norma ASHRAE-161 (2007), a temperatura no interior da cabine deve ficar na faixa de 18 a $24^{\circ} \mathrm{C}$.

O sistema de ventilação e distribuição de ar mais utilizado em cabines de aeronaves consiste no insuflamento de ar na parte superior e retorno na parte inferior com mistura do ar na cabine, como apresentado na Figura 2.1. Nesse tipo de sistema o ar é insuflado com uma elevada velocidade na parte superior e o retorno do ar ocorre na parte inferior produzindo a mistura de ar na cabine, fato que origina seu nome de ventilação por mistura, Mixing Ventilation (MV).

A característica desse sistema é conseguir uma temperatura quase uniforme na cabine. Por outro lado, a mistura e a recirculação do ar na cabine podem facilitar a dispersão de contaminantes pelo interior da aeronave (GAO; NIU, 2007a, ZHANG et al. 2007, FABICHAK JR., 2013). Como os filtros HEPA (High Efficiency Particulate Air) se encontram instalados nos dutos de ar de recirculação, os contaminantes gerados por um passageiro podem ser inalados por outros passageiros antes de serem coletados por estes filtros (CONCEIÇÃO; PEREIRA; TRIBESS, 2011).

Comparando os ambientes de cabines de aeronaves com ambientes de edificações, nota-se que os primeiros têm uma geometria mais complexa, uma maior densidade de ocupação, um menor volume e uma taxa de renovação ar por pessoa menor. Esses fatos tornam o projeto de um ambiente de aeronave, visando a saúde e o bem estar, um grande desafio. Segundo a norma ASHRAE-161 (2007) a vazão total de ar deve ser de $20 \mathrm{cfm} /$ pessoa $(9,5 \mathrm{~L} / \mathrm{s} /$ pessoa). Porém, é importante ressaltar que na maioria das aeronaves 
comerciais, como forma de melhorar o controle da umidade do ar e da eficiência no consumo de combustível, $50 \%$ do ar insuflado na cabine é recirculado (HOUSE OF LORDS, 2000).

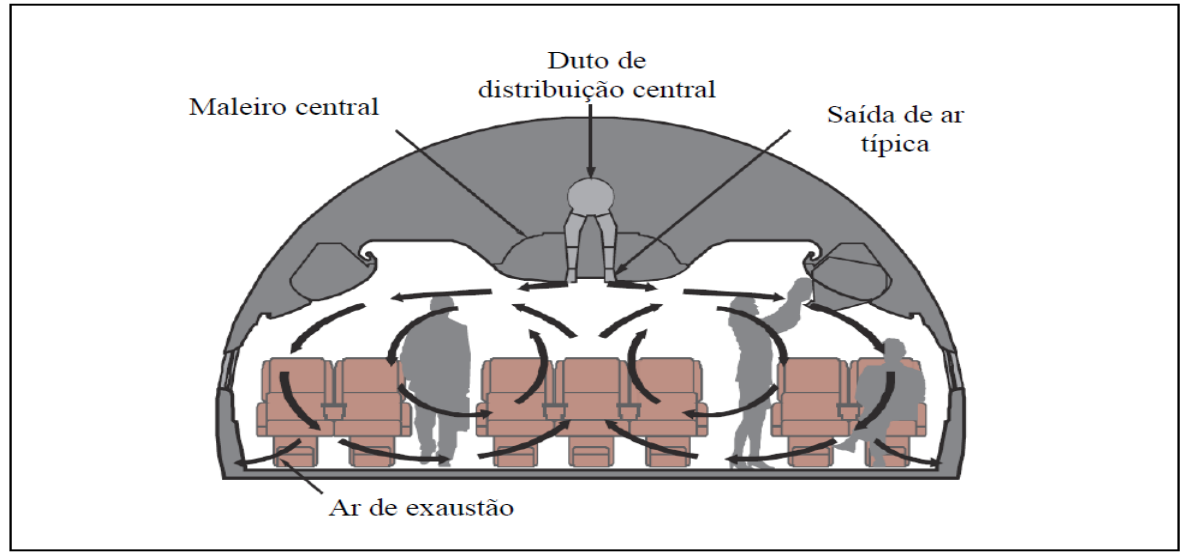

Figura 2.1. Sistema de distribuição por mistura de ar na cabine, MV Fonte: adaptado de HUNT; SPACE, 1994

Algumas aeronaves podem apresentar variações dessa arquitetura, por exemplo, os jatos particulares leves ou aeronaves regionais que possuem uma seção transversal menor. Nesses tipos de aeronaves o insuflamento do ar pode ocorrer tanto na região das malas (bins) como pela região lateral inferior e o retorno pelo centro do piso. Como nesses casos as saídas de ar ficam mais próximas dos ocupantes, devido ao fato da seção transversal da aeronave ser menor, pode potencializar o desconforto térmico local nos ocupantes (PEREIRA, 2004).

Embora o sistema MV, normalmente, proporcione um ambiente com baixa estratificação de temperatura, problemas de conforto térmico têm sido verificados (HINNINGHOFEN; ENCK, 2006, ZHANG et al., 2007, MOURA, 2009, STANCATO, 2009, CONCEIÇÃO, 2012, SILVA, 2013, DEHNE et al., 2018). Com o propósito de melhorar as condições de conforto térmico e minimizar a dispersão de partículas no interior de aeronaves, algumas propostas de sistemas de distribuição de ar vêm sendo estudadas. Dentre os sistemas propostos, destacam-se o sistema de ventilação por deslocamento, DV (Displacement Ventilation); o sistema de insuflamento de ar pelo piso, UFAD (Under Floor Air Distribution). 
O sistema por deslocamento (DV), figura 2.2, é formado por difusores que insuflam o ar próximo ao piso pela parte inferior das paredes e por grelhas de retorno que ficam localizadas nos maleiros (bins).

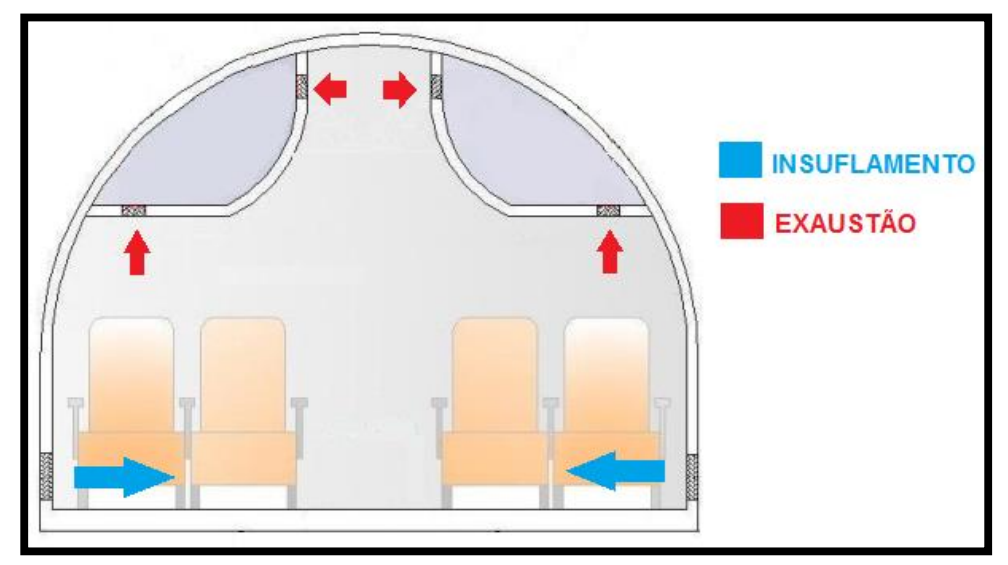

Figura 2.2. Sistema de distribuição de ar por deslocamento na cabine

A principal característica desse tipo de sistema é fazer com que o escoamento do ar à baixa velocidade ocorra na direção e no sentido natural da pluma térmica gerada pelas pessoas dentro do ambiente. Isto ocorre, pois à medida que a temperatura do ar aumenta devido ao contato com as pessoas ou outras fontes de calor, o ar sobe em direção ao teto pela convecção natural. Este fato auxilia na remoção dos contaminantes gerados pelos ocupantes. Por outro lado, o ar a uma temperatura baixa insuflado nas proximidades dos pés dos ocupantes do ambiente pode aumentar o risco de desconforto térmico local por diferença de temperatura e correntes de ar.

O comportamento ascendente do ar com este tipo de sistema cria uma estratificação da temperatura no interior dos ambientes em duas camadas, divididas pela altura de estratificação (Stratification Height - SH). A camada inferior contém o ar mais frio e a camada superior contém o ar aquecido e com maior quantidade de poluentes. A grande vantagem desse sistema é que o ar quente e mais poluído que sobe para a camada superior não retorna para a camada inferior devido à diferença de densidade (ABE, 2007).

De forma similar, o sistema de insuflamento de ar pelo piso (UFAD), figura 2.3, insufla o ar de baixo para cima através de difusores instalados no piso. 


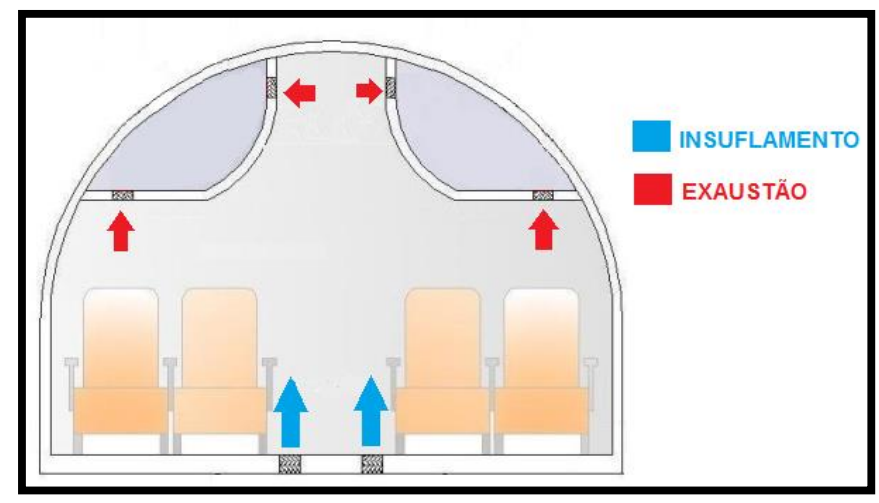

Figura 2.3. Sistema de distribuição por insuflamento de ar pelo piso

Em edificações o ar é proveniente de um plenum, em um espaço de aproximadamente $30 \mathrm{~cm}$ entre a laje e o piso elevado. Normalmente, o retorno do ar está localizado no teto. O sistema UFAD tem como principais características promover a troca de calor com o ambiente mais rapidamente, poder climatizar apenas volumes de ar do espaço ocupado e poder operar com temperaturas do ar mais altas do que as adotadas nos sistemas convencionais (LEITE, 2003). Assim como no sistema por deslocamento DV o escoamento do ar ocorre na direção e no sentido da pluma térmica gerada pelos ocupantes do ambiente, devido à convecção natural. Este fato contribui para melhorar a qualidade do ar, pois os contaminantes gerados pelas pessoas também são carregados pelo movimento do ar até a exaustão no teto.

Os sistemas DV e UFAD podem apresentar potencial para a economia de energia, pois esses sistemas têm a característica de trabalharem com o ar sendo insuflado com menores velocidades, conforme citado anteriormente, e com maiores temperaturas quando comparado a outros sistemas. Devido à eficiência causada pela direção ascendente do ar no ambiente na remoção de contaminantes esses tipos de sistemas poderão reduzir a taxa de ventilação por pessoa no ambiente, reduzindo o custo de operação.

Ambientes com distribuição de ar pelo piso, UFAD, são caracterizados pela estratificação do ar em duas zonas. Assim como no sistema por deslocamento DV, a zona ocupada que é a região de mistura do ar, onde o ar é mais frio e mais limpo, e a zona acima desta, que é a região de deslocamento do ar, que apresenta temperaturas mais elevadas e concentra uma maior quantidade de contaminantes (BAUMAN; DAILY, 2003).

Embora os sistemas DV e UFAD apresentem uma melhor qualidade do ar do que o sistema MV, estes sistemas podem apresentar estratificação de temperatura não desejável, o que aumenta a possibilidade de ocupantes sentirem desconforto térmico local. É 
importante ressaltar que este fato pode ser potencializado em cabines de avião, em função do menor volume ocupado e da menor altura comparada com os ambientes de edificações.

\subsection{Sistemas de Ventilação Personalizada em Cabines de Aeronaves}

Uma forma de melhorar o conforto térmico em cabines de aeronaves é utilizar sistemas de ventilação personalizada, Personalized Ventilation (PV). Estes sistemas têm como principal característica proporcionar um microclima no entorno do passageiro, possibilitando o controle de temperatura individualizado e o fornecimento de ar limpo na zona de respiração (MELIKOV, 2004, KACZMARCZYK et al., 2004, LEITE; TRIBESS, 2004, KACZMARCZYK et al., 2006, GAO; NIU, 2007b, LI et al., 2010, ZHANG; LI; WANG, 2011, CONCEIÇÃO, 2012, FANG et al. 2015, YOU et al., 2018a, YOU et al., 2018b), fato que pode contribuir para diminuir a contaminação cruzada entre os ocupantes.

Cabines de aeronaves comerciais comumente possuem sistema de ventilação personalizada, PV, que consiste em saídas de ar individualizadas, denominadas válvulas gasper. A figura 2.4 apresenta exemplos dessas válvulas e a sua aplicação em aeronaves. As válvulas gasper têm o objetivo de produzir efeitos de aquecimento ou resfriamento somente na região próxima à cabeça dos ocupantes e com isso não permite o ajuste térmico individualizado em torno de cada passageiro (Stancato e Tribess, 2008).

Estudos referentes à influência das válvulas gasper na dispersão de partículas entre os passageiros são bastante recentes.
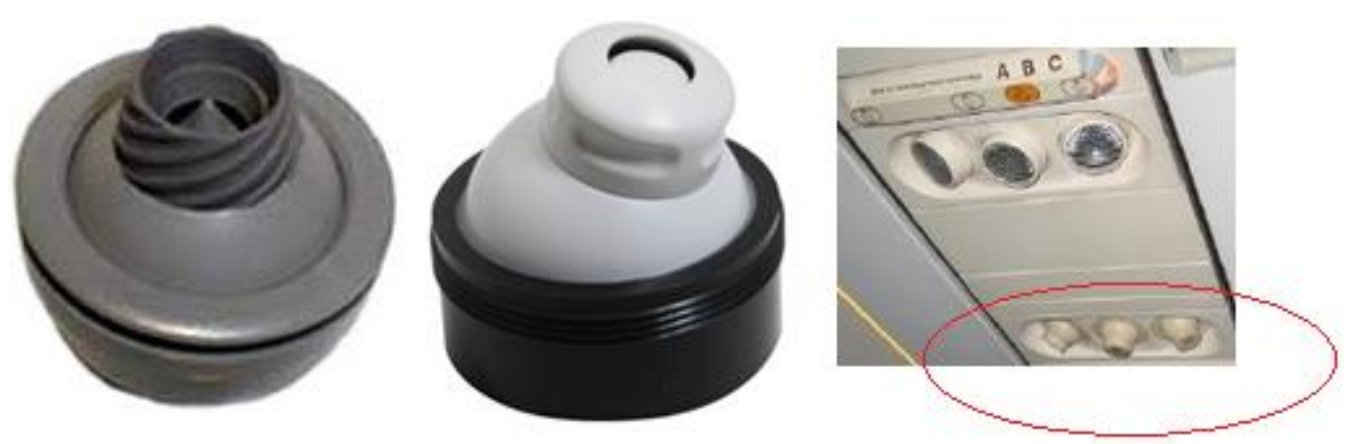

Figura 2.4. Saídas de ar personalizadas tipo válvula gasper Fonte: WALKINSHAW, 2011; CONCEIÇÃO, 2012 
Conceição (2012) analisou a influência da válvula gasper na dispersão de partículas expiratórias ao longo da cabine por meio de simulações computacionais e medições experimentais em cabine de mock-up instrumentado. Segundo Conceição (2012), a válvula gasper pode minimizar a dispersão de partículas devido ao fato de aumentar a taxa de deposição de partículas nas superfícies da cabine.

Fang et al. (2015) construíram uma câmara de teste que simula o interior das cabines de aeronaves modernas e realizaram pesquisa cujo objetivo foi o de estudar motivos que levam os passageiros a utilizar as válvulas gasper, bem como avaliar o ajuste do nível de fluxo de ar e as mudanças de direção do fluxo de ar realizadas pelos passageiros. Os resultados mostram que a sensação térmica dos passageiros muda ao longo do tempo na cabine de avião. Os autores verificaram que $70 \%$ abriram as válvulas gaspers nos primeiros 30 minutos do experimento para melhorar suas condições de conforto térmico e com relação à direção do ar apenas 15,2\% dos participantes no estudo escolheram ajustar o fluxo de ar na direção de suas faces e cabeças. Isto mostra que muitos voluntários preferiram não ter o escoamento do ar direto em suas faces, ao menos em períodos longos de tempo. Mesmo tendo este trabalho sido realizado focando as condições de conforto térmico, este resultado é importante no desenvolvimento de dispositivos de ventilação personalizada, pois mostra que a maioria das pessoas não escolheria direcionar o fluxo de ar direto na zona de respiração.

Li et al. (2016) realizaram estudo do impacto do fluxo de ar da válvula gasper na qualidade do ar na cabine de uma aeronave. Foram medidas velocidades e temperaturas do ar e concentração de contaminantes gasosos em cinco fileiras na classe econômica de um avião comercial MD-82. O contaminante gasoso foi simulado usando SF6 como um gás traçador com a fonte localizada na boca de um manequim sentado próximo ao corredor. Dados obtidos em um estudo anterior da cabine com todas as válvulas gasper desligadas foram usados para comparação. Os resultados mostram que os jatos dos gaspers tiveram um impacto substancial na velocidade do ar e no transporte de contaminantes na cabine. A velocidade do ar na cabina era mais alta, e a temperatura do ar era um pouco mais uniforme, quando os gaspers estavam ligados do que quando estavam desligados. Por outro lado, ligar os gaspers não melhorou a qualidade do ar na cabine

You et al. (2017) tiveram como objetivo responder a seguinte questão: se um passageiro liga seu gasper em um avião comercial, seu risco de infecção será reduzido? Primeiro esta investigação desenvolveu um modelo de turbulência para simulações de fluxo de ar de cabine e validou o modelo com dados experimentais. Em seguida os autores 
investigaram numericamente o impacto dos gaspers na qualidade do ar da cabine em uma seção de sete fileiras de cabine de classe econômica de Boeing 767 e Boeing 737. Os autores concluiram que os gaspers ligados/desligados podem influenciar significativamente o risco de infecção dos passageiros, tanto no Boeing 767 como no Boeing 737. Porém, mesmo a válvula gasper fornecendo ar limpo destinado ao passageiro, ela pode, na verdade, ter um impacto negativo na saúde do passageiro, pois os contaminantes que estão na região acima da cabeça do passageiro podem ser lançados diretamente na zona de respiração devido ao jato de ar que é lançado.

Alguns outros autores estudaram a influência do sistema de ventilação e distribuição de ar da cabine com outros tipos de sistemas de ventilação personalizada na dispersão de contaminantes (JACOBS; GIBS, 2005, GAO; NIU, 2007a, ZHANG; CHEN, 2007, NIELSEN et al., 2007, NIELSEN et al., 2008, ZHANG et al., 2008, ZHANG et al., 2011, FANG et al., 2015, YOU et al., 2018).

Jacobs e Gibs (2005) apresentam os resultados de medições para quantificar o escoamento do ar por convecção em torno de uma pessoa sentada e o efeito desse escoamento na trajetória do ar insuflado por sistemas personalizados. Para simular os contaminantes os autores adicionaram gás traçador $\left(\mathrm{SF}_{6}\right)$ no sistema de ventilação da cabine. O ar limpo foi insuflado próximo à cabeça do passageiro, simulado por manequins, dos dois lados, conforme mostrado na figura 2.5. A distância entre os difusores e a zona de respiração foi de aproximadamente $25 \mathrm{~cm}$.

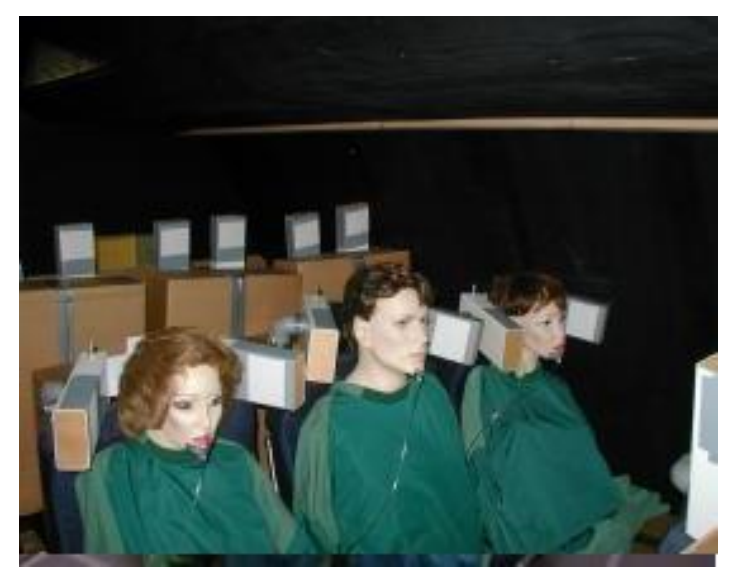

Figura 2.5. Insuflamento de ar personalizado próximo a cabeça Fonte: JACOBS; GIBS, 2005

Os experimentos foram realizados em mock-up de 30 lugares, que representa a cabine de uma aeronave, para estudar os efeitos do sistema de ventilação no insuflamento de ar local. Os autores puderam observar que não é possível insuflar ar acima dos ombros 
sem causar desconforto térmico local, e também observaram com o experimento utilizando gás traçador e manequins aquecidos, que em cada assento houve uma eficiência de remoção de contaminantes de até $96 \%$ na zona de respiração. Os autores puderam concluir que o insuflamento de ar próximo à zona de respiração do passageiro permite umidificação do ar e pode dar alguma proteção contra doenças infecciosas.

Em seguida Jacobs e Gibs (2005) apresentam um novo conceito de climatização em cabines de aeronaves. Os autores apresentam assentos com sistemas de controle de temperatura e contendo insuflamento e exaustão de ar. Com isso o passageiro é capaz de controlar a temperatura da superfície do assento e também lançar ar limpo próximo à zona de respiração. Segundo os autores, $20 \%$ do calor proveniente do corpo humano pode ser dissipado diretamente pelo controle da vazão de ar no assento, e assim a cabine da aeronave pode ser mantida a uma temperatura maior gerando economia de energia. Os ensaios foram realizados em um mock-up apresentado na figura 2.6.

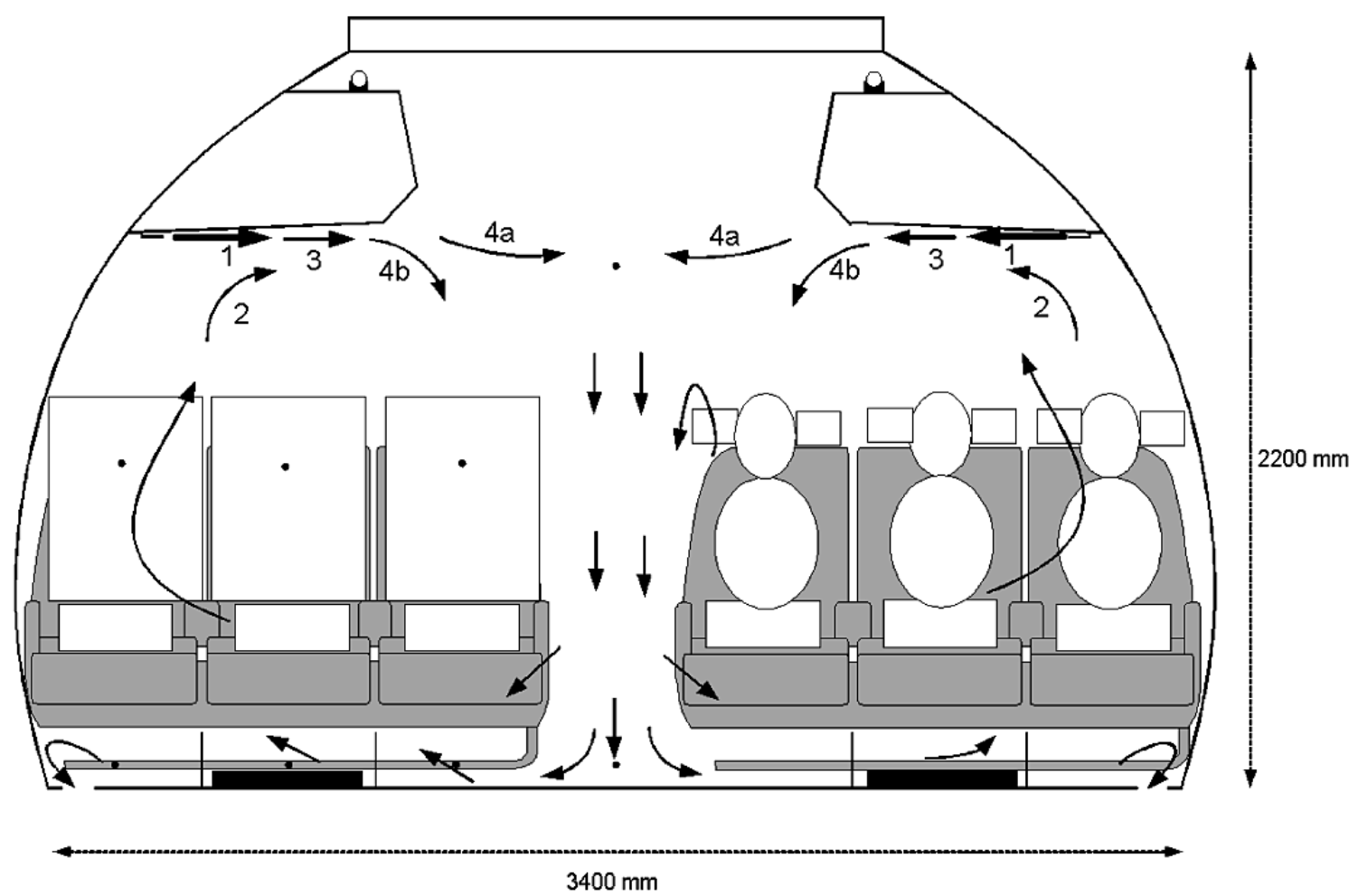

Figura 2.6. Geometria do mock-up com e o padrão de escoamento do ar Fonte: JACOBS; GIBS, 2005

Assim como no estudo anterior, os autores utilizaram gás traçador para simular os contaminantes e verificaram que para uma vazão pessoal de $0,002 \mathrm{~m}^{3} / \mathrm{s}$ a redução de 
contaminantes na zona de respiração é insignificante, já para uma vazão pessoal de $0,004 \mathrm{~m}^{3} / \mathrm{s}$ a redução na concentração de contaminantes variou de $57 \%$ a $96 \%$.

Os autores Gao e Niu (2007a) utilizaram um código de dinâmica dos fluidos computacional - CFD (Computational Fluid Dynamics) para simular e avaliar o sistema de ventilação por mistura MV e um sistema de ventilação personalizada PV em uma cabine de aeronave. Os autores demonstraram que um sistema personalizado de ventilação igual ao proposto, apresentado na figura 2.7, pode ser capaz de reduzir em $60 \%$ o nível de contaminantes na zona de respiração dos ocupantes. Por outro lado, segundo os autores os sistemas MV e MV+PV dispersam os contaminantes para outras regiões da cabine. Porém, não apresentam validação experimental para embasar os resultados de dispersão de contaminantes obtidos por CFD.

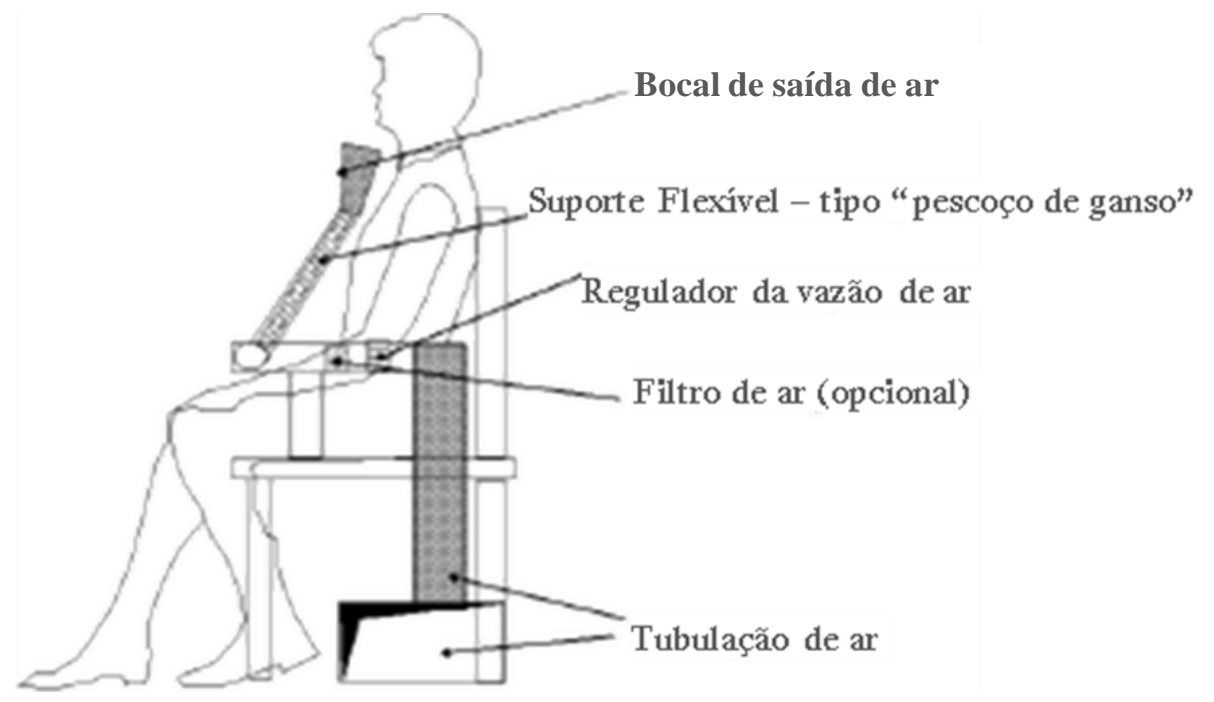

Figura 2.7. Sistema personalizado com insuflamento de ar por bocal instalado na poltrona Fonte: Adaptado de GAO; NIU, 2007a

Para modelar a dispersão de gases e de aerossóis, respectivamente, os autores consideraram taxa de inalação média constante de $0,14 \mathrm{~L} / \mathrm{s}(8,4 \mathrm{~L} / \mathrm{min})$ por pessoa e empregaram o método de Euler e o de Lagrange. Primeiro resolveram o escoamento com RANS e modelo de turbulência k- $\varepsilon$ padrão e funções de parede semi-empíricas. A fase dispersa foi modelada com partículas esféricas de $1 \mu \mathrm{m}$ de diâmetro e massa específica de $1000 \mathrm{~kg} / \mathrm{m}^{3}$. No método lagrangeano consideraram espirro horizontal com duração de $0,5 \mathrm{~s}$ e velocidade inicial de $20 \mathrm{~m} / \mathrm{s}$.

Os autores concluíram que, mesmo mantendo a vazão total de insuflamento inalterada, a solução de ventilação por mistura com PV reduz a probabilidade de contaminação cruzada entre os passageiros se comparada com a solução de ventilação por 
mistura somente. Porém, não analisaram impactos no conforto térmico dos ocupantes e não apresentam validação experimental para embasar os resultados de dispersão de contaminantes obtidos por CFD.

Por outro lado, Zhang e Chen (2007) estudaram, tanto experimentalmente quanto por meio de simulação numérica computacional (CFD), um sistema convencional MV, um sistema UFAD e um sistema UFAD juntamente com um sistema de ventilação personalizada PV, em um Boeing 767-300. A vazão de insuflamento de ar foi de $10 \mathrm{~L} / \mathrm{s}$ e a temperatura média de cabine foi ajustada para $24^{\circ} \mathrm{C}$. Os autores basearam-se em sistema personalizado proposto por Kaczmarczyk et al. (2004) para ambientes de escritórios.

Para o sistema UFAD e o sistema personalizado PV os autores utilizaram metade da vazão de ar diretamente por trás da poltrona imediatamente à frente do passageiro e a outra metade foi insuflada pelo piso (UFAD). Conforme mostrado na figura 2.8, pode ser visto o campo dos vetores de velocidade do ar resultantes do funcionamento do sistema PV.

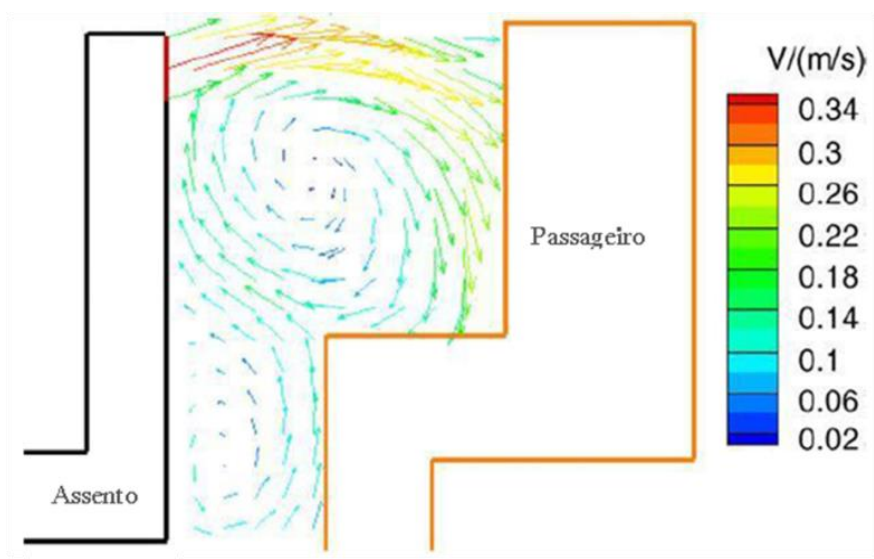

Figura 2.8. Vetores velocidade em sistema personalizado com insuflamento de ar pela poltrona à frente

Fonte: Adaptado de ZHANG; CHEN, 2007

Os autores apresentam como conclusão que os níveis de contaminantes presentes na zona de respiração são menores quando se utiliza o sistema UFAD com sistema de ventilação personalizada, PV. Apesar da estratificação da temperatura do ar que pode ser observada no sistema UFAD, a quantidade de partículas dispersas ao longo da cabine foi ligeiramente inferior quando comparada com o sistema MV. O fator importante a ressaltar é que os autores ainda puderam constatar que a utilização combinada do sistema UFAD junto com o sistema PV resultou em menores índices de concentração de $\mathrm{CO}_{2}$, com 
eliminação quase total do risco de partículas infecciosas na zona de respiração dos passageiros.

Nielsen et al. (2007) avaliaram experimentalmente a efetividade de dois tipos de sistemas PV em poltronas de avião: integradas ao travesseiro de pescoço; e outras integradas ao assento e encosto, conforme Figura 2.9. Os autores insuflaram ar limpo pelos sistemas PV, enquanto gás traçador $\mathrm{N}_{2} \mathrm{O}$ era adicionado ao ar de ventilação de cabine para manter o ambiente com uma dada concentração de "poluição". O mesmo gás foi monitorado no ambiente (entrada, saída, e ao longo da sala), no ar inalado e no ar proveniente do próprio PV. Além de utilizarem o $\mathrm{N}_{2} \mathrm{O}$ como gás traçador, os autores empregaram fumaça para avaliar qualitativamente a zona de abrangência dos PVs. Porém, não avaliaram a resposta dos sistemas personalizados PV quanto à contaminação cruzada de poluentes maiores (gotículas líquidas). Além disso, como o assento não foi inserido a um ambiente de avião, não captou a interação entre PV e a ventilação de cabine, bem como a influência dos obstáculos do interior da aeronave (demais assentos e passageiros vizinhos).

(a)

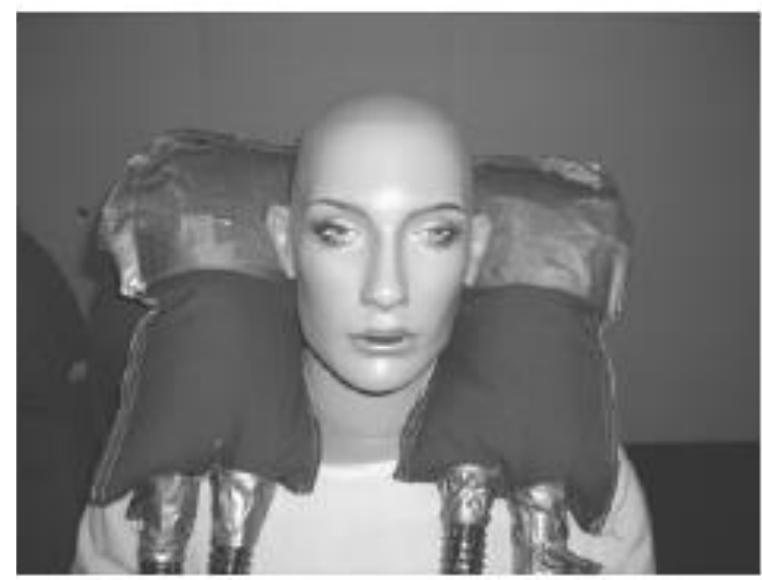

(b)

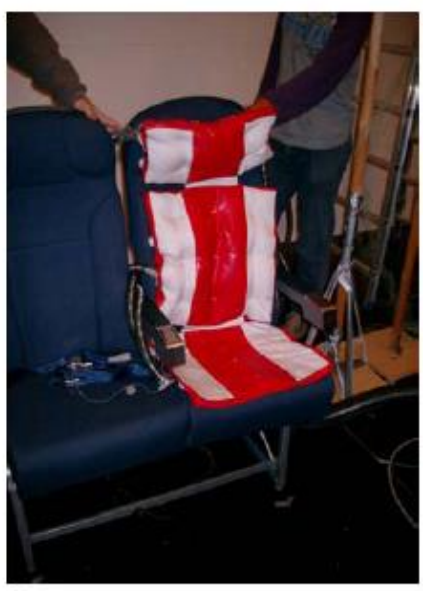

Figura 2.9. Estudos de ventilação personalizada em bancos de aeronaves. (a) solução integrada ao suporte de pescoço; (b) solução integrada à espuma do assento Fonte: NIELSEN et al., 2007

O experimento foi realizado em uma sala com dimensões de 8 × 6 × 4,6 m, com ventilação pelo teto, contendo um manequim térmico com respiração BTM - Breathing Thermal Manikin - sentado em uma poltrona de avião. Os autores concluíram que o sistema PV integrado ao travesseiro de pescoço é mais eficiente para evitar contaminação cruzada do que o sistema PV integrado ao assento. No entanto, a solução proposta (Figura 
2.9a) não parece ser suficientemente ergonômica a ponto de ser utilizada permanentemente em voos mais longos, nos quais a exposição ao risco de contaminação cruzada é maior.

Outro estudo importante com este mesmo tipo de sistema de ventilação personalizado foi o realizado por Nielsen et al. (2008), O sistema tem formato de travesseiro, e nele o passageiro apóia o pescoço, conforme modelo ilustrado na figura 2.10. Neste estudo os autores apresentam que o sistema PV é altamente eficiente na remoção da contaminação cruzada. Porém, isso só é possível se o sistema PV for capaz de controlar os níveis de contaminantes no ambiente por meio das taxas de renovação do ar recomendadas. O sistema de ventilação personalizada PV proposto fornecia ar fresco para a zona de respiração com uma vazão máxima de até $16 \mathrm{~L} / \mathrm{s}$. Os autores concluíram que o sistema é mais eficiente para taxas de insuflamento de ar total entre 7 a $8 \mathrm{~L} / \mathrm{s}$ - em conformidade com o preconizado pela norma ASHRAE-161 (2007), que recomenda vazões de ar entre 5,9 e 9,6 L/s/pessoa. Além disso, o risco de correntes de ar pode ser minorado ou até evitado pelo controle da temperatura do ar do sistema PV.
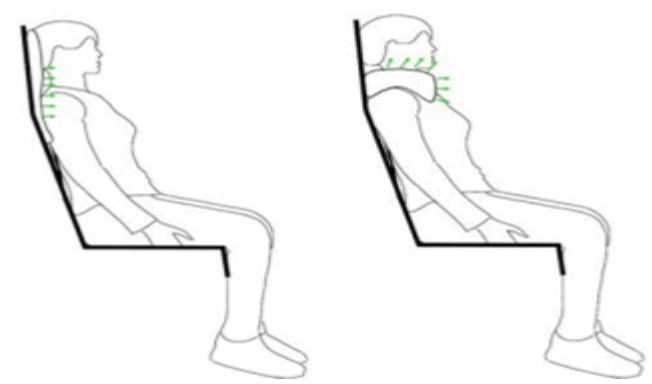

Figura 2.10. Sistema personalizado com insuflamento de ar tipo travesseiro de pescoço

Fonte: NIELSEN et al., 2008

Um outro trabalho realizado com o intuito de se fazer uma comparação entre a utilização de sistemas de ventilação e distribuição de ar de cabine e sistemas personalizados foi realizado por Zhang et al. (2008). Os autores também estudaram a dispersão de partículas em mock-up de aeronave Boeing 767-300, conforme figura 2.11. Os autores utilizaram para as avaliações simuladores térmicos de pessoas em formato de caixa. Inicialmente foi avaliado pelos autores o sistema de ventilação MV para estudar a dispersão de partículas no interior da cabine e, com base nas medições da velocidade e temperatura do ar e concentração de contaminantes, foi possível comparar os resultados obtidos experimentalmente com os resultados extraídos do modelo computacional, desenvolvido pelos próprios pesquisadores. Em seguida, os autores utilizaram o mesmo 
código CFD na estimativa da dispersão de contaminantes utilizando sistema de ventilação com insuflamento de ar pelo piso (UFAD) e sistema de insuflamento de ar pelo piso com ventilação personalizada (UFAD + PV).

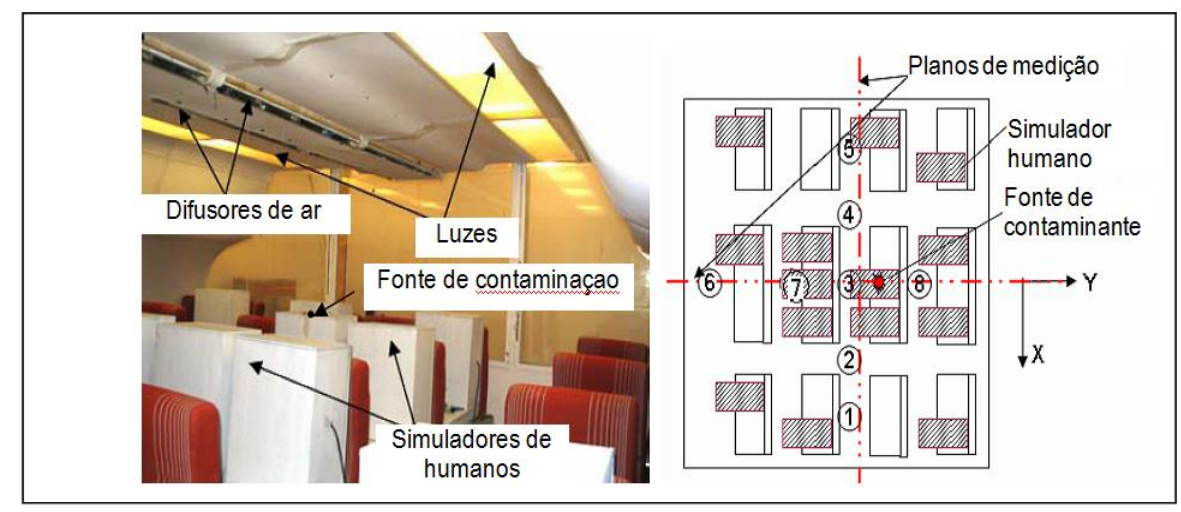

Figura 2.11. Mock-up de cabine de aeronave e planos de medição

Fonte: Adaptado de ZHANG et al., 2008)

Os autores puderam verificar, conforme apresentado na figura 2.12 , com os resultados obtidos da simulação numérica, que o sistema MV proporciona temperaturas mais homogêneas do ar. Porém, esse sistema oferece um risco maior de dispersar a contaminação gerada de um local para os demais. Por outro lado, no sistema UFAD o risco de contaminação diminui, pois as velocidades de insuflamento de ar são baixas e o ar segue um fluxo ascendente, mais regular. Mas o mais importante é que, segundo os autores, o sistema de insuflamento pelo piso aliado ao sistema de ventilação personalizada (UFAD + PV) proporciona os melhores resultados de qualidade do ar na zona de respiração.

Uma proposta de insuflar uma parte do ar pelo piso (UFAD) e a outra parte diretamente para a zona de respiração do passageiro por meio de um difusor localizado nos braços do assento, foi apresentada por Zhang et al. (2011). A figura 2.13 apresenta o sistema proposto. $\mathrm{O}$ estudo foi realizado tanto numérica quanto experimentalmente, sendo que o percentual de pessoas insatisfeitas devido a correntes de ar, avaliado quando o sistema PV era utilizado em todos os assentos, foi calculado diretamente pelo algoritmo de simulação CFD. Os autores apresentam que o percentual de pessoas insatisfeitas era ligeiramente menor quando o sistema de ventilação personalizada PV estava em funcionamento. Porém, não há uma conclusão quanto à eficiência do sistema de ventilação PV na remoção de partículas na zona de respiração dos passageiros. 
a)

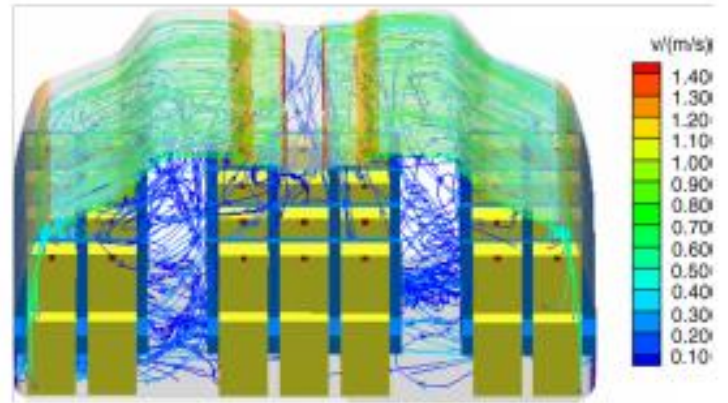

b)
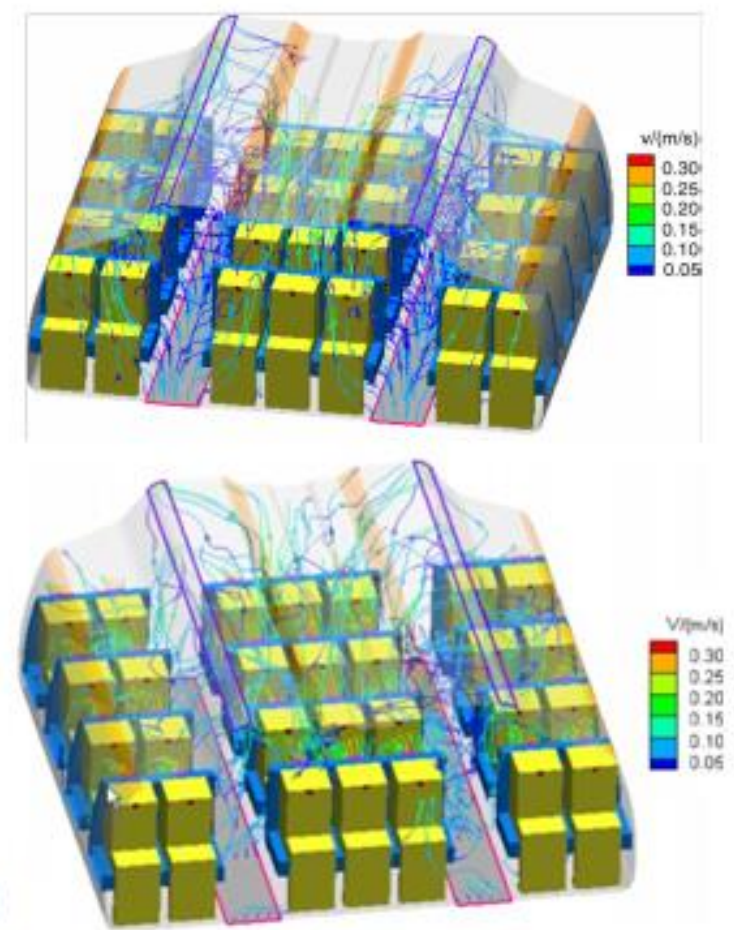

Figura 2.12. Linhas de corrente: (a) sistema MV, (b) sistema UFAD e (c) sistema UFAD com ventilação personalizada

Fonte: ZHANG; CHEN, 2008 


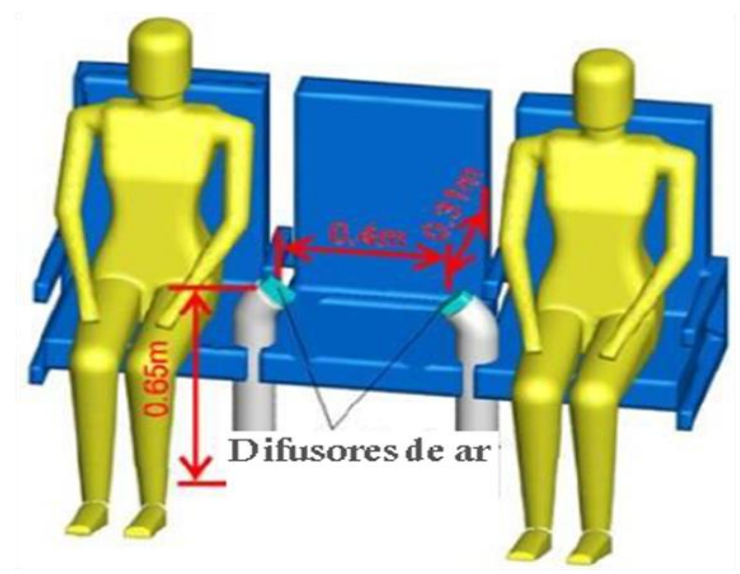

Figura 2.13. Sistema personalizado com insuflamento de ar pela lateral da poltrona Fonte: ZHANG et al, 2011

Mais recentemente, You et al. (2018a) e You et al. (2018b) desenvolveram um inovador sistema de ventilação que fornece ar a partir de difusores de ventilação individual embaixo do assento, figura 2.14, em substituição ao sistema MV, para reduzir o transporte de contaminantes em cabines de aeronaves. Para avaliar o desempenho desse novo sistema de ventilação no controle do transporte de contaminantes, o estudo utilizou CFD e baseouse em dados referentes ao surto de SARS em um voo de Hong Kong a Pequim durante as epidemias de 2003. Esta investigação avaliou o desempenho do novo sistema de ventilação em uma seção de sete fileiras da classe economica da cabine de Boeing 737. Os autores verificaram que o novo sistema poderia reduzir risco de infecção dos passageiros em comparação com o sistema de ventilação por mistura, pois o novo sistema de ventilação pode controlar melhor o transporte de contaminantes em comparação com o sistema de ventilação por mistura. Porém, apesar do insuflamento de ar ser individualizado em cada assento, os passageiros não tinham o controle individualizado do sistema como ocorre em sistemas personalizados PV, que operam em conjunto com o sistema da cabine. 


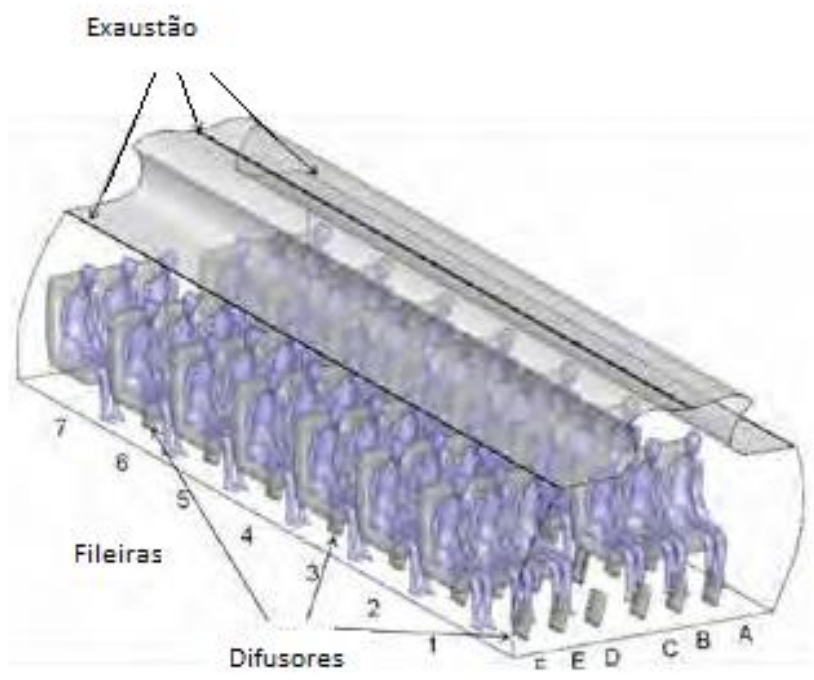

Figura 2.14. Sistema com isuflamento debaixo dos assentos Fonte: Adaptado de YOU et al., 2018

Um fato importante a se destacar é que a utilização de sistemas personalizados pode aumentar a possibilidade de contaminação de outros passageiros em função da dispersão das partículas na cabine, o que será estudado no presente trabalho.

Conforme apresentado, fica evidente que ainda existem muitos trabalhos a serem desenvolvidos nessa área com o intuito de verificar a eficiência dos sistemas personalizados juntamente com diferentes sistemas de ventilação e distribuição de ar na remoção e no controle da dispersão de contaminantes aéreos em cabines de aeronaves. E, principalmente, de avaliar o impacto da dispersão de partículas ao longo da cabine. Também é possível verificar que a combinação do sistema personalizado com outros sistemas de ventilação da cabine pode ser uma das estratégias para diminuir o risco da contaminação cruzada em cabines de aeronaves 


\section{Capitulo 3}

\section{DISPERSÃO DE PARTÍCULAS EM CABINES DE AERONAVES}

Neste capítulo são apresentadas as principais características da dispersão de partículas expiratórias em ambientes interiores focando, principalmente, na contaminação cruzada entre os ocupantes. Assim, inicialmente são apresentadas as características que definem a qualidade do ar e as características gerais da dispersão de partículas, seguidas da descrição específica da dispersão de partículas expiratórias que são as responsáveis pela contaminação cruzada entre os ocupantes de um ambiente.

\subsection{Qualidade do ar}

A qualidade do ar em ambientes, tanto internos como externos, está relacionada diretamente com a concentração de poluentes existentes no ar.

O ar atmosférico é constituído como nitrogênio (78,10\%), o oxigênio (20,94\%), o argônio $(0,93 \%)$ e o dióxido de carbono $(0,03 \%)$. Além desses gases, encontram-se no ar pequenas porcentagens de outros gases, como néon, hélio, metano, hidrogênio, ozônio, e xenônio entre outros, que, somados representam 0,003\% (30 ppm) da composição total da atmosfera (composição em volume de ar seco), bem como quantidades variáveis de vapor de água e pequenas quantidades de materiais sólidos, denominados de impurezas (PEREIRA, 2004).

Variações significantes na porcentagem da composição dos constituintes normais e a presença de outros materiais estranhos que podem ser classificados como contaminantes podem tornar o ar impróprio para o seu uso.

Contaminante ou poluente atmosférico é toda e qualquer matéria sólida, líquida ou gasosa que, presente na atmosfera, altera suas condições normais levando à ocorrência de efeitos nocivos reais ou potenciais. Os contaminantes atmosféricos podem ser classificados inicialmente, em função do seu estado físico, em material particulado e gases. Também podem ser classificados, de acordo com a classe química, em orgânicos e inorgânicos, e de acordo com a sua origem, em poluentes primários, emitidos já na forma de poluentes, e poluentes secundários, quando são formados na atmosfera por reações químicas ou fotoquímicas. 
O material particulado em suspensão (MPS) é um termo genérico para uma grande classe de substâncias químicas existentes na atmosfera na forma de partículas. A UNEP/WHO (1994) define o termo MPS como um conjunto de partículas sólidas e líquidas suspensas e dispersas no ar. As propriedades dessas partículas variam em composição química, morfologia (tamanho/forma), parâmetros ópticos (cor/espalhamento de luz) e características elétricas (carga/resistência) (ALMEIDA, 1999). Por outro lado, VASCONCELLOS (1996) define o material particulado em suspensão como sendo qualquer substância, exceto água pura, que existe no estado sólido ou líquido na atmosfera, que sob condições normais possui dimensões microscópicas a submicroscópicas, mas maior que as dimensões moleculares.

Os aerossóis são geralmente formados por processos de dispersão e condensação. Os aerossóis formados por dispersão são resultado da desintegração mecânica da matéria e possuem partículas com uma maior variação de forma e tamanho. Os aerossóis de condensação são formados pela condensação de vapores supersaturados ou pela reação entre gases. Nesses aerossóis as partículas sólidas são frequentemente agregados frouxos provenientes da coagulação de um grande número de partículas primárias de forma esférica ou cristalina regular. Por outro lado, nos aerossóis por dispersão a fase dispersa sólida consiste em partículas individuais ou agregadas de formas completamente irregulares (fragmentos). Nos aerossóis cuja fase dispersa é líquida, as partículas são esféricas e, quando colidem, podem se fundir, produzindo uma única partícula esférica (MESQUITA; GUIMARÃES; NEFUSSI, 1988, MACINTYRE, 1988).

Os aerossóis podem ser subdivididos de acordo com a sua forma física e seu método de geração. Não existem critérios científicos para a sua classificação (HINDS, 1999). As definições a seguir são comuns de serem encontradas na literatura científica.

Fumaças - São aerossóis formados por partículas sólidas, resultantes da combustão incompleta de materiais orgânicos, constituídas geralmente por partículas com diâmetros inferiores a $1 \mu \mathrm{m}$.

Poeiras - São aerossóis constituídos por partículas sólidas formadas pela desintegração mecânica de substâncias inorgânicas ou orgânicas, com diâmetros que variam de 0,1 a $100 \mu \mathrm{m}$ e possuem geralmente formas irregulares. 
Névoas - São aerossóis resultantes da condensação de vapores sobre certos núcleos, ou da dispersão mecânica de líquidos em consequência de operações de pulverização, nebulização, respingos, etc. São constituídos por gotículas líquidas com diâmetros entre 0,1 e $100 \mu \mathrm{m}$.

Bioaerossóis - A American Conference of Governmental Industrial Hygienists (ACGIH) adotou o termo bioaerossóis para substâncias aerotransportadas compostas ou derivadas de organismos vivos. Os bioaerossóis possuem dimensão que varia de 0,1 $\mu \mathrm{m}$ a $100 \mu \mathrm{m}$. Este termo também engloba combinações gasosas que liberam organismos. Os bioaerossóis podem ser células microbianas (por exemplo: culturáveis ou não culturáveis, microrganismos mortos, vírus, bactérias, protozoários e fungos) e fragmentos, toxinas e produtos particulados de dejetos de todas as variedades de coisas (por exemplo: microrganismos, plantas, artrópodes, pássaros e mamíferos).

O comportamento das partículas no ar e a sua velocidade de sedimentação é controlado pelo tamanho, pela forma, pela densidade e pela concentração das mesmas, associados ao movimento do ar. É importante ter o conhecimento dessas características para predizer o movimento das partículas num ambiente.

\subsection{Tamanho das partículas}

Existe muita complexidade quando se deseja definir o tamanho de uma partícula. Assim, em muitos casos, são definidas apenas aquelas partículas que pertencem a uma faixa de tamanho que pode ser medida ou calculada.

As partículas em um ambiente não tem uma forma esférica definida. Porém, os instrumentos de contagem utilizados apresentam faixas de medição de tamanho de partículas em função do seu diâmetro. Existe uma incerteza com relação ao seu diâmetro devido à posição da partícula no momento de leitura do sensor. Um exemplo é apresentado na figura 3.1, pois dependendo da posição da partícula o resultado pode ser bem diferente do real. Na figura pode-se verificar que a mesma partícula pode ficar retida em uma abertura maior (Figura 3.1a) ou passar por uma abertura menor (figura 3.1b). Porém, o tamanho de uma partícula é o principal fator determinante no comportamento de um aerossol, pois as partículas têm comportamentos característicos para suas diferentes faixas de tamanho, os quais são regidos por diferentes leis físicas (WILLEKE; BARON, 2005). Também, se trata de um dos parâmetros mais importantes no estudo da poluição 
atmosférica, pois exerce influência direta sobre vários fenômenos associados aos aerossóis, tais como o transporte, a deposição e a migração através do ambiente, além de efeitos nocivos (ALMEIDA, 1999).

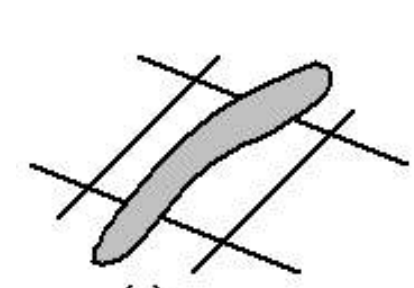

(a)

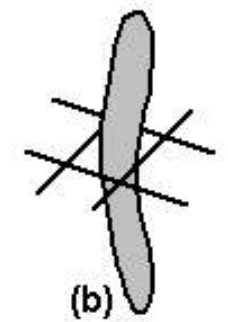

(b)

Figura 3.1. Efeito da forma da partícula para sua classificação

A forma de uma partícula individual é geralmente expressa em termos de uma propriedade que é independente do seu tamanho, chamada de esfericidade ( $\psi$ ). Para uma partícula esférica, a esfericidade é igual a 1. Para as demais formas de partículas, a esfericidade sempre é menor que 1, e segundo Yang (2003) e Motta (2009) é dada pela equação 1:

$$
\Psi=\left(\frac{\text { Área da superfície de uma esfera com mesmo volume }}{\text { Área da superfície da partícula }}\right)
$$

Devido à complexidade na determinação do tamanho das partículas, existem várias definições para o tamanho de partícula que dependem da técnica de medição ou do uso para o qual tal parâmetro será empregado.

\subsection{Qualidade do ar em ambientes de aeronaves}

Como citado anteriormente, as cabines de aeronaves caracterizam-se por serem ambientes onde os ocupantes encontram uma combinação de fatores que podem comprometer a qualidade do ar desses ambientes. Segundo Gao, Xieg e Yang (2015), em cabines de aeronaves os passageiros estão expostos a altas concentrações de ozônio $\left(\mathrm{O}_{3}\right)$, fato que é nocivo ao trato respiratório e ao sistema cardiovascular. Outro fator importante é que os ocupantes desses ambientes estão expostos a compostos orgânicos voláteis (VOCs) que segundo Guan et al. (2014a) tem efeitos adversos à saúde, como irritação nas membranas mucosas, fadiga, dificuldade de concentração, efeitos tóxicos e cancerígenos. 
Ainda, os ocupantes desses ambientes estão expostos à baixa umidade, baixa pressão do ar, material particulado e agentes biológicos (LEE et al., 1999, SPENGLER; SAMET; MCCARTHY, 2004, CHESTER et al., 2004, WANG et al., 2014, GAO; XIEG; YANG., 2015).

Segundo Walkinshaw (2010) muitos passageiros de aeronaves tem preocupação com germes durante o voo. Ainda mais se for levado em consideração a propagação mundial do vírus SARS (OLESEN; CHANG; CHEUNG, 2003), que ocorreu em função de que pessoas infectadas viajaram de avião entre diversas cidades. Também doenças como influenza e malária foram propagadas em cabines de aviões (MANGILI;GEANDREAU, 2005).

Um trabalho muito importante em relação à transmissão de contaminantes foi realizado por Wagner, Coburn e Blower (2009). Nesse trabalho os autores apresentam o potencial de transmissão de uma pessoa infectada com H1N1. Os autores concluem que 17 pessoas podem ser infectadas por uma pessoa com o vírus em um voo de $17 \mathrm{~h}$ de duração em classe econômica, e que de 2 a 5 pessoas podem ser infectadas em voo de 5 h de duração.

Contudo, Connor (2009) apresenta que a disseminação de doenças em função da contaminação cruzada pode ter uma proporção maior do que a registrada na literatura, até porque algumas enfermidades possuem um tempo de incubação maior do que aquele do voo. Com isso os sintomas podem aparecer em período posterior. Também deve-se levar em consideração que o número de pessoas que viajam em aviões aumentou.

\subsection{Contaminantes aéreos e a contaminação cruzada}

A contaminação aérea de modo geral vem sendo estudada em diversos ambientes tais como residências, hospitais, trens, ônibus, salas de aulas e em cabines de aviões (SILVERS et al.. 1994, COLE; COOK, 1998, GOLDMANN, 2000, BEGGS, 2003, OLESEN; CHANG; CHEUNG, 2003, YU et al., 2004, MANGILI; GEANDREAU, 2005, gao et al., 2008, TANG et al., 2006, CHEN; DENG, 2008, CONCEIÇÃO; PEREIRA; TRIBESS, 2011, KIM HEA; LEE; KIM, 2008, CHO et al., 2008, PARK et al., 2008, , ONGWANDEE, 2008, KIM SUN et al., 2008, NIELSEN, 2009, WAGNER; COBURN; BLOWER, 2009, CONCEIÇÃO, 2012, BURTSCHERS; SCHUEPP 2012, FABICHAK JR. et al., 2013, LI et al., 2014, CIUZAS et al., 2015). 
A concentração de microorganismos no ar surge principalmente dos ocupantes da cabine (MANGILI; GEANDREAU, 2005), pois as partículas expiratórias, liberadas pela respiração, fala, bocejo, soluço, tosse ou espirros, são eliminadas via oral e nasal e são a origem das fontes de contaminnates associadas aos passageiros.

Partículas respiráveis, com diâmetro inferior a $10 \mu \mathrm{m}$, podem ser formadas por partículas sólidas ou líquidas supensas no ar, que podem ser inaladas pelas pessoas expostas (ASHRAE, 2007). Mesmo que as partículas contenham microorganismos, não há interferência na dinâmica do escoamento destas.

A maioria dessas partículas é formada pelo processo de atomização na passagem de meios gasosos sobre superfícies líquidas (MORAWSKA, 2005). Isso também ocorre no processo respiratório, pois gotículas são formadas na passagem do ar pelas vias orais e nasais. Se essas partículas forem produzidas por pessoas infectadas, agentes patogênicos podem ser expelidos e contaminar outras pessoas via inalação ou pelo contato sobre superfícies contaminadas. Segundo Bémer et al. (2000), as partículas líquidas e sólidas seguem o escoamento como se fossem partículas gasosas. O que as diferenciam é que as partículas gasosas, normalmente, são refletidas quando ocorre o choque com superfícies sólidas, ao contrário das partículas líquidas e sólidas que, normalmente, se depositam nestas superfícies.

Partículas menores que $5 \mu \mathrm{m}$ possuem uma característica de transporte similar aos gases (BÉMER et al., 2000), e em função disso podem ser carregadas pelo escoamento e permanecer em suspensão por tempo suficiente para evaporar, formando os denominados droplet nuclei ou núcleo de gotículas que permanecem em suspensão por longos períodos de tempo e podem tranportar agentes patogênicos por maiores distânicias (TANG et al., 2006). Por outro lado, de acordo com Connor (2009), partículas com diâmetros maiores que $5 \mu \mathrm{m}$ tem a característica de se depositarem sobre superfícies em função do seu peso.

Assim, passageiros com eventuais doenças respiratórias causadas por vírus, bactérias, alérgenos (tais como caspa, cílios e demais partículas sólidas produzidas pelas pessoas) e suor, também podem ser potenciais fontes da contaminação cruzada. Em função das elevadas densidades ocupacionais e do volume interno em aeronaves ser relativamente reduzido, a dispersão dessas partículas pode resultar em potenciais agentes contaminantes para seus ocupantes.

É importante ressaltar que elevados picos de concentração de biocontaminantes ocorrem, segundo Dechow, Sohn e Steinhanses et al. (1997), nos momentos em que os passageiros espirram, tossem ou fazem qualquer outra ação respiratória mais intensa. Pois, 
do contrário, de modo geral, as concentrações de biocontaminantes em cabine de aeronaves são baixas.

No instante dessas atividades expiratórias milhares de partículas podem ser geradas. A grande maioria delas possuem tamanho médio entre 2 e $100 \mu \mathrm{m}$, representando cerca de 95\% do total. Porém, dessa parcela, a maior quantidade tem diâmetro entre 2 e $8 \mu \mathrm{m}$, conforme apresentado na figura 3.2 (DUGUID, 1946). Segundo o autor, a atividade expiratória que mais gera partículas é o espirro, seguida pela tosse e depois a fala, sendo que o espirro pode liberar até 200 vezes mais partículas do que as liberadas pela tosse.

Apesar da época em que foi realizado o estudo, pode-se notar que este trabalho é sempre referenciado em estudos mais recentes, como por exemplo, Chao e Wan (2006), Wan et al., (2005), Sze To et al. (2009), Wan et al. (209), Conceição (2012) e Fabichack Jr. (2018).

Duguid (1946) fez a coleta das partículas expiratórias em placas oleosas, posicionando as placas próximas da boca das pessoas e em seguida, utilizando um microscópio e micrômetro, contou e mediu a quantidade e o tamanho das partículas. Embora Papineni e Rosenthal (1997), tenham verificado, utilizando contadores óticos, que a maior parte das partículas geradas no processo expiratório seja menor que $1 \mu \mathrm{m}$, Nicas, Nazaroff e Hubband (2005), utilizando método ótico IMI (interferometric Mie Imaging), apresentaram valores próximos ao de Duguid (1946).

Porém, deve-se ressaltar que devido à dificuldade de medição das gotículas formadas na atividade expiratórias algumas divergências entre valores encontrados pelos pesquisadores podem ocorrer (Chao et al., 2009).

Como forma de avaliar a dispersão de contaminantes em cabines de aeronaves, alguns trabalhos experimentais utilizam gás traçador como $\mathrm{SF}_{6}, \mathrm{CO}_{2}$ e $\mathrm{N}_{2} \mathrm{O}$ com o objetivo de simular a movimentação dos contaminantes (NIELSEN et al., 2007, NIELSEN, 2009, YAN et al., 2009).

Além de gases traçadores, muitos autores utilizam geradores de partículas com o objetivo de simular a geração de partículas internamente. Tais equipamentos, também denominados atomizadores, podem gerar partículas de tamanho único, partículas monodispersas, e partículas de tamanho variado, partículas polidispersas. Alguns geradores de partículas produzem aerossóis com tamanho médio da ordem de décimos de micrometros. Esses geradores são muito utilizados na indústria para testar a eficiência de filtros de ar. 


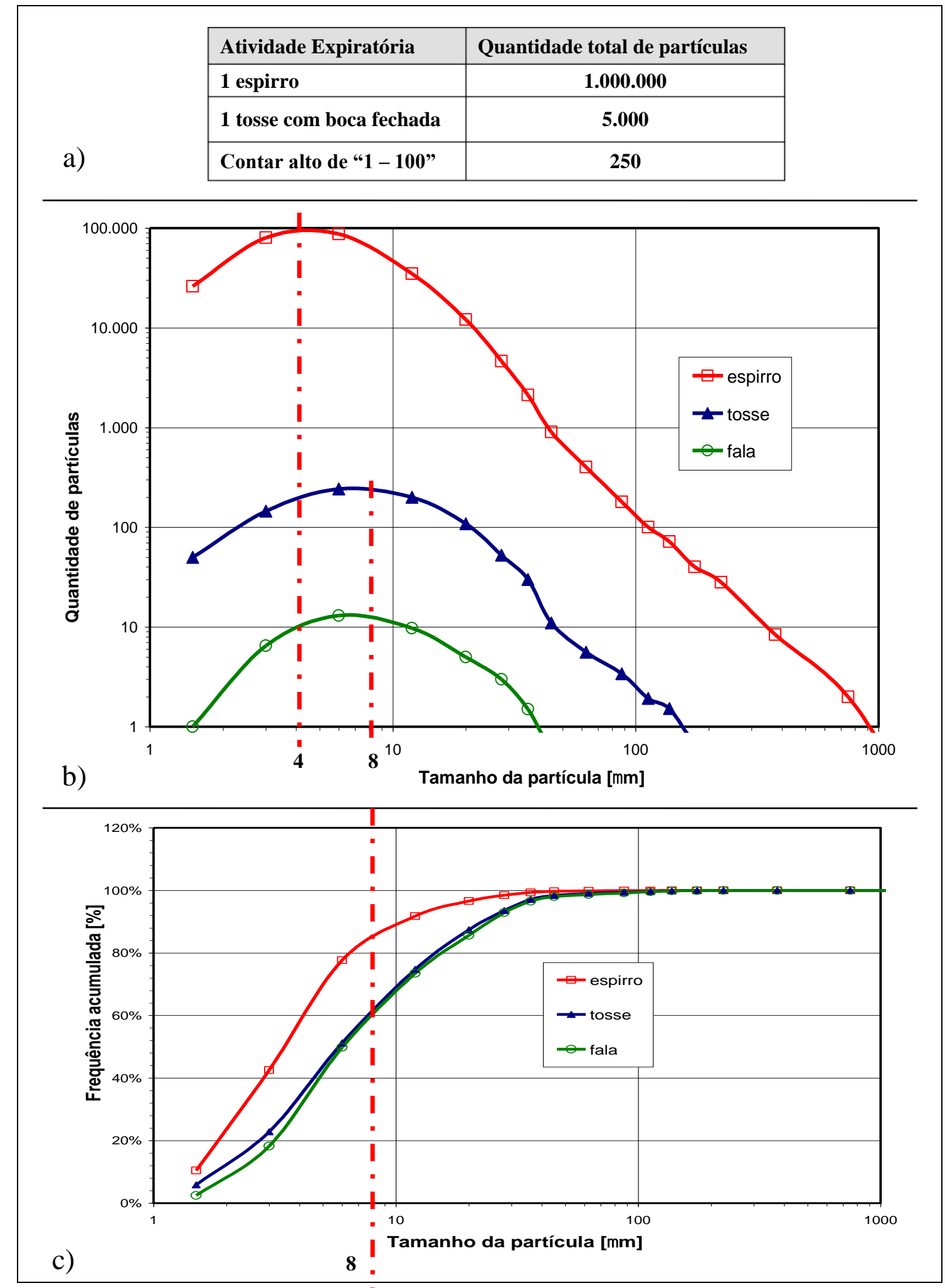

Figura 3.2. Gotículas expiratórias! baseado nas medições de Duguid, 1946. a) quantidade absoluta de partículas. b) distribuição do tamanho de partículas normalizada pelo intervalo de medição. c) distribuição acumulada.

Fonte: adaptado por CONCEIÇÃO, 2012 


\subsection{Estudos de dispersão de partículas em cabines de aeronaves usando geradores de partículas}

Shimada et al. (1996) estudaram a dispersão de contaminantes em mock-up. Os autores avaliaram a influência do ponto de liberação dos poluentes. Para isso, o ambiente era ventilado sem recirculação e utilizado filtro HEPA, com objetivo de evitar a reintrodução de partículas no experimento. Os autores geraram partículas com tamanho aproximado de $0,14 \mu \mathrm{m}$ e dispersavam na ordem $3.10^{10}$ partículas $/ \mathrm{m}^{3}$ de ar. As partículas geradas eram sólidas e sua composição era de poliestireno de látex.

Wan, Chao e Fang (2005) utilizaram um gerador de partículas polidisperso para avaliar a dispersão de contaminantes em mock-up instalado no International Center for Indoor Environment and Energy, da Dinamarca. O mock-up possui sistema de ventilação convencional (MV). A dispersão das partículas foi feita em dois locais dentro da cabine e a concentração de partículas foi quantificada a 1,1 m do piso e em 11 assentos ao longo da cabine, conforme figura 3.3. Para a ocupação dos assentos foram utilizados manequins aquecidos. A variação da concentração de partículas dispersadas pelo tamanho é apresentada na figura 3.4. Analisando a figura pode-se notar que o pico de concentração foi $2,5.10^{9}$ partículas $/ \mathrm{m}^{3}$ no tamanho médio de $6,75 \mu \mathrm{m}$. Os autores puderam verificar partículas a uma fileira de distância da fonte na direção longitudinal e a três fileiras na direção lateral, o que pôde ser explicado pelo perfil do escoamento na cabine. Os resultados mostraram que a dispersão de partículas foi menor quando a injeção foi feita simulando um passageiro sentado mais próximo da fuselagem em comparação com passageiro sentado em um assento no centro do mock-up. De acordo com os autores, sugere-se que o fluxo de ar descendente junto à fuselagem tenha suprimido a dispersão de partículas, ao passo que o fluxo ascendente no centro do mock-up tenha aumentado à dispersão. Também foi verificado que as maiores concentrações ocorreram com umidades relativas mais altas, fato que pode ser explicado pela menor taxa de evaporação das gotículas injetadas na cabine. 

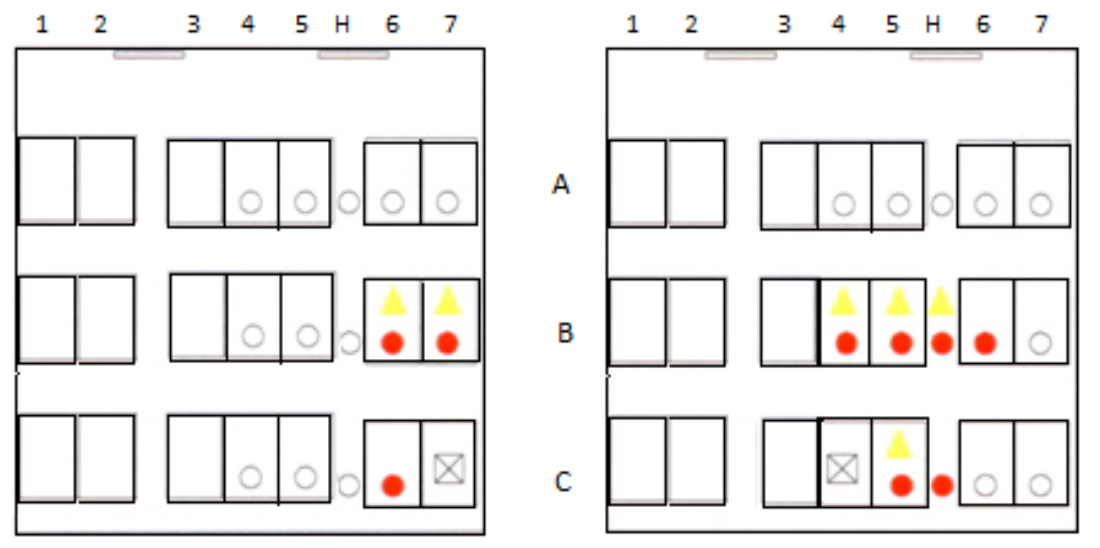

$\triangle$ Medição para $200 \mathrm{~L} / \mathrm{s}$

Medição para $100 \mathrm{~L} / \mathrm{s}$

Pontos de Medição

Pontos de Injeção

Figura 3.3. Pontos de injeção e de medição de partículas para diferentes vazões de ar em mock-up de cabine

Fonte: WAN; CHAO; FANG, 2005

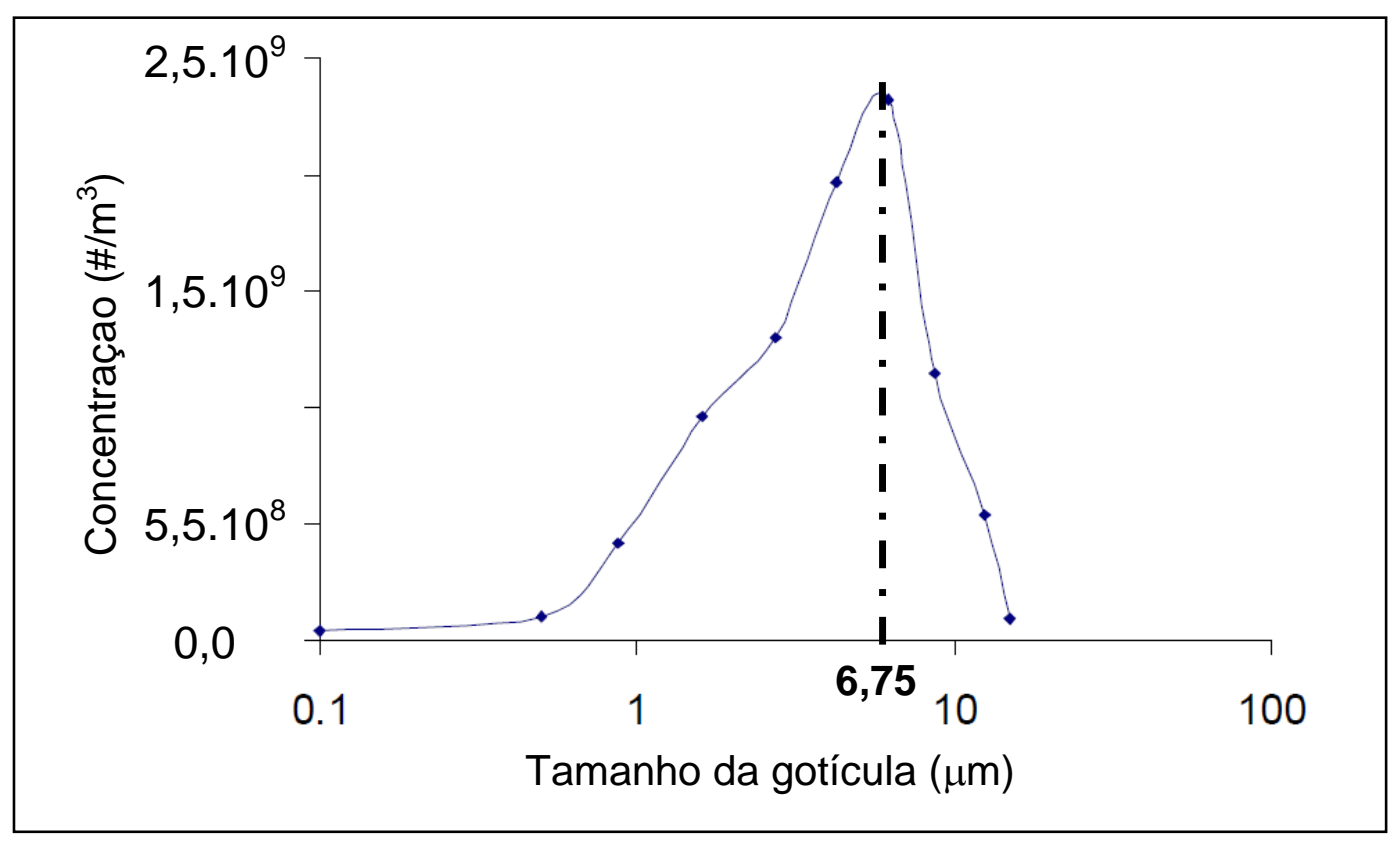

Figura 3.4. Distribuição do tamanho de gotículas produzidas por um gerador polidisperso próprio, medida a $10 \mathrm{~cm}$ do bico de saída do mesmo Fonte: WAN; CHAO; FANG, 2005 
Zhang et al. (2007) utilizaram um gerador monodisperso para simular contaminantes aéreos com tamanho em torno de $0,7 \mu \mathrm{m}$. Os autores também utilizaram manequins aquecidos para simular os passageiros. O gerador utilizado por Zhang et al. (2007) foi o TSI modelo 3475 e as partículas geradas eram de Di-etil-hexil-sebacato (DEHS). As partículas eram dispersas nos ambiente por tubos metálicos e quantificadas em 48 pontos, distribuídos em 2 planos de medição, conforme apresentado na figura 3.5.

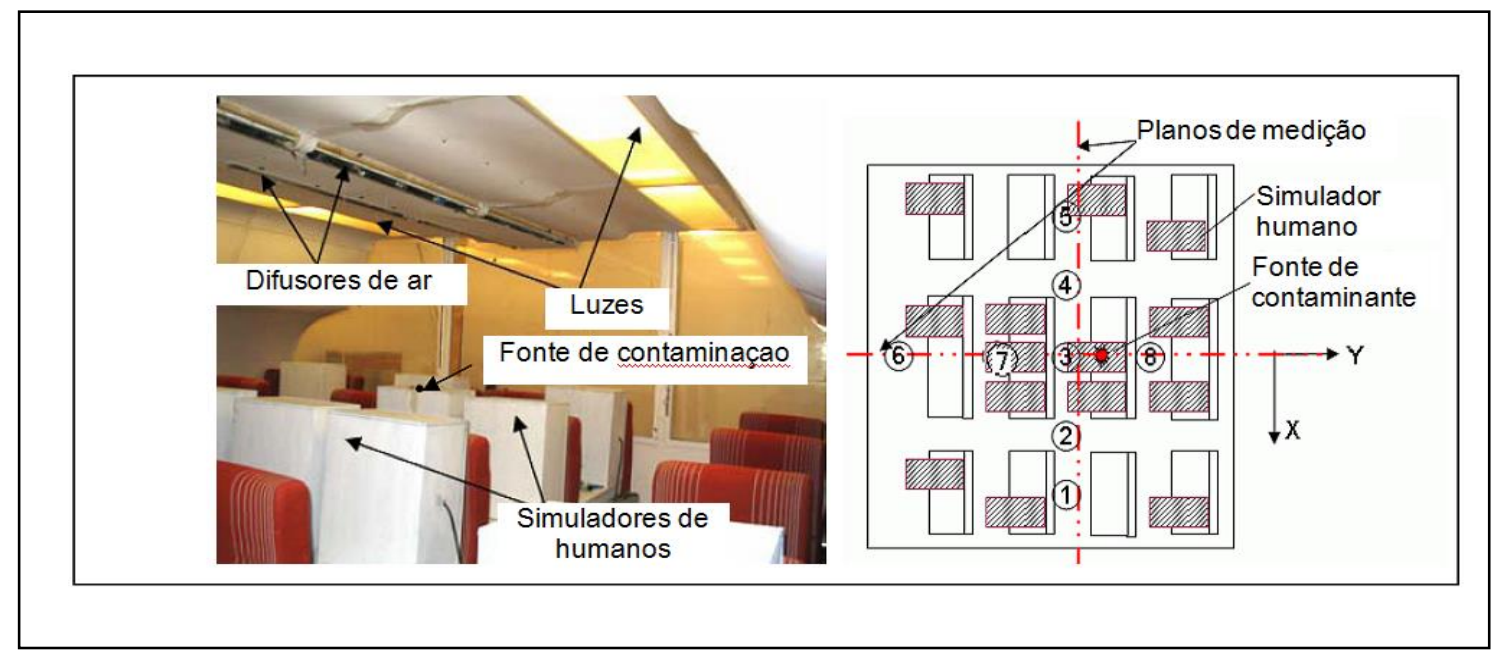

Figura 3.5. Mock-up de cabine de avião para estudar dispersão de partículas expiratórias Fonte: adaptado de ZHANG et al., 2007

Os autores utilizaram um sistema de ventilação MV para estudar a dispersão de partículas no interior da cabine e compararam os resultados obtidos experimentalmente com os resultados extraídos do modelo computacional. Em seguida, os pesquisadores realizaram a estimativa da dispersão de contaminantes utilizando sistema de ventilação com insuflamento de ar pelo piso (UFAD) e sistema de insuflamento de ar pelo piso com ventilação personalizada (UFAD + PV) utilizando o mesmo código CFD. Com os resultados da simulação numérica foi verificado que o sistema MV proporciona temperatura mais homogênea do ar. Por outro lado, um fato importante de ressaltar é que esse sistema oferece um maior risco de dispersar contaminantes. Já no sistema UFAD, o risco de contaminação diminui, em função das baixas velocidades de insuflamento de ar e também pelo ar seguir um fluxo ascendente regular. Mas o melhor resultado, ou seja aquele que proporcionou melhor qualidade do ar na zona de respiração foi o sistema de insuflamento pelo piso aliado ao sistema de ventilação personalizada (UFAD + PV). 
Com o objetivo de avaliar a deposição de partículas no piso e nas paredes, Jones e Nicas (2009) utilizaram gerador de partícula monodisperso da TSI modelo 3450 para gerar partículas com tamanho aproximado entre 3 e $14 \mu \mathrm{m}$. Os autores mediram efeitos turbulentos e de advecção do escoamento com anemômetros ultrassônicos, e também seu tempo de mistura empregando monóxido de carbono como gás traçador.

Outro trabalho com o objetivo de caracterizar a dispersão e deposição de partículas provenientes de atividades respiratórias foi o realizado por Sze To et al. (2009). Os autores também avaliaram os efeitos do sistema de ventilação de cabine na diluição e remoção dessas partículas. O gerador de partículas utilizado foi um do tipo polidisperso, que foi construído pelos próprios autores. Um fato importante de se destacar é que este equipamento foi construído e calibrado para gerar partículas com base na curva de Duguid (1946). Cilindros aquecidos foram utilizados para simular os passageiros. O método denominado fluorescence dye technique foi aplicado para medir a deposição de partículas nas superfícies da aeronave. Os autores puderam verificar que o aumento da vazão de ar de renovação provoca redução na concentração de partículas nas proximidades do ponto de injeção devido à diluição. Porém, houve um aumento na concentração de partículas nos assentos mais distantes do ponto de injeção.

Conceição (2012) desenvolveu uma metodologia para avaliar a dispersão de partículas em cabines de aeronaves, que será utilizada no presente trabalho. $\mathrm{O}$ trabalho foi realizado em um mock-up de aeronave de 20 lugares, mostrado na figura 3.6, utilizando sistema de ventilação MV. Um dos objetivos do trabalho foi avaliar a dispersão das partículas expiratórias na cabine e investigar se a válvula gasper pode oferecer proteção para os passageiros contra a contaminação gerada no interior da cabine.

O autor concluiu que com a aplicação do método proposto, tanto do ponto de vista numérico como experimental, a válvula gasper, operada nas mesmas condições que as ensaiadas pelo autor, pode minimizar a infecção cruzada entre os assentos avaliados, considerando uma fonte de contaminante no fundo da cabine. Os resultados da simulação numérica sugerem que uma das razões seja o aumento nas taxas de deposição de partículas nas superfícies da cabine, provocadas pelo jato do caso gasper $O N$, se comparadas com o caso gasper $O F F$. Esta foi a primeira vez que estudo semelhante foi apresentado, produzindo dados experimentais e numéricos consistentes, e que ressaltaram, mesmo que para uma situação operacional bem específica, algum tipo de benefício da válvula gasper para a qualidade do ar na zona de respiração dos ocupantes. 


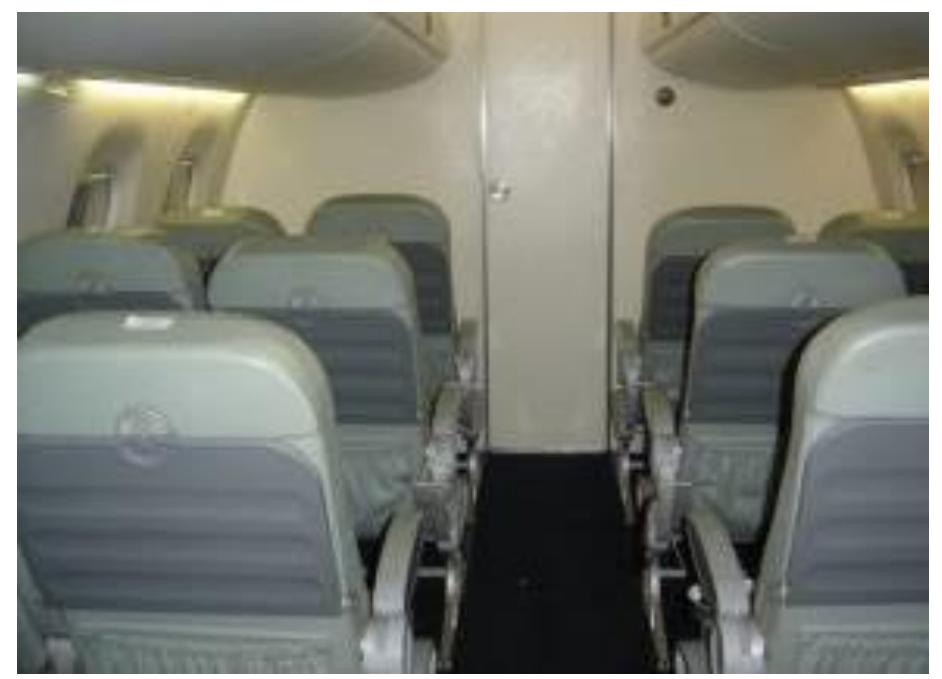

Figura 3.6. Mock-up de 20 lugares utilizado na avaliação da dispersão de partículas Fonte: CONCEIÇÃO, 2012

Outro trabalho realizado no Brasil foi o de Fabichak Jr. (2018). Neste trabalho o autor realizou análise experimental de dispersão de partículas expiratórias em cabine de aeronave, considerando arquiteturas de distribuição de ar dos tipos MV, UFAD e UFAD modificado em mock-up de 12 lugares, como mostrado na figura 3.7, porém sem a utilização de sistema de ventilação personalizada.

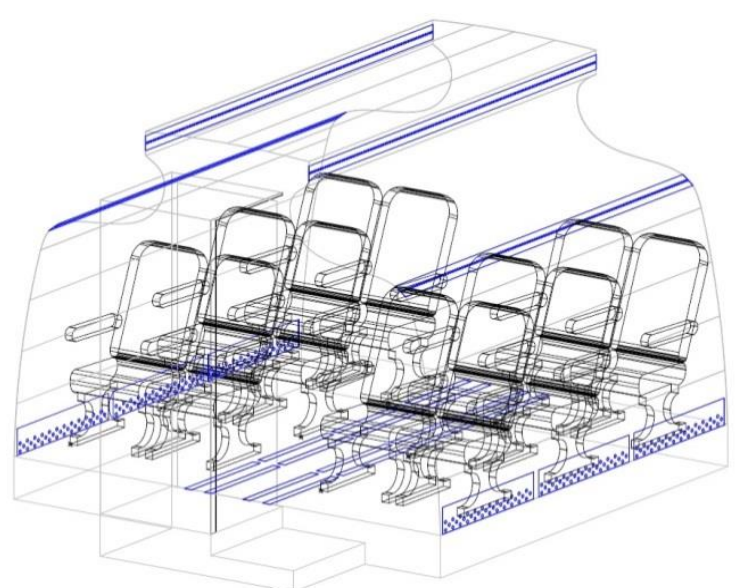

a)

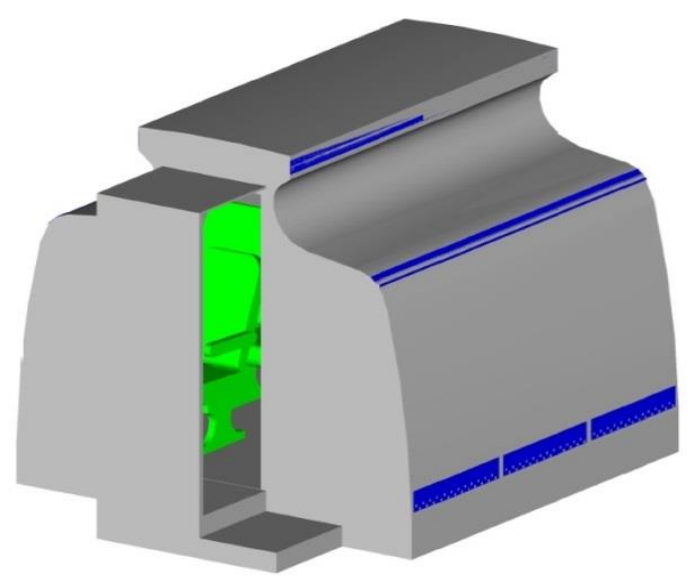

b)

Figura 3.7. Mock-up de 12 lugares: (a) Esquema interno e (b) Acesso e vista externa Fonte: FABICHAK JR., 2018

Segundo Fabichak Jr. (2018), o ponto de geração de partículas (próximo à fuselagem ou do corredor), bem como a temperatura do ar insuflado na cabine, têm grande influência na dispersão e na concentração de partículas ao longo da cabine nas três arquiteturas de 
distribuição de ar testadas, conforme verificado também por Wan, Chao e Fang (2005). A injeção de partículas na altura da zona de respiração do assento simulando passageiro junto à fuselagem resultou em uma menor dispersão de partículas na altura da zona de respiração ao longo da cabine em comparação com passageiro sentado em assento próximo ao corredor do mock-up. Ou seja, as partículas expiratórias geradas por um passageiro sentado junto ao corredor tem um potencial maior de serem inaladas por outros passageiros da cabine do que aquelas geradas por um passageiro sentado junto à fuselagem nas arquiteturas de distribuição analisadas. Em relação à temperatura do ar insuflado, quanto mais baixa for a temperatura mais favorável é a formação de plumas térmicas junto aos passageiros, aumentando a eficiência na remoção de partículas da cabine na zona de respiração. O autor enfatiza ainda que o sistema UFAD apresentou a maior eficiência na remoção de partículas, removendo partículas expiratórias de 3 a $5 \mu \mathrm{m}$ com eficácia de até $63 \%$ em relação ao sistema convencional.

Li et al. (2014) realizaram estudos experimentais e de simulação numérica para avaliar os campos de distribuição e de transporte de contaminantes expiratórios gerados por um passageiro na classe econômica e outro na primeira classe de uma cabine funcional de aeronave MD-82, que utilizava um sistema de ventilação MV capaz de fornecer até 10 $\mathrm{L} / \mathrm{s} /$ pessoa de ar na cabine. A temperatura do ar insuflado foi mantida em $20 \pm 1^{\circ} \mathrm{C}$. Todos os 12 assentos da primeira classe foram ocupados por manequins térmicos com carga térmica de $75 \mathrm{~W}$ cada. Os contaminantes foram gerados pelo gerador de partículas a partir da altura da zona de respiração de um passageiro sentado, conforme mostrado na figura 3.8, e medidos por meio de um contador de partículas.
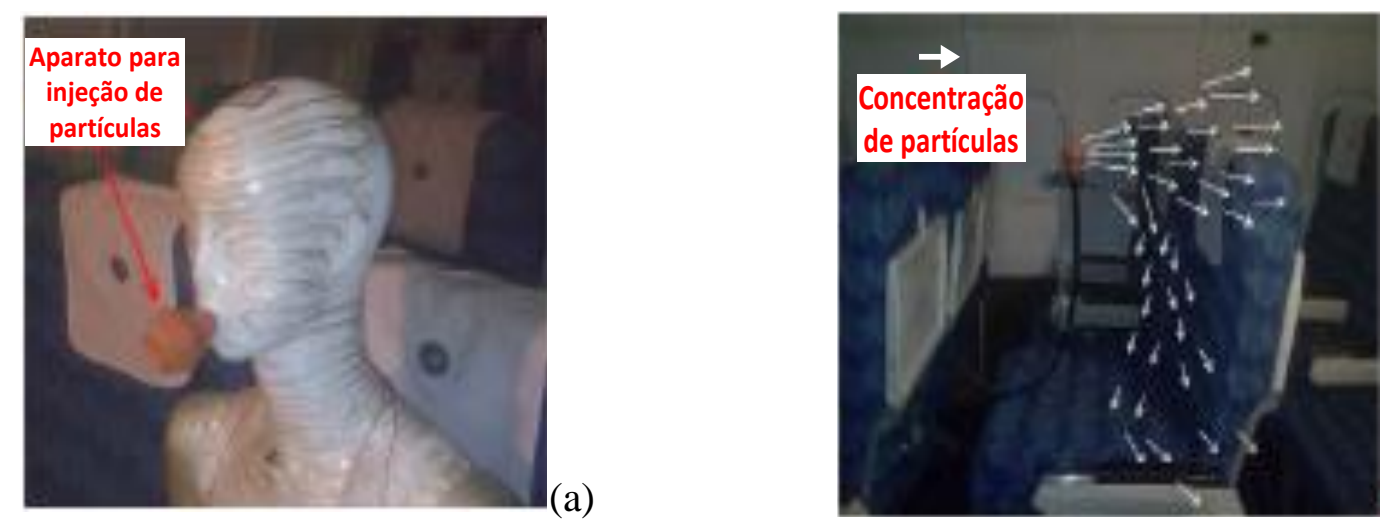

(b)

Figura 3.8. Simulação de partículas expiratórias: (a) exaladas por passageiro infectado e (b) caminho percorrido pelas partículas

Fonte: LI et al., 2014 
As principais conclusões dos autores foram que, devido ao campo de velocidade do ar provocado pelo sistema de ventilação, o local de origem e as plumas térmicas dos passageiros (simulados pelos manequins térmicos) afetam significativamente a dispersão de poluentes, isto é, os contaminantes gerados pelo passageiro na primeira classe foram mais rapidamente inalados pelos passageiros ao redor, ao passo que os contaminantes gerados na classe econômica, que por não estar totalmente ocupada, fez com que as partículas se dispersassem em uma maior área da cabine. Além disso, os resultados da simulação mostraram que as partículas com diâmetro menor que $3 \mu \mathrm{m}$ são mais difíceis de se depositarem, facilitando a disseminação de contaminantes ao longo da cabine.

Observa-se nos estudos apresentados que as análises experimentais sobre dispersão de partículas foram realizadas utilizando o sistema de ventilação por mistura (MV), por ser o sistema atualmente utilizado nas aeronaves comerciais.

É importante destacar que muitos desses estudos estão sendo desenvolvidos em centros de pesquisa e desenvolvimento ligados à indústria aeronáutica, a exemplo do mockup da Universidade de Illinois em Urbana-Champaign, EUA (WANG et al., 2006, YAN et al., 2009); do German Aerospace Center, Alemanha (GÜNTHER et al., 2006; ZEIDLER et al., 2008); do Air Transportation Center of Excellence for Airliner Cabin Environmental Research - School of Mechanical Engineering of Purdue University, EUA (ZHANG et al., 2007, MAZUMDAR; CHEN, 2007, GUPTA; LIN; CHEN, 2009, ZHANG et al., 2009, CHEN et al., 2012); do International Center for Indoor Environment and Energy, Dinamarca (WAN; CHAO; FANG, 2005, NIELSEN et al., 2008, SZE TO et al., 2009); do Jet Propulsion Laboratory of California Institute of Technology, EUA (OSMAN et al., 2008); do Institute for Environmental Research at Kansas State University, EUA (PADILLA, 2008, BENEKE, 2010, KHOSROW, 2012, ANDERSON, 2012); da School of Civil and Hydraulic Engineering of Dalian University of Technology, China (YIN; ZHANG, 2009, ZHANG; YIN; WANG, 2010, ZHANG; LI; WANG, 2012).

Paralelamente, no Laboratório de Conforto Térmico e Qualidade do Ar da Escola Politécnica da Universidade de São Paulo, também estão sendo realizados estudos para a análise do escoamento e distribuição do ar, do conforto térmico e da dispersão de partículas expiratórias em dois mock-ups construídos em parceria com a EMBRAER e financiamento da FAPESP e FINEP (MOURA, 2009, STANCATO, 2009, CONCEIÇÃO, 2012, SILVA, 2013, FABICHAK JR., 2018), onde foi desenvolvido o presente trabalho. 


\section{Capítulo 4 MÉTODO DE TRABALHO}

Neste capítulo são apresentados os procedimentos utilizados para a realização do trabalho experimental de avaliação da ventilação personalizada na concentração, dispersão e remoção de partículas no mock-up de cabine de aeronave.

\subsection{Introdução}

Os ensaios foram realizados em mock-up que utiliza o sistema de ventilação por mistura (MV) e o sistema de ventilação por deslocamento (DV) como sistema de ventilação da cabine. O interior do mock-up foi construído de forma a representar adequadamente o interior de uma seção de cabine de aeronaves comerciais, conforme será detalhado no próximo item. O mock-up possui um sistema personalizado (PV) que é proposto e que foi utilizado para avaliar a eficiência da ventilação personalizada na remoção de partículas no interior da cabine com relação aos dois sistemas da cabine, o sistema por mistura (MV) e o por deslocamento (DV).

O processo de análise de dispersão de partículas no mock-up foi baseado no processo desenvolvido por Conceição (2012) e também utilizado por Fabichak Jr. (2018). O presente trabalho avaliou a dispersão de partículas provenientes de atividades expiratórias (ex. espirro, tosse, fala ou respiração), protagonistas nos eventos de contaminação cruzada em cabines de avião.

\subsection{O Laboratório}

O mock-up de cabine de 12 lugares do Laboratório de Conforto Térmico e Qualidade do Ar da Escola Politécnica da Universidade de São Paulo é apresentado na figura 4.1.

$\mathrm{O}$ interior do mock-up foi construído de modo a representar adequadamente o interior de uma seção de cabine de aeronave comercial, contendo 12 lugares dispostos em três fileiras de quatro assentos e um corredor central. As curvas internas dos bagageiros (bins) e as paredes foram construídas em tubo estrutural e chapa metálica, com acabamento 
interno em revestimento melamínico, simulando acabamento superficial de interior de aeronaves. $\mathrm{O}$ piso foi confeccionado em madeira e revestido com carpete.

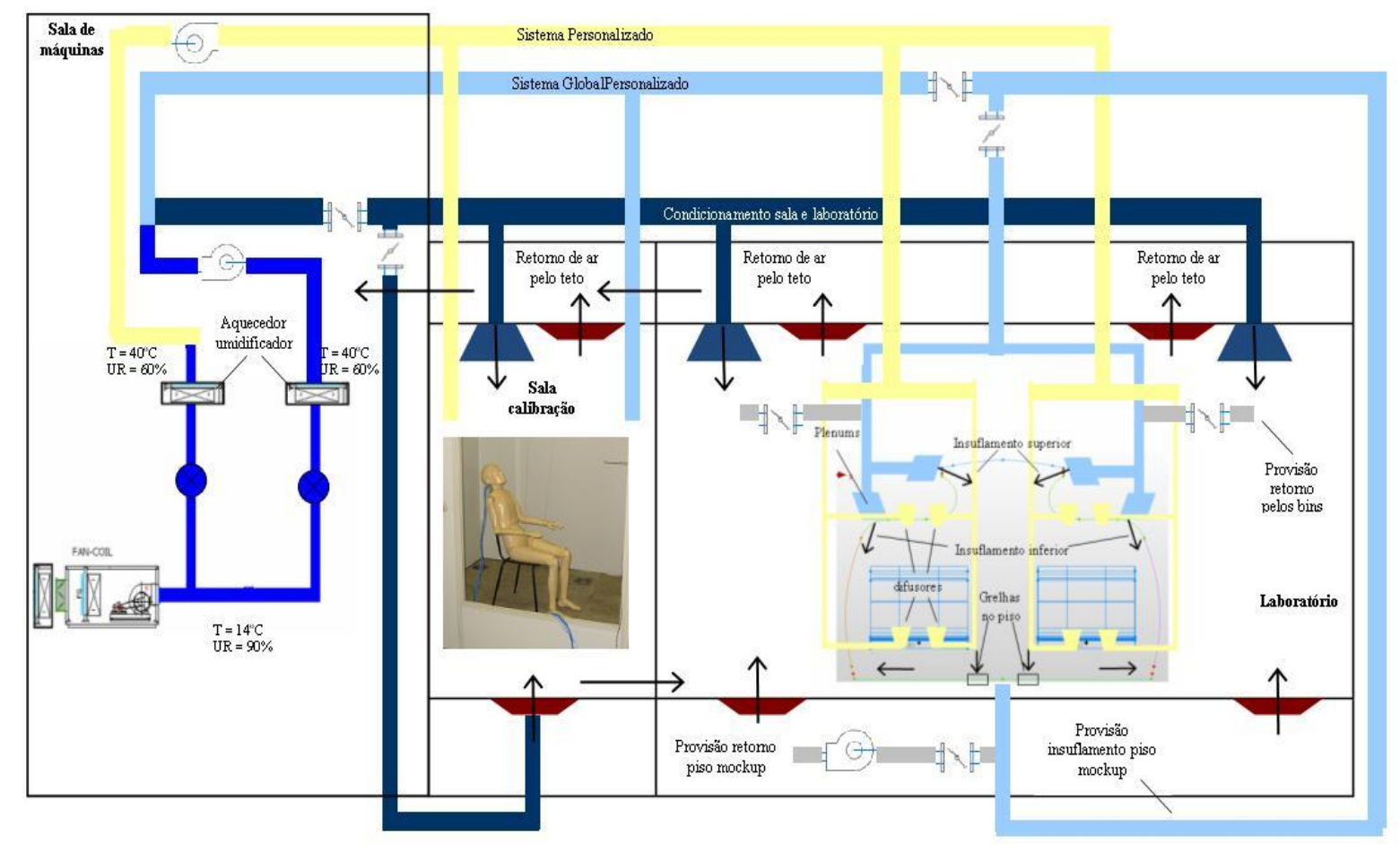

Figura 4.1. Representação esquemática do sistema de cabine (em azul claro) e personalizada (em amarelo) do mock-up

Fonte: FABICHAK JR., 2018

O laboratório possui um sistema de climatização do tipo expansão indireta, composto por chiller e fan-coil, e possibilidade de aquecimento e umidificação do ar, com controlador lógico programável (CLP), que fornece ar tratado ao mock-up instrumentado. A captação do ar do fan-coil é efetuada na casa de máquinas por meio de um duto com damper, ligado ao ambiente externo. Um exaustor instalado na linha de retorno do ar permite a exaustão e renovação de até $100 \%$ do ar, fundamental para a realização do presente trabalho.

O controle e o ajuste da temperatura e da umidade do ar são obtidos por meio de transmissores de temperatura e umidade relativa do ar, com faixas de operação situadas entre -40 e $80^{\circ} \mathrm{C}\left( \pm 0,2^{\circ} \mathrm{C}\right)$ e 0 a $100 \%$ UR $\pm(1,0+0,008$ x leitura $)$, respectivamente, e instalados nos dutos de insuflamento de ar do mock-up. 
A figura 4.2 mostra vistas esquemáticas internas e externas do mock-up. Os detalhes em vermelho, na vista isométrica, representam o posicionamento das entradas e saídas de ar do mock-up.
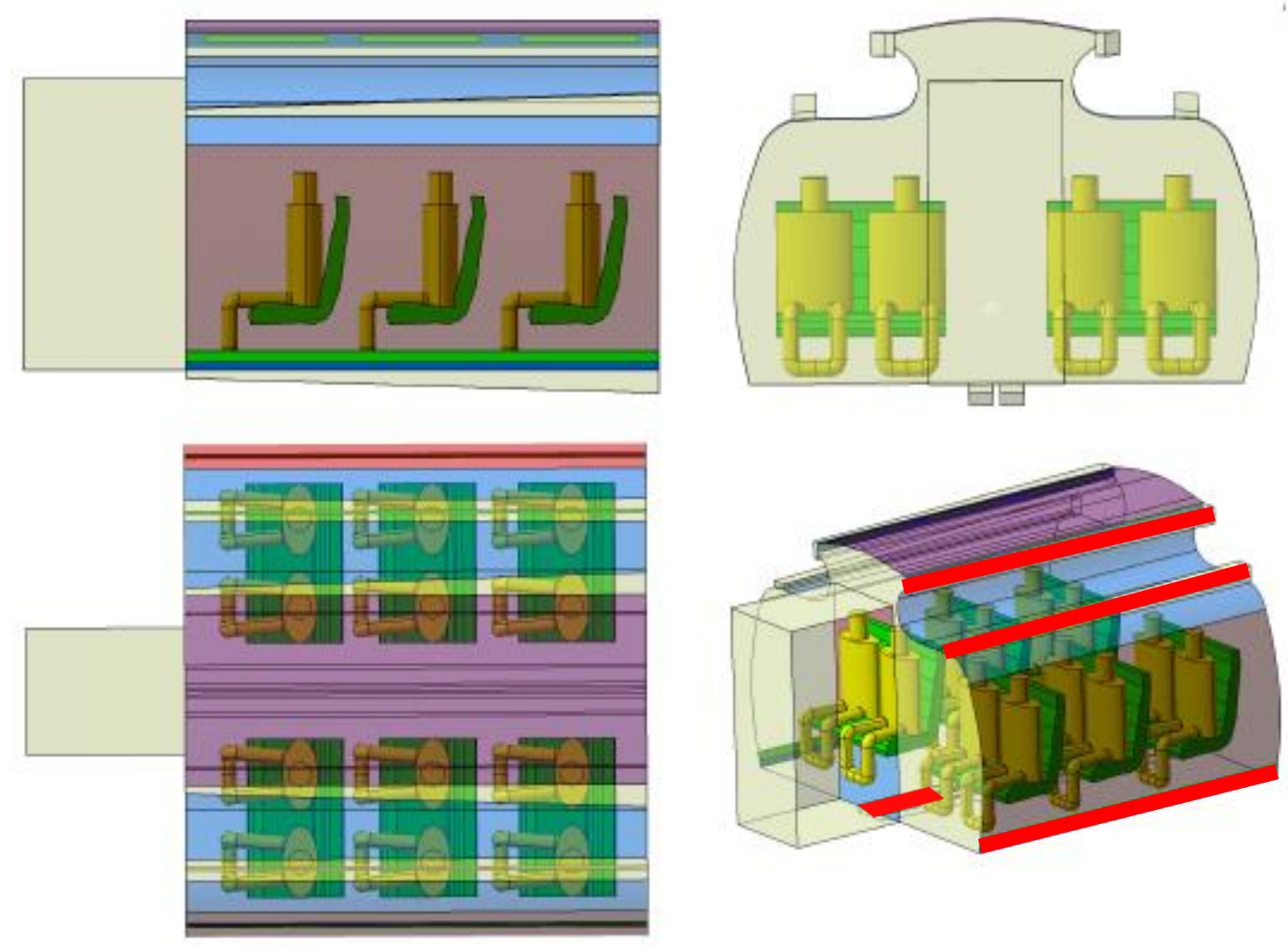

Figura 4.2. Configuração do mock-up.

Os assentos utilizados são assentos de aeronave comercial e suas dimensões e espaçamentos entre assentos representam o interior deste tipo de cabine de aeronave. A Figura 4.3 mostra o interior do mock-up, juntamente com os manequins aquecidos, simulando a presença de passageiros, detalhados no apêndice A. 


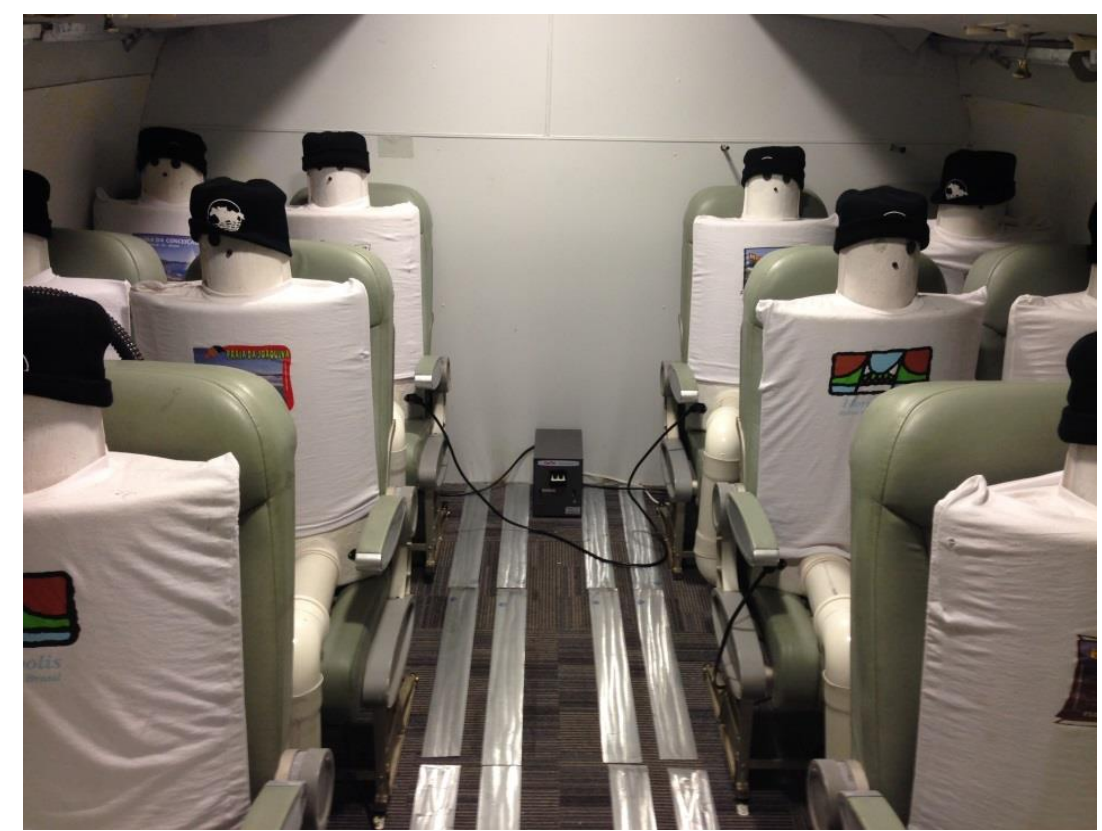

Figura 4.3. Vista interna do mock-up com os manequins aquecidos

\subsection{Sistema de ventilação personalizada proposto}

$\mathrm{Na}$ segunda fileira do mock-up está localizado o sistema de ventilação personalizado $(\mathrm{PV})$ instalado na parte de trás do banco da frente, um próximo ao corredor e outro próximo a fuselagem, conforme apresentado na figura 4.4. Apenas dois difusores foram analisados levando em consideração a simetria da cabine. Durante as medições os tubos de alimentação de ar do sistema foram posicionados de forma a não interferirem no escoamento do ar.

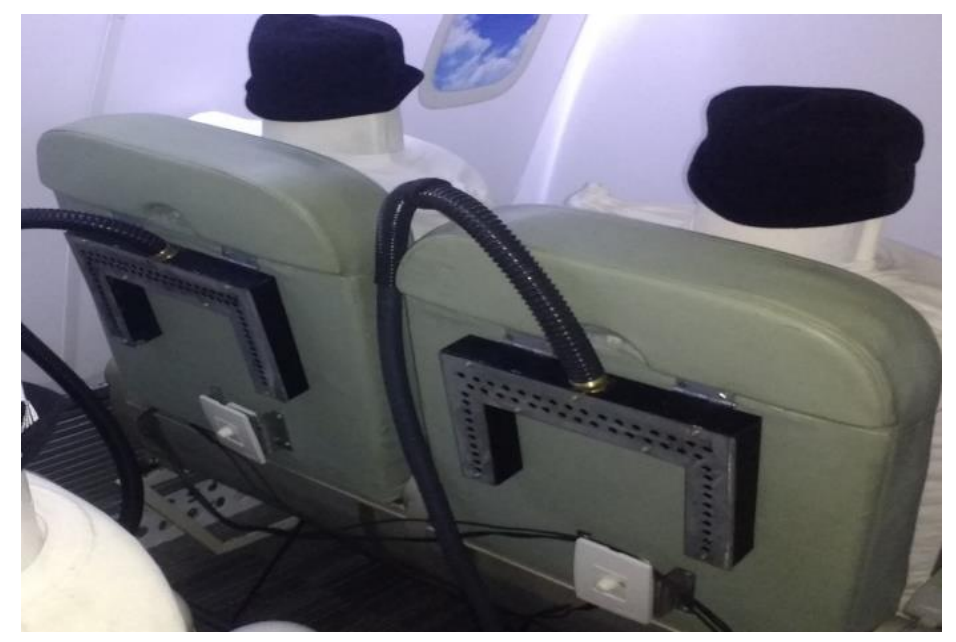

Figura 4.4. Sistema Personalizado (PV) 
O sistema PV recebe ar do sistema personalizado apresentado na figura 4.1, que é independente do sistema de ventilação da cabine do mock-up. Isto é, a temperatura de insuflamento do ar dos difusores da poltrona pode ser diferente da temperatura de insuflamento do ar na cabine.

O trabalho tem como objetivo principal analisar a influência que o padrão do escoamento tem na dispersão de partículas, focando a zona de respiração do ocupante. A figura 4.5 apresenta detalhadamente as características do difusor.

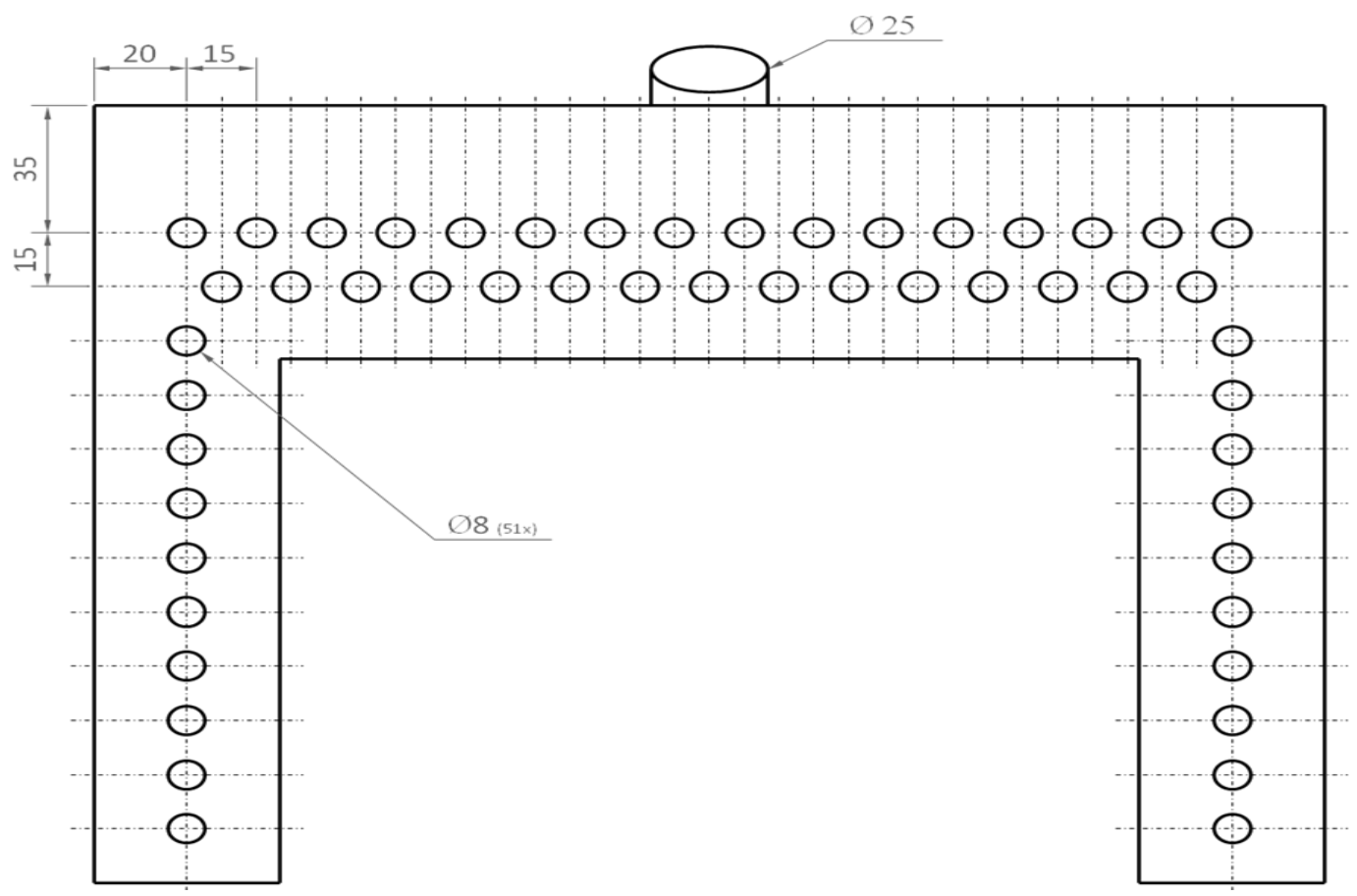

Figura 4.5. Detalhe do sistema da poltrona PV (medidas em mm)

A geometria do difusor como formato " $U$ " invertido foi definida considerando que um display multimídia central pode ser instalado no assento, fato que já ocorre em aeronaves.

\subsection{Arquiteturas de distribuição de ar analisadas}

As condições do experimento no interior do mock-up foram baseadas nas normas ASHRAE 161 (2007), ASHRAE 55 (2013) e ISO 7726 (1998).

Os ensaios foram realizados para as seguintes arquiteturas:

- Arquitetura 1 - Sistema de ventilação por mistura (MV), com 40\% de vazão de ar insuflada por difusores instalados na parte superior dos bins e $60 \%$ da vazão de ar insuflada pelos difusores na parte lateral inferior dos bins e com exaustão de $100 \%$ 
da vazão de ar por grelhas instaladas na parte inferior lateral da cabine, sistema convencional de distribuição de ar.

- Arquitetura 2- Sistema de ventilação por deslocamento (DV), com 100\% de vazão de ar insuflada por difusores instalados na parede próximos ao piso, e com exaustão de $40 \%$ da vazão de ar por grelhas localizadas na parte superior dos bins e com exaustão de $60 \%$ da vazão de ar pelas grelhas localizadas na parte lateral inferior dos bins.

As Figuras 4.6 a 4.7 ilustram as arquiteturas de distribuição de ar que foram analisadas no presente trabalho, respectivamente: sistema de ventilação por mistura (MV) e sistema de ventilação por deslocamento (DV), conforme detalhado a seguir:

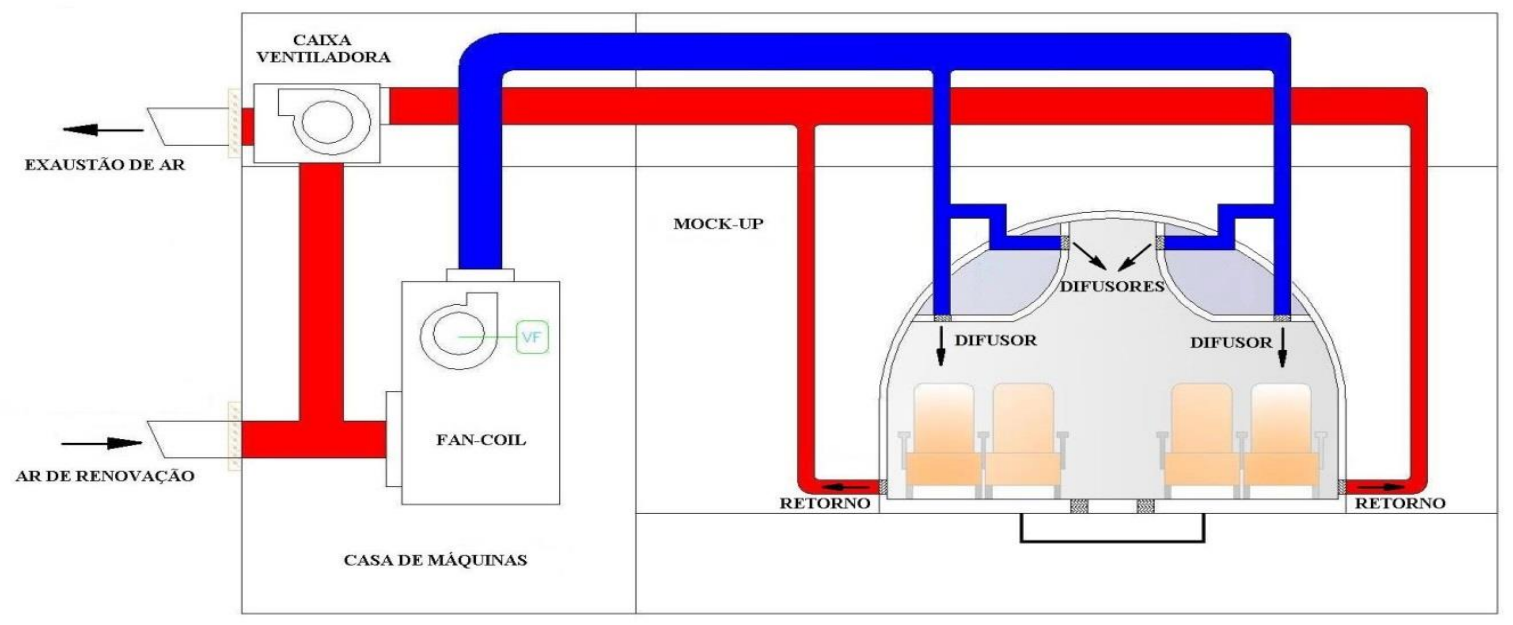

Figura 4.6. Arquitetura 1: Sistema de ventilação por mistura (MV)

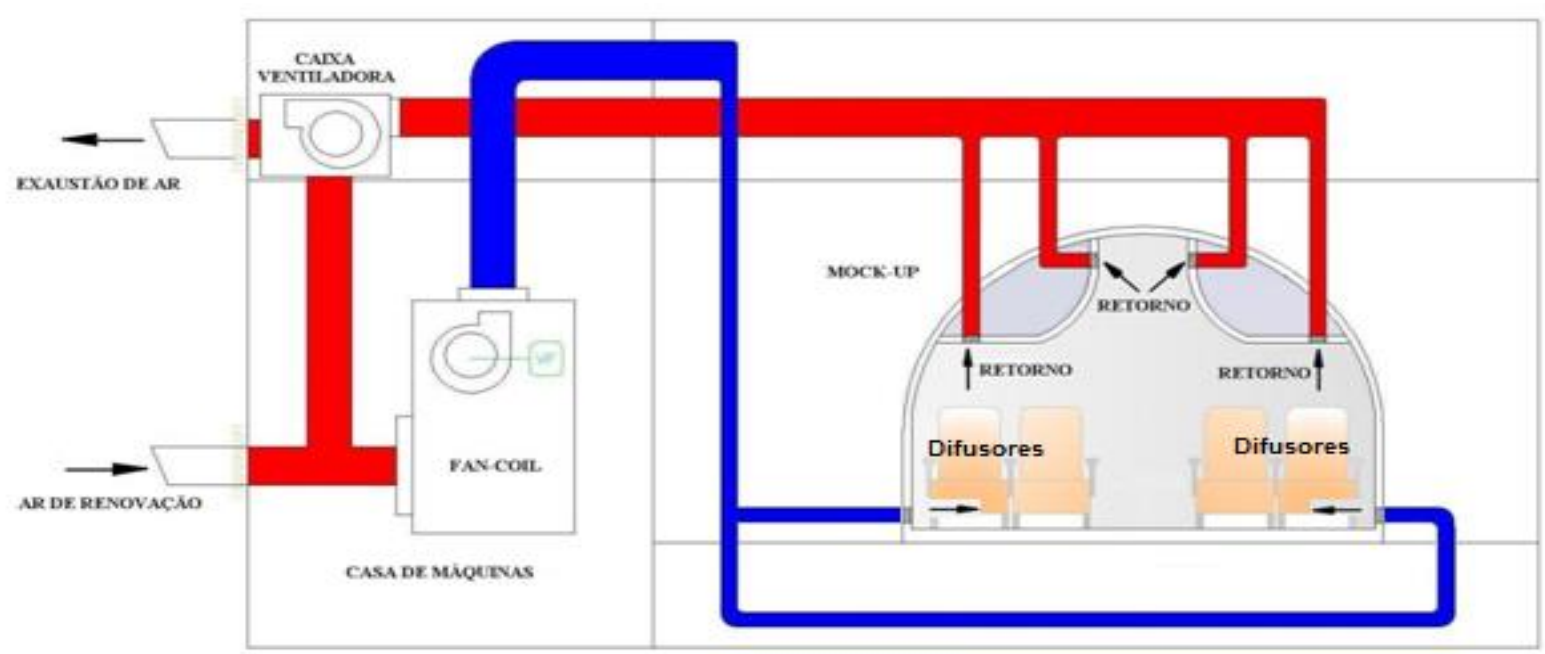

Figura 4.7. Arquitetura 2: Sistema por deslocamento (DV) 


\subsection{Geração de partículas}

Para a avaliação da dispersão das partículas que simulem atividades expiratórias, objetivo do trabalho, é conveniente que as partículas a serem geradas tenham a mesma forma e quantidade que as partículas geradas pelas pessoas, em situações normais. Para isso, a curva de distribuição proposta por Duguid (1946) foi a referência do presente trabalho. Assim sendo, considerou-se que a maior parte das partículas possui tamanho situado na faixa entre 4,0 e $8,0 \mu \mathrm{m}$, e a concentração na ordem de $10^{11}$ partículas $/ \mathrm{m}^{3}$.

Como citado anteriormente os procedimentos de geração de partículas foram baseados no trabalho realizado pro Conceição, (2012), assim foi escolhido o gerador de aerossol da TSI Modelo 3475, (figura 4.8) que permite variar o tamanho médio e a concentração das partículas geradas. Este equipamento necessita de uma fonte de nitrogênio para seu funcionamento, pressurizando a linha durante a operação em aproximadamente 6 bar. A escolha do equipamento também considerou a necessidade de aquisição de um gerador que esteja disponível no mercado.

Embora este gerador produza, em sua grande maioria, partículas com o tamanho e concentração desejados, ele também produz partículas, em menor quantidade, nas outras faixas de tamanho de 0,1 até $8,0 \mu \mathrm{m}$. A concentração de partículas geradas depende do tamanho de partícula escolhido, conforme figura 4.9. Na faixa de tamanho de partícula a ser estudada $(4,0 \pm 1,1 \mu \mathrm{m})$, a quantidade de partículas produzidas é da ordem de $1,2 \mathrm{x}$ $10 \% \mathrm{~cm}^{3}$. Foi realizado a geração contínua de contaminantes em uma dada região interna da cabine, a fim de simular a geração de aerossóis durante atividades expiratórias.

É conveniente propor o regime de geração das partículas imaginando o fenômeno físico de como ocorre a liberação de partículas expiratórias no ambiente. Normalmente, as gotículas são liberadas a partir de um jato, que pode ter maior ou menor intensidade a depender do tipo de atividade expiratória. Esse jato, aos poucos, se dispersa no ambiente, onde partículas com maior diâmetro são mais facilmente depositadas, e as partículas menores são carregadas pelo escoamento, alcançando pontos mais afastados ao seu ponto de injeção.

Este gerador não possui indicador do tamanho nem da concentração da partícula gerada. Por isso, é instalado em série um monitor de partículas PAM 3375, mostrado na figura 4.10, capaz de monitorar o diâmetro médio da partícula gerada, bem como a sua concentração (TSI, 2010). 


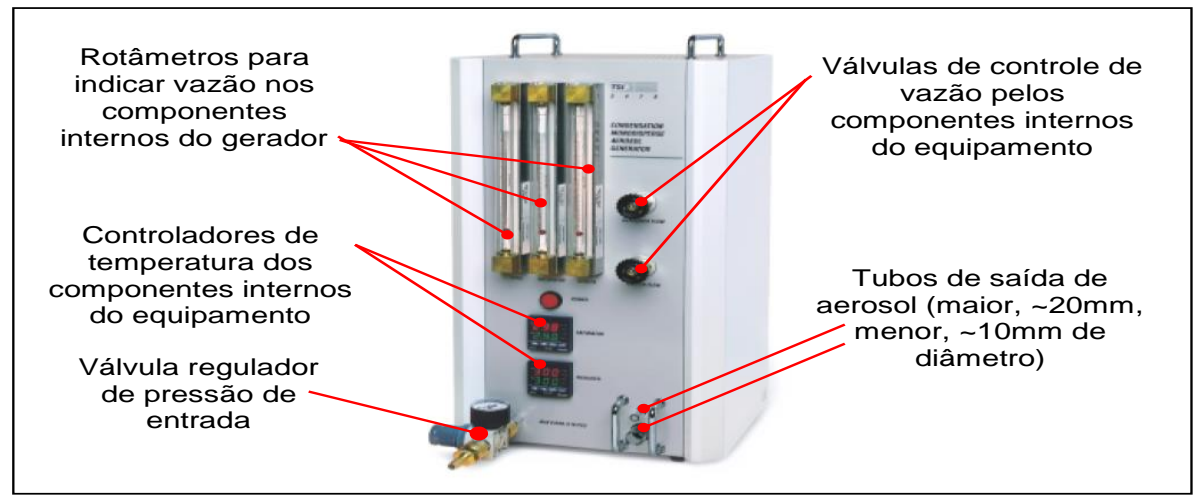

Figura 4.8. Gerador de aerossol TSI modelo 3475 (TSI, 2010) - imagem de catálogo

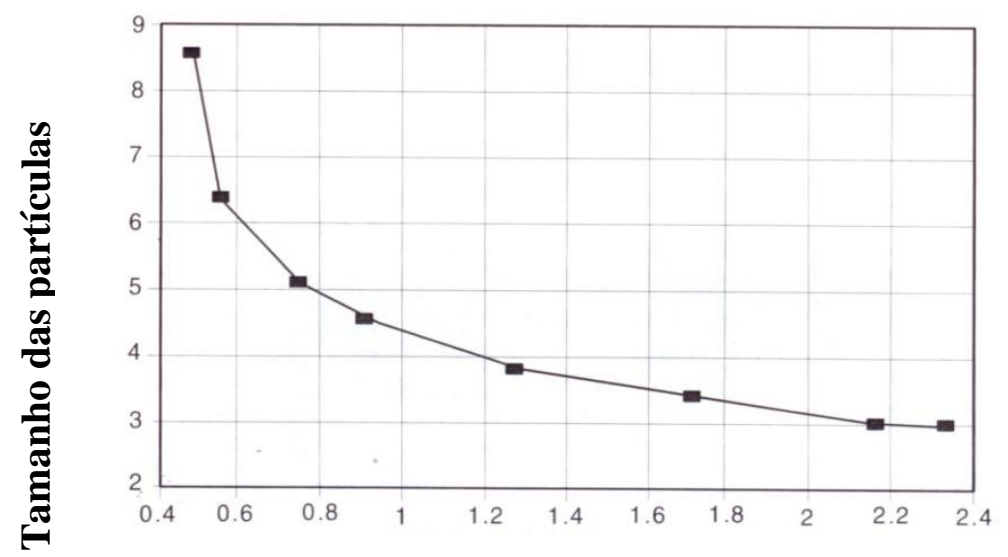

Figura 4.9. Concentração de partículas em função do tamanho da gotícula produzida pelo gerador TSI modelo 3475 (TSI, 2010) - imagem de catálogo

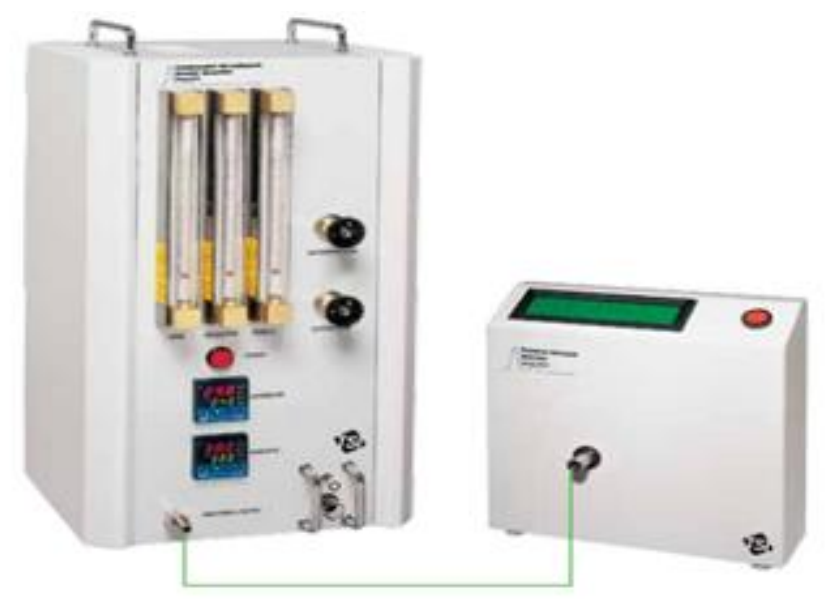

Figura 4.10. Gerador de aerossol TSI modelo 3475 associado ao indicador de monitoramento de partículas PAM 3375 (TSI, 2010) - imagem de catálogo 
A substância utilizada para a geração do aerossol é o DEHS (Di-etil-hexilsebacato), que é um líquido com baixa taxa de evaporação e massa específica de $915 \mathrm{~kg} / \mathrm{m}^{3}$ (HINDS, 1999). O fato da geração não ser totalmente monodispersa, mostra-se interessante, pois permite a análise da dispersão de partículas também em faixas de tamanhos além das que são propostas no presente trabalho.

O gerador de aerossol necessita de uma fonte de nitrogênio para seu funcionamento e um atomizador interno produz um spray a partir de uma solução aquosa de cloreto de sódio. As gotículas geradas passam através de uma coluna de secagem para retirar o excesso de umidade e, posteriormente, para formar um aerossol de alta concentração. Essas partículas seguem para uma unidade de reaquecimento, que serve para assegurar que o excesso de aerossol que não se aglutinou seja completamente vaporizado. Finalmente, as partículas seguem para uma câmara de condensação antes de serem injetadas no ambiente.

Este equipamento opera com vazão de aerossol entre 3,5 e 4,0 L/min., semelhante à vazão média de ar de inalação e exalação das pessoas (YAN et al., 2009). Considerando que o diâmetro do tubo de saída de aerossol é de aproximadamente $10 \mathrm{~mm}$, a velocidade das partículas na saída do duto é de cerca de $1 \mathrm{~m} / \mathrm{s}$. Esse mesmo modelo de gerador foi utilizado por outros pesquisadores em estudos correlatos, dentre eles Zhang et al., (2008); Jones e Nicas, (2009); Conceição, (2012) e Fabichak Jr., (2018).

\subsection{Quantificação das partículas}

A medição das partículas foi realizada com o auxílio de contadores ópticos da marca Met One, conforme mostrado na figura 4.11. O contador possui 6 canais para contagem de partículas na faixa de 1,0 a $10,0 \mu \mathrm{m}(1,0$ a $2,0 \mu \mathrm{m}$, de 2,0 a 3,0 $\mu \mathrm{m}$, de 3 a 5 $\mu \mathrm{m}$, de 5 a $7 \mu \mathrm{m}$, de 7 a $10 \mu \mathrm{m}$, e maior do que $10 \mu \mathrm{m}$ ), compatíveis com a faixa de partículas geradas pelo gerador TSI modelo 3475.

O contador opera pelo princípio de dispersão de um feixe luminoso (laser de diodo) ocasionada pela passagem das partículas presentes no ar aspirado por uma bomba interna do equipamento. Um tubo coletor de partículas com diâmetro interno de 10mm acompanha o contador de partículas. Segundo o manual deste equipamento, o erro de coincidência é da ordem 5\% para concentrações de $7,010^{9} / \mathrm{m}^{3}$ e a eficiência de contagem é de $50 \%$ para partículas de $0,3 \mu \mathrm{m}$ e de $100 \%$ para partículas maiores do que $0,45 \mu \mathrm{m}$. 

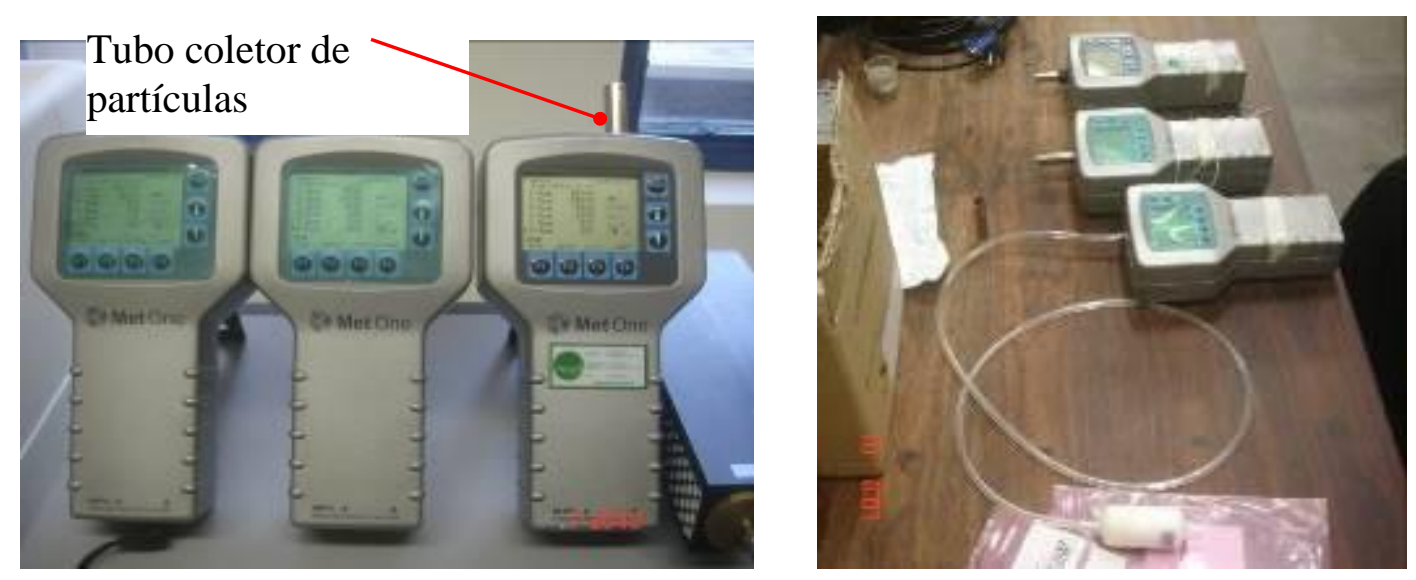

Figura 4.11. Contador de partículas da Met One, modelo HHPC6 Fonte: CONCEIÇÃO, 2012

Este tipo de contador de partículas captura o ar do seu entorno por sucção promovida pela bomba interna com vazão volumétrica de $0,1 \mathrm{cfm}(2,83 \mathrm{~L} / \mathrm{min}$.). A duração de cada amostragem pode ser definida entre 6 segundos e 10 minutos, o que determina o volume total de ar amostrado em cada medição. Já o intervalo entre as amostragens pode ser definido entre 1 segundo e 1 hora. $O$ tempo de duração mais adequado pode variar em função da aplicação específica e deve ser definido empiricamente.

A figura 4.11 mostra os contadores no momento da calibração de contagem zero, rotina realizada idealmente sempre antes de começar as medições. Com um filtro HEPA conectado ao tubo coletor de partículas por intermédio de uma mangueira flexível de silicone, esta verificação deve anteceder as medições para avaliar se o contador não possui impurezas aprisionadas nas proximidades do seu sensor ótico que possam alterar o resultado das medições. Esta rotina é executada colocando o contador em operação, o qual força o ar amostrado a passar pelo filtro HEPA deixando-o absolutamente livre de impurezas. Assim, espera-se que os contadores tenham feito de fato contagem nula.

Conforme artigo técnico publicado pelo fabricante do equipamento (LATIMER; TANG, 2012), a incerteza de medição na classificação de tamanhos das partículas coletadas é da ordem $7 \%$.

Segundo Hinds (1999) o erro sistemático de um contador de partículas óptico é função, principalmente, do diâmetro da partícula e de seu índice de refração. Como, de fato, os contadores utilizados são calibrados com partículas esféricas de latéx de poliestireno, que possuem índice de refração de 1,59 (MET ONE HHPC6, 2010), ao passo que o aerossol de DEHS utilizado nos experimentos possui índice de refração de 1,45 (TOPAS, 2012), este desvio precisaria ser investigado. Porém, com base nos estudos 
desenvolvidos por Yoo, Chen e Li (1996) com contadores ópticos semelhantes ao empregado no presente trabalho, entende-se que uma diferença de aproximadamente 0,15 no índice de refração não deve impactar significativamente nos resultados das medições.

Não obstante, se considerado que a incerteza na contagem de partículas segue a estatística de Poisson (KULKARNI; BARON; WILLEKE, 2011), a mesma poderia ser estimada pela raiz quadrada do número de partículas contadas em cada medição.

Portanto, utiliza-se como valor de incerteza na contagem das partículas $(\Delta N)$, o maior valor numérico obtido por qualquer um dos três critérios listados a seguir:

- $\Delta N= \pm \sqrt{N}$, (estatística de Poisson);

- $\Delta N=+5 \% N($ perdas por coincidência);

- $\Delta N= \pm \sqrt{\frac{\sum\left(N_{i}-\bar{N}\right)^{2}}{n(n-1)}}$ (erro quadrático de Gauss), em que " $N_{i}$ " é o valor contado em uma dada medição; " $\bar{N}$ " é a média dos valores medidos; e " $n$ " é o número de amostras.

\subsection{Variáveis ambientais e condições dos ensaios}

As variáveis críticas referentes ao ensaio são aquelas que estão relacionadas com o ambiente interno do mock-up. A norma ISO 7726 (ISO, 1998) apresenta recomendações de procedimento para realizar a medição das variáveis ambientais (temperatura, umidade, velocidade e vazão de ar). Além disso, para garantir as condições propostas no set-up do sistema, deve-se atentar às recomendações do fabricante do sistema de ar condicionado, que em geral, recomenda o monitoramento das variáveis ambientais até sua estabilização, cujo tempo médio costuma ser em torno de 10 a 15 minutos (ZHANG et al., 2007, ZHANG et al., 2008, STANCATO, 2009, CONCEIÇÃO, 2012, FABICHAK JR., 2018). Esse procedimento deve ser adotado também quando o sistema for submetido à mudança de qualquer uma das variáveis acima mencionadas. A seguir, cada uma das condições dos ensaios é apresentada.

As temperaturas do ar insuflado no mock-up foram estabelecidas em conformidade com a norma ASHRAE 161 (ASHRAE, 2007), que recomenda temperaturas de cabine entre $18^{\circ} \mathrm{C}$ a $24^{\circ} \mathrm{C}$ - com tolerância de set-up de $\pm 1,1^{\circ} \mathrm{C}$ - além de, eventualmente, poder 
atingir cerca de $27^{\circ} \mathrm{C}$ em curtos períodos durante o voo, e cerca de $29^{\circ} \mathrm{C}$ em operações em solo.

Portanto, o ar foi insuflado pelo sistema de ventilação da cabine a $18^{\circ} \mathrm{C} \pm 0,5^{\circ} \mathrm{C}$, correspondendo a uma leve sensação de frio no modelo Fanger (FANGER, 1972). Deste modo, a temperatura de cabine no interior do mock-up manteve-se na faixa entre $21^{\circ} \mathrm{C}$ e $23^{\circ} \mathrm{C}$ durante todos os ensaios, reproduzindo uma condição frequentemente encontrada em situações normais de voo. Esta situação de leve sensação de frio, também justifica a utilização do sistema personalizado proposto como medida paliativa para propiciar condições de conforto térmico ao ocupante do assento avaliado. O fluxo de ar da cabine foi de 9,6 L/s por pessoa (ASHRAE 161, 2007), com renovação total do ar. O sistema personalizado insuflou ar insuflado a $24^{\circ} \mathrm{C} \pm 0,5^{\circ} \mathrm{C}$ visando criar uma condição de conforto térmico ao ocupante. O fluxo de ar do sistema personalizado foi de 3,0 L/s, essa vazão de ar fornecida pelo sistema personalizado foi calculada de acordo com o critério de Draught Rate (FANGER et al., 1988), considerando o percentual de pessoas insatisfeitas sendo $\leq$ 20\% (ASHRAE 55, 2013), o memorial de cálculo encontra-se disponível no apêndice C. A escolha das temperaturas de cabine de $18^{\circ} \mathrm{C}$ está relacionada com os ensaios que foram realizados com o sistema $\mathrm{PV}$, na busca de condição de microclima para o passageiro resultando em temperatura intermediária, mais próxima da neutralidade térmica.

Nos ensaios realizados anteriormente a umidade relativa do ar não teve influência significativa na concentração de partículas dispersas no ambiente (CONCEIÇÃO, 2012; FABICHAK JR., 2013), pois o tipo de partícula gerada utiliza um fluido com baixa taxa de evaporação para geração do aerossol. De qualquer forma, a umidade relativa do ar foi apenas monitorada ao longo dos ensaios.

Em todas as arquiteturas de distribuição de ar propostas a vazão de ar de insuflamento da cabine foi a mesma e em conformidade com os valores preconizados na norma ASHRAE 161 (ASHRAE, 2007), que estabelece um limite de 9,6 L/s/ocupante. Considerando que a cabine do mock-up comporta até 12 pessoas, a vazão total de ar foi controlada para serem fornecidos aproximadamente $415 \mathrm{~m}^{3} / \mathrm{h}$ de ar $(244 \mathrm{cfm})$. Considerando que o volume total do mock-up é de $18,85 \mathrm{~m}^{3}$, tem-se o equivalente a 22 renovações completas de ar por hora.

Conforme ressaltado no Capitulo 2, na maioria das aeronaves comerciais 50\% do ar fornecido ao passageiro é recirculado como forma de melhorar o controle da circulação do ar na cabine, a umidade e a eficiência da aeronave no consumo de combustível. Para 
controlar a quantidade de partículas devido à recirculação, filtros HEPA são instalados nos dutos de recirculação para reter os contaminantes gerados na cabine.

No presente trabalho, contudo, conforme descrito no item 4.2, o sistema de climatização do mock-up conta com sistema de exaustão, instalado na linha de retorno do ar, que permite a exaustão e renovação de $100 \%$ do ar do mock-up. Assim, não há a necessidade da instalação de filtro HEPA para retenção das partículas geradas na cabine, que são eliminadas na exaustão.

Paralelamente, o sistema de filtragem instalado na linha de insuflamento do ar na cabine impede a passagem de partículas acima de 5,0 $\mu \mathrm{m}$. Medições de partículas no ar insuflado no mock-up mostraram valores bastante baixos para partículas entre 3,0 e 5,0 $\mu \mathrm{m}$ (FABICHAK JR., 2018). Portanto, também não há a necessidade de instalação de filtro adicional no sistema de climatização.

\subsection{Procedimentos de medição e instrumentação}

A seguir é detalhado o processo de medição das variáveis críticas, apresentada a instrumentação utilizada e discutidos os procedimentos de ensaio realizados em conformidade com a norma ISO 7726 (ISO, 1998).

A velocidade e a temperatura do ar foram obtidos a partir de medições com o sistema ComfortSense da Dantec Dynamics, mostrado na figura 4.12. Foram utilizados três transdutores, compostos de três sondas omnidirecionais para medição de velocidades do ar com frequência de resposta de $5 \mathrm{~Hz}$ e com sensores de temperatura de resposta rápida integrados, com intervalo de operação de 0,05 até $10 \mathrm{~m} / \mathrm{s}$ e de $-20^{\circ} \mathrm{C}$ até $70^{\circ} \mathrm{C}$, e incertezas de medição, respectivamente, de $\pm 0,02 \mathrm{~m} / \mathrm{s}$ e $\pm 0,2^{\circ} \mathrm{C}$, que atendem aos requisitos de precisão de equipamentos da norma ISO 7726 (ISO, 1998). 


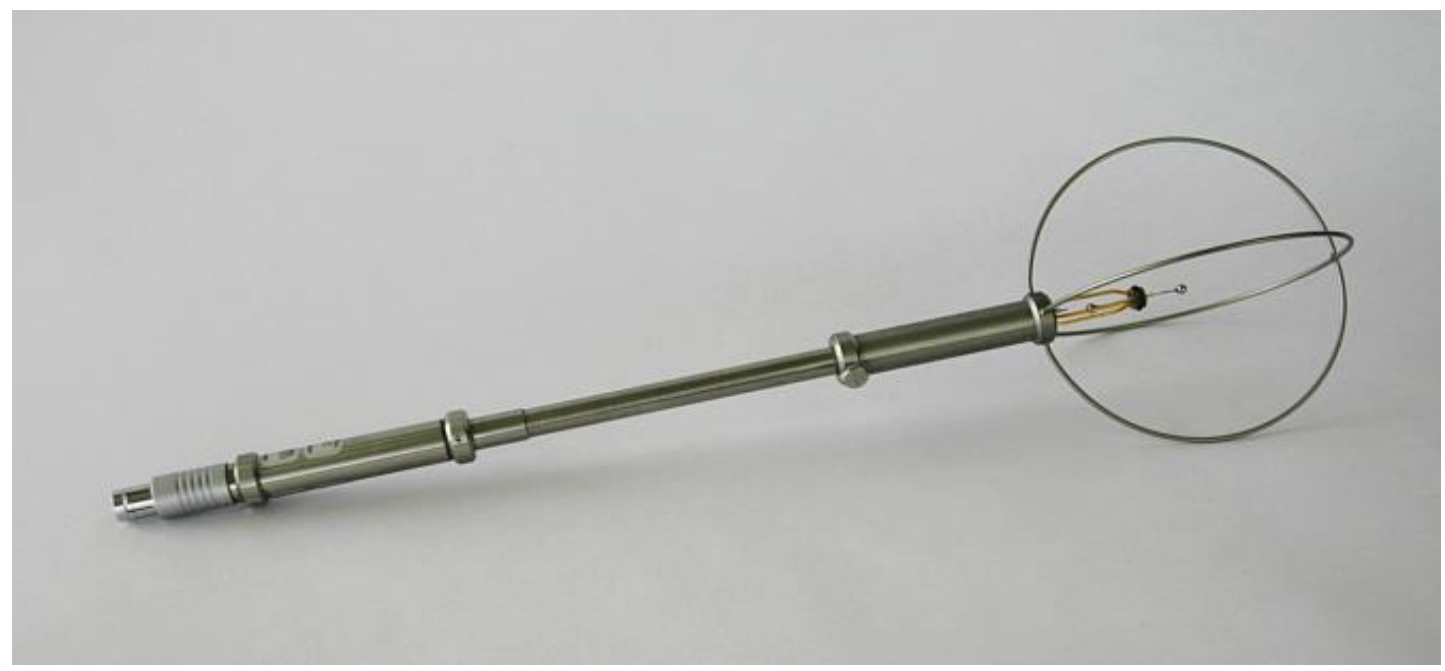

Figura 4.12. Sensor de anemômetro omnidirecional (elemento sensor livre) Fonte: FABICHAK JR., 2018

As medidas foram realizadas em três pontos longitudinais, abordando as fileiras 1, 2 e 3, contidas nas cinco retas transversais, colunas A, B, C, D e E, e seguiram recomendação da ASHARE 55 (2013) com medição nas alturas de 0,10 m, 0,60 m e 1,10 m a partir do piso, correspondendo à região dos pés e tornozelos, das mãos e braços e do pescoço e cabeça, respectivamente, de uma pessoa sentada. Todas as medições foram simultâneas nas três alturas, o aparato ficou localizado no espaço entre os assentos na linha central do assento, entre os joelhos de uma sentado . Para a situação de pessoas em pé (corredor) foi adotada altura de 1,60 m. A disposição dos transdutores de velocidade no mock-up é mostrada na figura 4.13 e 4.14 .
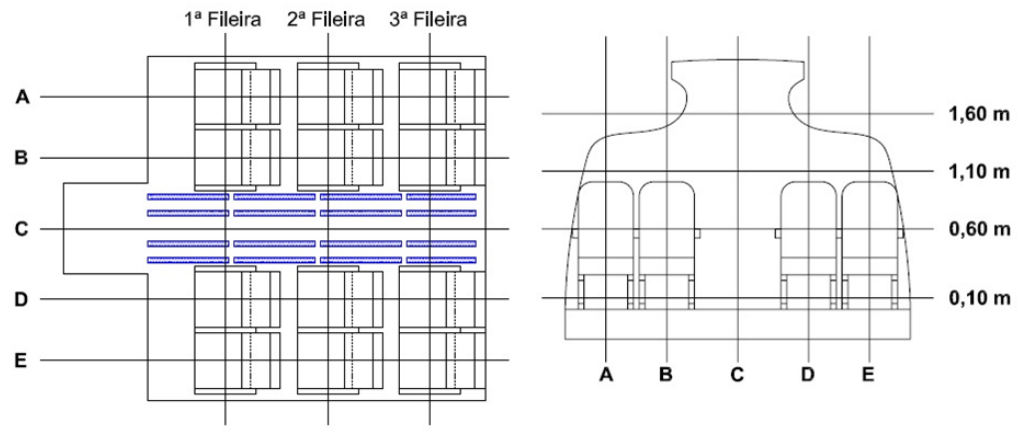

Figura 4.13. Distribuição dos pontos de medição de velocidade e de temperatura do ar

Fonte: FABICHAK JR., 2018 


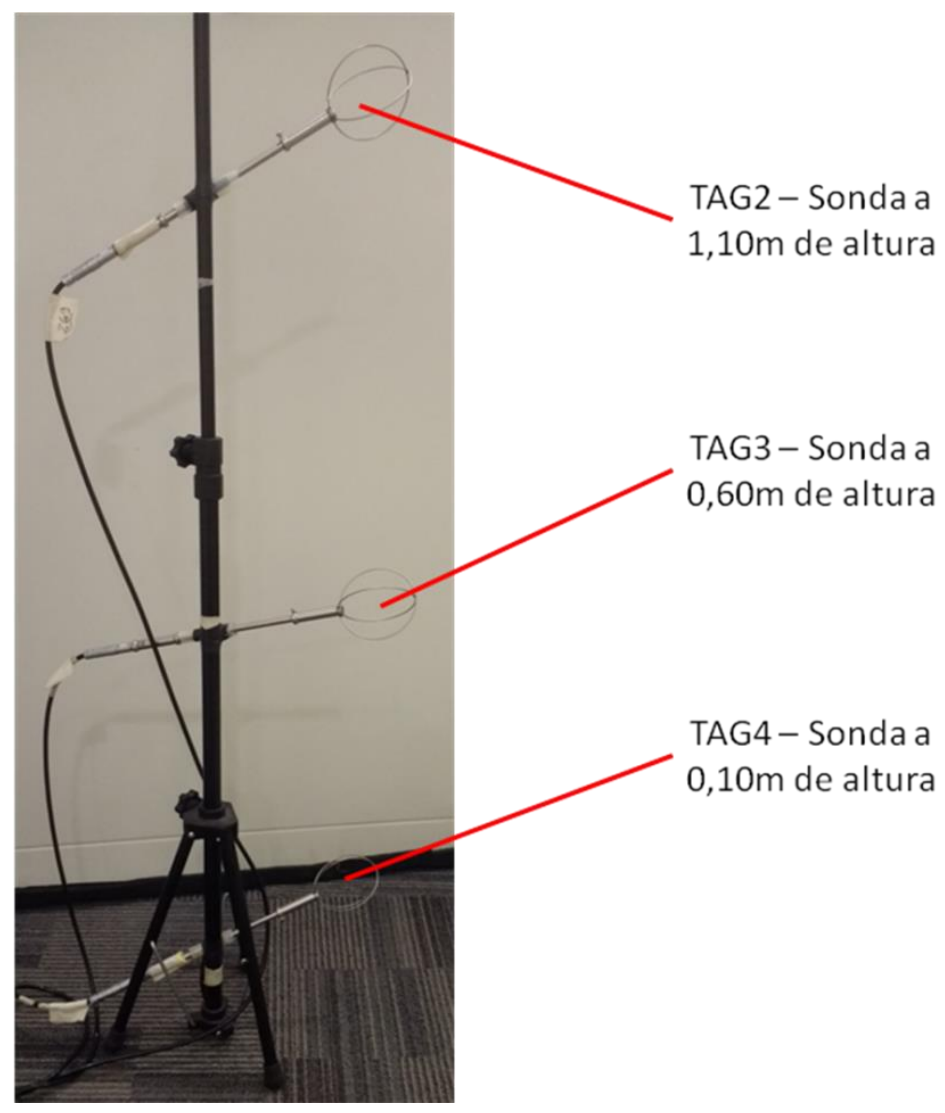

Figura 4.14. Pedestal para posicionamento da sondas do Comfort Sense

As temperaturas superficiais das paredes do mock-up foram medidas e monitoradas por meio de termopares tipo T (cobre/constantan), bitola AWG $8(\varnothing=3,26 \mathrm{~mm})$ e haste de $200 \mathrm{~mm}$ de comprimento, com faixa de operação de $-270{ }^{\circ} \mathrm{C}$ a $370{ }^{\circ} \mathrm{C}$ e f.e.m. (força eletromotriz) de $-6,258 \mathrm{mV}$ a $20,872 \mathrm{mV}$. Os termopares foram conectados a um Data Logger Agilent, modelo 34970A. Um dos termopares foi posicionado no duto de insuflamento para comparar os valores com o transmissor do sistema de automação e controle.

A vazão de ar da cabine foi determinada e monitorada a partir da medição de velocidade do ar nos dutos de exaustão do ar da cabine utilizando tubos de Pitot, mostrados na figura 4.15. Foi projetado um sistema composto por um conjunto de manômetros diferenciais e tubos de Pitot instalados em tubos de PVC de 100 mm de diâmetro nas linhas de exaustão. 


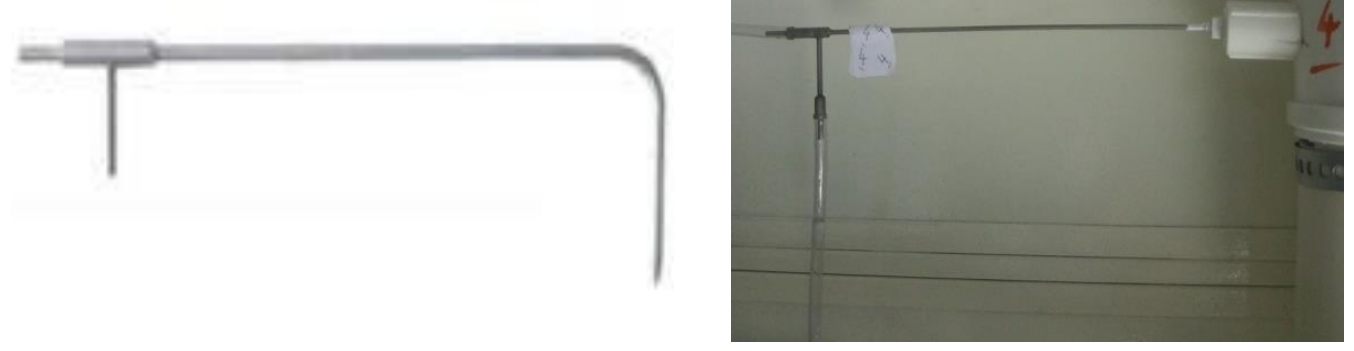

Figura 4.15. Vistas do tubo de Pitot antes e após a instalação

Fonte: FABICHAK JR., 2018

O tubo de Pitot utilizado é da série 160 de aço inoxidável. Os manômetros diferenciais, mostrados na figura 4.16, são do fabricante Dwyer. A conexão dos tubos de Pitot com os manômetros foi realizada com mangueiras transparentes de silicone com diâmetro de $8 \mathrm{~mm}$. Foi realizado um memorial de cálculo ${ }^{1}$ para converter o valor da diferença de pressão do manômetro em vazão.

$\mathrm{Na}$ entrada das linhas de exaustão (saídas do mock-up) foram instaladas telas metálicas retificadoras de fluxo e a $1000 \mathrm{~mm}$ (correspondente a 10 diâmetros dos dutos de PVC) das telas retificadoras foram instalados os tubos de Pitot, para garantir condições de perfil completamente desenvolvido no local de medição de velocidades máximas do ar no centro dos dutos (FOX; MC DONALD; PRITCHARD, 2006).

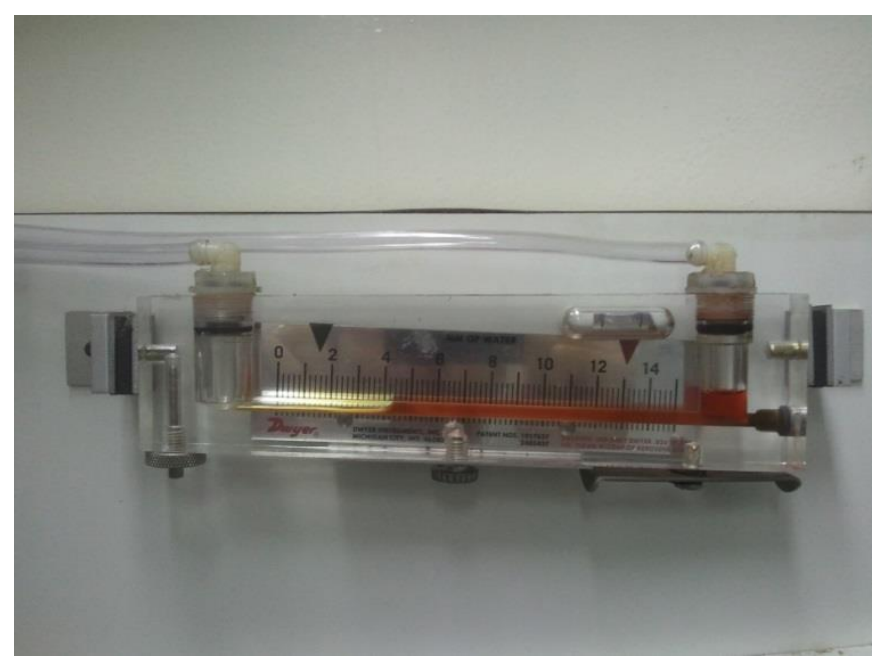

Figura 4.16. Manômetro diferencial para a determinação e monitoramento da vazão de ar Fonte: FABICHAK JR., 2018

\footnotetext{
${ }^{1} \mathrm{O}$ memorial de cálculo encontra-se no Apêndice B.
} 
Uma vez que cada linha de exaustão do ar é independente uma da outra, a vazão total foi calculada como a soma das vazões em cada linha. Este fato é importante, pois permite ajustar, de forma independente, a vazão de ar conforme a necessidade de cada ensaio.

Para a medição da vazão de ar no sistema personalizado, foi utilizado um medidor de fluxo de massa do fabricante Contech, modelo FT2. Este equipamento é um fluxômetro de massa térmica que contém um transdutor de temperatura. $\mathrm{O}$ sensor aquecido é colocado junto a uma sonda com comprimento calibrado e introduzido dentro da tubulação do sistema de ventilação personalizada, de modo a permanecer exatamente no centro da tubulação. Um segundo sensor, isolado e calibrado sob uma temperatura de referencia prédefinida, é mantido a uma temperatura constante. A diferença de temperatura entre os dois sensores é monitorada pelo sistema de controle que gera uma diferença de potencial, que é lida pelo circuito interno a uma frequência máxima de $100 \mathrm{~Hz}$. Este circuito faz a respectiva conversão do valor da diferença de potencial para velocidade da massa de fluido que está sendo lida instantaneamente. Como são conhecidos os valores da velocidade do ar, da área do volume de controle onde está localizada a sonda e da temperatura do ar, o sistema de controle faz o cálculo e exibe no display do equipamento o valor instantâneo da vazão mássica de ar, medido em Normal Metro Cúbico por unidade de tempo. A Figura 4.17 mostra a configuração do equipamento e na Figura 4.18, é mostrada a sua instalação nos dutos do sistema personalizado do mock-up.

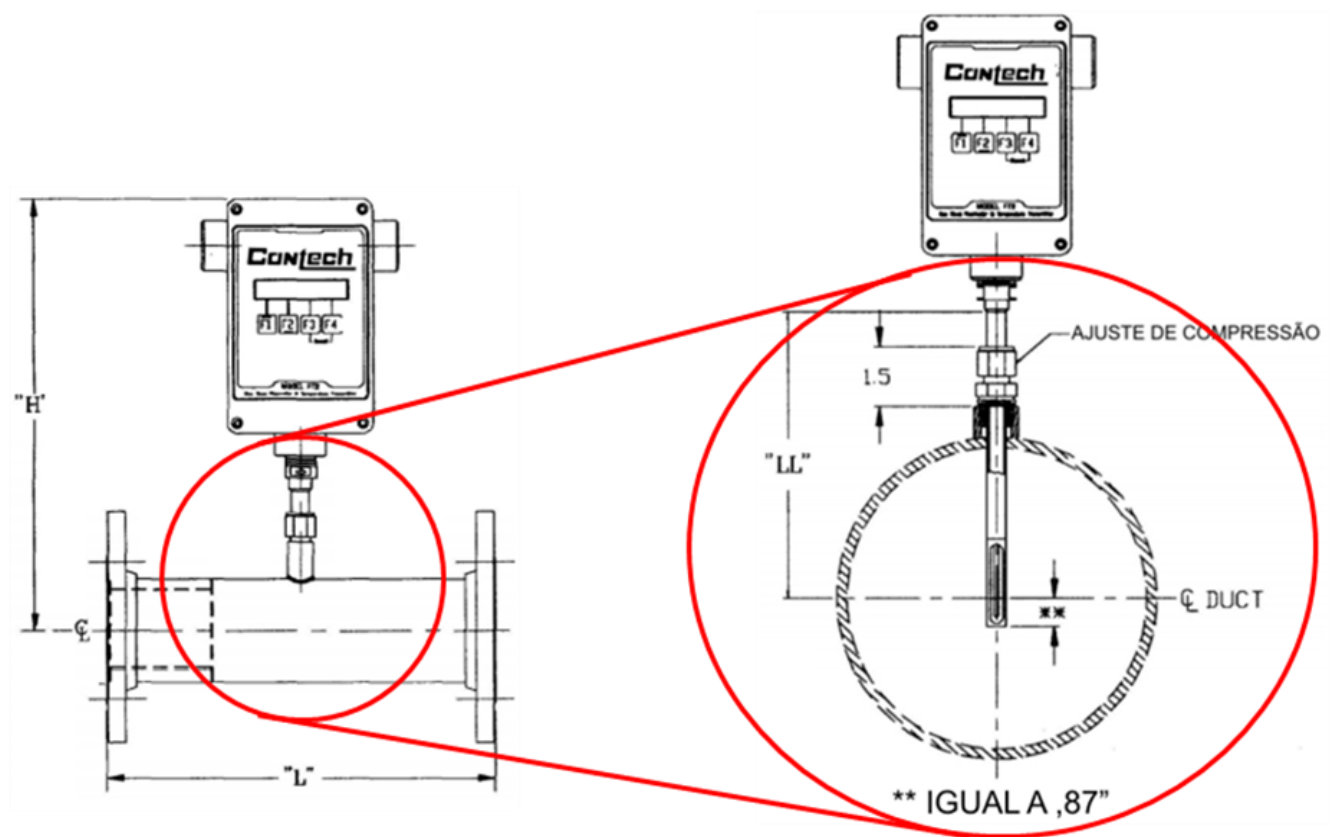

Figura 4.17. Configuração para instalação do medidor de vazão - imagem de catalogo 


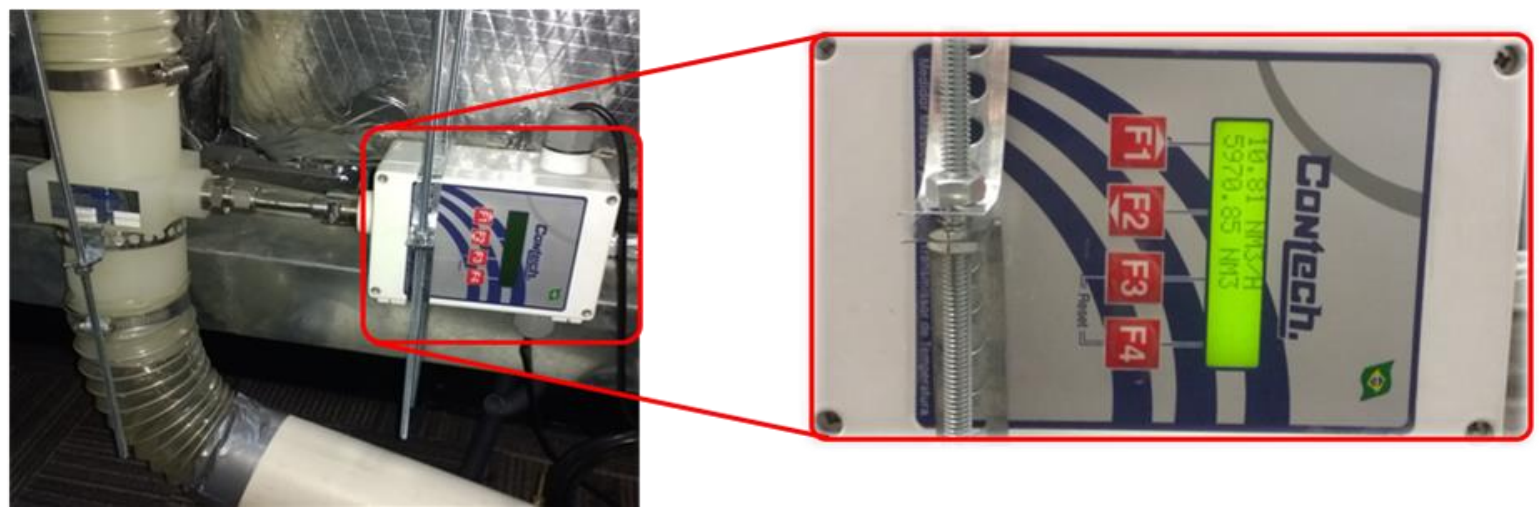

Figura 4.18. Instalação do medidor de vazão - em detalhe, valor da vazão no sistema personalizado

\subsection{Processo de geração e de medição da concentração de partículas}

Para minimizar influências no escoamento do ar no interior da cabine, o gerador de aerossol foi posicionado externamente ao mock-up, como mostra a figura $4.19 \mathrm{a}$, e o aerossol gerado injetado no ambiente interno da cabine mediante tubos metálicos e mangueiras de silicone de $10 \mathrm{~mm}$ de diâmetro interno, como ilustrado no detalhe na figura 4.19b.

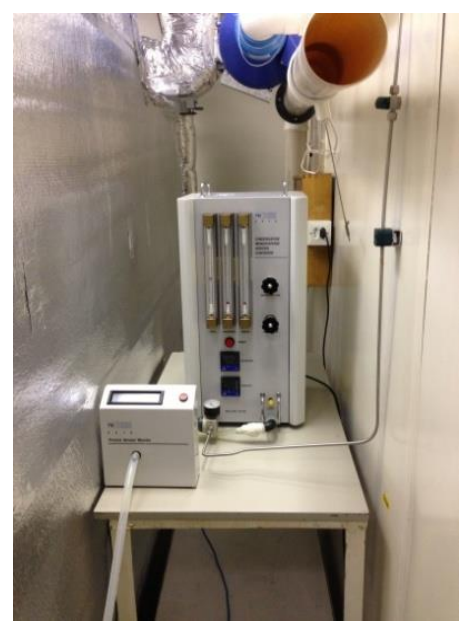

a)

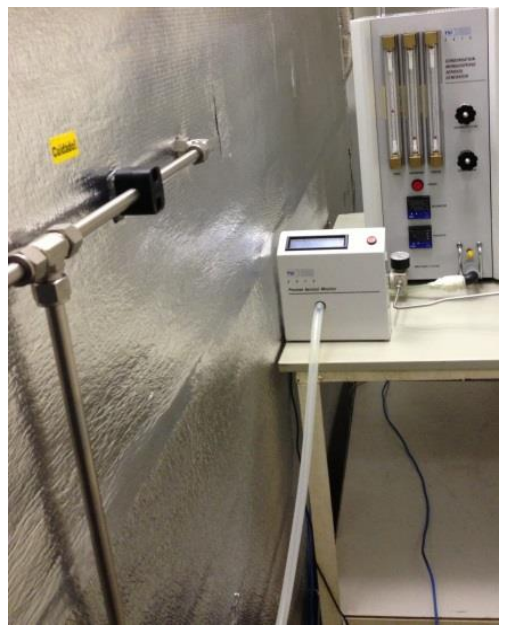

b)

Figura 4.19. (a) Gerador de aerossol TSI modelo 3475 e monitor PAM 3475 posicionados externamente ao mock-up e (b) Detalhe dos tubos e mangueiras de conexão Fonte: FABICHAK JR., 2018

O tamanho e a concentração das partículas geradas foram constantemente monitorados com o uso do monitor PAM 3475. Este procedimento é de importância fundamental, porque assim pode-se garantir que todos os testes sejam realizados com a mesma 
quantidade e concentração de partículas geradas e injetadas no ambiente.

Adotando procedimento similar ao realizado por Wan, Chao e Fang (2005) e Fabichak Jr. (2018), a injeção das partículas, simulando pessoa liberando partículas expiratórias ao tossir, foi feita, inicialmente, na poltrona junto à fuselagem e, posteriormente, na poltrona do passageiro sentado junto ao corredor. As partículas foram injetadas a 1,10m a partir do piso, que corresponde à zona de respiração das pessoas, nas posições 3E e 3D, respectivamente, como ilustrado na figura 4.20.

Na medição da concentração de partículas em cada poltrona do mock-up (figura 4.20) os contadores de partículas também foram posicionados na zona de respiração dos manequins, a 1,10 $\mathrm{m}$ do piso, como mostra a figura 4.21 .

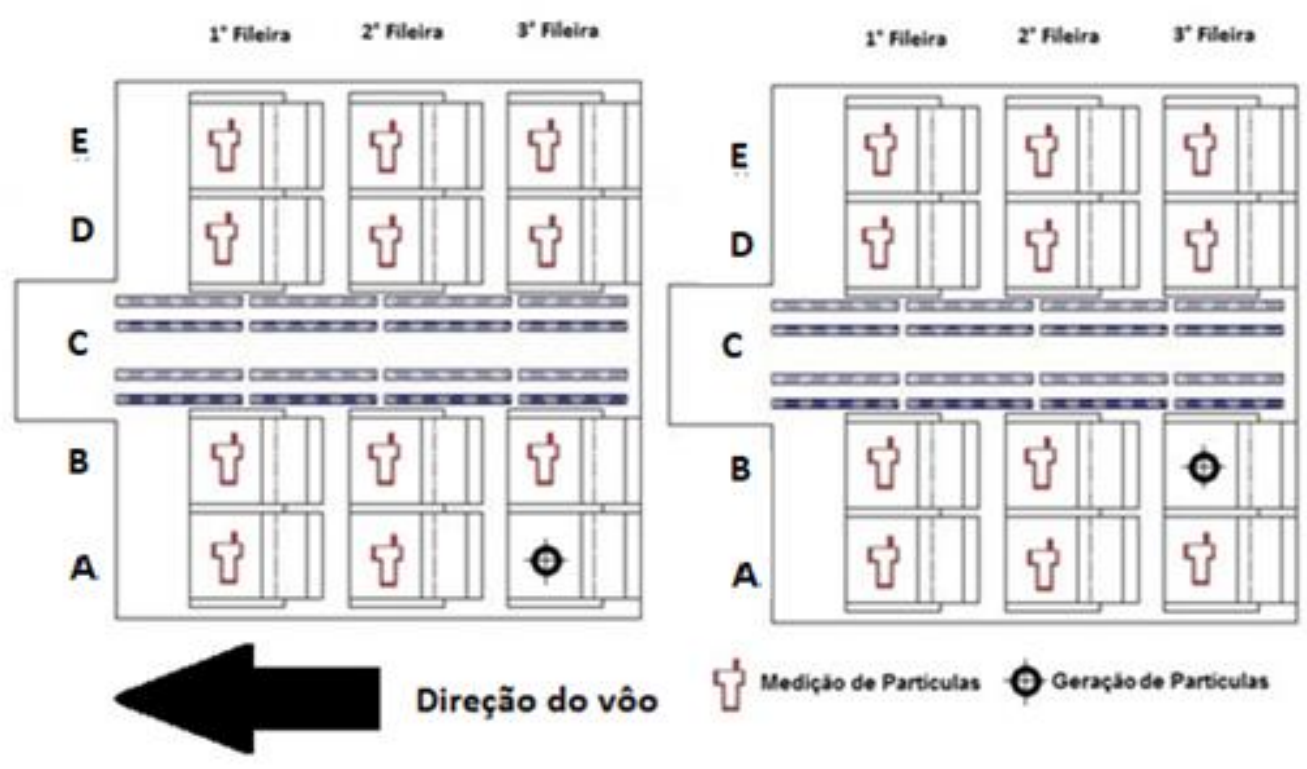

a)

b)

Figura 4.20. Pontos de injeção e medição de partículas no mock-up: (a) injeção de partículas na poltrona 3A e (b) injeção de partículas na poltrona 3B 


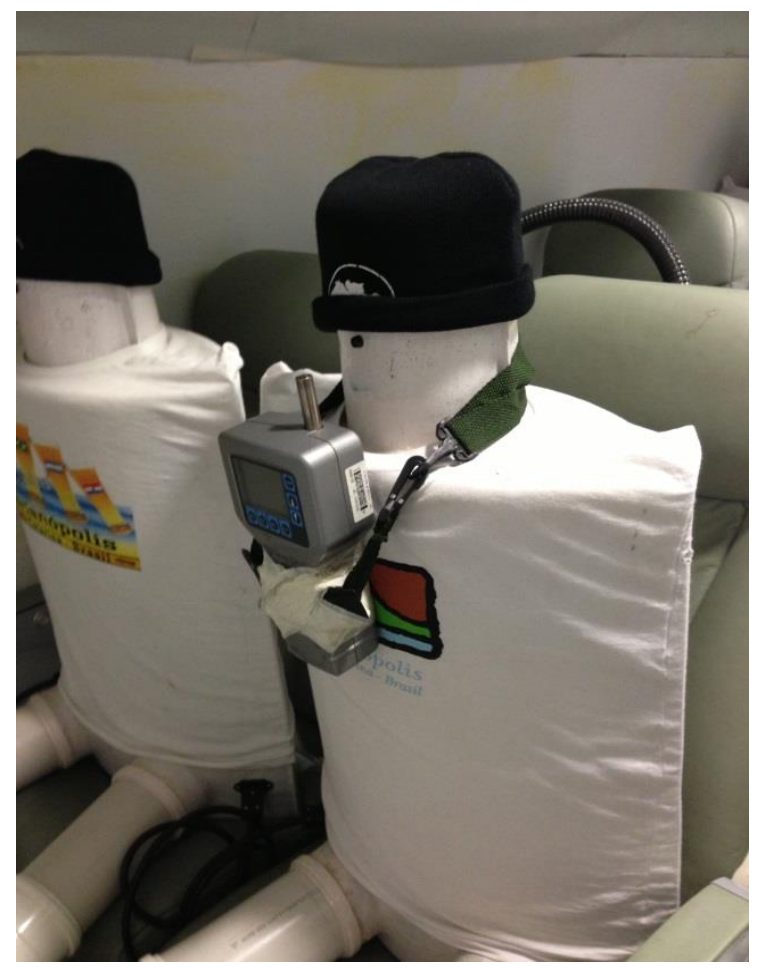

Figura 4.21. Posição dos contadores de partículas

\subsubsection{Intervalo entre medições e tempo de medição das partículas}

O intervalo entre medições é função do tamanho das partículas analisadas. Quanto menor o tamanho das partículas, maior o tempo para a sua deposição após a ressuspensão causada pela movimentação no interior da cabine na troca da posição do contador de partículas.

Fabichak Jr. (2018) verificou a necessidade de 10 minutos para que ocorra a estabilização de partículas maiores que $3 \mu \mathrm{m}$, que também é a situação de estudo no presente trabalho. O tempo de medição também foi de 10 minutos, que é o mesmo tempo adotado na medição da velocidade e da temperatura do ar e de partículas por Zhang et al. (2007).

\subsection{Repetitividade dos ensaios}

Para aumentar a confiabilidade das medições e dos resultados cada ensaio foi repetido em três dias diferentes. 


\subsection{Sequência experimental}

A seguir é apresentada a sequencia experimental efetuada para cada sistema de ventilação personalizada e de distribuição de ar estudados, conforme procedimento realizado por Fabichak Jr.(2018).

Inicialmente, foram ajustadas as válvulas dos dutos de insuflamento e exaustão do ar para a arquitetura em estudo;

$\checkmark$ Em seguida, foi ligado o sistema de automação e controle e demais equipamentos e configurados todos os parâmetros para o ensaio;

Depois, foram ligados os manequins aquecidos para iniciar o processo de estabilização;

Feito isso, foram ligados os ventiladores instalados nos dutos de exaustão do mock-up;

$\checkmark$ Em seguida, foram realizadas medições da diferença de pressão nos manômetros diferenciais e realizados cálculos de vazão de ar, para o ajuste dessas vazões utilizando os dampers instalados em cada linha de exaustão;

Depois, foi iniciado o registro de dados do sistema de automação e controle e no Data Logger para determinar o período de estabilização das condições ambientais na cabine;

$\checkmark$ Nesse momento, o gerador de partículas foi ligado para que sua resistência seja aquecida, configurando-o para a geração do diâmetro e da concentração de partículas desejados;

Feito isso, as sondas omnidirecionais foram posicionadas na posição a ser medida, simultaneamente com o contador de partículas, colocados próximos à zona de respiração (a 1,10 $\mathrm{m}$ do piso);

Após a estabilização das condições ambientais na cabine, foram efetuadas as medições para cada uma das posições do plano de medição do mock-up; 
$\checkmark$ Finalizadas as medições, são efetuados os registros e armazenamento dos dados;

$\checkmark$ Finalmente, verifica-se novamente a diferença de pressão nos manômetros para assegurar que não houve variação durante os ensaios e;

Após as etapas anteriores, os equipamentos são desligados e o processo de medição é concluído. 


\section{Capítulo 5}

\section{RESULTADOS EXPERIMENTAIS}

Neste capítulo são apresentados os resultados e a análise dos resultados das variáveis ambientais que caracterizam o ambiente interno da cabine e da concentração de partículas no mock-up nos testes do sistema de ventilação personalizada (PV) proposto, considerando os sistemas de ventilação por mistura (MV) e por deslocamento (DV).

Objetivando a realização de análise comparativa dos resultados para o sistema PV juntamente com os sistemas MV e DV de ventilação e distribuição de ar testados, os resultados de contagem de partículas são apresentados na forma de barras e os de velocidades e temperaturas na forma de perfis.

A figura 5.1 apresenta um esquema do mock-up com a identificação dos seus respectivos assentos. Cada local analisado é representado pelo assento, conforme consta na figura 5.1. Por exemplo, o assento da $1^{\circ}$ fileira na fileira A será indicado como assento $1 \mathrm{~A}$.

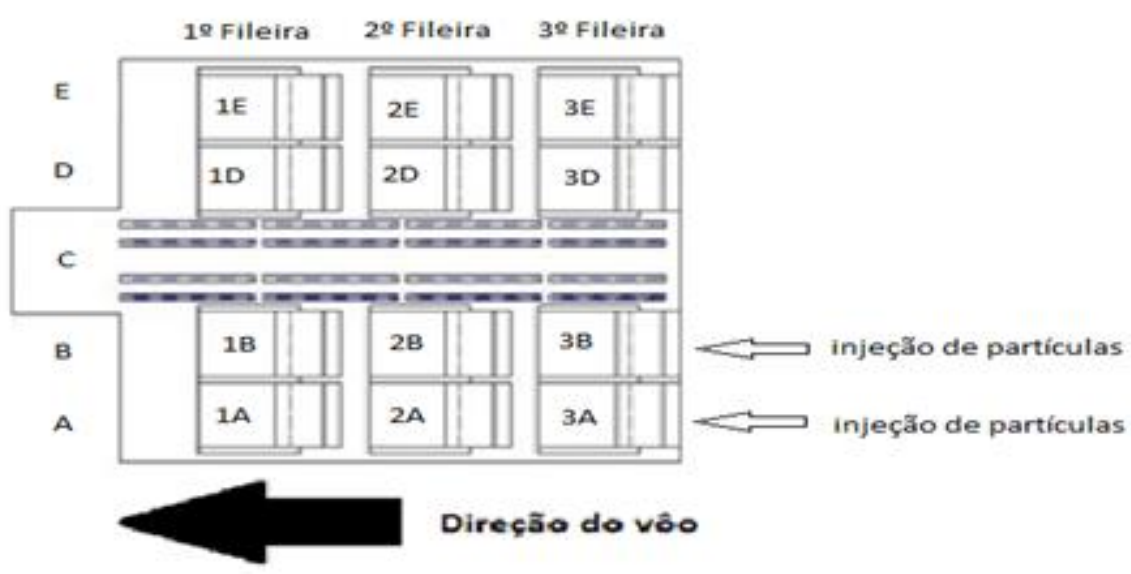

Figura 5.1. Identificação dos assentos

No presente trabalho o sistema personalizado PV está instalado na parte de trás dos assentos 1A e 1B. Todavia, a ação do sistema PV em operação ocorre nos assentos $2 \mathrm{~A}$ e 2B, respectivamente. Assim, o sistema PV irá ser referenciado aos assentos 2A (PV2A) e 2B (PV2B), ligados alternadamente, e a geração (injeção) de partículas ocorre pelos assentos 3A e 3B, respectivamente, também em operação alternadamente. 
A tabela 5.1 apresenta as situações nas quais foram realizados os ensaios, destacando a combinação de sistemas ligados e desligados (em operação) alternada ou simultaneamente, bem como a temperatura do ar de insuflamento em cada sistema.

Tabela 5.1. Caracterização das situações de ensaio

\begin{tabular}{|l|c|c|}
\hline \multirow{2}{*}{$\begin{array}{c}\text { Sistema de Ventilação da } \\
\text { Cabine }\left(\mathbf{1 8}^{\mathbf{0}} \mathbf{C}\right)\end{array}$} & PV - Sistema de ventilação personalizada $\left(\mathbf{2 4}^{\mathbf{0}} \mathbf{C}\right)$ \\
\cline { 2 - 3 } & PV 2A & PV 2B \\
\hline \multirow{2}{*}{$\begin{array}{l}\text { MV - Sistema de ventilação } \\
\text { por mistura ligado }\end{array}$} & Desligado & Desligado \\
\cline { 2 - 3 } & Ligado & Desligado \\
\cline { 2 - 3 } & Desligado & Ligado \\
\hline \multirow{2}{*}{$\begin{array}{l}\text { DV - Sistema de ventilação } \\
\text { por deslocamento ligado }\end{array}$} & Desligado & Desligado \\
\cline { 2 - 3 } & Ligado & Desligado \\
\cline { 2 - 3 } & Desligado & Ligado \\
\hline
\end{tabular}

Conforme ressaltado no Capítulo 1, o objetivo do presente trabalho é realizar análise da influência de sistema de ventilação personalizada proposto, PV, na dispersão e na remoção de partículas na zona de respiração, considerando os sistemas de ventilação de cabine MV e DV. É importante ressaltar que em trabalho desenvolvido concomitantemente a este trabalho, Fabichak Jr (2018) realizou estudo pormenorizado da influência dos sistemas de ventilação de cabine MV e DV na dispersão e remoção de partículas na região de respiração. Portanto, no presente trabalho os resultados dos ensaios com o sistema personalizado desligado, ou seja, com somente o sistema de ventilação de cabine MV ou DV operando, são apresentados aqui com o objetivo tão somente de realizar análise comparativa com e sem o uso do sistema PV.

\subsection{Perfis de Velocidades e de Temperaturas do Ar}

Conforme mostrado na tabela 5.1 e no Capítulo 4, o ar foi insuflado na cabine a $18^{\circ} \mathrm{C}$ pelo sistema de ventilação da cabine, sistemas MV e DV, em operação alternadamente. No sistema PV, também em operação alternadamente, nos assentos $2 \mathrm{~A}$ (PV2A) e 2B (PV2B), o ar foi insuflado a uma temperatura de $24{ }^{\circ} \mathrm{C}$ e a uma vazão de 3,0 L/s. A vazão de ar fornecida pelo sistema PV foi calculada de forma a que o percentual de pessoas insatisfeitas devido a correntes de ar, PD, Percentage of Dissatisfied ou Draught Rate, DR (FANGER et al., 1988) atenda critério preconizado nas normas ASHRAE 55 
(ASHRAE, 2013) e ISO 7730 (ISO, 2005) com PD = DR < 20\%. Os cálculos para se chegar a este valor são apresentados no apêndice C .

Os valores das temperaturas e das velocidades do ar, com respectivas incertezas de medição, são apresentados no apêndice D.

\subsubsection{Perfis de Velocidades do Ar}

Inicialmente, nas figuras 5.2 e 5.3 são apresentados os resultados dos perfis de velocidade do ar para todos os assentos considerando, respectivamente, o sistema PV no assento 2A (PV2A) e 2B (PV2B), ligado e desligado, operando alternadamente.

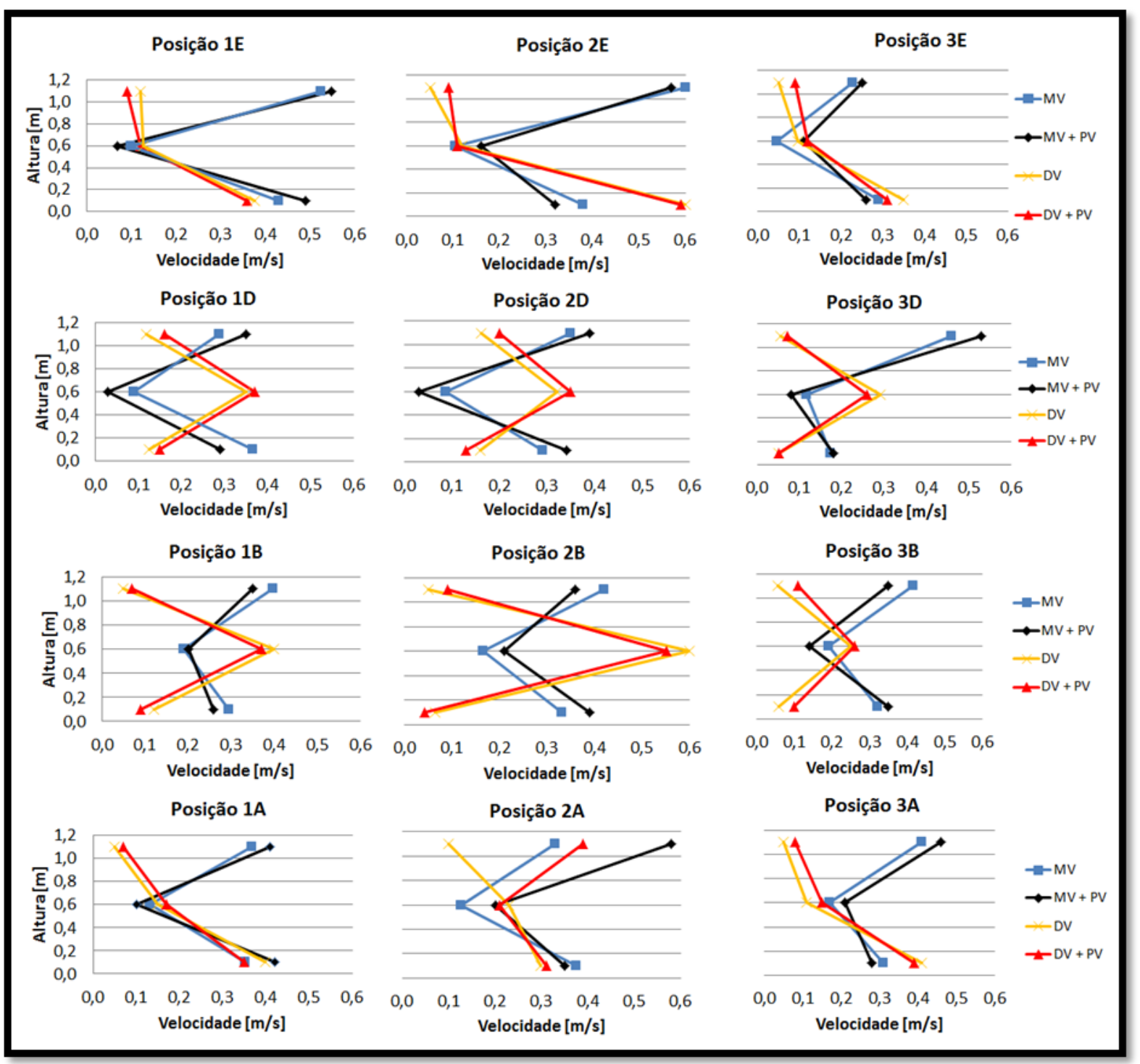

Figura 5.2. Perfis de velocidades do ar nos sistemas MV e DV com o sistema PV no assento 2A (PV2A) ligado e desligado 


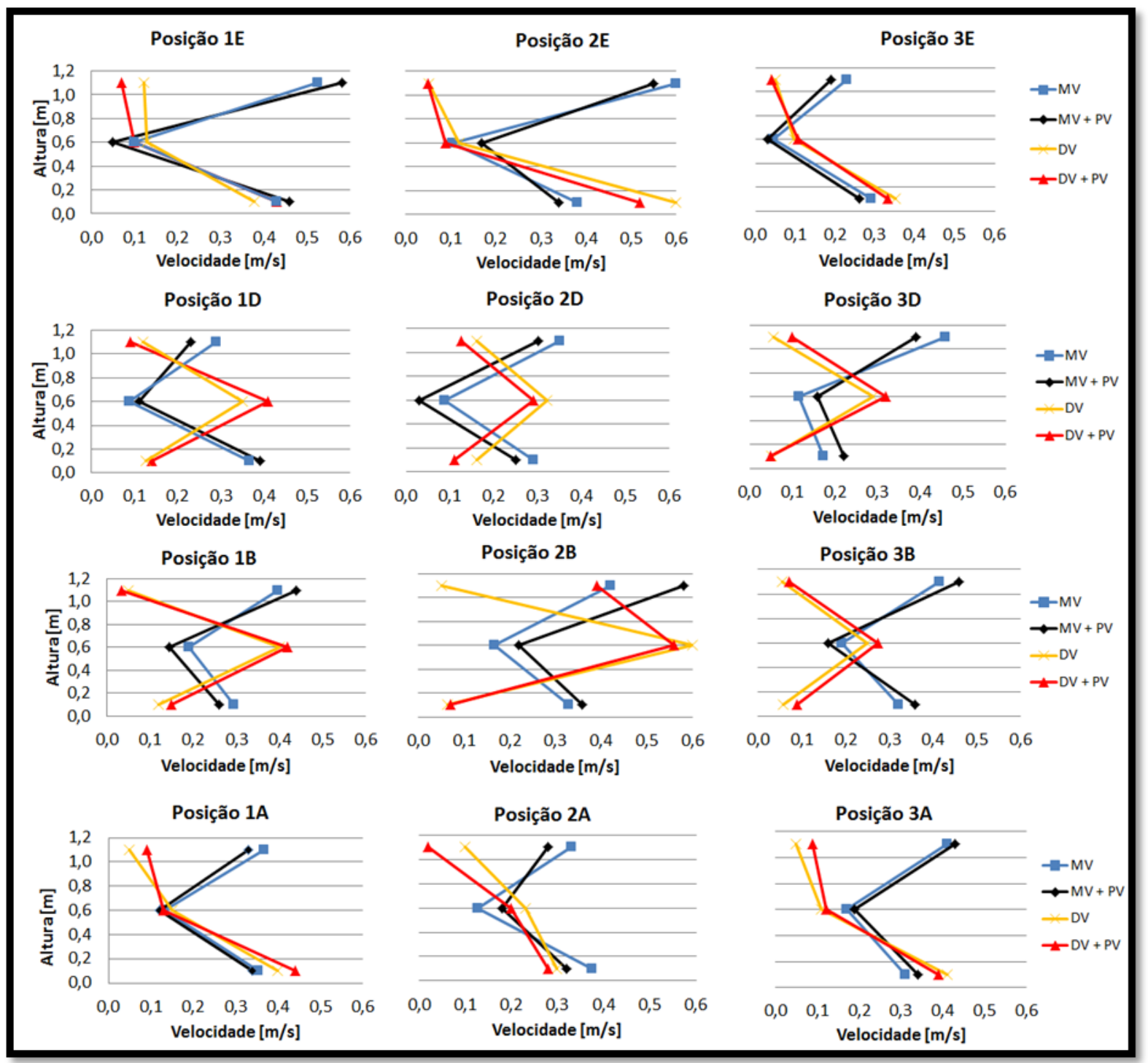

Figura 5.3. Perfis de velocidades do ar nos sistemas MV e DV com o sistema PV no assento 2B (PV2B) ligado e desligado

Analisando os resultados das figuras 5.2 e 5.3 é possível observar que nos assentos onde o sistema PV não está operando há uma mesma tendência no perfil de velocidade do ar, tanto quando os ensaios foram realizados com apenas o sistema da cabine em funcionamento, quanto quando os ensaios foram realizados com o sistema PV ligado. Dois perfis se destacam. Um com apenas o sistema da cabine em funcionamento e outro com o sistema PV ligado. Isso tanto para o sistema MV quanto o DV.

Sem o sistema PV ligado, os perfis de velocidade do ar em todos os assentos correspondem às características dos sistemas, MV e DV, e à localização do assento. Por exemplo, nos assentos próximos à fuselagem, finais A e E, o sistema DV apresenta uma tendência de velocidades maiores próximo à região dos pés, que corresponde à região 
próxima aos difusores de insuflamento de ar no sistema DV. Já no sistema MV, os perfis de velocidade do ar apresentam velocidades maiores na região da cabeça, próxima à área de insuflamento, com redução na região das coxas, mãos e antebraços, aumentando novamente na região dos pés. É importante destacar que comportamento similar da velocidade do ar para o sistema MV, também foi verificado no trabalho de simulação numérica de Zhang e Chen (2007), e no sistema DV, no trabalho experimental desenvolvido por Zhang et al. (2017). Análise detalhada da influência do sistema de ventilação MV e DV nos perfis de velocidade do ar pode ser encontrada em Fabichack Jr. (2018).

Com o sistema PV ligado, verifica-se que no assento 2A da figura 5.2 e no assento 2B da figura 5.3, existe um aumento significativo dos valores da velocidade do ar na altura de 1,1m, região da zona de respiração, conforme esperado.

Com o objetivo de verificar se o sistema personalizado PV influencia nas velocidades do ar nos demais assentos, a figura 5.4 apresenta as diferenças de velocidades para todos os assentos quando os ensaios foram realizados com o sistema PV do assento 2A (PV 2A) ligado e desligado e também, da mesma forma, apresenta as diferenças de velocidades quando os ensaios foram realizados com o sistema PV do assento 2B (PV2B) ligado e desligado para as três alturas analisadas, 0,1m, 0,6m e 1,1m. A figura 5.5, por sua vez, apresenta a comparação dos valores das incertezas de medição com as diferenças de velocidade em módulo em cada assento para a altura de $1,1 \mathrm{~m}$. O objetivo é verificar se as diferenças encontradas são maiores que os valores das incertezas, principalmente, na zona de respiração.

Analisando os resultados das figuras 5.4 e 5.5 é possível verificar que:

a) Todos os valores das diferenças de velocidades do ar encontradas entre os ensaios com o sistema PV ligado e desligado são menores que os valores de incertezas calculadas, exceto no assento 2A quando o sistema PV está em operação no assento 2A (PV2A) e no assento 2B quando o sistema PV está em operação no assento 2B (PV2B). Nestes casos os valores da diferença encontrada entre os ensaios do sistema MV e MV+PV e entre os ensaios do sistema DV e DV+PV são significativamente superiores às incertezas de medição. 


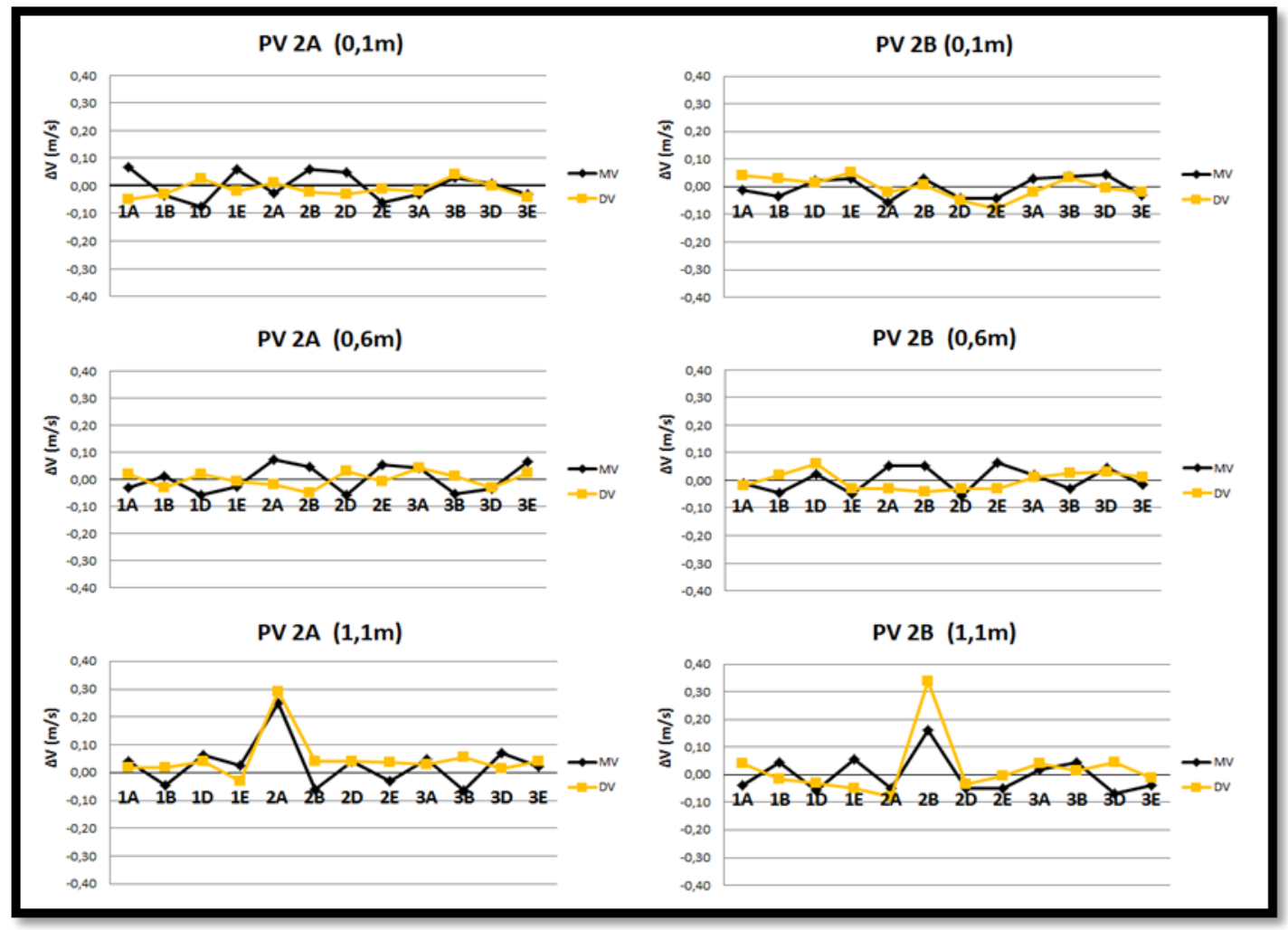

Figura 5.4. Diferenças de velocidades do ar entre os ensaios com o sistema PV ligado e desligado, sistemas MV e DV

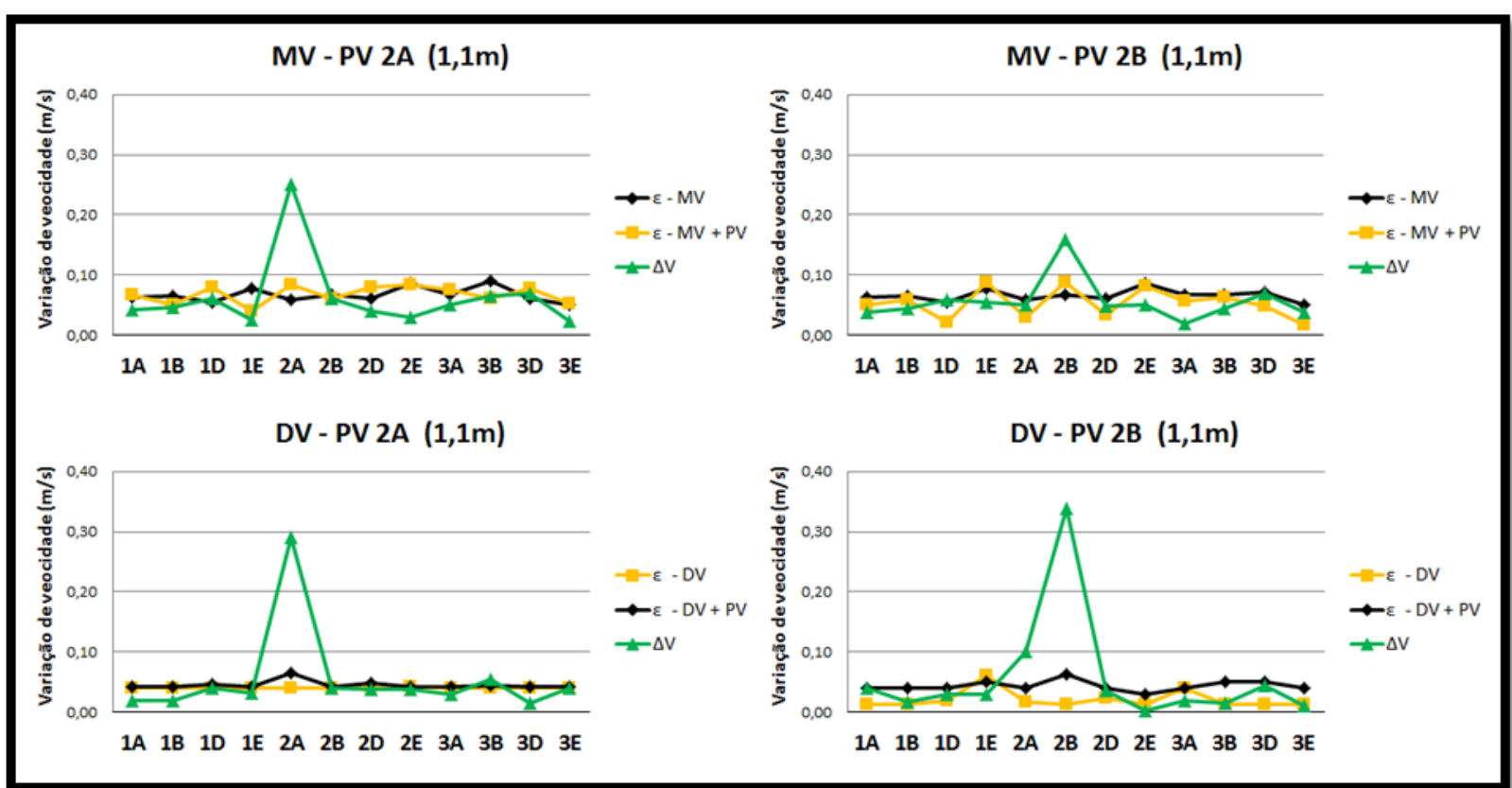

Figura 5.5. Comparação entre as incertezas de medição $(\varepsilon)$ e as diferenças de velocidades do ar entre os ensaios com o sistema PV ligado e desligado, $\Delta \mathrm{V}$, nos sistemas MV e DV 
b) Para os ensaios realizados com o sistema PV operando, respectivamente, nos assentos 2A (PV2A) e 2B (PV2B), alternadamente, houve um aumento significativo da velocidade do ar com relação ao sistema PV desligado no assento $2 \mathrm{~A}$ e $2 \mathrm{~B}$, respectivamente, somente na altura de $1,1 \mathrm{~m}$, zona de respiração, tanto no sistema MV quanto no DV.

c) A velocidade do ar no assento $2 \mathrm{~A}$, altura $1,10 \mathrm{~m}$, com o sistema PV operando no assento 2A (PV2A) em relação ao sistema desligado foi de $0,25 \mathrm{~m} / \mathrm{s}$ maior no sistema MV e 0,29 m/s no sistema DV. Por sua vez, com o sistema PV operando no assento 2B (PV2B), a velocidade do ar no assento 2B com relação ao sistema desligado, altura $1,10 \mathrm{~m}$, foi de $0,16 \mathrm{~m} / \mathrm{s}$ maior no sistema MV e em torno de 0,34 $\mathrm{m} / \mathrm{s}$ maior no sistema DV.

d) A velocidade do ar no assento próximo ao sistema PV, isto é, no assento $2 \mathrm{~B}$ com o sistema PV operando no assento 2A (PV2A) e no assento 2A com o sistema PV operando no assento 2B (PV2B), praticamente não é afetada pelo sistema PV, com diferenças entre o sistema ligado e desligado abaixo das incertezas de medição, exceto no assento 2A quando o sistema PV do assento 2B (PV2B) estava em operação no sistema DV, neste caso a velocidade medida na altura de $1,1 \mathrm{~m}$ foi menor em $0,1 \mathrm{~m} / \mathrm{s}$ e essa diferença ficou acima do valor das incertezas, como pode ser observado na figura 5.5.

Os diferentes valores da velocidade do ar com o sistema PV ligado e desligado, nos sistemas MV e DV, são função do local de insuflamento e exaustão do ar em cada sistema de ventilação da cabine e do escoamento ser descendente no sistema MV e ascendente no sistema DV. O movimento descendente do ar tende a diminuir a velocidade relativa do ar do sistema PV no sistema MV, enquanto o movimento ascendente do ar tende a aumentar a velocidade do ar do sistema PV no sistema DV. A maior ou menor proximidade dos difusores e grelhas do assento onde o sistema PV está operando também influencia na velocidade do ar. Neste caso, contudo, a análise é mais complexa, podendo a localização do assento contribuir no aumento ou na diminuição da velocidade do ar na região de respiração de diferentes formas, tanto no sistema MV, quanto no DV. Neste caso, haveria a necessidade de ensaios com maior número de assentos com o sistema PV ligado e não para se chegar a uma análise mais conclusiva. 


\subsubsection{Perfis de Temperaturas do Ar}

De forma similar aos perfis de velocidade do ar, inicialmente, nas figuras 5.6 e 5.7 são apresentados os perfis de temperatura do ar para todos os assentos considerando, respectivamente, o sistema PV no assento 2A (PV2A) e no assento 2B (PV2B), ligado e desligado, operando alternadamente.

Devido à utilização de manequins térmicos, que simulam a transferência de calor dos passageiros, é esperado que a temperatura do ar dentro da cabine seja maior que a temperatura de insuflamento do sistema da ventilação da cabine, conforme observado nas figuras 5.6 e 5.7.

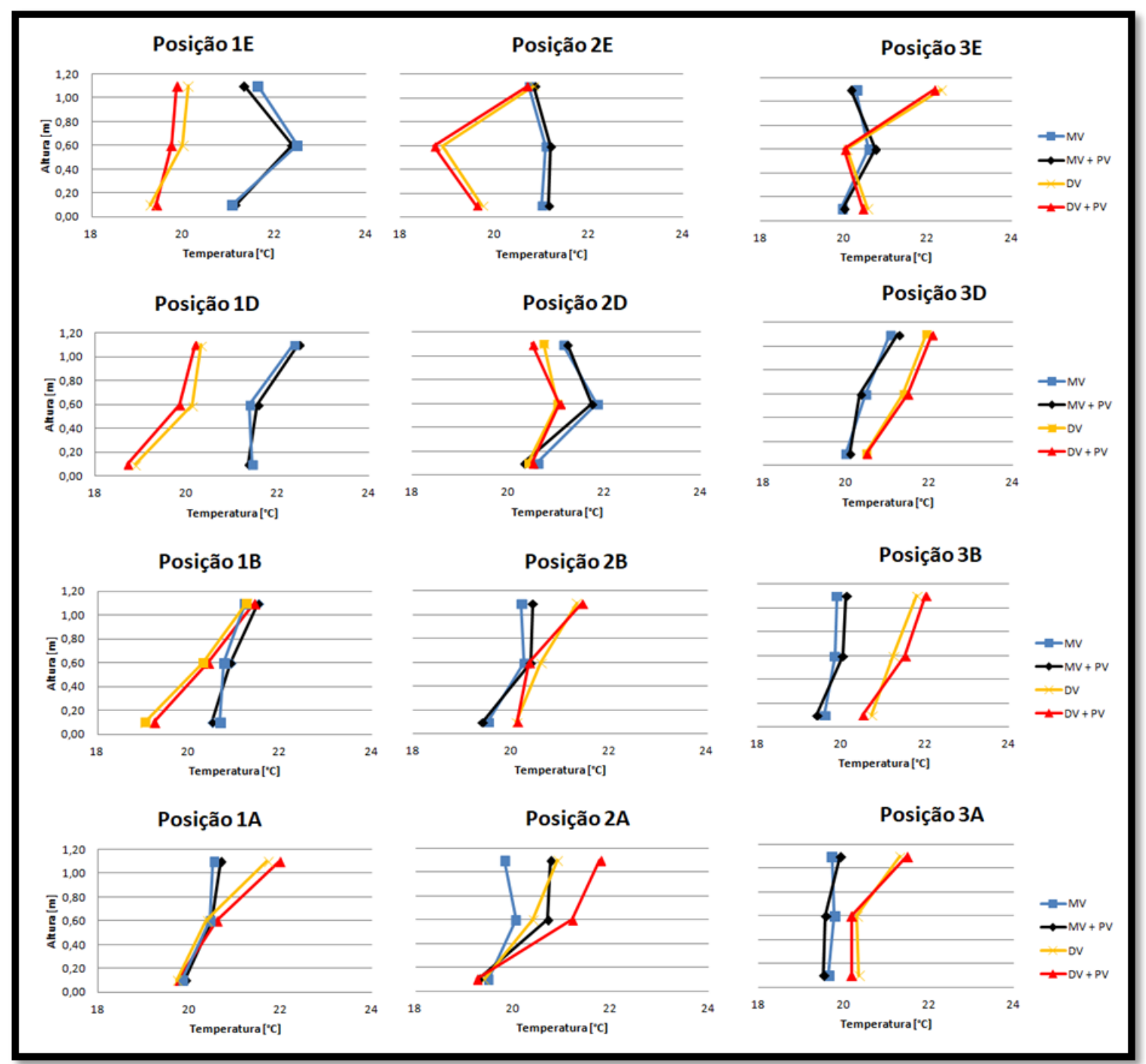

Figura 5.6. Perfis de temperaturas do ar nos sistemas MV e DV com o sistema PV2A ligado e desligado 

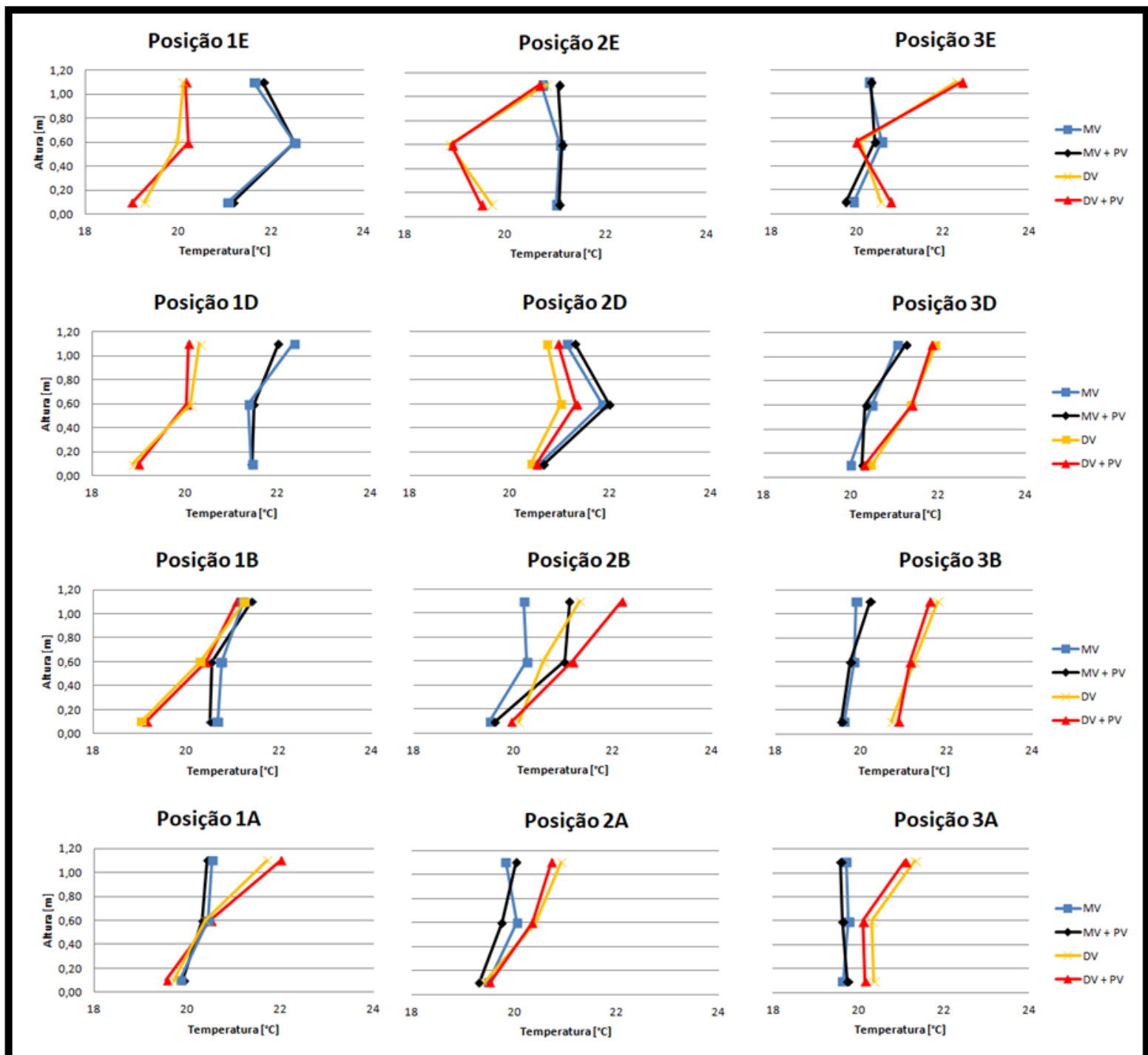

Figura 5.7. Perfis de temperaturas do ar nos sistemas MV e DV com o sistema PV2B ligado e desligado

$\mathrm{Na}$ análise das figuras 5.6 e 5.7 verifica-se a ocorrência de valores máximos de diferença de temperatura do ar entre os pés e a cabeça de aproximadamente $1,4^{\circ} \mathrm{C}$ para o sistema de mistura MV, e de aproximadamente $2,0^{\circ} \mathrm{C}$ para o sistema de ventilação por deslocamento DV nos assentos sem o sistema PV em operação. Conforme esperado, o sistema por deslocamento DV apresenta estratificação de temperatura ligeiramente superior ao sistema de mistura MV.

Por outro lado, embora os perfis de temperatura do ar nos assentos onde o sistema PV não está operando tenham apresentado pequenas diferenças de temperatura do ar com o sistema PV ligado e desligado, não é possível concluir que essa diferença seja influência 
direta do sistema PV, pois existe a impossibilidade de se reproduzir as condições de ensaio de forma fidedigna e também porque ocorrem flutuações no escoamento que tem influência também nas temperaturas do ar.

Assim, com o objetivo de verificar se o sistema personalizado PV influencia nesses valores, a figura 5.8 apresenta as diferenças de temperatura do ar para todos os assentos quando os ensaios foram realizados com o sistema PV do assento 2A (PV2A) e o sistema do assento 2B (PV2B) ligados e desligados, alternadamnete, para as três alturas analisadas, 0,1m, 0,6m e 1,1m. Como complemento, a figura 5.9 apresenta a comparação dos valores das incertezas calculadas com as diferenças de temperatura do ar em módulo em cada assento para a altura de $1,1 \mathrm{~m}$. O objetivo é verificar se as diferenças encontradas são maiores que os valores das incertezas, principalmente, na região de respiração.

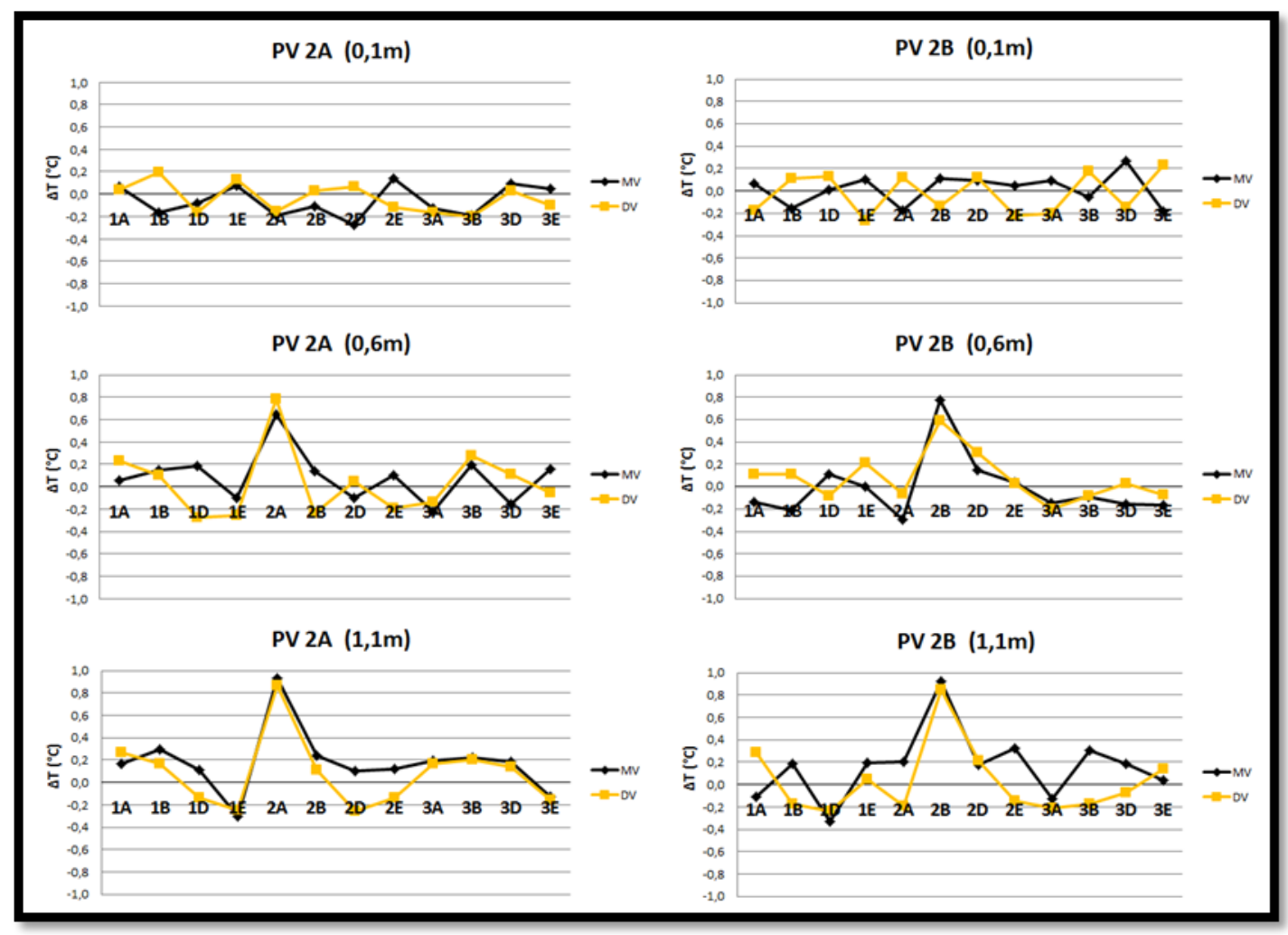

Figura 5.8. Diferenças de temperaturas do ar entre ensaios com o sistema PV ligado e desligado, sistemas MV e DV 


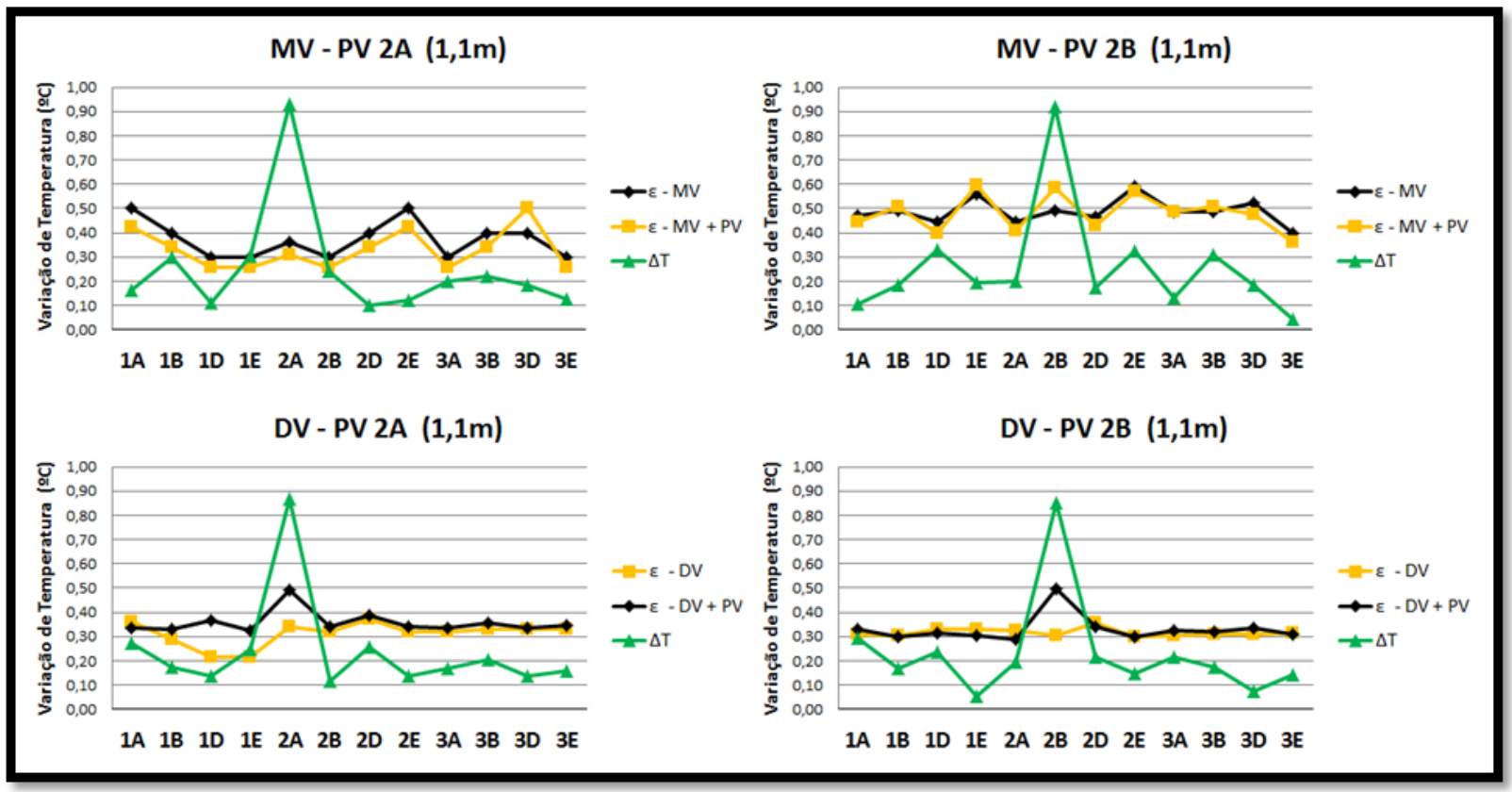

Figura 5.9. Comparação entre as incertezas de medição $(\varepsilon)$ e as diferenças de temperaturas do ar entre os ensaios com o sistema PV ligado e desligado, $\Delta \mathrm{T}$, sistemas MV e DV

Analisando os resultados das figuras 5.8 e 5.9, é possível verificar que:

a) Todas as diferenças de temperaturas do ar, $\Delta \mathrm{T}$, entre os ensaios com o sistema PV ligado e desligado são menores que as incertezas de medição, exceto no assento 2A quando o sistema PV do assento 2A (PV2A) está em operação e no assento 2B quando o sistema PV do assento 2B (PV2B) está em operação. Nestes casos os valores das diferenças de temperaturas do ar encontradas entre os ensaios do sistema MV e MV+PV e entre os ensaios do sistema DV e DV+PV são significativamente superiores às incertezas de medição.

b) No assento $2 \mathrm{~A}$ quando o sistema PV estava ligado foi notado um aumento maior dos valores de temperaturas do ar em duas alturas, a $0,6 \mathrm{~m}$ e $1,1 \mathrm{~m}$. Os valores médios para os dois sistemas, $\mathrm{MV}$ e $\mathrm{DV}$, foram em torno de $0,9{ }^{\circ} \mathrm{C}$ maiores com o sistema PV ligado. Fato que demonstra que o sistema personalizado influencia nessas regiões, conforme esperado, com o sistema PV insuflando ar a $24^{\circ} \mathrm{C}$ na zona de respiração.

c) Da mesma forma que o verificado no assento $2 \mathrm{~A}$ também houve um aumento significativo dos valores de temperatura no assento $2 \mathrm{~B}$ quando o sistema personalizado PV (PV2B) está ligado. Também foram encontrados valores médios em torno de $0,9^{\circ} \mathrm{C}$ maiores que quando o sistema estava desligado nas 
alturas de 0,6m e 1,1m para os dois sistemas MV e DV, o que mostra que o sistema personalizado PV aumenta a temperatura nessa região, conforme esperado.

De forma geral, mesmo que o sistema personalizado PV influencie nos valores de temperatura do ar, não foram encontradas diferenças de temperaturas entre os pés e a cabeças maiores que $2,5^{\circ} \mathrm{C}$, observado no sistema DV + PV $2 \mathrm{~A}$ da figura 5.6 assento $2 \mathrm{~A}$, Essa diferença maior de temperatura do ar entre os pés e a cabeça ocorre devido à influência do sistema personalizado nessa região. Nos demais assentos essa diferença não chegou a $2^{\circ} \mathrm{C}$. Esse fato mostra que embora a estratificação da temperatura seja um fenômeno associado ao insuflamento de baixo para cima do sistema de ventilação por deslocamento, a sua influência não foi significativa. Ademais, o sistema personalizado não causa desconforto térmico local por estratificação de temperatura, pois esse valor atende, ao preconizado nas normas ASHRAE 55 (2017) e ISO 7730 (2005), com valores máximos inferiores a $3{ }^{\circ} \mathrm{C}$ entre a região dos pés e a região da cabeça.

\subsection{Concentração, Dispersão e Remoção de Partículas na Região de Respiração}

Nas Figuras 5.10 a 5.13 são apresentados os resultados de concentração de partículas para a análise da influência do sistema PV na concentração, dispersão e remoção de partículas na região de respiração. Para tal foram medidas concentrações de partículas a 1,10 m do piso em todos os assentos, considerando injeção de partículas nos assentos 3A e 3B com o sistema PV operando nos assentos 2A (PV2A) e 2B (PV2B), alternadamente, nos sistemas de ventilação de cabine MV e DV.

Nas Figuras 5.10 e 5.11 são apresentados os resultados de concentração de partículas para o sistema de ventilação de cabine MV, considerando injeção de partículas nos assentos 3A e 3B, respectivamente, com o sistema PV ligado e desligado, operando alternadamente, nos assentos 2A (PV2A) e 2B (PV2B). Nas mesmas condições de operação, nas Figuras 5.12 e 5.13 são apresentados os resultados de concentração de partículas para o sistema DV.

Os valores das medições de concentração de partículas, juntamente com as incertezas de medição, em cada situação analisada, são apresentados nas Tabelas E.1 a E.12 do Apêndice E. 

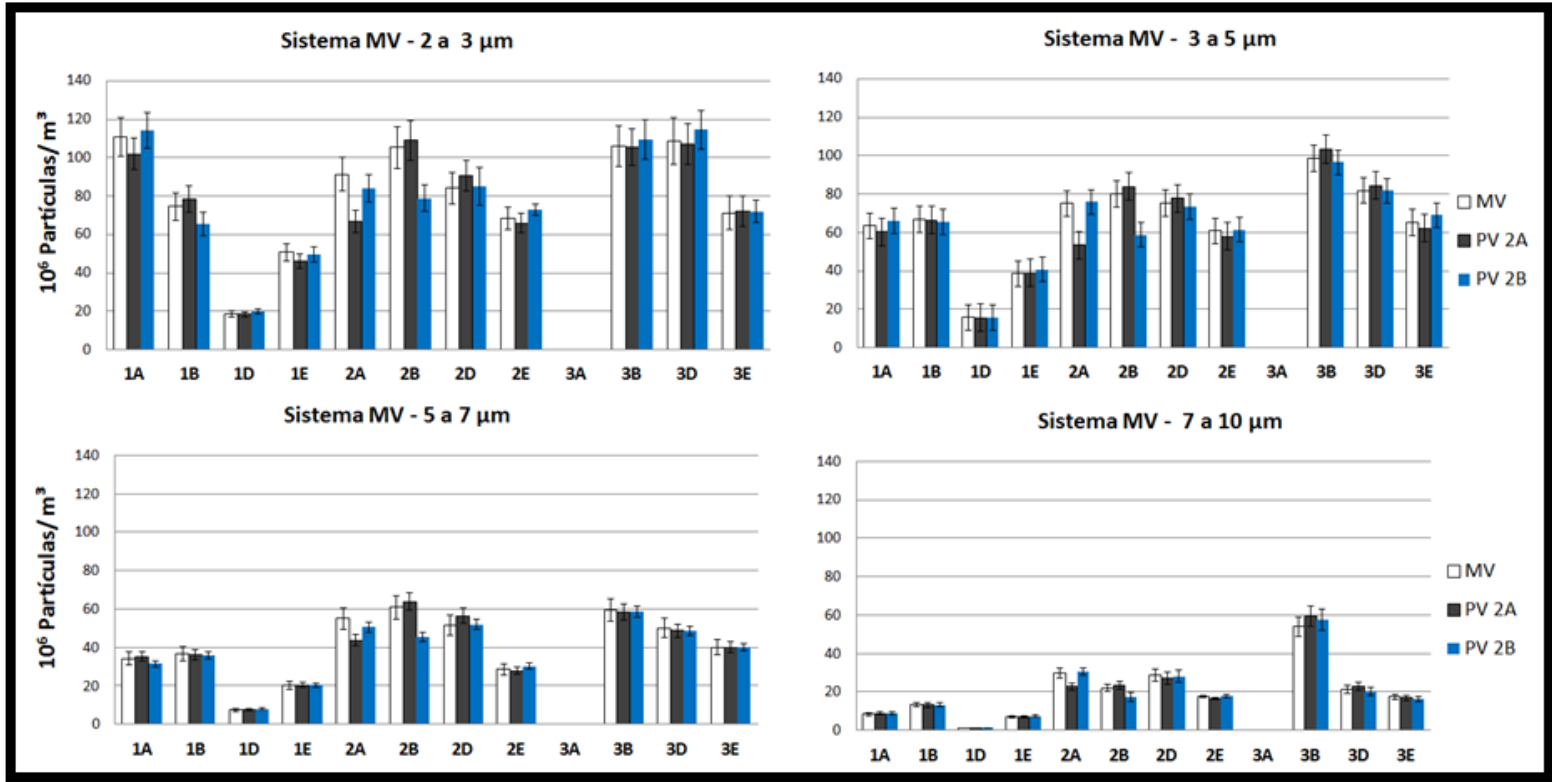

Figura 5.10. Concentração de partículas com o sistema PV ligado e desligado, operando alternadamente nas poltronas $2 \mathrm{~A}$ e $2 \mathrm{~B}$, com injeção de partículas no assento $3 \mathrm{~A}$ e sistema MV

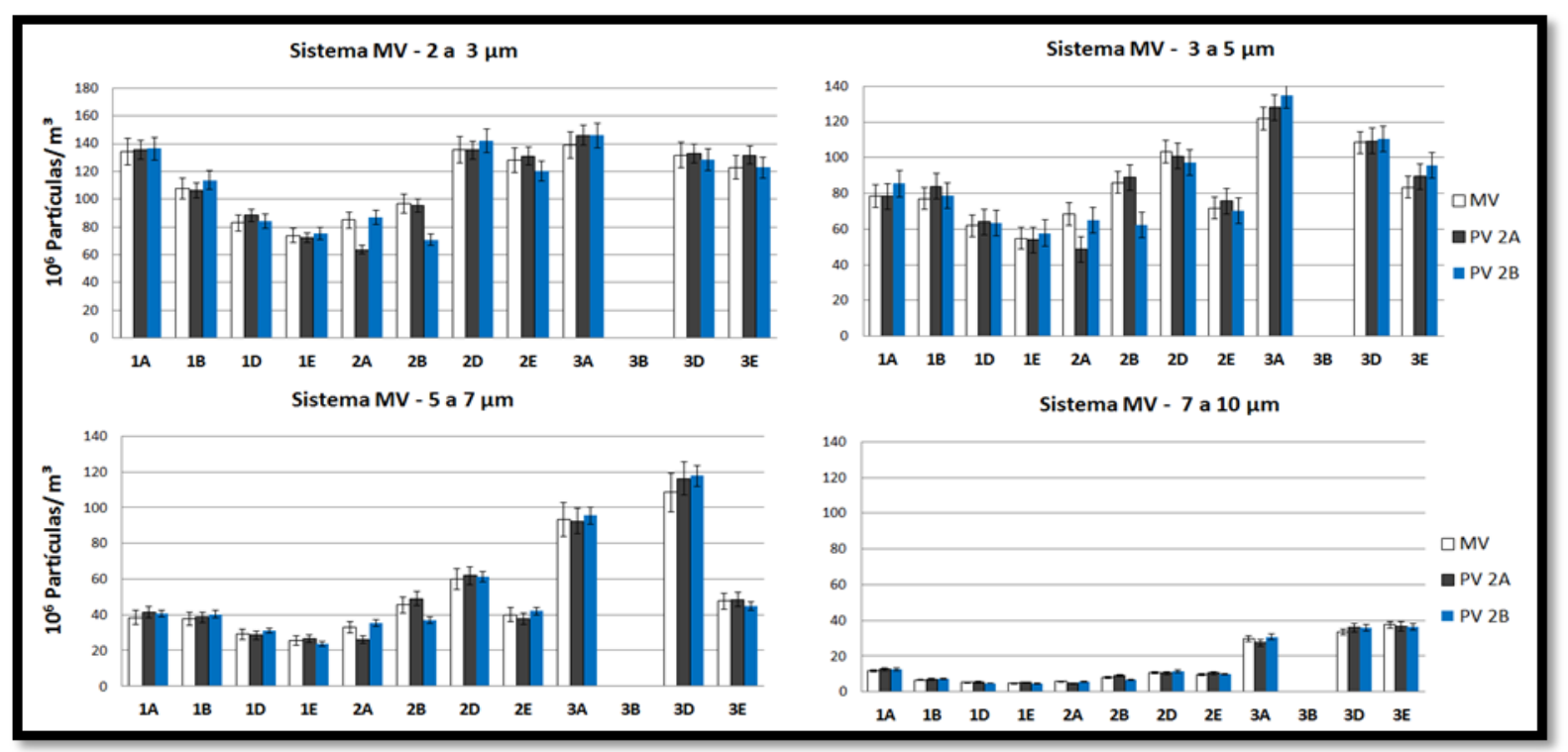

Figura 5.11. Concentração de partículas com o sistema PV ligado e desligado, operando alternadamente nas poltronas $2 \mathrm{~A}$ e $2 \mathrm{~B}$, com injeção de partículas no assento $3 \mathrm{~B}$ e sistema MV 


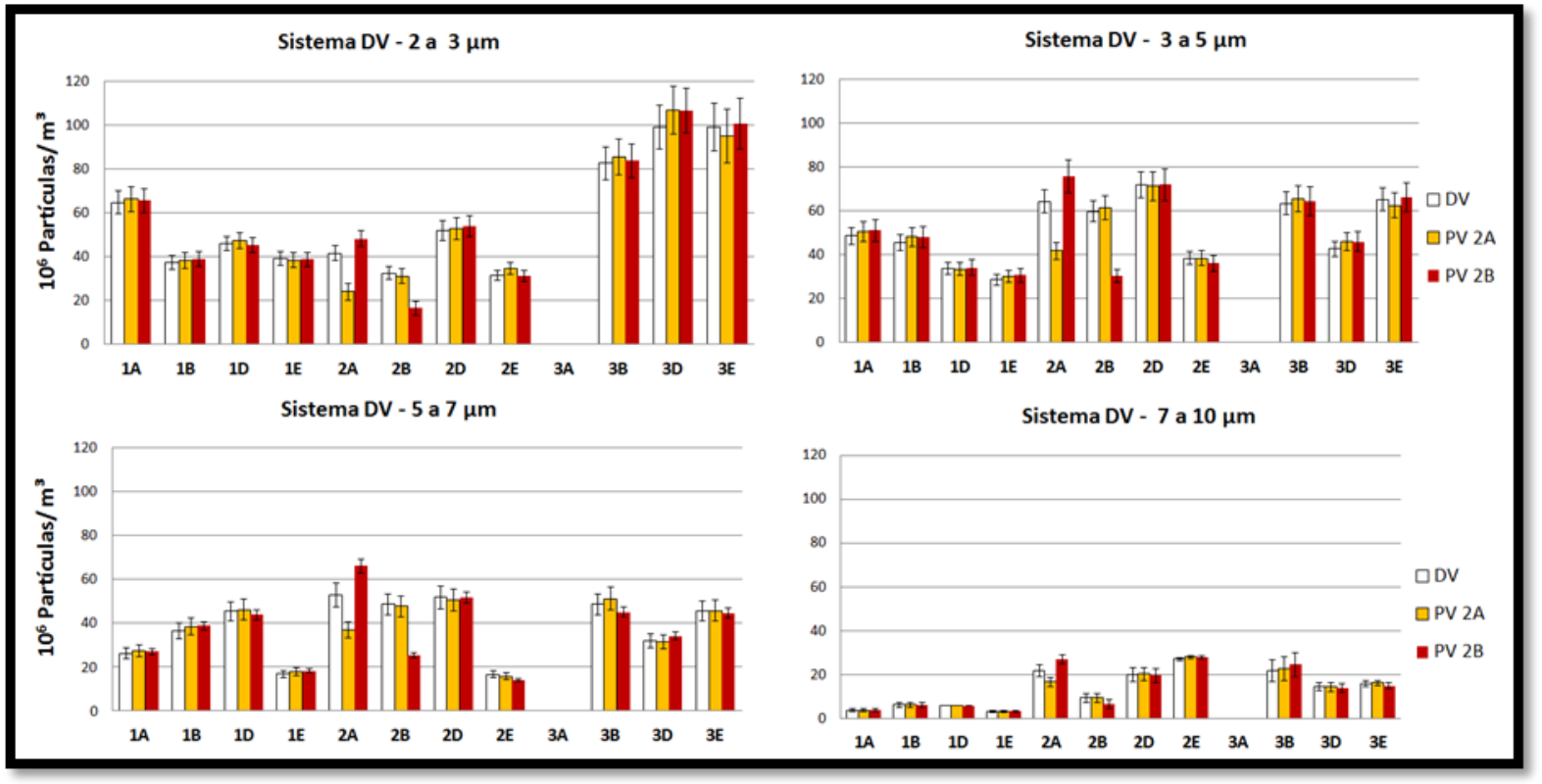

Figura 5.12. Concentração de partículas com o sistema PV ligado e desligado, operando alternadamente nas poltronas $2 \mathrm{~A}$ e $2 \mathrm{~B}$, com injeção de partículas no assento $3 \mathrm{~A}$ e sistema DV

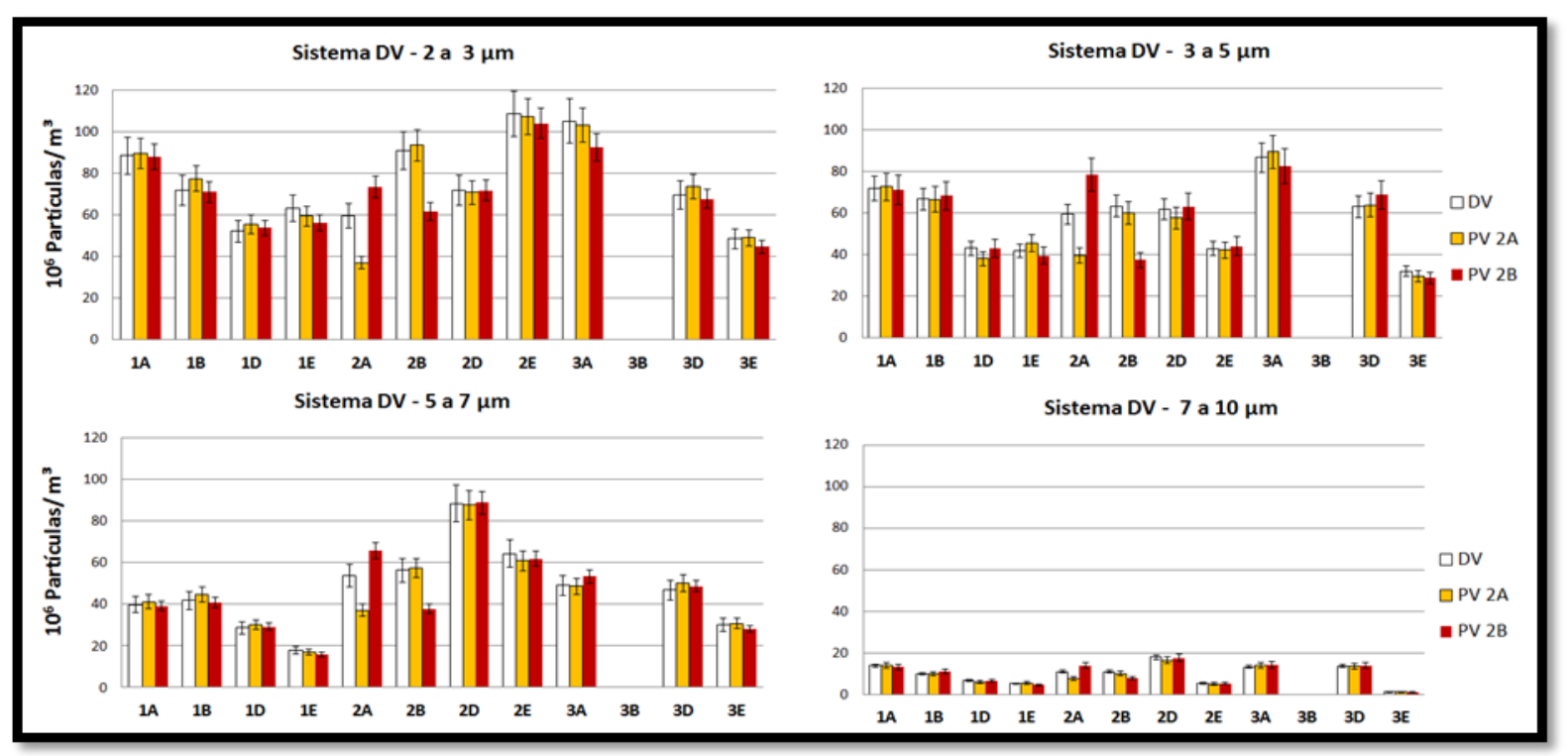

Figura 5.13. Concentração de partículas com o sistema PV ligado e desligado, operando alternadamente nas poltronas $2 \mathrm{~A}$ e $2 \mathrm{~B}$, com injeção de partículas no assento $3 \mathrm{~B}$ e sistema DV 
5.2.1 Análise da influência do sistema PV na concentração e dispersão de partículas

Da análise das figuras 5.10 a 5.13, verifica-se, de uma maneira geral, em todas as faixas de tamanhos de partículas, que:

a) O sistema PV diminuiu a concentração de partículas nos assentos $2 \mathrm{~A}$ e $2 \mathrm{~B}$ onde o sistema PV estava operando alternadamente, PV2A e PV2B, tanto no sistema de cabine MV quanto no sistema DV, bem como na injeção de partículas no assento 3A quanto no assento 3B. Nestes assentos, 2A e 2B, a diminuição da concentração de partículas, com e sem o sistema PV ligado, é nitidamente maior que a incerteza de medição, conforme apresentado nas figuras 5.10 a 5.13 .

b) O sistema PV operando no assento 2A (PV2A) tem pouca influência na concentração de partículas no assento ao lado, 2B, tanto no sistema MV quanto no DV, com diferenças de concentração entre o sistema ligado e desligado menores que as incertezas de medição, conforme mostrado nas figuras $5.10 \mathrm{e}$ 5.11. O sistema PV operando no assento 2B (PV2B) também tem pouca influência no assento ao lado, 2A, no sistema MV. No sistema DV, contudo, ocorreram aumentos mais significativos na concentração de partículas no assento ao lado, 2A, com valores um pouco maiores que as incertezas de medição (figuras 5.12 e 5.13).

c) Nos demais assentos as diferenças entre as concentrações de partículas, com e sem o sistema PV e PV ligado, alternadamente, são menores que as incertezas de medição, conforme mostrado nas figuras 5.10 a 5.13 .

Da análise acima, tem-se que:

a) O sistema PV influencia significativamente a concentração de partículas no assento no qual o sistema está operando, tanto no sistema MV quanto no sistema DV.

b) O sistema PV influencia de maneira diferente a concentração de partículas no assento ao lado onde o sistema PV está operando, tanto no sistema MV, quanto no sistema DV.

c) O sistema PV apresenta influência marginal na concentração de partículas nos demais assentos no sistema MV e no sistema DV. 
Função destes resultados, doravante será realizada análise pormenorizada da influência do sistema PV somente no assento onde o sistema PV está operando e no assento ao lado.

\subsubsection{Análise da influência do sistema PV na concentração e dispersão de} partículas no sistema MV e DV

Para a análise da influência do sistema PV na concentração e dispersão de partículas no assento onde o sistema PV está operando e no assento ao lado nos sistemas de ventilação MV e DV, nas Figuras 5.14 e 5.15 são apresentadas as diferenças entre as concentrações de partículas com e sem o sistema PV em operação, no sistema MV e no sistema DV, respectivamente.

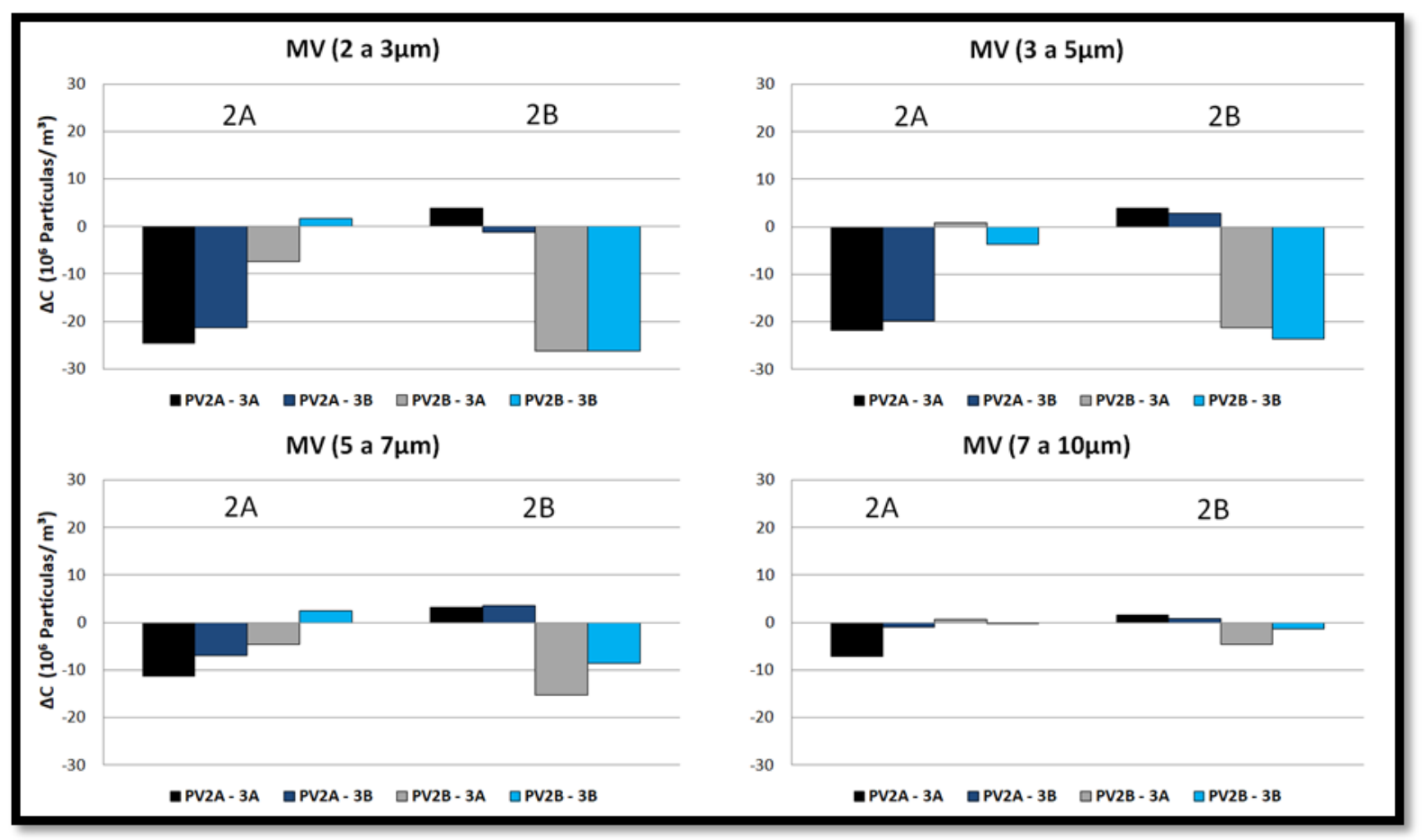

Figura 5.14. Diferenças entre as concentrações de partículas com e sem o sistema PV em operação nos assentos 2A e 2B, alternadamente, no sistema MV. 


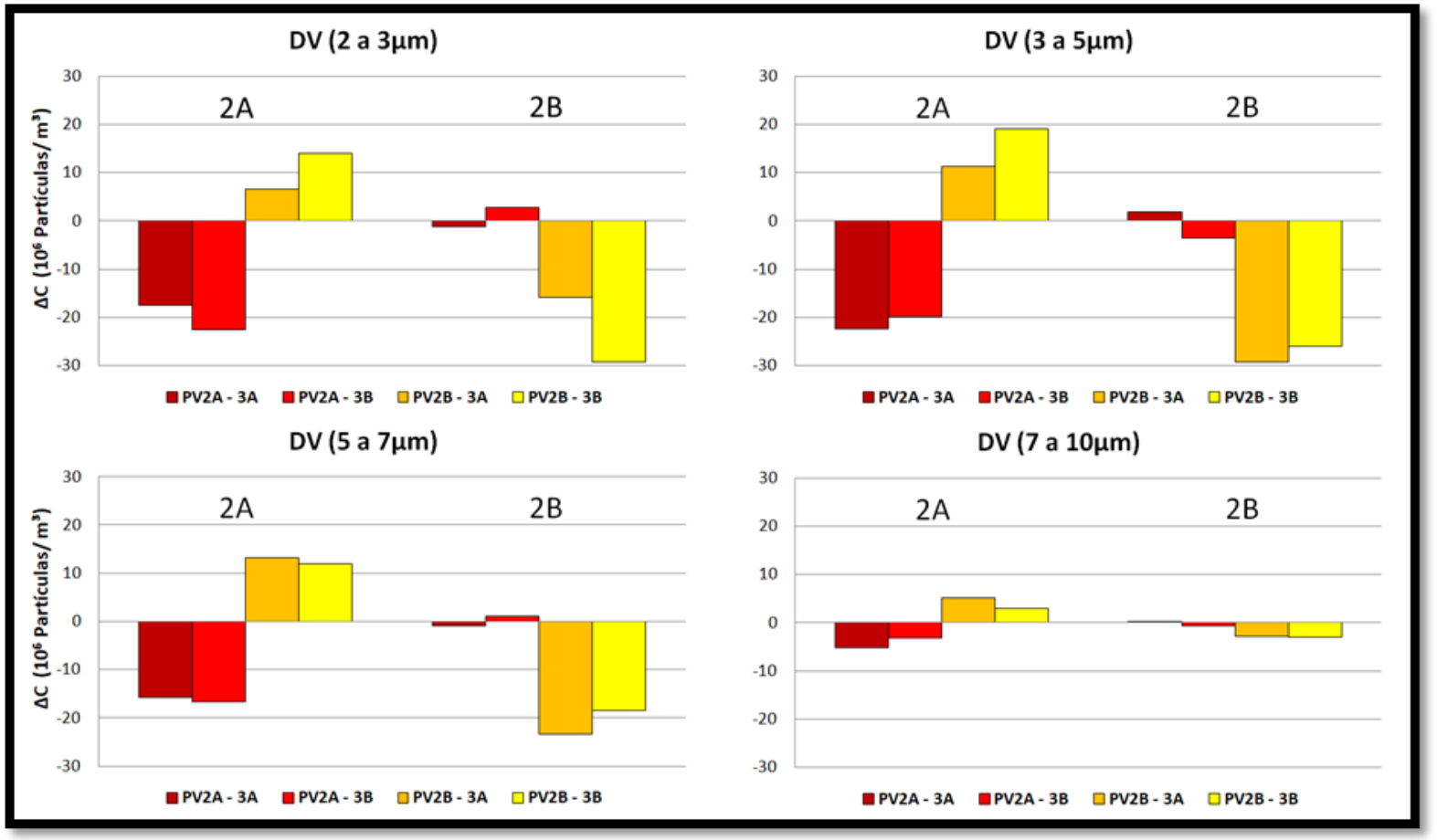

Figura 5.15. Diferenças entre as concentrações de partículas com e sem o sistema PV em operação nos assentos $2 \mathrm{~A}$ e $2 \mathrm{~B}$, alternadamente, no sistema DV.

Os resultados apresentados nas figuras 5.14 e 5.15, com injeção de partículas tanto no assento 3A, quanto no assento 3B, alternadamente, mostram que:

a) De uma forma geral, o sistema PV operando no assento 2B (PV2B) tem influência um pouco maior sobre a concentração de partículas no assento $2 \mathrm{~B}$ - com diminuição maior da concentração de partículas no assento $2 \mathrm{~B}$, do que o sistema PV operando no assento 2A (PV2A) tem sobre a concentração de partículas no assento 2A, tanto no sistema MV quanto no sistema DV.

b) Nos assentos onde o sistema está operando houve redução nos valores de concentração de partículas entre 20 e $30 \times 10^{+6} \mathrm{P} / \mathrm{m}^{3}$, para o sistema MV, e de 15 a $30 \times 10^{+6}$ para o sistema DV, para partículas na faixa de diâmetros entre 2 e $5 \mu \mathrm{m}$. Para os diâmetros maiores, na faixa de diâmetros de 5 a $10 \mu \mathrm{m}$, as diferenças nos valores de concentração foram menores, o que está relacionado com a maior dificuldade destas partículas serem arrastadas para fora da região de respiração em função da sua maior força peso.

c) Por outro lado, o sistema PV influencia de maneira diferente a concentração de partículas no assento ao lado conforme o sistema PV esteja operando no assento $2 \mathrm{~A}$ ou $2 \mathrm{~B}$. 
d) $\mathrm{O}$ sistema PV operando no assento 2A (PV2A) praticamente não influencia na concentração de partículas no assento $2 \mathrm{~B}$, tanto no sistema MV, quanto no sistema DV, com diferenças na concentração menores que as incertezas de medição (figuras 5.10 a 13$)$.

e) O sistema PV operando no assento 2B (PV2B) também não tem influência na concentração de partículas no assento $2 \mathrm{~A}$, no sistema MV. No sistema DV, contudo, o aumento na concentração de partículas no assento 2A com o sistema PV operando no assento 2B é maior que as incertezas de medição (figuras 5.12 e 5.13)

A análise conjunta dos resultados de concentração de partículas acima e das velocidades do ar do item 5.1.1

"A velocidade do ar no assento $2 \mathrm{~A}$, altura $1,10 \mathrm{~m}$, com o sistema PV operando no assento 2A (PV2A) em relação ao sistema desligado foi em torno de $0,25 \mathrm{~m} / \mathrm{s}$ maior tanto no sistema MV, quanto no sistema DV. Por sua vez, com o sistema PV operando no assento 2B (PV2B), a velocidade do ar no assento 2B com relação ao sistema desligado, altura $1,10 \mathrm{~m}$, foi de $0,16 \mathrm{~m} / \mathrm{s}$ maior no sistema MV e de $0,34 \mathrm{~m} / \mathrm{s}$ maior no sistema DV."

“A velocidade do ar no assento próximo ao sistema PV, isto é, no assento $2 \mathrm{~B}$ com o sistema PV operando no assento 2A (PV2A) e no assento 2A com o sistema PV operando no assento 2B (PV2B), praticamente não é afetada pelo sistema PV, com diferenças entre o sistema ligado e desligado abaixo das incertezas de medição, exceto no assento 2A quando o sistema PV do assento 2B (PV2B) estava em operação no sistema DV, neste caso a velocidade medida na altura de $1,1 \mathrm{~m}$ foi menor em $0,1 \mathrm{~m} / \mathrm{s}$ e essa diferença ficou acima do valor das incertezas, como pode ser observado na figura 5.5."

mostra que os resultados de concentração de partículas na região de respiração decorrentes da atuação do sistema PV refletem o efeito do escoamento do ar na cabine, resultante da forma como o insuflamento e a exaustão do ar da cabine são realizados nos sistemas de ventilação MV e DV. 


\subsubsection{Análise da influência do sistema PV em função do ponto de injeção de} partículas no assento $3 A$ e $3 B$

Para a análise da influência do sistema PV na concentração de partículas no assento onde o sistema PV está operando, função do ponto onde se dá a geração (injeção) de partículas, nas Figuras 5.16 e 5.17 são apresentados os valores de concentrações de partículas com e sem o sistema PV em operação, considerando injeção de partículas no assento $3 \mathrm{~A}$ e $3 \mathrm{~B}$, respectivamente.

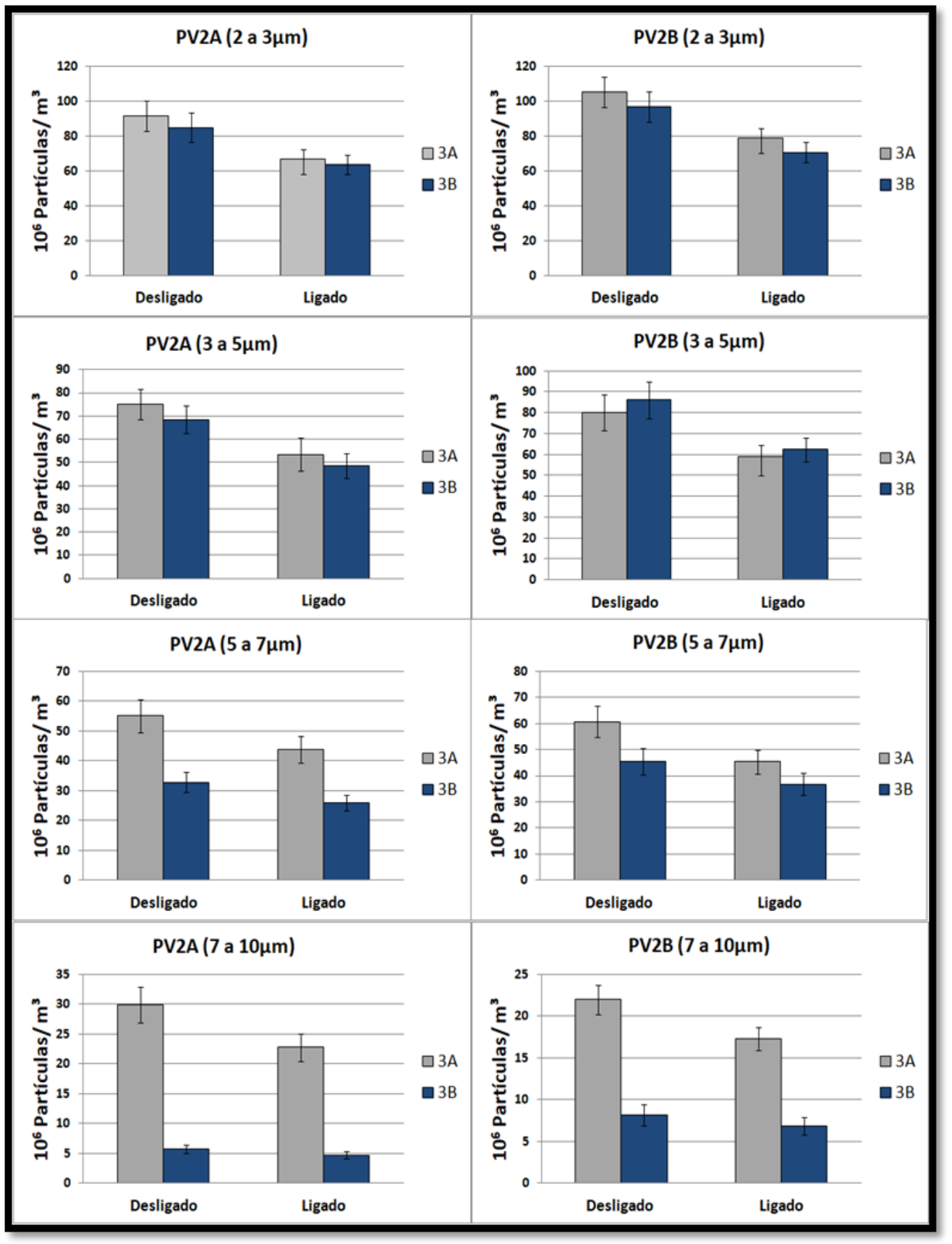

Figura 5.16. Concentração de partículas nos assentos $2 \mathrm{~A}$ e $2 \mathrm{~B}$ no sistema MV 


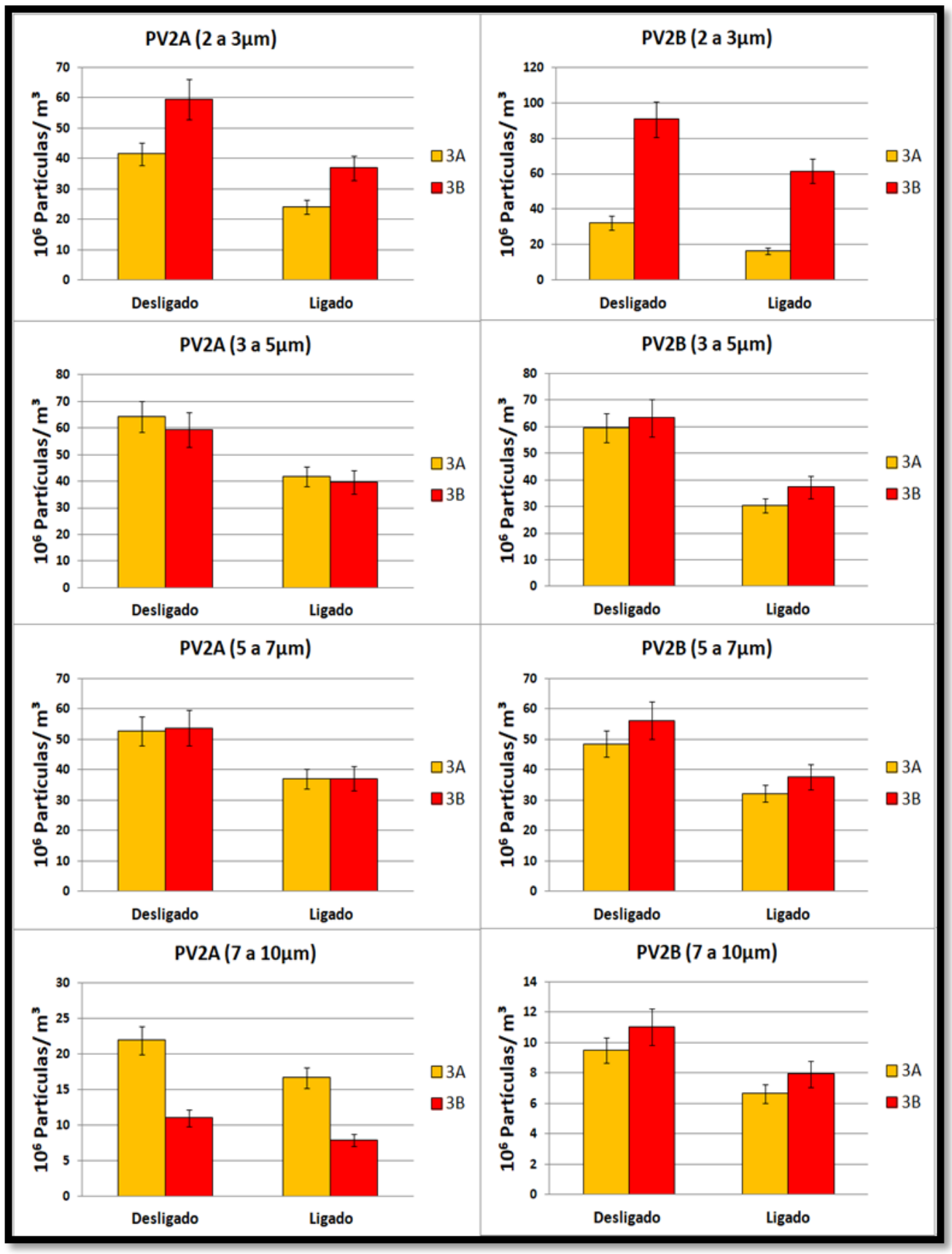

Figura 5.17. Concentração de partículas nos assentos $2 \mathrm{~A}$ e $2 \mathrm{~B}$ no sistema DV

Da análise das Figuras 5.16 e 5.17 verifica-se que:

a) A influência do ponto de injeção de partículas com e sem o sistema PV em operação é similar, tanto no sistema MV quanto no sistema DV.

b) No sistema MV, figura 5.16, a influência do ponto de injeção de partículas é marginal nos diâmetros de partículas entre 2 e $5 \mu \mathrm{m}$. Já as partículas com diâmetros entre 5 e $10 \mu \mathrm{m}$ têm concentrações maiores de partículas quando a geração ocorre no assento próximo à fuselagem, assento 3A, em ambos os assentos e ambas situações, sistema PV ligado e desligado . 
c) No sistema DV, figura 5.17, observa-se que somente as partículas com diâmetros entre 2 e $3 \mu \mathrm{m}$ sofrem influência mais significativa do ponto de geração de partículas, sendo que as maiores concentrações ocorrem quando a geração é próxima ao corredor, assento $3 \mathrm{~B}$, com o sistema $\mathrm{PV}$ operando em ambos os assentos, $2 \mathrm{~A}$ e $2 \mathrm{~B}$.

Resultados similares, com maior concentração de partículas quando a injeção de partículas ocorre no assento 3B (corredor) em relação à injeção de partículas no assento 3A (fuselagem) foram verificados por Wan, Chao e Fang (2005) para o sistema MV e por Fabichack Jr. (2018), para partículas entre 2 a $5 \mu \mathrm{m}$, tanto no sistema MV, quanto no sistema DV.

No sistema MV o fluxo do ar descendente junto à fuselagem, com exaustão próxima ao piso, tende a carregar as partículas nos assentos próximos à fuselagem, enquanto o fluxo ascendente no centro do mock-up tende a aumentar a dispersão de partículas nos assentos junto ao corredor. No caso do sistema DV, embora os fenômenos envolvidos sejam diferentes, com fluxo ascendente de ar, também ocorre maior remoção de partículas junto à parede em função da maior exaustão de ar nesta região do mock-up (60\%).

No caso da atuação do sistema PV, o fluxo de ar dos difusores, com maiores velocidades do ar na região de respiração, minimiza a influência do ponto de injeção de partículas na concentração de partículas nos assentos onde o sistema PV está operando.

\subsubsection{Análise da influência do sistema PV na remoção de partículas}

Com o objetivo de verificar a influência do sistema PV na remoção de partículas no assento onde o sistema PV está operando e no assento ao lado, as figuras 5.18 e 5.19 apresentam a eficiência de remoção de partículas para os assentos 2A e 2B com o sistema PV operando no assento $2 \mathrm{~A}$ e no assento $2 \mathrm{~B}$, respectivamente.

A eficiência na remoção de partículas foi calculada segundo a equação (5.1)

$$
E=\left(\frac{C_{s}-C_{P V}}{C_{S}}\right) \cdot 100
$$

onde:

$E=$ Eficiência de remoção $(\%)$

$\mathrm{C}_{\mathrm{PV}}=$ Concentração de partículas com o sistema $\mathrm{PV}$ em operação $\left(\mathrm{P} / \mathrm{m}^{3}\right)$

$\mathrm{C}_{\mathrm{S}}=$ Concentração de partículas sem o sistema $\mathrm{PV}$ em operação $\left(\mathrm{P} / \mathrm{m}^{3}\right)$ 


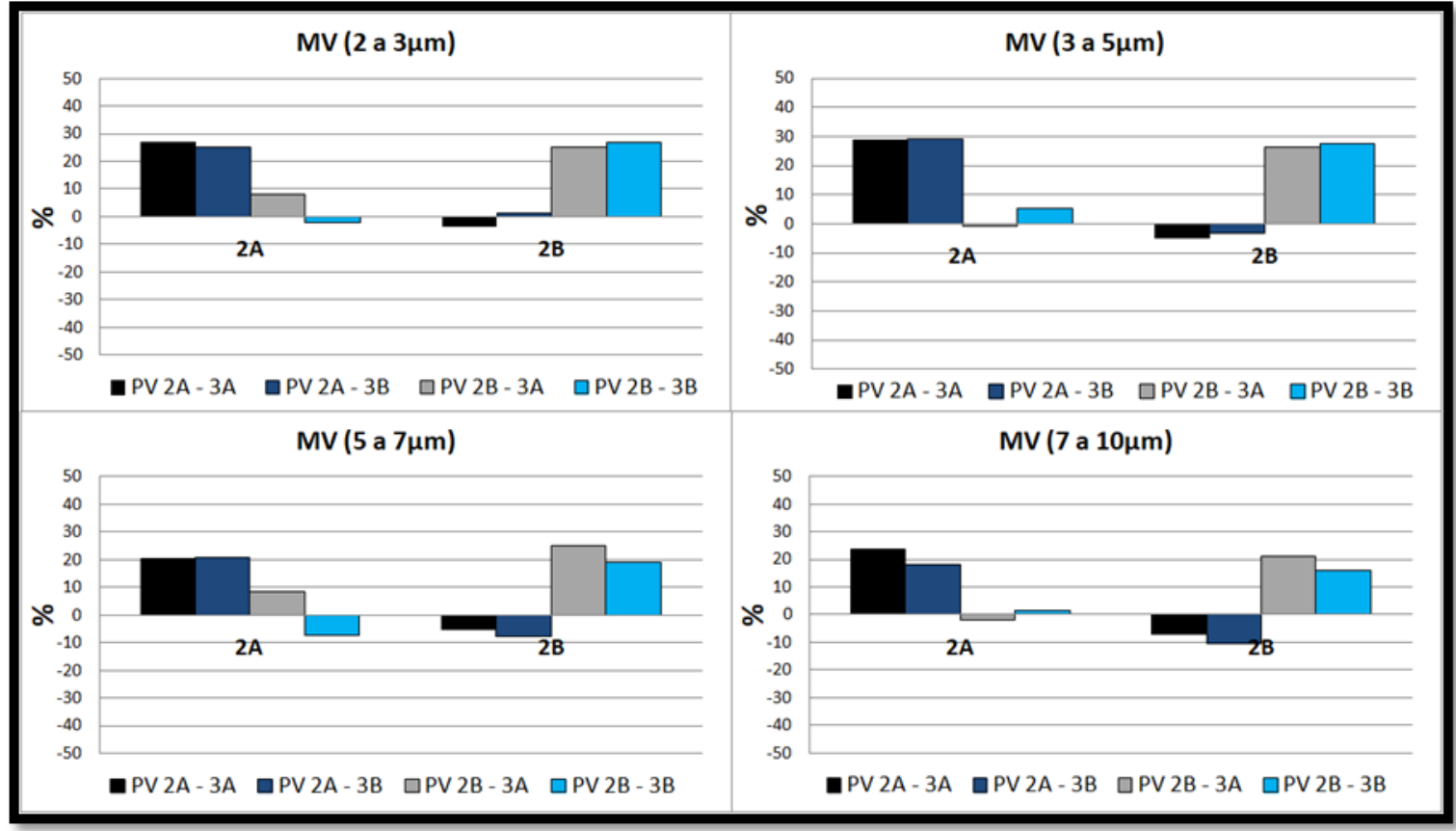

Figura 5.18 Eficiência na remoção de partículas com e sem o sistema PV em operação nos assentos $2 \mathrm{~A}$ e $2 \mathrm{~B}$, alternadamente, no sistema MV.

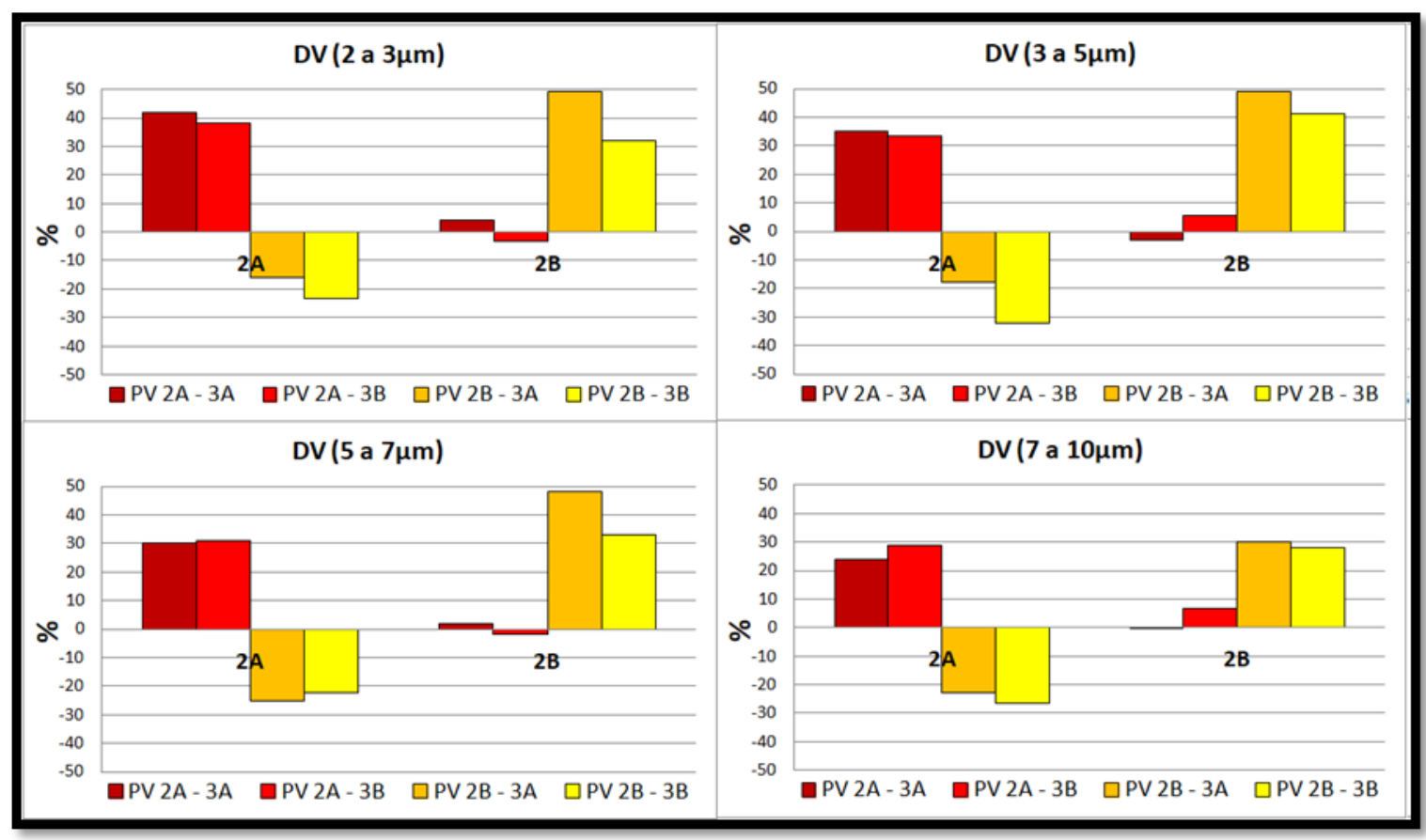

Figura 5.19 Eficiência na remoção de partículas com e sem o sistema PV em operação nos assentos $2 \mathrm{~A}$ e $2 \mathrm{~B}$, alternadamente, no sistema DV. 
De maneira similar às diferenças de concentração de partículas mostradas nas Figuras 5.14 e 5.15, os resultados de remoção de partículas das figuras 5.18 e 5.19 mostram que:

a) O sistema PV influencia significativamente a remoção de partículas no assento no qual o sistema está operando, tanto no sistema MV quanto no sistema DV.

b) O sistema PV influencia de maneira diferente a remoção de partículas no assento ao lado onde o sistema PV está operando, no sistema MV e DV.

Para os assentos onde o sistema PV está operando, verifica-se que:

a) No sistema MV a eficiência de remoção de partículas é praticamente a mesma para o sistema PV operando no assento $2 \mathrm{~A}$ quanto no $2 \mathrm{~B}$ para todos os tamanhos de partículas. A eficiência é maior para partículas de 2 a $5 \mu \mathrm{m}$, com valores de 25 a $30 \%$. Para faixa de 5 a $10 \mu \mathrm{m}$ os valores são menores, de 16 a $25 \%$.

b) No sistema MV praticamente não ocorre alteração na remoção de partículas com relação ao assento ao lado, tanto com o sistema PV operando no assento $2 \mathrm{~A}$, quanto no assento $2 \mathrm{~B}$.

c) No sistema DV a eficiência de remoção de partículas é maior com o sistema PV operando no assento $2 \mathrm{~B}$ em todos os tamanhos de partículas. Com o sistema PV operando no assento 2A a eficiência de remoção de partículas é de 33 a $42 \%$ para partículas de 2 a $5 \mu \mathrm{m}$ e de 24 a $31 \%$ para partículas de 5 a $10 \mu \mathrm{m}$. Para o sistema PV operando no assento $2 \mathrm{~B}$ a eficiência de remoção de partículas é de 32 a $49 \%$ para partículas de 2 a $5 \mu \mathrm{m}$ e de 28 a $49 \%$ para partículas de 5 a $10 \mu \mathrm{m}$

d) No sistema DV também praticamente não ocorre diferença de eficiência de remoção de partículas com relação ao assento ao lado com o sistema PV operando no assento 2A. Enquanto isso, no sistema PV operando no assento 2B, a remoção de partículas no assento $2 \mathrm{~A}$ é negativa, isto é, ocorre diminuição na remoção de partículas de 16 a 32\% para partículas de 2 a $5 \mu$ m e de 22 a $27 \%$ partículas de 5 a $10 \mu \mathrm{m}$ 


\section{Capítulo 6}

\section{CONCLUSÕES}

Neste capítulo são apresentadas as conclusões e sugestões de continuidade do presente trabalho. Inicialmente são apresentadas as conclusões com relação à influência do sistema PV na velocidade e na temperatura do ar na cabine. Em seguida são apresentadas as conclusões da influência do sistema PV na concentração e dispersão de partículas. Finalmente, são apresentadas as conclusões referentes à eficiência do sistema PV na remoção de partículas na região de respiração. Ao final do Capítulo são apresentadas sugestões de trabalhos futuros.

\subsection{Influência do sistema PV na velocidade e temperatura do ar}

Verifica-se dos resultados experimentais que a atuação do sistema PV alterou as condições de velocidade do ar somente nos assentos onde o sistema foi colocado em operação e no assento ao lado, na altura de 1,10m:

a) O aumento da velocidade do ar com o sistema PV operando no assento da janela foi de $0,25 \mathrm{~m} / \mathrm{s}$ neste assento no sistema MV e de $0,29 \mathrm{~m} / \mathrm{s}$ no sistema DV. Com o sistema PV operando no assento do corredor o aumento da velocidade do ar foi de $0,16 \mathrm{~m} / \mathrm{s}$ neste assento no sistema MV e em torno de $0,34 \mathrm{~m} / \mathrm{s}$ no sistema DV.

b) Com relação à influência do sistema PV no assento ao lado, somente ocorreu diminuição da velocidade do ar em $0,10 \mathrm{~m} / \mathrm{s}$ no assento da janela com o sistema operando no assento do corredor, no sistema DV.

Quanto à temperatura do ar a atuação do sistema PV proposto resultou em aumento dos valores de temperatura do ar somente nos assentos onde o sistema foi colocado em operação, janela e corredor, em duas alturas, a 0,60m e 1,10m. Os valores médios para os dois sistemas, MV e DV, foram em torno de $0,9^{\circ} \mathrm{C}$ maiores com o sistema PV ligado.

Os resultados de velocidade e temperatura do ar mostram que o sistema PV interfere praticamente nada no escoamento do ar no assento ao lado; o que é um ótimo resultado. Quanto menos o uso do sistema PV interferir nas condições do passageiro ao lado, melhor. Além disso, o aumento médio da temperatura do ar em $0,9^{\circ} \mathrm{C}$, mostra que o sistema está desempenhando a sua função em diminuir o desconforto térmico devido ao frio, conforme esperado. 


\subsection{Influência do sistema PV na dispersão de partículas e características do ambiente}

De forma similar, os resultados de concentração e dispersão de partículas também mostram que a atuação do sistema PV somente interfere na concentração de partículas nos assentos onde o sistema foi colocado em operação, janela e corredor, e no assento ao lado:

a) Nos assentos onde o sistema foi colocado em operação, assentos $2 \mathrm{~A}$ e 2B, houve redução nos valores de concentração de partículas nestes assentos entre 20 e $30 \times 10^{+6} \mathrm{P} / \mathrm{m}^{3}$, para o sistema $\mathrm{MV}$, e de 15 a $30 \times 10^{+6}$ partículas $/ \mathrm{m}^{3}$ para o sistema DV, para partículas na faixa de diâmetros entre 2 e $5 \mu \mathrm{m}$. Para os diâmetros maiores, na faixa de diâmetros de 5 a $10 \mu \mathrm{m}$, as diferenças nos valores de concentração foram algo menores; o que está relacionado com a maior dificuldade destas partículas serem arrastadas para fora da região de respiração em função da sua maior força peso.

b) No assento ao lado o sistema PV acarretou alteração somente quando em operação no corredor no sistema DV. Neste caso houve um aumento na concentração de partículas no assento da janela de 6,6 a $19,0 \times 10^{+6}$ partículas $/ \mathrm{m}^{3}$ para a faixa de diâmetros de 2 a $5 \mu$ m e de 3,0 a $13,2 \times 10^{+6}$ partículas $/ \mathrm{m}^{3}$.

Ainda com relação à concentração e dispersão de partículas, foi verificada pouca influência do ponto de injeção das partículas. No caso da atuação do sistema PV, o fluxo de ar dos difusores, com maiores velocidades do ar na região de respiração, minimiza a influência do ponto de injeção de partículas na concentração de partículas nos assentos onde o sistema PV está operando.

\subsection{Eficiência de remoção de partículas}

Dos resultados de eficiência de remoção de partículas conclui-se que o sistema PV influencia significativamente a remoção de partículas no assento no qual o sistema está operando, tanto no sistema MV quanto no sistema DV:

a) No sistema MV a eficiência de remoção de partículas é praticamente a mesma para o sistema PV operando no assento da janela quanto no assento do corredor para todos os tamanhos de partículas. A eficiência é maior para partículas de 2 a $5 \mu \mathrm{m}$, com valores de até $30 \%$ na eficiência de remoção. Para faixa de 5 a $10 \mu \mathrm{m}$ os valores são menores, de até $25 \%$. 
b) No sistema DV a eficiência de remoção de partículas é maior com o sistema PV operando no assento do corredor em todos os tamanhos de partículas, com eficiência de remoção de partículas de até $49 \%$ para partículas para todos os tamanhos de partículas Com o sistema PV operando no assento da janela a eficiência de remoção de partículas é de até $42 \%$ para partículas de 2 a $5 \mu \mathrm{m}$ e de até $31 \%$ para partículas de 5 a $10 \mu \mathrm{m}$.

Adicionalmente, os resultados de eficiência de remoção de partículas também mostram que o sistema PV influencia somente a remoção de partículas no assento ao lado quando o sistema PV atua no assento do corredor e no sistema DV. Neste caso a remoção de partículas no assento da janela é negativa, isto é, ocorre diminuição na remoção de partículas de até $32 \%$ para partículas de 2 a $5 \mu \mathrm{m}$ e de até $27 \%$ para partículas de 5 a $10 \mu \mathrm{m}$.

Finalmente, considerando que as partículas de 3 a $5 \mu \mathrm{m}$ representam as maiores concentrações de partículas nas atividades expiratórias (DUGUID, 1946) e que partículas de 2 a $3 \mu \mathrm{m}$ podem rapidamente se alojar no pulmão (CHAO; WAN; SZE, 2008, WAN et al., 2009), tem-se que o sistema PV operando no sistema DV tem um potencial maior de remoção destas partículas da região de respiração no assento em que está instalado, podendo chegar a $49 \%$, enquanto no sistema MV este potencial chega no máximo a $30 \%$. Por outro lado, no sistema DV, a operação do sistema PV no assento do corredor diminui a eficiência de remoção de partículas no assento junto à janela em até $32 \%$ nas condições analisadas.

\subsection{Sugestões para trabalhos futuros}

Como proposta para a continuidade do presente trabalho, são sugeridos os seguintes estudos:

a) Fazer o mapeamento da concentração, dispersão e remoção de partículas operando, paulatinamente, o sistema PV em todos assentos da aeronave;

b) Avaliar a influência do sistema PV, juntamente com o sistema UFAD, na concentração, dispersão e remoção de partículas na cabine;

c) Investigar se o sistema de ventilação PV proposto influencia significativamente no conforto térmico e na qualidade do ar local, comparando entre si diferentes arquiteturas de distribuição de ar; 
d) Avaliar a influência da variação da vazão do sistema PV na concentração, dispersão e remoção de partículas expiratórias, no conforto térmico;

e) Desenvolver estudos de simulação numérica na avaliação de condições de conforto térmico e de qualidade do ar com diferentes sistemas PV em cabines de aeronaves;

f) Otimizar a geometria do difusor. Como propostas, poderiam ser objeto de estudo:

$\checkmark$ Melhorar a distribuição de entrada do ar no interior do difusor, propondo múltiplos pontos de entrada de ar;

$\checkmark$ Propor uma geometria de direcionamento do fluxo de ar através de aletas. 


\section{Capítulo 7}

\section{REFERÊNCIAS BIBLIOGRÁFICAS}

ABE, V. C., 2007 Determinação de parâmetros de operação de sistema de distribuição de ar frio pelo piso em ambientes de escritórios Dissertação de Mestrado. Departamento de Engenharia Civil. Escola Politécnica da Universidade de São Paulo (USP), São Paulo, $132 \mathrm{p}$.

ALMEIDA, I. T., 1999. A poluição atmosférica por material particulado na mineração a céu aberto. Dissertação (Mestrado em Engenharia Mineral). Escola Politécnica, Universidade de São Paulo, São Paulo, 194 p., 1999.

ANDERSON, M. D., 2012. Effect Of Gaspers On Airflow Patterns And The Transmission Of Airborne Contaminants Within An Aircraft Cabin Environment. A. Thesis For Master Of Science Degree. Department Of Mechanical And Nuclear Engineering Of Kansas State University.

ANSI/ASHRAE Standard 161, 2007. Air Quality Within Commercial Aircraft. American Society Of Heating, Refrigerating And Air-Conditioning Engineers, Inc., 1791 Tullie Circle, Ne, Atlanta, Ga 30329.

ASHRAE 55, 2013. Thermal Environmental Conditions For Human Occupancy. American Society Of Heating, Refrigerating And Air Conditioning Engineers Inc., 1791 Tullie Circle, Ne, Atlanta, Ga 30329.

ASHRAE Guideline 28p, 2008. Air Quality Within Commercial Aircraft. American Society Of Heating, Refrigerating And Air-Conditioning Engineers, Inc., 1791 Tullie Circle, Ne, Atlanta, Ga 30329.

BAUMAN F.; DAILY A., 2003. Underfloor Air Distribution (UFAD) Design Guide. American Society Of Heating, Refrigerating And Air-Conditioning Engineers, Inc., Atlanta.

BEGGS, C.B., 2003, The Airborne Transmission of Infection in Hospital Buildings: Fact or Fiction?, Journal of Indoor and Built Environment 12:9-18. 
BÉMER, D.; CALlÉ, S.; GODINOT, S.; RÉGNIER, R.; DESSAGNE， J.M. Measurement of the Emission Rate of an Aerosol Source-Comparison of Aerosol and Gas Transport Coefficients, Journal of Appl. Occup. Environ. Hyg. 2000, 15:904-910.

BENEKE, J. M., 2010. Small Diameter Particle Dispersion In A Commercial Cabin Aircraft. A. Thesis For Master Of Science Degree. Department Of Mechanical And Nuclear Engineering Of Kansas State University.

BOEING, 2015. Operations Manual Of B737-300/-400/-500. The Boeing Company Seattle, Washington 98124-2207.

BOSBACH, J.; HEIDER, A.; DEHNE, T.; MARKWART, M.; GORES, I.; BENDFELDT, P., 2012. Evaluation Of Cabin Displacement Ventilation Under Fight Conditions. Icas 2012, Brisbane.

BOSBACH, J.; LANGE, S.; DEHNE, T.; LAVENROTH, G.; HESSELBACH, T.; ALLZEIT, M. Alternative ventilation concepts for aircraft cabins. CEAS Aeronaut J., 2013, 4: 301-313

BURTSCHER, H.; SCHÜEPP, K. 2012. The occurrence of ultrafine particles in the specific environment of children. Paediatr. Respir. Rev. 13: 89-94.

CAO, Q.; LIU, Y.; LIU, W.; LIN, C-H.; WEI, D.; BAUGHCUM, S.; NORRIS, S.; SHEN, X.; LONG, Z.; AND CHEN, Q. 2016 Experimental study of particle deposition in the environmental control systems of commercial airlines. Building and Environment, 2016, 96:62-71

CHAO, C.Y.H.; WAN, M.P., 2006. A Study Of The Dispersion Of Expiratory Aerosols In Unidirectional Downward And Ceiling-Return Type Airflows Using A Multiphase Approach, Journal Of Indoor Air 16:296-312.

CHAO, C.Y.H.; WAN, M.P.; MORAWSKA, L.; JOHNSON, G.R.; RISTOVSKI, Z.D.; HARGREAVES, M.; MENGERSEN, K.; CORBETTE, S.; LI, Y.; XIE, X.; KATOSHEVSKI, D., 2009. Characterization Of Expiration Air Jets And Droplet Size Distributions Immediately At The Mouth Opening, Journal Of Aerosol Science 40:122133.

CHAO, C.Y.H.; WAN, M.P.; SZE, G.N., 2008. Transport and removal of expiratory droplets in hospital ward enviroment. Aerosol science and technology. Issue 5, 2008, 42:377-394 
CHEN, Q.; GLICKSMAN, L., 2003. System Performance Evaluation And Design Guidelines For Displacement Ventilation. Altanta, Ga: Ashrae; 2003.

CHEN, S.; DENG, D., 2008. Air pollution and ventilation inside vehicles, Anais do congresso Indoor Air, Copenhague, Dinamarca - Número do artigo: 679.

CHEN, Q. MCDEVITT, J. J.; GUPTA, J. K.; JONES, B. W.; MAZUMDAR, S; POUSSOU, S. B.., 2012 Infectious Disease Transmission In Airliner Cabins. Report No. Rite-Acer-Coe-2012-1. Auburn, Usa: National Air Transportation Center Of Excellence Rite/Acer, 2012.

CHESTER, W. S.; MICHEL, J. M.; MICHEL, W. H.; JEFFREY, D. M.; IAN, C. M.; 2004. Relate air quality and other factors to comfort and health symptoms reported by passengers and crew on commercial transport aircraft (part I). 2004. ASHRAE Project 1262-TRP. Atlanta, GA. American Society of Heating, Refrigerating and Air Conditioning Engineers.

CHO, Y.; PARK, D. S.; KWON, S. B.; PARK, E.Y., 2008. Development of clean train for better indoor air quality of passenger cabin, Anais do congresso Indoor Air, Copenhague, Dinamarca. Número do artigo: 382

CIUZAS D. PRASAUSKAS, T.; KRUGLY, E.; SIDARAVICIUTE, R.; JURELIONIS, R.; SEDUIKYTE, L.; KAUNELIENE, V.; WIERZBICKA, A.; MARTUZEVICIUS, D., 2015 Characterization of indoor aerosol temporal variations for the real-time management of indoor air quality Atmospheric Environment, Volume 118, October 2015, Pages 107-117

COLE; C.E., COOK; C.E., 1998, Characterization of infectious aerosols in health care facilities: An aid to effective engineering controls and preventive strategies, Sate of the Science, American Journal of Infection Control 26(4):453-464.

COLEMAN, H. W.; STEELE, W. G., 1989 Experimentation and uncertainty analysis for engineers. John Wiley \& Son. New York.

CONCEIÇÃO, S. T., 2012. Contaminação Aérea Em Cabines Climatizadas: Processo De Avaliação E Análise Da Influência De Sistema De Ventilação Personalizada. Tese De Doutorado. Departamento De Engenharia Mecânica, Escola Politécnica Da Usp, São Paulo, 218p. 
CONCEIÇÃO, S.T., MASSÃO, F., TAKASE, M., 2008, Indoor air quality assessment inside a regional jet, Part 1: Measurement of air contaminants, Proceedings of Indoor Air, Copenhague, Dinamarca.

CONCEIÇÃO, S.T., PEREIRA, M.L., TRIBESS, A., 2011, A review of methods applied to study airborne biocontaminants inside aircraft cabins, Hindawi Publishing Corporation, International Journal of Aerospace Engineering, paper 824591.

Connor, M., 2009. Transmission Of Diseases And Long-Haul Flights, Ice International Aviation Conference, Nhs Dumfires \& Galloway, Uk Scotland.

CUI, W.; OUYANG, Q.; ZHU, Y., 2014. Field study of thermal environment spatial distribuition and passanger local thermal comfort in aircraft cabin. Building and Environment, 2014, 80: 213-220

DECHOW, M., SOHN, J. AND STEINHANSES, J., 1997. Concentrations Of Cabin Air Of Airbus Arcraft, Chemosphere, 35, 21-31

DEHNE, T., BOSBACH, J., LECHNER, T., HESSELBACH, F., 2018. Multi-zonal temperature control of transient thermal loads In aircraft cabin airflow. Proceedings: Roomvent \& Ventilation 2018, Espoo, Finland, 785:796.

DRIVER, C.R., VALWAY, S.E., MORGAN, W.M., ONORATO, I.M., CASTRO, K.G., 1994, Transmission of Mycobacterium tuberculosis associated with air travel, JAMA 272:1031-1035.

DUAN, R.; LIU, W.; XU, L.; HUANG, Y.; SHEN, X.; LIN, C.-H; LIU, J.; CHEN, Q.; SASANAPURI, B., 2015. Mesh type and number for CFD simulations of air distribution in an aircraft cabin. Numerical heat transfer, part B: fundamentals, 2015, 67(6), 489-506

DUGUID, J. P., 1946. The Size And The Duration Of Air-Carriage Of Respiratory Droplets And Droplet-Nuclei, J. Hyg. 44:471-479.

FABICHAK JR, D., 2018. Análise experimental da influência do sistema de ventilação e distribuição de ar no conforto térmico e na dispersão e remoção de partículas expiratórias em cabine de aeronave. Tese De Doutorado. Departamento De Engenharia Mecânica, Escola Politécnica Da Usp, São Paulo, 184p.

FABICHAK JR, D; SOUZA, E.S; MOREL, J.C.O.; TRIBESS, A. “Análise Experimental Da Distribuição De Partículas Aéreas Em Cabine De Aeronave Com Insuflamento De 
Ar Pelo Piso". Xii Encontro Nacional De Conforto No Ambiente Construído, Brasília. Xii Encontro Nacional De Conforto No Ambiente Construído - Encac 2013,10p.

FANG, Z., H. LIU, B. LI, A. BALDWIN, J. WANG, K. XIA. 2015. Experimental investigation of personal air supply nozzle use in aircraft cabins. Applied Ergonomics 47:193-202

FANGER, P.O., 1972 Thermal comfort. Analysis and applications in environmental engineering. McGraw-Hill Book Company, New York, 1972, 244p.

FANGER, P. O.; MELIKOV, A. K.; HAMNZAWA, H.; RING, J., 1988. Air turbulence and sensation of draught. Energy and Buildings, 1988, 12: 21-39.

FISER, J.; MIROSLAV, J., 2013. Impact Of Air Distribution System On Quality Of Ventilation In Small Aircraft Cabin. Building And Environment Technická 2896/2, 616 69 Brno, Czech Republic.

FOX, R. W., Mcdonald, A. T., Pritchard, P. J. Introdução À Mecânica Dos Fluidos. Ltc, 6 . Ed., Rio De Janeiro, 2006.

GAO, N.P.; NIU, J.L., 2007a. Personalized Ventilation For Commercial Aircraft Cabins. 45th Aiaa Aerospace Sciences Meeting And Exhibit. 8-11 January 2007, Reno, Nevada. Aiaa 2007-514.

GAO, N.P.; NIU, J.L., 2007b. Investigation Indoor Air Quality And Thermal Comfort Using Numerical Thermal Manikin. Indoor And Built Environment 2007;16;1:7-17.

GAO, N.P., NIU, J.L., PERINO, M., HEISELBERG, P., 2008, The airborne transmission of infection between flats in high-rise residential buildings: Tracer gas simulation, Journal of Building and Environment 43:1805-1817.

GAO, K., XIE, J., YANG, X. 2015. Estimation of the contribution of human skin and ozone reaction to volatile organic compounds (VOC) concentration in aircraft cabins. Building and Environment, Volume 94, Part 1, December 2015, Pages 12-20.

GOLDMANN, D., A., 2000, Transmission of viral respiratory infections in the home. The healthy home summit: the significance of cleanliness and disinfection in the home and its link to infection control, Journal of Pediatr. Infect. Dis. 19 (Suppl. 10), S97S102. 
GRUN, G.; HELLWIG, R. T.; TRIMMEL M.; HOLM, A. H. ,2008. Interrrelations Of Comfort Parameters In A Simulated Aircraft Cabin. Proccedings Of Indoor Air 2008. Copenhagen, Dinamarca.

GUAN, J., GAO, K., WANG, C., YANG, X., LIN, C. H., LU, C., GAO, P. 2014a. Measurements of volatile organic compounds in aircraft cabins. Part I: Methodology and detected VOC species in 107 commercial flights. Building and Environment, Volume 72, February 2014, Pages 154-161

GUAN, J., GAO, K., WANG, C., YANG, X., LIN, C. H., LU, C., GAO, P. 2014b. Measurements of volatile organic compounds in aircraft cabins. Part II: Target list, concentration levels and possible influencing factors. Building and Environment, Volume 75, May 2014, Pages 170-175.

GÜNTHER, G., J. BOSBACH, J. PENNECOT, C. WAGNER, T. LERCHE, AND I. GORES. 2006. Experimental And Numerical Simulations Of Idealized Aircraft Cabin Flows. Aerospace Science And Technology 10: 563-73.

GUPTA, J.K., LIN, C.H., CHEN, Q., 2009, Flow Dynamics And Characterization Of A Cough, Indoor Air 2009; 19, 517-525.

GUPTA, J.K., LIN, C.H., CHEN, Q., 2011, Transport Of Expiratory Droplets In An Aircraft Cabin, Indoor Air 2011; 21: 3-11.

HAINES, R. W., WILSON, C. L. 1998. HVAC Systems Design Handbook. 3. ed. New York: McGraw-Hill, 528 p.

HINDS, W. C., 1999. Aerosol Technology. New York, John Wiley Sons, Inc.

HINNINGHOFEN, H; ENCK, P., 2006. Passenger well-being in airplanes. Autonomic neuroscience : basic \& clinical. 129. 80-5.

HOCKING, M. B., 1998. Indoor air quality: recommendations relevant to aircraft passengers cabins. American IndustrialHygiene Association Journal 59: 446-454.

HOCKING, M. B., 2000. Passengers aircraft cabin air quality: trends, effects, societal costs, proposals. Environmental Science \& Pollution Research International (7): Part 3: 173. 
HOUSE OF LORDS UK, 2000., Select Committee on Science and Technology. Air TravelandHealth:fifthreport.http://www.publications.parliament.uk/pa/ld199900/ldselect/ ldsctech/121/12101.htm (accessed Nov 20, 2018).

HUNT, E.H.; SPACE, D.R., 1994. "The Airplane Cabin Environment - Issues Pertaining To Flight Attendant Comfort", The Boeing Company, International In-Flight Service Management Organization Conference, Montreal, Canada.

INMETRO, 1998. Guia para expressão da incerteza de medição, segunda edição brasileira publicada pelo INMETRO e pela ABNT, Agosto, 1998.

ISO 7726. Thermal Environments - Instruments And Methods For Measuring Physical Quantities. International Organization For Standardization, Geneva, 1998.

ISO 7730. 2005. Ergonomics of the Thermal Environment - Analytical Determination and Interpretation of Thermal Comfort using Calculation of the PMV and PPD Indices and Local Thermal Comfort Criteria. European Committee for Standardization, 2005 .

JACOBS, P., GIDS, W. F. The aircraft seat as indoor air quality and temperature control system. Proceedings of Indoor Air 2005. p.1-10. Beijing, 2005.

JONES, R.; NICAS, M., 2009. Experimental Determination Of Supermicrometer Particle Fate Subsequent To A Point Release Within A Room Under Natural And Forced Mixing, Aerosol Science And Technology, 43:9, 921-938.

KACZMARCZYK, J.; MELIKOV, A.K., FANGER, P.O., 2004. Human Response To Personalized Ventilation And Mixing Ventilation, Journal Of Indoor Air 14(8): 17-29.

KACZMARCZYK, J.; MELIKOV, A.K., BOLASHIKOV, Z., NIKOLAIEV, L., FANGER, P.O., 2006. Human Response To Five Designs Of Personalized Ventilation, Hvac\&R Research, 12(2): 367-384.

KENYON, T.A., VALWAY, S.E, IHLE, W.W., 1996, Transmission of multidrugresistant mycobacterium tuberculosis during a long airplane flight, New England Journal of Medicine, 334:933-938.

KIM HEA, J., LEE, Y.G., KIM, S.S., 2008, A research for the characteristics of contaminants of indoor air in the car. Anais do congresso Indoor Air, Copenhague, Dinamarca. Número do artigo 486. 
Kim SUN, S., Kang, Y.K., Doe, G.Y., Lee, Y.G., 2008, Comparison of indoor air quality on a passenger ship and a chemical ship. Anais congresso Indoor Air, Copenhague, Dinamarca. Número do artigo 490.

KHOSROW, E., 2012. Numerical Simulation Of A Turbulent Airflow, Tracer Gas Diffusion And Particle Dispersion In A Mock-Up Cabin Aircraft. Thesis For Doctor Of Philosophy Degree. Department Of Mechanical And Nuclear Engineering Of Kansas State University.

KULKARNI, P., BARON, P.A., WILLEKE, K., 2011. Aerosol Measurement: Principles, Techniques, And Applications, John Wiley \& Sons.

LATIMER, B.; TANG, P., 2012. Iso 21501-4: Calibration Of Air Particle Counters From A Metrology Perspective, Hach White Paper.

LEE, S. C., POON, C. S., LI, X. D., LUK, F. 1999. Indoor air quality investigation on commercial aircraft cabins. Indoor Air; 9:180-7.

LEITE, B.C.C., 2003, Sistema de ar condicionado com insuflamento pelo piso em ambientes de escritórios: Avaliação do conforto térmico e condições de operação. Tese de doutorado, Escola Politécnica da Universidade de São Paulo, Brasil.

LEITE, B.C.C., TRIBESS, A., 2004, Individually controlled office environments Thermal comfort parameters determination, Anais do congresso Roomvent, Portugal.

LI, B., DUAN, R., LI, J., HUANG, Y., YIN, H., LIN, C.H., WEI, D., SHEN, X., LIU, J. AND CHEN, Q., 2016. Experimental studies of thermal environment and contaminant transport in a commercial aircraft cabin with gaspers on. Indoor Air, DOI: 10.1111/ina.12265.

LI, Y., LEUNG, G.M., TANG, J.W., YANG, X., CHAO, C.Y.H., LI, J.Z., LU, J.W., NIELSEN, P.V., NIU, J., QIAN, H., SLEIGH, A.C., SU, J., SUNDELL, J., WONG, T.W., YUEN, P.L., 2007. Role Of Ventilation In Airborne Transmission Of Infectious Agents In The Built Environment - A Multidisciplinary Systematic Review. Indoor Air, 17, Pp. 2-18.

LI, F., LIU, J., PEI, J., LIN, C.-H., CHEN, Q., 2014. “Experimental Study Of Gaseous And Particulate Contaminants Distribution In An Aircraft Cabin" Atmospheric Environment, 85, 223-233. 
LI, F., LIU, J., REN, J., CAO, X., ZHU, Y, 2016. Numerical investigation of airborne contaminant transport under different vortex structures in the aircraft cabin. International Journal of Heat and Mass Transfer, Volume 96, May 2016, Pages 287-295.

LIU, W.; CHEN, Q., 2013. “Current Studies On Air Distribution In Commercial Airliner Cabins”. Accepted By Theoretical \& Applied Mechanics Letters.

LIU, W.; WEN, J.; LIN, C.-H.; LIU, J.; LONG, Z.; CHEN, Q., 2013. Evalution of various categories of turbulence models for predicting air distribution in an airliner cabin. Building and Environment, 2013, 65:118-131

LIU, W.; DUAN, R.; CHEN, C.; LIN, C.,-H.; CHEN, Q., 2015. Inverse design of the thermal environment in airliner cabin by use of the CFD- based adjunt method, Energy and Buildings, 2015.

MACINTYRE, A. J., 1988. Ventilação Industrial e Controle da Poluição. Ed. Guanabara, Rio de Janeiro. 404p.

MANGILI, A.; GENDREAU, M.A., 2005. Transmission Of Infectious Diseases During Commercial Air Travel. Lancet 2005; 365: 989-96

MASTERTON, R. G.; GREEN, A. D., 1991. Dissemination Of Human Pathogens By Airline Travel. Soc. Appl. Bacteriol. Symp Ser. 20:31s-38s.

MAZUMDAR, S.; CHEN, Q., 2007. Response Of Contaminant Detection Sensors And Sensor Systems In A Commercial Aircraft Cabin. Proceedings: Building Simulation 2007.

MELIKOV, A.K., 2004, Personalized ventilation, Journal of Indoor Air 14, suppl. 7:157167.

MELIKOV, A.K., POPIOLEK, Z., CARE, I., SEFKER, T., 2007, Accuracy Limitations for Low-Velocity Measurements and Draft Assessment in Rooms, HVAC\&RESEARCH, Vol 13, numero 6, ASHRAE.

MELIKOV, A.K., 2010. Indoor Environment: Health, Comfort And Performance. State Of Art. Ctu In Prague, October 20th 2010. International Centre For Indoor Environment And Energy.

MESQUITA, A. L. S.GUIMARÃES, F. A., NEFUSSI, N., 1998. Engenharia de Ventilação Industrial. Ed. CETESB, São Paulo, 442p. 
MET ONE HHPC-6, 2010. Handheld Airborne Particle Counter Data Sheet, Hach Ultra Analytics, Estados Unidos Da América.

MORAWSKA, L., 2005. "Droplet Fate In Indoor Environments, Or Can We Prevent The Spread Of Infection?", Proceedings Of Indoor Air 2005, Beijing, China.

MOTTA, E.P., 2009 , Queda de pressão em um leito de partículas de xisto: Avaliação de modelos de modelos para distribuição granulométrica e diâmetros médios equivalentes, estudo do efeito da altura do leito e avaliação de modelos para predição da queda de pressão. Dissertação de mestrado submetido à Universidade Federal do Paraná - UFPR - Curitiba.

MOURA, D., 2009. Condições Do Escoamento E De Conforto Térmico Em Cabine De Aeronave. Dissertação De Mestrado. Departamento De Engenharia Mecânica Da Escola Politécnica Da USP, São Paulo, 74 P.

MÜlleR, D., SCHMIDT, M., MÜlleR, B.: Application Of A Displacement Ventilation System For Air Distribution In Aircraft Cabins, Ast 2011, Hamburg, Germany, March 31-April 1. (2011)

NAGDA NL, RECTOR HE, ZHIDONG L, SPACE Dr,: Aircraft Cabin Air Quality: A Critical Review Of Past Monitoring Studies, Air Quality And Comfort In Airliner Cabins, Astmstp 1393, N L Nagda Ed. Astm, West Conshohocken, Ps, 2000.

NAGDA, N. L. HODGSON, M., 2001. Low relative humidity and aircraft cabin air quality. Indoor air. 11. 200-14.

NBR 16401-1, 2008, Instalações de ar-condicionado - Sistemas centrais e unitários Parte 1: Projetos das instalações, ABNT, Rio de Janeiro.

NICAS, M., NAZAROFF, W.W., HUBBARD, A., 2005. Toward Understanding The Risk Of Secondary Airborne Infection: Emission Of Respirable Pathogens, J. Occup. Environ. Hyg. 2:143-154.

NIELSEN, P.V., 2009, Control of airborne infectious diseases in ventilated spaces. J. R. Soc. Interface 6, S747-S755.

NIELSEN, P.V, BARTHOLOMAEUSSEN, N.M., JAKUBOWSKA, E., JIANG, H., JONSSON, O.T., KRAWIECKA, K., MIERZEJEWSKI, A., THOMAS, S.J., TRAMPCZYNSKA, K., POLAK, M., SOENNICHSEN, M., 2007. Chair With 
Integrated Personalized Ventilation For Minimizing Cross Infection. Proceedings Of Roomvent 2007.

NIELSEN, P.V., BARSZCZ, E., CZARNOTA, T., DYMALSKI, D.P., JASIENSKI, M.A., NOWOTKA, A., MOZER, A., WIANKOWSKA, S.M., JENSEN, R.L., 2008. The Influence Of Draught On A Seat With Integrated Personalized Ventilation. Proceedings Of Indoor Air 2008, Copenhagen, Denmark - Paper Id: 247.

OLSEN S.J., CHANG H.L., CHEUNG T.Y., 2003. Transmission Of The Severe Acute Respiratory Syndrome On Aircraft. New England Journal Of Medicine, 349, Pp. 24162422.

ONGWANDEE, M., 2008, Levels of aromatic volatile organic compounds in public transportation modes in Bangkok, Thailand, Proceedings of Indoor Air, Copenhague, Dinamarca. Número do artigo: 220.

OSMAN S., M. T. LA DUC, A. DEKAS, D. NEWCOMBE AND K. VENKATESWARAN, 2008. Microbial Burden And Diversity Of Commercial Airline Cabin Air During Short And Long Durations Of Travel. 2008 International Society For Microbial Ecology. The Isme Journal (2008) 2, 482-497.

PADILLA, A. M., 2008. Experimental Analysis Of Particulate Movement In A Large Eddy Simulation Chamber. A. Thesis For Master Of Science Degree. Department Of Mechanical And Nuclear Engineering Of Kansas State University.

PAPINENI, R. S., AND ROSENTHAL, F. S., 1997. The Size Distribution Of Droplets In The Exhaled Breath Of Healthy Human Subjects, J. Aerosol Med. 10:105-161.

PARK, D.S., CHO, Y.M., KWON, S.B., PARK, E.Y., KIM, D.S., 2008, Analysis of air quality and PM10 source in the railway vehicles, Proceedings of Indoor Air, Copenhague, Dinamarca.

PARRA, M., A., ELUSTONDO, D., BERMEJO, R., SANTAMARÍA, J.M., 2008, Measurement of in-vehicle VOC concentrations in public buses, Anais do congresso Indoor Air, Copenhague, Dinamarca. Número do artigo: 55.

PEREIRA, G.C., 2004, Simulação numérica do transiente térmico na cabine de um avião, Dissertação de Mestrado do Instituto Tecnológico de Aeronáutica, SJK, Brasil 
PEREIRA, M. L., GRAUDENZ, G., TRIBESS, A., MORAWSKA, L., 2009. Determination Of Particle Concentration In The Breathing Zone For Four Different Types Of Office Ventilation Systems. Building And Environment. 44: 904-911.

QUADROS, M. E. V. 2008. Qualidade do ar em ambientes internos hospitalares: parâmetros físico-químicos e microbiológicos. Dissertação de mestrado. Universidade Federal de Santa Catarina, Centro Tecnológico. Programa de Pós-Graduação em Engenharia Ambiental.

SILVA, E. S., 2013. Arquiteturas de distribuição de ar em cabines de aeronaves: Análise experimental do desconforto térmico local, Dissertação de Mestrado, Departamento de Eng. Mecânica, Escola Politécnica da USP, São Paulo, Brasil, 2013. $131 \mathrm{p}$.

SHIMADA, M., OKUYAMA, K., OKAZAKI, S., ASAI, T., MATSUKURA, M., ISHIZU, Y., 1996. Numerical Simulation And Experiment On The Transport Of Fine Particles In A Ventilated Room, Aerosol Science And Technology, 25: 3, 242-255.

SPENGLER, J. D.; SAMET, J. M.; MCCARTHY, J.F. 2004. Indoor Air Quality Handbook. New York: McGraw-Hill, 1448 p.

SPENGLER, J. D., WILSON, D. G., 2003. Air quality in aircraft. Proceedings of the Institution of Mechanical Engineers, Part E: Journal of Process Mechanical Engineering, 217(4), 323-335.

StAnCATO, F., 2009. Análise Do Ambiente Térmico De Cabine De Aeronave, Tese De Doutorado, Departamento De Eng. Mecânica, Escola Politécnica Da Usp, São Paulo, Brasil.

SEKHAR, S.C., GONG, N., THAM, K.W.,CHEONG, K.W.D., MELIKOV, A.K., WYON,D.P. AND FANGER, P.O., 2005 Findings of personalized ventilation studies in a hotand humid climate, HVAC\&R Res.,11,603-620.

STROM-TEJSEN, P.S; WYON, D. P.; ZUKOWSJA, D.; JAMA, A.; FANG, L., 2005. Occupant Evaluation Of 7-Hours Exposures In A Simulated Aircraft Cabin. Part 2: Thermaleffects. Proceedings Indoor Air 2005. Beijing, China.

SZE TO, G.N., WAN, M. P., CHAO, C. Y. H., FANG, L. MELIKOV, A., 2009. 'Experimental Study Of Dispersion And Deposition Of Expiratory Aerosols In 
Aircraft Cabins And Impact On Infectious Disease Transmission', Aerosol Science And Technology, 43: 5, 466 - 485.

TANG, J.W., LI, Y., EAMES, I., CHAN, P.K.S., RIDGWAY, G.L., 2006. Factors Involved In The Aerosol Transmission Of Infection And Control Of Ventilation In Healthcare Premises, Journal Of Hospital Infection 64, 100-114.

TYLER, T. (2015). Annual review 2015 - 71st annual general meeting. Technical report, International Air Transport Association (IATA).

TOPAS, 2012. Descrição Técnica Do Aerossol Dehs (Di-Etil-Hexil-Sebacato), Disponível Em Www.Topas-Gmbh.De, Acessado Em Julho De 2015.

TSI, Particle Generator Model 3079. Manufacturer Manual Available In: Www.Atitest.Com/. Acessado Em Julho, 2015. Tsi, 2004, Model 3475 Condensation Monodisperse Aerosol Generator Instruction Manual, Revision E, Outubro 2004, Tsi.

UVA, A. S., 2000. Exposição A Ozono Em Cabinas De Avião, Saúde Ocupacional, Escola Nacional De Saúde Pública, Universidade Nova De Lisboa. Julho-Dezembro 2000, Vol 18, No. 2, P. 35-54.

UVA, A. S., 2002. Qualidade Do Ar Interior Em Aeronaves De Aviação Comercial, Observatório Português De Sistemas De Saúde, Escola Nacional De Saúde Pública, Universidade Nova De Lisboa.

VASCONCELLOS, P. C., 1996. Um estudo sobre a caracterização de hidrocarbonetos policíclicos aromáticos e seus derivados, e hidrocarbonetos alifáticos saturados em material particulado atmosférico proveniente de sítios urbanos, suburbano e florestais. São Paulo, 1996. 130p. Tese (Doutorado) - Instituto de Química, Universidade de São Paulo.

VOlAVÝ, J., FISER, J., NÖSKE, I., 2013. Prediction Of Air Temperature In The Aircraft Cabin Under Different Operational Conditions. Epj Web Of Conferences 45 01096.

VUOLO, J. H., 1996. Fundamentos da teoria de erros, $2^{\circ}$ ed., Edgard Blücher Ltda. WAGNER, B.G., COBURN., BLOWER., 2009. Calculating The Potential For WithinFlight Transmission Of Influenza A (H1N1), Bmc Medicine, 7:81 Doi:10.1186/17417015-7-81 
WALKINSHAW, D.S., 2010. Germs Flying And The Truth, Ashrae Journal, Vol. 52.

WALKINSHAW, D.S., 2011. Venturi Filtration Added To Gaspers, Diffusers, Vav Boxes And Air Curtains - C162-10. Published In Ashrae Iaq Conference 2010.

WAN, M.P., CHAO, C.Y.H., FANG, L., 2005. Transmission Characteristics Of Passenger-Exhaled Droplets In A Simulated Air-Cabin Environment. Proceedings Of Indoor Air 2005.

WAN, M. P., SZE TO, G.N., CHAO, C. Y. H., FANG, L. MELIKOV, A., 2009. Modeling The Fate Of Expiratory Aerosols And The Associated Infection Risk In An Aircraft Cabin Environment', Aerosol Science And Technology, 43: 4, 322-343.

WANG, A. J., ZHANG, Y. H., TOPMILLER, J. L., BENNETT, J. S., DUNN, K. H., 2006. Tracer Study Of Airborne Disease Transmission In An Aircraft Cabin Mock-Up. Ashrae Transactions 2006; 112: Part 2.

WANG, C., YANG, X., GUAN, J., GAO, K, LI, Z. 2014. Volatile organic compounds in aircraft cabin: measurements and correlations between compounds, Build. Environ. 78: 89-94.

WANG, M., LIN, C.H., CHEN, Q., 2011. Simulation Of Particle Deposition In An Airplane Cabin Mockup. Simul 2011: The Third Conference On Advances In Systems Simulation. Isbn: 978-1-61208-169-4 (2011) 38-43.

WEI, Y.; ZHANG, T.; WANG, S., 2016. Prompt design of te air-supply opening size for a commercial airplane based on the proper orthogonal decompositon of flows. Building and Environment, 2016, 96: 131-141.

WILlEKE, K., BARON, P., 2005 Aerosol Measurement: Principles, Techniques, and Applications, Van Nostrand Reinhold, New York, 2005.

WINZEN, J., MARGGRAF-MICHEEL, M., 2013. Climate Preferences And Expectations And Theirinfluence On Comfort Evaluations In An Aircraft Cabin.2013, 146-151.

YAN, Y. 2017. Numerical characterisation of contaminant transport and distribution in airliner cabins. PhD Thesis, School of Engineering College of Science, Engineering and Health, RMIT University, Meulborne, Austrália. 
YAN, W., ZHANG, Y., SUN, Y., LI, D., 2009. Experimental And Cfd Study Of Unsteady Airborne Pollutant Transport Within An Aircraft Cabin Mock-Up. Building And Environment 44 (2009) 34-43.

YANG, W. C., 2003 Handbook of fluidization and fluid particle systems. New York: CRC Press, 2003, $861 \mathrm{p}$

YANG, C., YANG, X., XU, Y., SREBRIC, J., 2007. Contaminant Dispersion In Personal Displacement Ventilation, Proceedings Of Building Simulation.

YIN S., ZHANG T., 2009. A New Under-Aisle Displacement Air Distribution System For Wide-Body Aircraft Cabins. Building Simulation 2009. Eleventh International Ibpsa Conference - Glasgow, Scotland. July 27-30 (2009).

YOO, S.H., CHAE, S.K., LIU, B.Y.H., 1996. Influence Of Particle Refractive Index On The Lower Detection Limit Of Light Scattering Aerosol Counters, Aerosol Science And Technology, 25:1, 1-10, First.

YOU,R.; CHEN, J.; SHI, Z.; LIU, W.; LIN, C.-H.; WEI, D.; CHEN, Q., 2016. Experimental and numerical study of airflow distribution in an aircraft cabin mockup with a gasper on. Building performance simulation, 2016

YOU, R., CHEN, J., LIN, C.-H., WEI, D., AND CHEN, Q.. 2017. "Investigating the impact of gaspers on cabin air quality in commercial airliners with a hybrid turbulence model," Building and Environment, 111: 110-122.

YOU, R., LIN, C.H., WEI, D., CHEN Q. 2018a. Assessment of a new ventilation system for commercial aircraft cabins. Proceedings: Roomvent \& Ventilation 2018, Espoo, Finland, 767:772.

YOU, R, LIN, C.-H, WEI, D, AND CHEN, Q, 2018b. An Innovative Personalized Displacement Ventilation System for Airliner Cabins. Building and Environment, 137, 41-50.

YU, I.T.S, LI, Y., WONG, T.W., TAM, W., CHAN, A.T., LEE, J.H.W., LEUNG, D.Y.C., HO, T., 2004, Evidence of airborne transmission of the severe acute respiratory syndrome virus, The New England Journal of Medicine, 350(17):1731-1739.

ZEIDLER, O., M. DANILAK, D. MÜLLER, I. GORES, AND P. BENDFELD., 2008. Experimental Study Of Different Air Distribution Systems For Aircraft Cabins. Indoor Air 2008, 17-22 August 2008, Copenhagen, Denmark - Paper Id:925. 
ZHANG T., CHEN X., MAZUNDAR S., ZHANG T., CHEN Q., 2007. Experimental And Numerical Investigation Of Airflow And Contaminant Transport In An Airliner Cabin Mock-Up. Proceedings Of The 10th International Conference On Air Distribution In Rooms - Roomvent 2007. Helsinki.

ZHANG, Z., CHEN, X., MAZUNDAR, S., ZHANG, T. CHEN, Q., 2008, Experimental and numerical investigation of airflow and contaminant transport in an airliner cabin mock-up, Building and Environment, doi:10.1016/j.buildenv.2008.01.012.

ZHANG T.; CHEN Q., 2007. Novel Air Distribution Systems For Commercial Aircraft Cabins. Building And Environment (42):1675-1684

ZHANG T., YIN S., WANG S., 2010. An Under-Aisle Air Distribution System Facilitating Humidification Of Commercial Aircraft Cabins. Building And Environment. 45(4):907-915.

ZHANG T., LI P.H., WANG S.G., 2012. A Personal Air Distribution System With Air Terminals Embedded In Chair Armrests On Commercial Airplanes. Building And Environment 2012; 41:89-99.

ZHANG, Z.; CHEN, Q., 2006. Experimental Measurements And Numerical Simulations Of Particle Transport And Distribution In Ventilated Rooms. Atmospheric Environment, 40(18), 3396-3408.

ZHANG Z., CHEN X., MAZUNDAR S., ZHANG, T. CHEN, Q., 2009. Experimental And Numerical Investigation Of Airflow And Contaminant Transport In An Airliner Cabin Mock-Up. Building And Environment, 44(1) 85-94.

ZHENG, L.; CHEN, Q.; XU, J.; WU, F., 2016. Evaluation of intervention measures for repiratory disease transmission on cruise ships. Indoor and built environment, 2016 


\section{APÊEDICE A MANEQUINS AQUECIDOS}

Os manequins aquecidos foram construídos em fibra de vidro e tubos e conexões de PVC com forma semelhante a um corpo humano sentado, conforme mostrado na Figura A1.

Na parte interna existe uma resistência elétrica, que dissipa calor, e um ventilador que propicia uma distribuição uniforme da temperatura do ar ao longo de toda a superfície do manequim. Os manequins são acoplados a uma unidade de potência por meio de cabos tripolares. A potência de dissipação de calor é ajustável por meio de software. A faixa de operação dos manequins aquecidos é de 30 a $120 \mathrm{~W} / \mathrm{m}^{2}$.
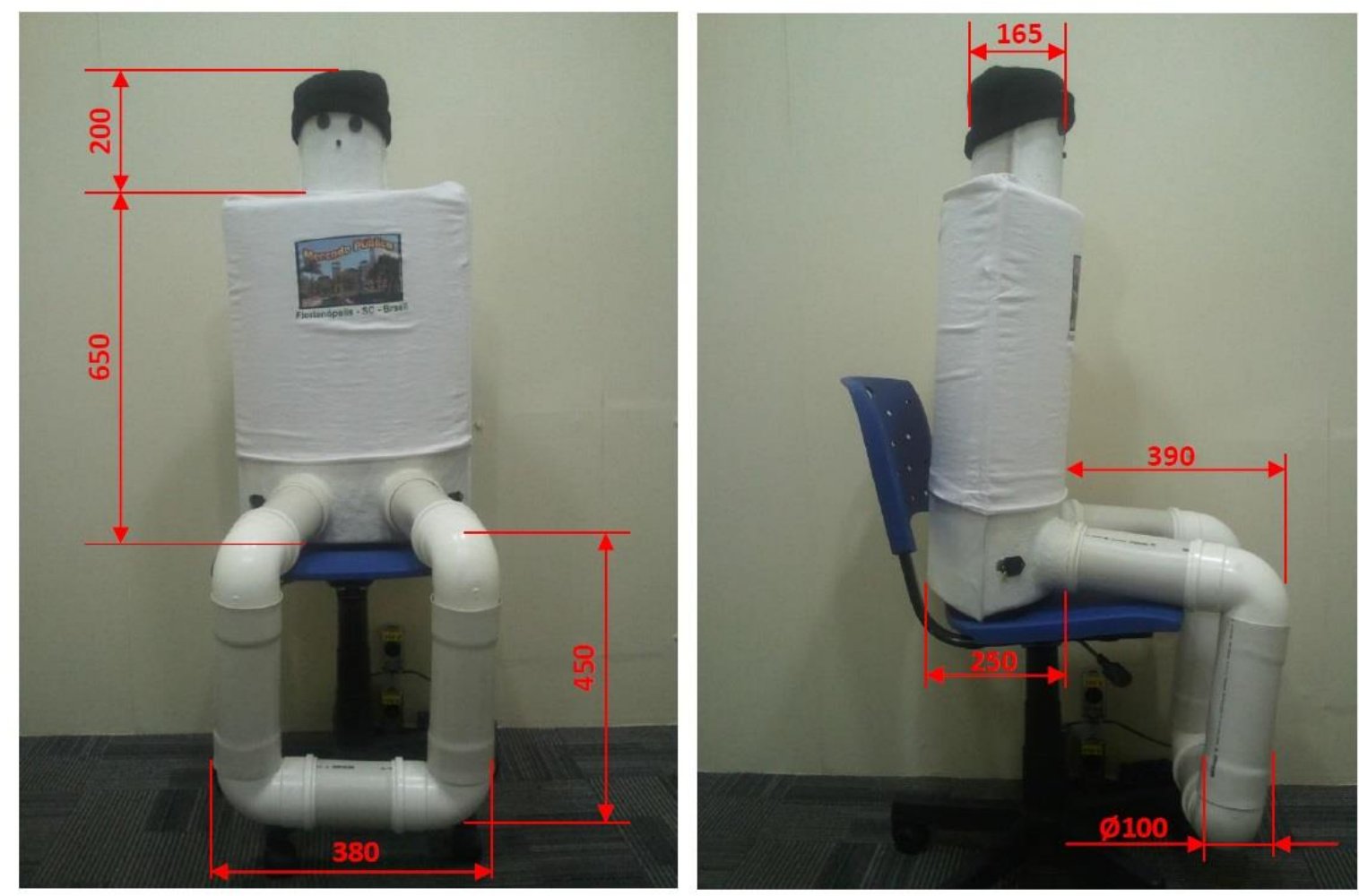

Figura A-1 - Os manequins aquecidos e suas respectivas dimensões Fonte: MOURA, 2009 


\section{APÊEDICE B}

\section{MANÔMETRO DIFERENCIAL}

O seguinte memorial de cálculo para o manômetro diferencial foi proposto por Fabichak Jr. (2013) em sua dissertação, baseado nas dimensões do equipamento disponível no laboratório.

\section{Memorial de cálculo do manômetro diferencial}

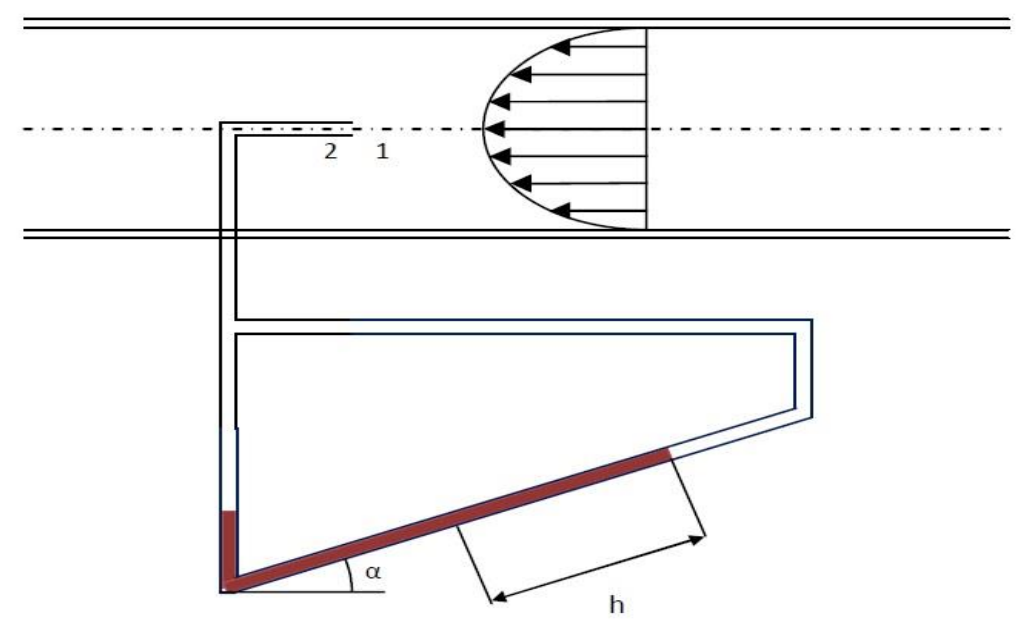

Utilizando a equação de conservação de energia

$H_{1}=H_{2}$
$\frac{v_{1}^{2}}{2 g}+\frac{P_{1}}{\gamma}+z_{1}=\frac{v_{2}^{2}}{2 g}+\frac{P_{2}}{\gamma}+z_{2}$

Adotando-se o ponto 1 muito próximo do ponto 2 tem-se:

$v_{1}=\sqrt[2]{2 g\left(\frac{P_{2}-P_{1}}{\gamma_{a r}}\right)}$

Pois,

$z_{1}=z_{2}=0$

$v_{2}=0$ (ponto de estagnação)

Aplicando-se a equação manométrica entre os pontos 1 e 2 tem-se:

$P_{2}+\gamma_{a x} \cdot h-y_{f} \cdot h=P_{1}$

Portanto, tem-se:

$\frac{P_{2}-P_{1}}{\gamma_{a r}}=h\left(\frac{y_{f}}{\gamma_{a r}}-1\right)$

Substituindo (2) em (1) tem-se:

$v_{1}=\sqrt[2]{2 g\left[h\left(\frac{\gamma_{f}}{\gamma_{a r}}-1\right)\right]}$

Em que:

$v_{1}=v_{\text {máx }}$ 
Se o escoamento for turbulento, $\operatorname{Re}>2400$

$v_{\text {méd }}=\frac{49}{60} v_{\text {máx }}$

Se o escoamento for laminar, $\operatorname{Re}<2400$

$v_{\text {méd }}=0,5 \cdot v_{\text {max }}$

A vazão média é dada por:

$Q_{\text {méd }}=A \cdot v_{\text {méd }}$

Em que:

$A=\frac{\pi \cdot d^{2}}{4}$

Dados para o cálculo do manômetro

glocal $=9,7856 \frac{\mathrm{m}}{\mathrm{s}}$

Par @20 ${ }^{2} \mathrm{C}=1,204 \frac{\mathrm{kg}}{\mathrm{m}^{\mathrm{a}}}$

$\rho_{\text {fluido }}=0,8260 @ 20{ }^{\circ} \mathrm{C}$

$\rho_{\mathrm{H}_{2}}$ @ @20 ${ }^{\circ \mathrm{C}}=998,2071 \frac{\mathrm{kg}}{\mathrm{m}^{\mathrm{a}}}$

$\mu_{\text {ary }}=1,74 \times 10^{-5} \mathrm{~Pa} \cdot \mathrm{s}$

$d_{\text {duto }}=100 \mathrm{~mm}$

Substituindo os valores, tem-se:

$v_{1}=115,685 \sqrt[2]{h}$

( $h$ é dado em metros)

$\mathrm{ou}$

$v_{1}=3,658 \sqrt[2]{h}$

( $h$ é dado em milímetros) 


\section{APÊEDICE C \\ VAZÃO DO SISTEMA PV}

O critério de correntes de ar (Draught Rate) é um dos métodos de avaliação do desconforto térmico local. Esse resfriamento localizado é mais sensível às partes expostas do corpo, tais como pés, tornozelos, ombro, pescoço e face.

Em unidades do sistema métrico, a equação que rege o percentual de pessoas insatisfeitas por correntes de ar é:

$$
P P D_{D R}=\left(34-T_{A R}\right)\left(\overline{v_{A R}}-0,0508\right)^{0,6223}\left(0,3696 \cdot \overline{v_{A R}} \cdot T_{U}+3,143\right)
$$

Onde:

$\mathrm{T}_{\mathrm{AR}}$ é a temperatura do ar local, em $\left[{ }^{\circ} \mathrm{C}\right] ;$

$\bar{v}_{A R}^{--}$é a velocidade média do ar local, em $[\mathrm{m} / \mathrm{s}]$

$T_{\mathrm{U}}$ é a intensidade de turbulência, em [\%].

$$
T_{U}=\frac{\sigma_{v_{A R}}}{\overline{v_{A R}}} \times 100 \%
$$

$\sigma_{v_{A R}}$ é o desvio padrão da velocidade do ar local, em $[\mathrm{m} / \mathrm{s}]$;

Conforme recomendação das normas ASHRAE-55 (2013) e NBR-16401 (2008), o percentual de pessoas insatisfeitas devido a correntes de ar $\left(\mathrm{PPD}_{\mathrm{DR}}\right)$ deve ser menor igual a $20 \%$.

Aplicando a equação da conservação de massa entre a entrada e a saída:

$$
Q m_{1}=Q m_{2}
$$

Sendo a vazão média dada por:

$Q_{\text {méd }}=A . v_{\text {méd }}$

Onde: 


$$
A=\frac{\pi \cdot d^{2}}{4}
$$

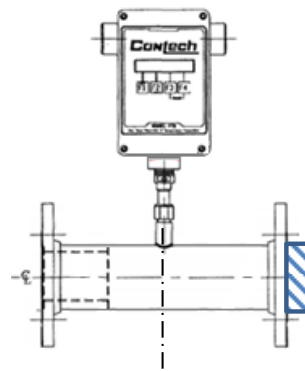

(1)
(2)

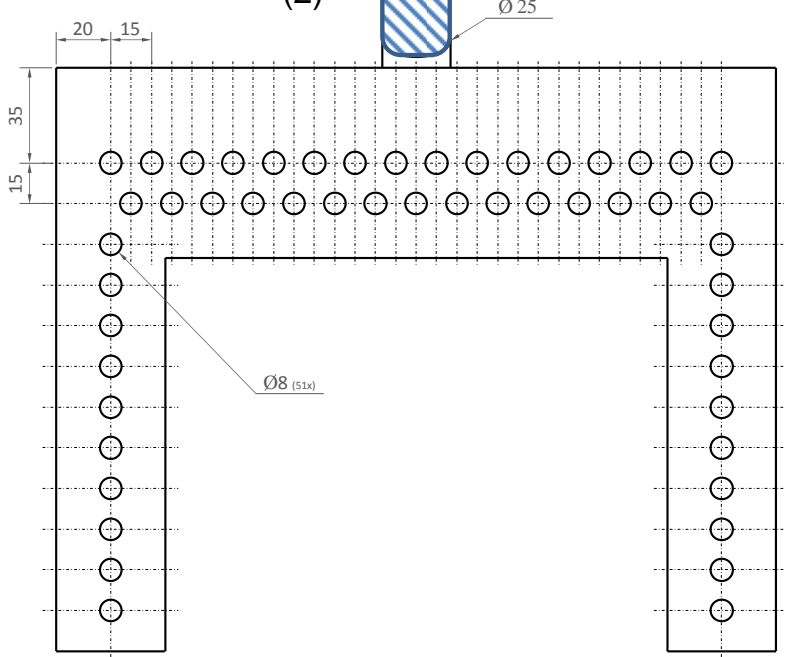

Sendo:

$d_{1}=35,7 \mathrm{~mm}$ (Diâmetro do bocal onde está localizado o elemento sensor)

$d_{2}=25,0 \mathrm{~mm}$ (Diâmetro do bocal do difusor)

A velocidade no bocal de saída do difusor foi medida com anemômetro de fio quente.

Os valores de velocidade foram medidos em intervalos de $5 \mathrm{~s}$, durante 10 minutos. Com isso, obteve-se uma velocidade média no bocal de saída:

$v_{2}=7,45 \pm 0,26 \mathrm{~m} / \mathrm{s}$

Substituindo-se os valores em (3), temos que:

$v_{1} A_{1}=v_{2} A_{2}$

$v_{1}=3,65 \pm 0,26 \mathrm{~m} / \mathrm{s}$

Logo:

$Q_{1}=3,65 \cdot\left(\frac{\pi \cdot\left(35,7 \times 10^{-3}\right)^{2}}{4}\right) \cdot 3600$ 


$$
Q_{1}=13,17 m^{3} / h
$$

Porém, vale ressaltar que o medidor de vazão empregado nos fornece o resultado da vazão em Normal Metro Cúbico por hora. $\mathrm{O}$ valor de $\mathrm{Q}_{1}$ acima está em escala absoluta. Portanto, é necessário realizar uma conversão, de acordo com os dados ensaiados para o sistema personalizado.

$$
Q_{1(\mathrm{NORM})}=Q_{1} \cdot\left(\frac{273,15}{273,15+T_{1}}\right) \cdot\left(\frac{P_{1}-(R h \cdot P v)}{1,033}\right)
$$

Onde:

$\mathrm{T}_{1}=$ Temperatura do ar do sistema personalizado (igual a $24^{\circ} \mathrm{C}$ )

$\mathrm{P}_{1}=$ Pressão atmosférica local (igual a $0,95 \mathrm{kgf} / \mathrm{cm}^{2}$ )

$\mathrm{Rh}=$ Umidade relativa do ar (em torno de 50\%)

$\mathrm{Pv}=$ Pressão parcial do vapor de água (para a temperatura de insuflamento do ar de $24^{\circ} \mathrm{C}$, este valor vale $0,03016 \mathrm{kgf} / \mathrm{cm}^{2}$ (FOX,McDonald \& Pritchard, 2006)

Deste modo:

$$
\begin{aligned}
& Q_{1(\text { NORM })}=10,93 \mathrm{Nm}^{3} / \mathrm{h} \text { ou } \\
& Q_{1(\text { NORM })}=3,04 \ell / s
\end{aligned}
$$

Fazendo-se a verificação se a vazão de insuflamento proposta para o sistema personalizado tende a causar desconforto por correntes de ar, recorremos aos dados experimentais.

Os valores médios para a temperatura e velocidade do ar e de intensidade de turbulência foram em média:

$$
\begin{aligned}
& \bar{T}_{A R}^{--}=24^{\circ} \mathrm{C} \\
& \overline{v_{A R}}=0,25 \mathrm{~m} / \mathrm{s} \\
& T_{U}=30 \%
\end{aligned}
$$

Finalmente, substituindo-se os valores em (1), temos que:

$$
P P D_{D R}=20,6 \%
$$


Portanto, a vazão de insuflamento de ar proposto para o funcionamento do sistema personalizado, mesmo muito próximo do valor máximo recomendado, não tende a causar desconforto térmico por correntes de ar. 


\section{APÊEDICE D}

\section{RESULTADOS DAS MEDIÇÕES E RESPECTIVAS INCERTEZAS DAS VELOCIDADES E DAS TEMPERATURAS DO AR}

Os resultados das médias das velocidades e das temperaturas do ar e as incertezas de medição, são apresentados nas Tabelas D.1 a D.24.

Os valores das velocidades e das temperaturas do ar são a média dos valores dos resultados dos três ensaios (ensaios em triplicata) em cada posição e em cada condição estudada. As incertezas são o resultado da combinação das incertezas dos equipamentos de medição e dos desvios padrão em cada posição e em cada condição de ensaio (COLEMAN; STEELE, 1989; VUOLO, 1996; INMETRO, 1998).

A média das variáveis foi calculada utilizando a seguinte equação:

$$
\bar{x}=\frac{1}{n} \sum_{i=1}^{n} x_{i}
$$

Onde,

x representa o valor da variável e $\mathrm{n}$ o número de amostras.

O desvio padrão das variáveis foi calculado utilizando a seguinte equação.

$$
\sigma_{x}=\sqrt[2]{\frac{\sum(x-\bar{x})^{2}}{n-1}}
$$

O desvio padrão para o valor médio foi calculado utilizando a equação:

$$
\sigma_{m}=\frac{\sigma_{x}}{\sqrt{n}}
$$

E por fim, a incerteza padrão $\varepsilon$ que é a combinação da incerteza sistemática residual (incerteza do instrumento) e o desvio padrão para o valor médio, foi calculada utilizando a equação:

$$
\varepsilon=\sqrt[2]{\sigma_{m}^{2}+\sigma_{T}^{2}}
$$

onde:

or é a incerteza sistemática residual (incerteza do instrumento). 
As tabelas a seguir apresentam os valores médios e incertezas das velocidades e temperaturas medidas ao longo dos ensaios.

Tabela D.1 - Médias dos valores de Velocidade do Ar em m/s para o sistema MV.

\begin{tabular}{|c|c|c|c|c|c|}
\hline Altura $(\mathbf{m})$ & & $\mathbf{1 A}$ & $\mathbf{1 B}$ & $\mathbf{1 D}$ & $\mathbf{1 E}$ \\
\hline $\mathbf{0 , 1}$ & V médio & 0,35 & 0,29 & 0,37 & 0,43 \\
\hline $\mathbf{0 , 6}$ & V médio & 0,13 & 0,19 & 0,09 & 0,10 \\
\hline $\mathbf{1 , 1}$ & V médio & 0,37 & 0,40 & 0,29 & 0,53 \\
\hline Altura (m) & & $\mathbf{2 A}$ & $\mathbf{2 B}$ & $\mathbf{2 D}$ & $\mathbf{2 E}$ \\
\hline $\mathbf{0 , 1}$ & V médio & 0,38 & 0,33 & 0,29 & 0,38 \\
\hline $\mathbf{0 , 6}$ & V médio & 0,13 & 0,17 & 0,09 & 0,11 \\
\hline $\mathbf{1 , 1}$ & V médio & 0,33 & 0,42 & 0,35 & 0,60 \\
\hline Altura (m) & & $\mathbf{3 A}$ & $\mathbf{3 B}$ & $\mathbf{3 D}$ & $\mathbf{3 E}$ \\
\hline $\mathbf{0 , 1}$ & V médio & 0,31 & 0,32 & 0,17 & 0,29 \\
\hline $\mathbf{0 , 6}$ & V médio & 0,17 & 0,19 & 0,12 & 0,05 \\
\hline $\mathbf{1 , 1}$ & V médio & 0,41 & 0,42 & 0,46 & 0,23 \\
\hline
\end{tabular}

Tabela D.2 - Médias dos valores de Velocidade do Ar em m/s para o sistema MV+PV2A.

\begin{tabular}{|c|c|c|c|c|c|}
\hline Altura $(\mathbf{m})$ & & $\mathbf{1 A}$ & $\mathbf{1 B}$ & $\mathbf{1 D}$ & $\mathbf{1 E}$ \\
\hline $\mathbf{0 , 1}$ & V médio & 0,42 & 0,22 & 0,29 & 0,49 \\
\hline $\mathbf{0 , 6}$ & V médio & 0,10 & 0,20 & 0,03 & 0,01 \\
\hline $\mathbf{1 , 1}$ & V médio & 0,41 & 0,35 & 0,35 & 0,55 \\
\hline Altura (m) & & $\mathbf{2 A}$ & $\mathbf{2 B}$ & $\mathbf{2 D}$ & $\mathbf{2 E}$ \\
\hline $\mathbf{0 , 1}$ & V médio & 0,35 & 0,39 & 0,34 & 0,32 \\
\hline $\mathbf{0 , 6}$ & V médio & 0,20 & 0,21 & 0,03 & 0,16 \\
\hline $\mathbf{1 , 1}$ & V médio & 0,58 & 0,36 & 0,39 & 0,57 \\
\hline Altura $(\mathbf{m})$ & & $\mathbf{3 A}$ & $\mathbf{3 B}$ & $\mathbf{3 D}$ & $\mathbf{3 E}$ \\
\hline $\mathbf{0 , 1}$ & V médio & 0,25 & 0,35 & 0,18 & 0,26 \\
\hline $\mathbf{0 , 6}$ & V médio & 0,23 & 0,14 & 0,08 & 0,11 \\
\hline $\mathbf{1 , 1}$ & V médio & 0,50 & 0,35 & 0,53 & 0,25 \\
\hline
\end{tabular}


Tabela D.3 - Médias dos valores de Velocidade do Ar em m/s para o sistema MV+PV2B.

\begin{tabular}{|c|c|c|c|c|c|}
\hline Altura $(\mathbf{m})$ & & $\mathbf{1 A}$ & $\mathbf{1 B}$ & $\mathbf{1 D}$ & $\mathbf{1 E}$ \\
\hline $\mathbf{0 , 1}$ & V médio & 0,34 & 0,26 & 0,39 & 0,46 \\
\hline $\mathbf{0 , 6}$ & V médio & 0,12 & 0,15 & 0,11 & 0,05 \\
\hline $\mathbf{1 , 1}$ & V médio & 0,33 & 0,44 & 0,23 & 0,58 \\
\hline Altura (m) & & $\mathbf{2 A}$ & $\mathbf{2 B}$ & $\mathbf{2 D}$ & $\mathbf{2 E}$ \\
\hline $\mathbf{0 , 1}$ & V médio & 0,32 & 0,36 & 0,25 & 0,34 \\
\hline $\mathbf{0 , 6}$ & V médio & 0,18 & 0,22 & 0,03 & 0,17 \\
\hline $\mathbf{1 , 1}$ & V médio & 0,28 & 0,58 & 0,30 & 0,55 \\
\hline Altura (m) & & $\mathbf{3 A}$ & $\mathbf{3 B}$ & $\mathbf{3 D}$ & $\mathbf{3 E}$ \\
\hline $\mathbf{0 , 1}$ & V médio & 0,34 & 0,36 & 0,22 & 0,26 \\
\hline $\mathbf{0 , 6}$ & V médio & 0,19 & 0,16 & 0,16 & 0,03 \\
\hline $\mathbf{1 , 1}$ & V médio & 0,43 & 0,46 & 0,39 & 0,19 \\
\hline
\end{tabular}

Tabela D.4 - Incertezas dos valores velocidade do Ar calculadas em m/s para o sistema MV.

\begin{tabular}{|c|c|c|c|c|c|}
\hline Altura (m) & & $\mathbf{1 A}$ & $\mathbf{1 B}$ & $\mathbf{1 D}$ & $\mathbf{1 E}$ \\
\hline $\mathbf{0 , 1}$ & $\varepsilon( \pm)$ & 0,06 & 0,06 & 0,06 & 0,07 \\
\hline $\mathbf{0 , 6}$ & $\varepsilon( \pm)$ & 0,04 & 0,05 & 0,04 & 0,04 \\
\hline $\mathbf{1 , 1}$ & $\varepsilon( \pm)$ & 0,06 & 0,06 & 0,06 & 0,08 \\
\hline Altura (m) & & $\mathbf{2 A}$ & $\mathbf{2 B}$ & $\mathbf{2 D}$ & $\mathbf{2 E}$ \\
\hline $\mathbf{0 , 1}$ & $\varepsilon( \pm)$ & 0,06 & 0,06 & 0,06 & 0,06 \\
\hline $\mathbf{0 , 6}$ & $\varepsilon( \pm)$ & 0,04 & 0,05 & 0,04 & 0,04 \\
\hline $\mathbf{1 , 1}$ & $\varepsilon( \pm)$ & 0,06 & 0,07 & 0,06 & 0,09 \\
\hline Altura (m) & & $\mathbf{3 A}$ & $\mathbf{3 B}$ & $\mathbf{3 D}$ & $\mathbf{3 E}$ \\
\hline $\mathbf{0 , 1}$ & $\varepsilon( \pm)$ & 0,06 & 0,06 & 0,05 & 0,06 \\
\hline $\mathbf{0 , 6}$ & $\varepsilon( \pm)$ & 0,05 & 0,05 & 0,04 & 0,04 \\
\hline $\mathbf{1 , 1}$ & $\varepsilon( \pm)$ & 0,07 & 0,07 & 0,07 & 0,05 \\
\hline
\end{tabular}


Tabela D.5 - Incertezas dos valores velocidade do Ar calculadas em m/s para o sistema $\mathrm{MV}+\mathrm{PV} 2 \mathrm{~A}$.

\begin{tabular}{|c|c|c|c|c|c|}
\hline Altura (m) & & $\mathbf{1 A}$ & $\mathbf{1 B}$ & $\mathbf{1 D}$ & $\mathbf{1 E}$ \\
\hline $\mathbf{0 , 1}$ & $\varepsilon( \pm)$ & 0,07 & 0,05 & 0,06 & 0,07 \\
\hline $\mathbf{0 , 6}$ & $\varepsilon( \pm)$ & 0,04 & 0,05 & 0,04 & 0,04 \\
\hline $\mathbf{1 , 1}$ & $\varepsilon( \pm)$ & 0,07 & 0,06 & 0,06 & 0,08 \\
\hline Altura (m) & & $\mathbf{2 A}$ & $\mathbf{2 B}$ & $\mathbf{2 D}$ & $\mathbf{2 E}$ \\
\hline $\mathbf{0 , 1}$ & $\varepsilon( \pm)$ & 0,06 & 0,06 & 0,06 & 0,06 \\
\hline $\mathbf{0 , 6}$ & $\varepsilon( \pm)$ & 0,05 & 0,05 & 0,04 & 0,05 \\
\hline $\mathbf{1 , 1}$ & $\varepsilon( \pm)$ & 0,08 & 0,06 & 0,06 & 0,08 \\
\hline Altura (m) & & $\mathbf{3 A}$ & $\mathbf{3 B}$ & $\mathbf{3 D}$ & $\mathbf{3 E}$ \\
\hline $\mathbf{0 , 1}$ & $\varepsilon( \pm)$ & 0,05 & 0,06 & 0,05 & 0,05 \\
\hline $\mathbf{0 , 6}$ & $\varepsilon( \pm)$ & 0,05 & 0,05 & 0,04 & 0,04 \\
\hline $\mathbf{1 , 1}$ & $\varepsilon( \pm)$ & 0,08 & 0,06 & 0,08 & 0,05 \\
\hline
\end{tabular}

Tabela D.6 - Incertezas dos valores velocidade do Ar calculadas em m/s para o sistema $\mathrm{MV}+\mathrm{PV} 2 \mathrm{~B}$.

\begin{tabular}{|c|c|c|c|c|c|}
\hline Altura (m) & & $\mathbf{1 A}$ & $\mathbf{1 B}$ & $\mathbf{1 D}$ & $\mathbf{1 E}$ \\
\hline $\mathbf{0 , 1}$ & $\varepsilon( \pm)$ & 0,04 & 0,03 & 0,05 & 0,06 \\
\hline $\mathbf{0 , 6}$ & $\varepsilon( \pm)$ & 0,02 & 0,04 & 0,03 & 0,05 \\
\hline $\mathbf{1 , 1}$ & $\varepsilon( \pm)$ & 0,05 & 0,06 & 0,02 & 0,09 \\
\hline Altura (m) & & $\mathbf{2 A}$ & $\mathbf{2 B}$ & $\mathbf{2 D}$ & $\mathbf{2 E}$ \\
\hline $\mathbf{0 , 1}$ & $\varepsilon( \pm)$ & 0,04 & 0,04 & 0,03 & 0,04 \\
\hline $\mathbf{0 , 6}$ & $\varepsilon( \pm)$ & 0,02 & 0,09 & 0,06 & 0,03 \\
\hline $\mathbf{1 , 1}$ & $\varepsilon( \pm)$ & 0,03 & 0,09 & 0,03 & 0,08 \\
\hline Altura (m) & & $\mathbf{3 A}$ & $\mathbf{3 B}$ & $\mathbf{3 D}$ & $\mathbf{3 E}$ \\
\hline $\mathbf{0 , 1}$ & $\varepsilon( \pm)$ & 0,04 & 0,04 & 0,02 & 0,03 \\
\hline $\mathbf{0 , 6}$ & $\varepsilon( \pm)$ & 0,02 & 0,03 & 0,02 & 0,04 \\
\hline $\mathbf{1 , 1}$ & $\varepsilon( \pm)$ & 0,06 & 0,06 & 0,05 & 0,02 \\
\hline
\end{tabular}


Tabela D.7 - Médias dos valores de Velocidade do Ar em m/s para o sistema DV.

\begin{tabular}{|c|c|c|c|c|c|}
\hline Altura $(\mathbf{m})$ & & $\mathbf{1 A}$ & $\mathbf{1 B}$ & $\mathbf{1 D}$ & $\mathbf{1 E}$ \\
\hline $\mathbf{0 , 1}$ & V médio & 0,40 & 0,12 & 0,13 & 0,38 \\
\hline $\mathbf{0 , 6}$ & V médio & 0,15 & 0,40 & 0,35 & 0,13 \\
\hline $\mathbf{1 , 1}$ & V médio & 0,05 & 0,05 & 0,12 & 0,12 \\
\hline Altura (m) & & $\mathbf{2 A}$ & $\mathbf{2 B}$ & $\mathbf{2 D}$ & $\mathbf{2 E}$ \\
\hline $\mathbf{0 , 1}$ & V médio & 0,30 & 0,06 & 0,16 & 0,60 \\
\hline $\mathbf{0 , 6}$ & V médio & 0,23 & 0,60 & 0,32 & 0,12 \\
\hline $\mathbf{1 , 1}$ & V médio & 0,10 & 0,05 & 0,16 & 0,05 \\
\hline Altura (m) & & $\mathbf{3 A}$ & $\mathbf{3 B}$ & $\mathbf{3 D}$ & $\mathbf{3 E}$ \\
\hline $\mathbf{0 , 1}$ & V médio & 0,41 & 0,06 & 0,05 & 0,35 \\
\hline $\mathbf{0 , 6}$ & V médio & 0,11 & 0,25 & 0,29 & 0,10 \\
\hline $\mathbf{1 , 1}$ & V médio & 0,05 & 0,06 & 0,06 & 0,05 \\
\hline
\end{tabular}

Tabela D.8 - Médias dos valores de Velocidade do Ar em m/s para o sistema DV+PV2A.

\begin{tabular}{|c|c|c|c|c|c|}
\hline Altura $(\mathbf{m})$ & & $\mathbf{1 A}$ & $\mathbf{1 B}$ & $\mathbf{1 D}$ & $\mathbf{1 E}$ \\
\hline $\mathbf{0 , 1}$ & V médio & $\mathbf{0 , 3 5}$ & $\mathbf{0 , 0 9}$ & 0,15 & 0,36 \\
\hline $\mathbf{0 , 6}$ & V médio & 0,17 & 0,37 & 0,37 & 0,08 \\
\hline $\mathbf{1 , 1}$ & V médio & 0,07 & 0,07 & 0,16 & 0,09 \\
\hline Altura (m) & & $\mathbf{2 A}$ & $\mathbf{2 B}$ & $\mathbf{2 D}$ & $\mathbf{2 E}$ \\
\hline $\mathbf{0 , 1}$ & V médio & 0,31 & 0,04 & 0,13 & 0,59 \\
\hline $\mathbf{0 , 6}$ & V médio & 0,21 & 0,55 & 0,35 & 0,08 \\
\hline $\mathbf{1 , 1}$ & V médio & 0,39 & 0,09 & 0,20 & 0,10 \\
\hline Altura (m) & & $\mathbf{3 A}$ & $\mathbf{3 B}$ & $\mathbf{3 D}$ & $\mathbf{3 E}$ \\
\hline $\mathbf{0 , 1}$ & V médio & 0,37 & 0,10 & 0,05 & 0,31 \\
\hline $\mathbf{0 , 6}$ & V médio & 0,15 & 0,26 & 0,26 & 0,12 \\
\hline $\mathbf{1 , 1}$ & V médio & 0,08 & 0,11 & 0,07 & 0,09 \\
\hline
\end{tabular}


Tabela D.9 - Médias dos valores de Velocidade do Ar em m/s para o sistema DV+PV2B.

\begin{tabular}{|c|c|c|c|c|c|}
\hline Altura $(\mathbf{m})$ & & $\mathbf{1 A}$ & $\mathbf{1 B}$ & $\mathbf{1 D}$ & $\mathbf{1 E}$ \\
\hline $\mathbf{0 , 1}$ & V médio & 0,44 & 0,15 & 0,14 & 0,43 \\
\hline $\mathbf{0 , 6}$ & V médio & 0,13 & 0,42 & 0,41 & 0,10 \\
\hline $\mathbf{1 , 1}$ & V médio & 0,09 & 0,03 & 0,09 & 0,07 \\
\hline Altura (m) & & $\mathbf{2 A}$ & $\mathbf{2 B}$ & $\mathbf{2 D}$ & $\mathbf{2 E}$ \\
\hline $\mathbf{0 , 1}$ & V médio & 0,28 & 0,07 & 0,11 & 0,52 \\
\hline $\mathbf{0 , 6}$ & V médio & 0,20 & 0,56 & 0,29 & 0,09 \\
\hline $\mathbf{1 , 1}$ & V médio & 0,02 & 0,39 & 0,13 & 0,05 \\
\hline Altura (m) & & $\mathbf{3 A}$ & $\mathbf{3 B}$ & $\mathbf{3 D}$ & $\mathbf{3 E}$ \\
\hline $\mathbf{0 , 1}$ & V médio & 0,39 & 0,09 & 0,05 & 0,33 \\
\hline $\mathbf{0 , 6}$ & V médio & 0,12 & 0,28 & 0,32 & 0,11 \\
\hline $\mathbf{1 , 1}$ & V médio & 0,09 & 0,07 & 0,10 & 0,04 \\
\hline
\end{tabular}

Tabela D.10 - Incertezas dos valores velocidade do Ar calculadas em m/s para o sistema DV.

\begin{tabular}{|c|c|c|c|c|c|}
\hline Altura (m) & & $\mathbf{1 A}$ & $\mathbf{1 B}$ & $\mathbf{1 D}$ & $\mathbf{1 E}$ \\
\hline $\mathbf{0 , 1}$ & $\varepsilon( \pm)$ & 0,07 & 0,04 & 0,04 & 0,06 \\
\hline $\mathbf{0 , 6}$ & $\varepsilon( \pm)$ & 0,05 & 0,07 & 0,06 & 0,04 \\
\hline $\mathbf{1 , 1}$ & $\varepsilon( \pm)$ & 0,04 & 0,04 & 0,04 & 0,04 \\
\hline Altura (m) & & $\mathbf{2 A}$ & $\mathbf{2 B}$ & $\mathbf{2 D}$ & $\mathbf{2 E}$ \\
\hline $\mathbf{0 , 1}$ & $\varepsilon( \pm)$ & 0,06 & 0,04 & 0,05 & 0,09 \\
\hline $\mathbf{0 , 6}$ & $\varepsilon( \pm)$ & 0,05 & 0,09 & 0,06 & 0,04 \\
\hline $\mathbf{1 , 1}$ & $\varepsilon( \pm)$ & 0,04 & 0,04 & 0,05 & 0,04 \\
\hline Altura (m) & & $\mathbf{3 A}$ & $\mathbf{3 B}$ & $\mathbf{3 D}$ & $\mathbf{3 E}$ \\
\hline $\mathbf{0 , 1}$ & $\varepsilon( \pm)$ & 0,07 & 0,04 & 0,04 & 0,06 \\
\hline $\mathbf{0 , 6}$ & $\varepsilon( \pm)$ & 0,04 & 0,05 & 0,06 & 0,04 \\
\hline $\mathbf{1 , 1}$ & $\varepsilon( \pm)$ & 0,04 & 0,04 & 0,04 & 0,04 \\
\hline
\end{tabular}


Tabela D.11 - Incertezas dos valores velocidade do Ar calculadas em m/s para o sistema $\mathrm{DV}+\mathrm{PV} 2 \mathrm{~A}$.

\begin{tabular}{|c|c|c|c|c|c|}
\hline Altura (m) & & $\mathbf{1 A}$ & $\mathbf{1 B}$ & $\mathbf{1 D}$ & $\mathbf{1 E}$ \\
\hline $\mathbf{0 , 1}$ & $\varepsilon( \pm)$ & 0,06 & 0,04 & 0,05 & 0,06 \\
\hline $\mathbf{0 , 6}$ & $\varepsilon( \pm)$ & 0,05 & 0,06 & 0,06 & 0,04 \\
\hline $\mathbf{1 , 1}$ & $\varepsilon( \pm)$ & 0,04 & 0,04 & 0,05 & 0,04 \\
\hline Altura (m) & & $\mathbf{2 A}$ & $\mathbf{2 B}$ & $\mathbf{2 D}$ & $\mathbf{2 E}$ \\
\hline $\mathbf{0 , 1}$ & $\varepsilon( \pm)$ & 0,06 & 0,04 & 0,04 & 0,09 \\
\hline $\mathbf{0 , 6}$ & $\varepsilon( \pm)$ & 0,05 & 0,08 & 0,06 & 0,04 \\
\hline $\mathbf{1 , 1}$ & $\varepsilon( \pm)$ & 0,06 & 0,04 & 0,05 & 0,04 \\
\hline Altura (m) & & $\mathbf{3 A}$ & $\mathbf{3 B}$ & $\mathbf{3 D}$ & $\mathbf{3 E}$ \\
\hline $\mathbf{0 , 1}$ & $\varepsilon( \pm)$ & 0,06 & 0,04 & 0,04 & 0,06 \\
\hline $\mathbf{0 , 6}$ & $\varepsilon( \pm)$ & 0,05 & 0,05 & 0,05 & 0,04 \\
\hline $\mathbf{1 , 1}$ & $\varepsilon( \pm)$ & 0,04 & 0,04 & 0,04 & 0,04 \\
\hline
\end{tabular}

Tabela D.12- Incertezas dos valores velocidade do Ar calculadas em m/s para o sistema DV+PV2B.

\begin{tabular}{|c|c|c|c|c|c|}
\hline Altura (m) & & $\mathbf{1 A}$ & $\mathbf{1 B}$ & $\mathbf{1 D}$ & $\mathbf{1 E}$ \\
\hline $\mathbf{0 , 1}$ & $\varepsilon( \pm)$ & 0,07 & 0,03 & 0,03 & 0,07 \\
\hline $\mathbf{0 , 6}$ & $\varepsilon( \pm)$ & 0,02 & 0,07 & 0,07 & 0,02 \\
\hline $\mathbf{1 , 1}$ & $\varepsilon( \pm)$ & 0,02 & 0,02 & 0,02 & 0,02 \\
\hline Altura (m) & & $\mathbf{2 A}$ & $\mathbf{2 B}$ & $\mathbf{2 D}$ & $\mathbf{2 E}$ \\
\hline $\mathbf{0 , 1}$ & $\varepsilon( \pm)$ & 0,04 & 0,02 & 0,02 & 0,09 \\
\hline $\mathbf{0 , 6}$ & $\varepsilon( \pm)$ & 0,03 & 0,10 & 0,05 & 0,02 \\
\hline $\mathbf{1 , 1}$ & $\varepsilon( \pm)$ & 0,02 & 0,06 & 0,02 & 0,02 \\
\hline Altura (m) & & $\mathbf{3 A}$ & $\mathbf{3 B}$ & $\mathbf{3 D}$ & $\mathbf{3 E}$ \\
\hline $\mathbf{0 , 1}$ & $\varepsilon( \pm)$ & 0,06 & 0,03 & 0,03 & 0,05 \\
\hline $\mathbf{0 , 6}$ & $\varepsilon( \pm)$ & 0,03 & 0,04 & 0,05 & 0,04 \\
\hline $\mathbf{1 , 1}$ & $\varepsilon( \pm)$ & 0,02 & 0,03 & 0,03 & 0,02 \\
\hline
\end{tabular}


Tabela D.13 - Valores médios de Temperatura do Ar calculadas em ${ }^{\circ} \mathrm{C}$ para o sistema MV.

\begin{tabular}{|c|c|c|c|c|c|}
\hline Altura $(\mathbf{m})$ & & $\mathbf{1 A}$ & $\mathbf{1 B}$ & $\mathbf{1 D}$ & $\mathbf{1 E}$ \\
\hline $\mathbf{0 , 1}$ & T médio & 19,84 & 20,68 & 21,43 & 21,07 \\
\hline $\mathbf{0 , 6}$ & T médio & 20,44 & 20,76 & 21,37 & 22,49 \\
\hline $\mathbf{1 , 1}$ & T médio & 20,53 & 21,22 & 22,34 & 21,64 \\
\hline Altura (m) & & $\mathbf{2 A}$ & $\mathbf{2 B}$ & $\mathbf{2 D}$ & $\mathbf{2 E}$ \\
\hline $\mathbf{0 , 1}$ & T médio & 19,49 & 19,53 & 20,58 & 21,01 \\
\hline $\mathbf{0 , 6}$ & T médio & 20,05 & 20,27 & 21,83 & 21,08 \\
\hline $\mathbf{1 , 1}$ & T médio & 19,83 & $\mathbf{2 0 , 2 1}$ & 21,12 & 20,72 \\
\hline Altura $(\mathbf{m})$ & & $\mathbf{3 A}$ & $\mathbf{3 B}$ & $\mathbf{3 D}$ & $\mathbf{3 E}$ \\
\hline $\mathbf{0 , 1}$ & T médio & 19,65 & 19,60 & 19,98 & 19,93 \\
\hline $\mathbf{0 , 6}$ & T médio & 19,78 & 19,84 & 20,47 & 20,58 \\
\hline $\mathbf{1 , 1}$ & T médio & 19,72 & 19,89 & 21,06 & 20,29 \\
\hline
\end{tabular}

Tabela D.14 - Valores médios de Temperatura do Ar calculadas em ${ }^{\circ} \mathrm{C}$ para o sistema $\mathrm{MV}+\mathrm{PV} 2 \mathrm{~A}$.

\begin{tabular}{|c|c|c|c|c|c|}
\hline Altura $(\mathbf{m})$ & & $\mathbf{1 A}$ & $\mathbf{1 B}$ & $\mathbf{1 D}$ & $\mathbf{1 E}$ \\
\hline $\mathbf{0 , 1}$ & T médio & 19,90 & 20,51 & 21,35 & 21,14 \\
\hline $\mathbf{0 , 6}$ & T médio & 20,50 & 20,91 & 21,55 & 22,39 \\
\hline $\mathbf{1 , 1}$ & T médio & $\mathbf{2 0 , 6 9}$ & $\mathbf{2 1 , 5 2}$ & $\mathbf{2 2 , 4 5}$ & $\mathbf{2 1 , 3 3}$ \\
\hline Altura $(\mathbf{m})$ & & $\mathbf{2 A}$ & $\mathbf{2 B}$ & $\mathbf{2 D}$ & $\mathbf{2 E}$ \\
\hline $\mathbf{0 , 1}$ & T médio & 19,30 & 19,42 & 20,31 & 21,15 \\
\hline $\mathbf{0 , 6}$ & T médio & 20,70 & 20,41 & 21,73 & 21,19 \\
\hline $\mathbf{1 , 1}$ & T médio & $\mathbf{2 0 , 7 6}$ & $\mathbf{2 0 , 4 5}$ & 21,22 & 20,84 \\
\hline Altura $(\mathbf{m})$ & & $\mathbf{3 A}$ & $\mathbf{3 B}$ & $\mathbf{3 D}$ & $\mathbf{3 E}$ \\
\hline $\mathbf{0 , 1}$ & T médio & 19,52 & 19,41 & 20,08 & 19,98 \\
\hline $\mathbf{0 , 6}$ & T médio & 19,56 & 20,03 & 20,32 & 20,74 \\
\hline $\mathbf{1 , 1}$ & T médio & 19,92 & 20,11 & 21,24 & 20,16 \\
\hline
\end{tabular}


Tabela D.15-Valores médios de Temperatura do Ar calculadas em ${ }^{\circ} \mathrm{C}$ para o sistema $\mathrm{MV}+\mathrm{PV} 2 \mathrm{~B}$.

\begin{tabular}{|c|c|c|c|c|c|}
\hline Altura $(\mathbf{m})$ & & $\mathbf{1 A}$ & $\mathbf{1 B}$ & $\mathbf{1 D}$ & $\mathbf{1 E}$ \\
\hline $\mathbf{0 , 1}$ & T médio & 19,90 & 20,52 & 21,44 & 21,17 \\
\hline $\mathbf{0 , 6}$ & T médio & 20,31 & 20,55 & 21,48 & 22,50 \\
\hline $\mathbf{1 , 1}$ & T médio & 20,42 & 21,41 & 22,01 & 21,83 \\
\hline Altura $(\mathbf{m})$ & & $\mathbf{2 A}$ & $\mathbf{2 B}$ & $\mathbf{2 D}$ & $\mathbf{2 E}$ \\
\hline $\mathbf{0 , 1}$ & T médio & 19,32 & 19,64 & 20,68 & 21,06 \\
\hline $\mathbf{0 , 6}$ & T médio & 19,76 & 21,04 & 21,98 & 21,12 \\
\hline $\mathbf{1 , 1}$ & T médio & 20,03 & 21,13 & 21,29 & 21,05 \\
\hline Altura $(\mathbf{m})$ & & $\mathbf{3 A}$ & $\mathbf{3 B}$ & $\mathbf{3 D}$ & $\mathbf{3 E}$ \\
\hline $\mathbf{0 , 1}$ & T médio & 19,74 & 19,54 & 20,25 & 19,75 \\
\hline $\mathbf{0 , 6}$ & T médio & 19,63 & 19,75 & 20,32 & 20,42 \\
\hline $\mathbf{1 , 1}$ & T médio & 19,59 & 20,20 & 21,24 & 20,33 \\
\hline
\end{tabular}

Tabela D.16 - Incertezas dos valores de temperatura do Ar calculadas em ${ }^{\circ} \mathrm{C}$ para o sistema MV.

\begin{tabular}{|c|c|c|c|c|c|}
\hline Altura $(\mathbf{m})$ & & $\mathbf{1 A}$ & $\mathbf{1 B}$ & $\mathbf{1 D}$ & $\mathbf{1 E}$ \\
\hline $\mathbf{0 , 1}$ & $\varepsilon( \pm)$ & 0,3 & 0,4 & 0,3 & 0,4 \\
\hline $\mathbf{0 , 6}$ & $\varepsilon( \pm)$ & 0,4 & 0,5 & 0,5 & 0,3 \\
\hline $\mathbf{1 , 1}$ & $\varepsilon( \pm)$ & 0,5 & 0,4 & 0,3 & 0,3 \\
\hline Altura (m) & & $\mathbf{2 A}$ & $\mathbf{2 B}$ & $\mathbf{2 D}$ & $\mathbf{2 E}$ \\
\hline $\mathbf{0 , 1}$ & $\varepsilon( \pm)$ & 0,4 & 0,3 & 0,4 & 0,4 \\
\hline $\mathbf{0 , 6}$ & $\varepsilon( \pm)$ & 0,4 & 0,5 & 0,6 & 0,3 \\
\hline $\mathbf{1 , 1}$ & $\varepsilon( \pm)$ & 0,4 & 0,3 & 0,4 & 0,5 \\
\hline Altura $(\mathbf{m})$ & & $\mathbf{3 A}$ & $\mathbf{3 B}$ & $\mathbf{3 D}$ & $\mathbf{3 E}$ \\
\hline $\mathbf{0 , 1}$ & $\varepsilon( \pm)$ & 0,3 & 0,4 & 0,3 & 0,4 \\
\hline $\mathbf{0 , 6}$ & $\varepsilon( \pm)$ & 0,4 & 0,5 & 0,4 & 0,3 \\
\hline $\mathbf{1 , 1}$ & $\varepsilon( \pm)$ & 0,3 & 0,4 & 0,4 & 0,3 \\
\hline
\end{tabular}


Tabela D.17- Incertezas dos valores de temperatura do Ar calculadas em ${ }^{\circ} \mathrm{C}$ para o sistema $\mathrm{MV}+\mathrm{PV} 2 \mathrm{~A}$.

\begin{tabular}{|c|c|c|c|c|c|}
\hline Altura (m) & & $\mathbf{1 A}$ & $\mathbf{1 B}$ & $\mathbf{1 D}$ & $\mathbf{1 E}$ \\
\hline $\mathbf{0 , 1}$ & $\varepsilon( \pm)$ & 0,3 & 0,3 & 0,3 & 0,3 \\
\hline $\mathbf{0 , 6}$ & $\varepsilon( \pm)$ & 0,3 & 0,4 & 0,4 & 0,3 \\
\hline $\mathbf{1 , 1}$ & $\varepsilon( \pm)$ & 0,4 & 0,3 & 0,3 & 0,3 \\
\hline Altura (m) & & $\mathbf{2 A}$ & $\mathbf{2 B}$ & $\mathbf{2 D}$ & $\mathbf{2 E}$ \\
\hline $\mathbf{0 , 1}$ & $\varepsilon( \pm)$ & 0,3 & 0,3 & 0,4 & 0,3 \\
\hline $\mathbf{0 , 6}$ & $\varepsilon( \pm)$ & 0,3 & 0,4 & 0,5 & 0,3 \\
\hline $\mathbf{1 , 1}$ & $\varepsilon( \pm)$ & 0,3 & 0,3 & 0,3 & 0,4 \\
\hline Altura (m) & & $\mathbf{3 A}$ & $\mathbf{3 B}$ & $\mathbf{3 D}$ & $\mathbf{3 E}$ \\
\hline $\mathbf{0 , 1}$ & $\varepsilon( \pm)$ & 0,3 & 0,3 & 0,5 & 0,3 \\
\hline $\mathbf{0 , 6}$ & $\varepsilon( \pm)$ & 0,3 & 0,4 & 0,3 & 0,4 \\
\hline $\mathbf{1 , 1}$ & $\varepsilon( \pm)$ & 0,3 & 0,3 & 0,5 & 0,3 \\
\hline
\end{tabular}

Tabela D.18 - Incertezas dos valores de temperatura do Ar calculadas em ${ }^{\circ} \mathrm{C}$ para o sistema MV+PV2B.

\begin{tabular}{|c|c|c|c|c|c|}
\hline Altura (m) & & $\mathbf{1 A}$ & $\mathbf{1 B}$ & $\mathbf{1 D}$ & $\mathbf{1 E}$ \\
\hline $\mathbf{0 , 1}$ & $\varepsilon( \pm)$ & 0,4 & 0,4 & 0,5 & 0,5 \\
\hline $\mathbf{0 , 6}$ & $\varepsilon( \pm)$ & 0,3 & 0,3 & 0,3 & 0,3 \\
\hline $\mathbf{1 , 1}$ & $\varepsilon( \pm)$ & 0,4 & 0,5 & 0,4 & 0,6 \\
\hline Altura (m) & & $\mathbf{2 A}$ & $\mathbf{2 B}$ & $\mathbf{2 D}$ & $\mathbf{2 E}$ \\
\hline $\mathbf{0 , 1}$ & $\varepsilon( \pm)$ & 0,4 & 0,4 & 0,4 & 0,4 \\
\hline $\mathbf{0 , 6}$ & $\varepsilon( \pm)$ & 0,3 & 0,4 & 0,3 & 0,4 \\
\hline $\mathbf{1 , 1}$ & $\varepsilon( \pm)$ & 0,4 & 0,6 & 0,4 & 0,6 \\
\hline Altura (m) & & $\mathbf{3 A}$ & $\mathbf{3 B}$ & $\mathbf{3 D}$ & $\mathbf{3 E}$ \\
\hline $\mathbf{0 , 1}$ & $\varepsilon( \pm)$ & 0,4 & 0,4 & 0,4 & 0,4 \\
\hline $\mathbf{0 , 6}$ & $\varepsilon( \pm)$ & 0,4 & 0,3 & 0,3 & 0,3 \\
\hline $\mathbf{1 , 1}$ & $\varepsilon( \pm)$ & 0,5 & 0,5 & 0,5 & 0,4 \\
\hline
\end{tabular}


Tabela D.19- Valores médios de Temperatura do Ar calculadas em ${ }^{\circ} \mathrm{C}$ para o sistema DV.

\begin{tabular}{|c|c|c|c|c|c|}
\hline Altura $(\mathbf{m})$ & & $\mathbf{1 A}$ & $\mathbf{1 B}$ & $\mathbf{1 D}$ & $\mathbf{1 E}$ \\
\hline $\mathbf{0 , 1}$ & T médio & 19,71 & 19,04 & 18,88 & 19,28 \\
\hline $\mathbf{0 , 6}$ & T médio & 20,37 & 20,30 & 20,12 & 19,99 \\
\hline $\mathbf{1 , 1}$ & T médio & 21,71 & 21,26 & 20,31 & 20,11 \\
\hline Altura (m) & & $\mathbf{2 A}$ & $\mathbf{2 B}$ & $\mathbf{2 D}$ & $\mathbf{2 E}$ \\
\hline $\mathbf{0 , 1}$ & T médio & 19,41 & 20,10 & 20,41 & 19,73 \\
\hline $\mathbf{0 , 6}$ & T médio & 20,41 & 20,61 & 21,01 & 18,89 \\
\hline $\mathbf{1 , 1}$ & T médio & 20,92 & 21,33 & 20,73 & $\mathbf{2 0 , 8 2}$ \\
\hline Altura (m) & & $\mathbf{3 A}$ & $\mathbf{3 B}$ & $\mathbf{3 D}$ & $\mathbf{3 E}$ \\
\hline $\mathbf{0 , 1}$ & T médio & 20,36 & 20,70 & 20,46 & 20,55 \\
\hline $\mathbf{0 , 6}$ & T médio & 20,31 & 21,23 & 21,36 & 20,07 \\
\hline $\mathbf{1 , 1}$ & T médio & 21,32 & 21,78 & 21,92 & 22,31 \\
\hline
\end{tabular}

Tabela D.20 - Valores médios de Temperatura do Ar calculadas em ${ }^{\circ} \mathrm{C}$ para o sistema $\mathrm{DV}+\mathrm{PV} 2 \mathrm{~A}$.

\begin{tabular}{|c|c|c|c|c|c|}
\hline Altura $(\mathbf{m})$ & & $\mathbf{1 A}$ & $\mathbf{1 B}$ & $\mathbf{1 D}$ & $\mathbf{1 E}$ \\
\hline $\mathbf{0 , 1}$ & T médio & 19,75 & 19,23 & 18,71 & 19,41 \\
\hline $\mathbf{0 , 6}$ & T médio & 20,61 & 20,41 & 19,84 & 19,74 \\
\hline $\mathbf{1 , 1}$ & T médio & 21,98 & 21,43 & 20,18 & 19,86 \\
\hline Altura (m) & & $\mathbf{2 A}$ & $\mathbf{2 B}$ & $\mathbf{2 D}$ & $\mathbf{2 E}$ \\
\hline $\mathbf{0 , 1}$ & T médio & 19,26 & 20,13 & 20,48 & 19,61 \\
\hline $\mathbf{0 , 6}$ & T médio & 21,20 & 20,37 & 21,06 & 18,70 \\
\hline $\mathbf{1 , 1}$ & T médio & 21,78 & 21,45 & 20,48 & $\mathbf{2 0 , 6 8}$ \\
\hline Altura $(\mathbf{m})$ & & $\mathbf{3 A}$ & $\mathbf{3 B}$ & $\mathbf{3 D}$ & $\mathbf{3 E}$ \\
\hline $\mathbf{0 , 1}$ & T médio & 20,19 & 20,50 & 20,49 & 20,45 \\
\hline $\mathbf{0 , 6}$ & T médio & 20,18 & 21,51 & 21,47 & 20,01 \\
\hline $\mathbf{1 , 1}$ & T médio & 21,49 & 21,99 & 22,06 & 22,15 \\
\hline
\end{tabular}


Tabela D.21 - Valores médios de Temperatura do Ar calculadas em ${ }^{\circ} \mathrm{C}$ para o sistema $\mathrm{DV}+\mathrm{PV} 2 \mathrm{~A}$.

\begin{tabular}{|c|c|c|c|c|c|}
\hline Altura $(\mathbf{m})$ & & $\mathbf{1 A}$ & $\mathbf{1 B}$ & $\mathbf{1 D}$ & $\mathbf{1 E}$ \\
\hline $\mathbf{0 , 1}$ & T médio & 19,54 & 19,15 & 19,01 & 19,01 \\
\hline $\mathbf{0 , 6}$ & T médio & 20,49 & 20,42 & 20,03 & 20,21 \\
\hline $\mathbf{1 , 1}$ & T médio & 22,00 & 21,09 & 20,08 & 20,16 \\
\hline Altura (m) & & $\mathbf{2 A}$ & $\mathbf{2 B}$ & $\mathbf{2 D}$ & $\mathbf{2 E}$ \\
\hline $\mathbf{0 , 1}$ & T médio & 19,53 & 19,97 & 20,53 & 19,51 \\
\hline $\mathbf{0 , 6}$ & T médio & 20,35 & 21,20 & 21,32 & 18,92 \\
\hline $\mathbf{1 , 1}$ & T médio & 20,72 & 22,19 & 20,95 & 20,67 \\
\hline Altura $(\mathbf{m})$ & & $\mathbf{3 A}$ & $\mathbf{3 B}$ & $\mathbf{3 D}$ & $\mathbf{3 E}$ \\
\hline $\mathbf{0 , 1}$ & T médio & 20,15 & 20,88 & 20,31 & 20,78 \\
\hline $\mathbf{0 , 6}$ & T médio & 20,11 & 21,15 & 21,39 & 19,99 \\
\hline $\mathbf{1 , 1}$ & T médio & 21,11 & 21,61 & 21,85 & 22,45 \\
\hline
\end{tabular}

Tabela D.22 - Incertezas dos valores de temperatura do Ar calculadas em ${ }^{\circ} \mathrm{C}$ para o sistema DV.

\begin{tabular}{|c|c|c|c|c|c|}
\hline Altura (m) & & $\mathbf{1 A}$ & $\mathbf{1 B}$ & $\mathbf{1 D}$ & $\mathbf{1 E}$ \\
\hline $\mathbf{0 , 1}$ & $\varepsilon( \pm)$ & 0,4 & 0,3 & 0,2 & 0,3 \\
\hline $\mathbf{0 , 6}$ & $\varepsilon( \pm)$ & 0,3 & 0,4 & 0,4 & 0,2 \\
\hline $\mathbf{1 , 1}$ & $\varepsilon( \pm)$ & 0,4 & 0,3 & 0,2 & 0,2 \\
\hline Altura (m) & & $\mathbf{2 A}$ & $\mathbf{2 B}$ & $\mathbf{2 D}$ & $\mathbf{2 E}$ \\
\hline $\mathbf{0 , 1}$ & $\varepsilon( \pm)$ & 0,4 & 0,3 & 0,4 & 0,5 \\
\hline $\mathbf{0 , 6}$ & $\varepsilon( \pm)$ & 0,4 & 0,6 & 0,5 & 0,4 \\
\hline $\mathbf{1 , 1}$ & $\varepsilon( \pm)$ & 0,3 & 0,3 & 0,4 & 0,3 \\
\hline Altura $(\mathbf{m})$ & & $\mathbf{3 A}$ & $\mathbf{3 B}$ & $\mathbf{3 D}$ & $\mathbf{3 E}$ \\
\hline $\mathbf{0 , 1}$ & $\varepsilon( \pm)$ & 0,5 & 0,3 & 0,3 & 0,5 \\
\hline $\mathbf{0 , 6}$ & $\varepsilon( \pm)$ & 0,3 & 0,4 & 0,4 & 0,3 \\
\hline $\mathbf{1 , 1}$ & $\varepsilon( \pm)$ & 0,3 & 0,3 & 0,3 & 0,3 \\
\hline
\end{tabular}


Tabela D.23 - Incertezas dos valores de temperatura do Ar calculadas em ${ }^{\circ} \mathrm{C}$ para o sistema DV+PV2A.

\begin{tabular}{|c|c|c|c|c|c|}
\hline Altura (m) & & $\mathbf{1 A}$ & $\mathbf{1 B}$ & $\mathbf{1 D}$ & $\mathbf{1 E}$ \\
\hline $\mathbf{0 , 1}$ & $\varepsilon( \pm)$ & 0,5 & 0,3 & 0,3 & 0,5 \\
\hline $\mathbf{0 , 6}$ & $\varepsilon( \pm)$ & 0,4 & 0,5 & 0,5 & 0,3 \\
\hline $\mathbf{1 , 1}$ & $\varepsilon( \pm)$ & 0,3 & 0,3 & 0,4 & 0,3 \\
\hline Altura (m) & & $\mathbf{2 A}$ & $\mathbf{2 B}$ & $\mathbf{2 D}$ & $\mathbf{2 E}$ \\
\hline $\mathbf{0 , 1}$ & $\varepsilon( \pm)$ & 0,4 & 0,3 & 0,4 & 0,6 \\
\hline $\mathbf{0 , 6}$ & $\varepsilon( \pm)$ & 0,4 & 0,6 & 0,5 & 0,3 \\
\hline $\mathbf{1 , 1}$ & $\varepsilon( \pm)$ & 0,5 & 0,3 & 0,4 & 0,3 \\
\hline Altura (m) & & $\mathbf{3 A}$ & $\mathbf{3 B}$ & $\mathbf{3 D}$ & $\mathbf{3 E}$ \\
\hline $\mathbf{0 , 1}$ & $\varepsilon( \pm)$ & 0,5 & 0,3 & 0,3 & 0,4 \\
\hline $\mathbf{0 , 6}$ & $\varepsilon( \pm)$ & 0,4 & 0,4 & 0,4 & 0,3 \\
\hline $\mathbf{1 , 1}$ & $\varepsilon( \pm)$ & 0,3 & 0,4 & 0,3 & 0,3 \\
\hline
\end{tabular}

Tabela D.24 - Incertezas dos valores de temperatura do Ar calculadas em ${ }^{\circ} \mathrm{C}$ para o sistema DV+PV2B.

\begin{tabular}{|c|c|c|c|c|c|}
\hline Altura (m) & & $\mathbf{1 A}$ & $\mathbf{1 B}$ & $\mathbf{1 D}$ & $\mathbf{1 E}$ \\
\hline $\mathbf{0 , 1}$ & $\varepsilon( \pm)$ & 0,5 & 0,3 & 0,3 & 0,5 \\
\hline $\mathbf{0 , 6}$ & $\varepsilon( \pm)$ & 0,3 & 0,5 & 0,5 & 0,3 \\
\hline $\mathbf{1 , 1}$ & $\varepsilon( \pm)$ & 0,3 & 0,3 & 0,3 & 0,3 \\
\hline Altura (m) & & $\mathbf{2 A}$ & $\mathbf{2 B}$ & $\mathbf{2 D}$ & $\mathbf{2 E}$ \\
\hline $\mathbf{0 , 1}$ & $\varepsilon( \pm)$ & 0,4 & 0,3 & 0,3 & 0,5 \\
\hline $\mathbf{0 , 6}$ & $\varepsilon( \pm)$ & 0,4 & 0,6 & 0,4 & 0,3 \\
\hline $\mathbf{1 , 1}$ & $\varepsilon( \pm)$ & 0,3 & 0,5 & 0,3 & 0,3 \\
\hline Altura $(\mathbf{m})$ & & $\mathbf{3 A}$ & $\mathbf{3 B}$ & $\mathbf{3 D}$ & $\mathbf{3 E}$ \\
\hline $\mathbf{0 , 1}$ & $\varepsilon( \pm)$ & 0,5 & 0,3 & 0,3 & 0,5 \\
\hline $\mathbf{0 , 6}$ & $\varepsilon( \pm)$ & 0,3 & 0,4 & 0,4 & 0,3 \\
\hline $\mathbf{1 , 1}$ & $\varepsilon( \pm)$ & 0,3 & 0,3 & 0,3 & 0,3 \\
\hline
\end{tabular}




\section{APÊEDICE E}

\section{RESULTADOS DAS MEDIÇÕES E RESPECTIVAS INCERTEZAS DAS CONCENTRAÇÕES DE PARTÍCULAS}

Conforme apresentado no apêndice D, serão apresentados os valores das concentrações médias dos ensaios e as incertezas de medição calculadas.

Tabela E.1 - Valores de concentração de partículas para o sistema MV em Partículas $/ \mathrm{m}^{3}$.

\begin{tabular}{|c|c|c|c|c|c|c|c|c|c|}
\hline \multicolumn{10}{|c|}{2 a $3 \mu \mathrm{m}$} \\
\hline \multirow{6}{*}{ 3A } & $1 \mathrm{~A}$ & 1B & 1D & $1 E$ & \multirow{6}{*}{ 3B } & $1 \mathrm{~A}$ & $1 B$ & 1D & $1 E$ \\
\hline & 110795000 & 74500000 & 18578333 & 50803333 & & 134253333 & 107830000 & 83128333 & 73896667 \\
\hline & $2 A$ & 2B & 2D & $2 E$ & & $2 A$ & 2B & 2D & $2 E$ \\
\hline & 91400000 & 105238333 & 84043333 & 68576667 & & 85048333 & 96998333 & 135536667 & 128298333 \\
\hline & $3 A$ & 3B & 3D & $3 E$ & & $3 A$ & 3B & 3D & $3 E$ \\
\hline & Injeção & 105991667 & 108526667 & 71203333 & & 138950000 & Injeção & 131683333 & 122938333 \\
\hline \multicolumn{10}{|c|}{3 a $5 \mu \mathrm{m}$} \\
\hline \multirow{6}{*}{$3 A$} & $1 \mathrm{~A}$ & $1 \mathrm{~B}$ & 1D & $1 E$ & \multirow{6}{*}{$3 B$} & $1 \mathrm{~A}$ & 1B & 1D & $1 E$ \\
\hline & 63513333 & 66773333 & 15748333 & 38540000 & & 78533333 & 77081667 & 61926667 & 54776667 \\
\hline & $2 A$ & 2B & $2 \mathrm{D}$ & $2 \mathrm{E}$ & & $2 A$ & 2B & $2 \mathrm{D}$ & $2 \mathrm{E}$ \\
\hline & 75153333 & 80000000 & 75290000 & 60833333 & & 68461667 & 86060000 & 103376667 & 71833333 \\
\hline & $3 A$ & $3 B$ & 3D & $3 E$ & & $3 A$ & 3B & 3D & $3 E$ \\
\hline & Injeção & 98466667 & 81866667 & 65156667 & & 121806667 & Injeção & 108400000 & 83333333 \\
\hline \multicolumn{10}{|c|}{5 a $7 \mu \mathrm{m}$} \\
\hline \multirow{6}{*}{ 3A } & $1 \mathrm{~A}$ & 1B & 1D & $1 E$ & \multirow{6}{*}{ 3B } & $1 \mathrm{~A}$ & 1B & 1D & $1 \mathrm{E}$ \\
\hline & 34166667 & 36766667 & 7411667 & 20186667 & & 38466667 & 37665000 & 29121667 & 25560003 \\
\hline & $2 A$ & $2 B$ & 2D & $2 \mathrm{E}$ & & $2 A$ & $2 B$ & 2D & $2 \mathrm{E}$ \\
\hline & 55066667 & 60733333 & 51480000 & 28490000 & & 32825000 & 45500000 & 59960000 & 40020000 \\
\hline & $3 A$ & 3B & 3D & $3 E$ & & $3 A$ & 3B & 3D & $3 E$ \\
\hline & Injeção & 59496667 & 49996667 & 40010000 & & 93333333 & Injeção & 108400000 & 47501800 \\
\hline \multicolumn{10}{|c|}{7 a $10 \mu \mathrm{m}$} \\
\hline \multirow{6}{*}{$3 A$} & $1 \mathrm{~A}$ & 1B & 1D & $1 E$ & \multirow{6}{*}{$3 B$} & $1 \mathrm{~A}$ & 1B & 1D & $1 E$ \\
\hline & 8366667 & 13373333 & 1253333 & 6853333 & & 11666667 & 6686667 & 5360000 & 4786667 \\
\hline & $2 A$ & 2B & 2D & $2 E$ & & $2 A$ & 2B & 2D & $2 \mathrm{E}$ \\
\hline & 29846667 & 21963333 & 28533333 & 17533333 & & 5771667 & 8171667 & 10590000 & 9705000 \\
\hline & 3A & 3B & 3D & $3 E$ & & $3 A$ & 3B & 3D & $3 E$ \\
\hline & Injeção & 53993333 & 21266667 & 17366667 & & 29806667 & Injeção & 33333333 & 37546667 \\
\hline
\end{tabular}


Tabela E.2 - Valores das incertezas calculadas das concentrações de partículas para o sistema MV em Partículas $/ \mathrm{m}^{3}$.

\begin{tabular}{|c|c|c|c|c|c|c|c|c|c|}
\hline \multicolumn{10}{|c|}{2 a $3 \mu \mathrm{m}$} \\
\hline \multirow{6}{*}{3} & $1 \mathrm{~A}$ & 1B & 1D & $1 \mathrm{E}$ & \multirow{6}{*}{$3 B$} & $1 \mathrm{~A}$ & 1B & 1D & $1 \mathrm{E}$ \\
\hline & 9920584 & 7301000 & 1449110 & 4470693 & & 15411048 & 8691141 & 5940874 & 5969668 \\
\hline & $2 A$ & 2B & 2D & $2 \mathrm{E}$ & & $2 A$ & 2B & 2D & $2 \mathrm{E}$ \\
\hline & 8683000 & 10992144 & 8362312 & 5856447 & & 7417065 & 8632852 & 15451180 & 5128827 \\
\hline & $3 A$ & 3B & 3D & $3 E$ & & $3 A$ & 3B & 3D & $3 E$ \\
\hline & Injeção & 10588568 & 12046460 & 8796460 & & 5123196 & Injeção & 11719817 & 9589190 \\
\hline \multicolumn{10}{|c|}{3 a $5 \mu \mathrm{m}$} \\
\hline \multirow{6}{*}{3} & $1 \mathrm{~A}$ & 1B & 1D & $1 \mathrm{E}$ & \multirow{6}{*}{ 3B } & $1 \mathrm{~A}$ & 1B & 1D & $1 \mathrm{E}$ \\
\hline & 5220651 & 6007196 & 1127644 & 3113415 & & 8838141 & 6090993 & 4338892 & 4338312 \\
\hline & $2 A$ & 2B & 2D & $2 \mathrm{E}$ & & $2 A$ & 2B & 2D & $2 \mathrm{E}$ \\
\hline & 6554122 & 7120000 & 8583060 & 2431860 & & 5853473 & 8090070 & 9257381 & 5521110 \\
\hline & $3 A$ & 3B & 3D & $3 E$ & & 3A & 3B & 3D & $3 E$ \\
\hline & Injeção & 9073211 & 7286133 & 5082220 & & 8605641 & Injeção & 10829160 & 5775000 \\
\hline \multicolumn{10}{|c|}{5 a $7 \mu \mathrm{m}$} \\
\hline \multirow{6}{*}{ 3A } & $1 \mathrm{~A}$ & 1B & 1D & 1E & \multirow{6}{*}{ 3B } & $1 \mathrm{~A}$ & 1B & 1D & 1E \\
\hline & 2808422 & 3307676 & 530705 & 1630760 & & 4329039 & 2976288 & 2040410 & 2024352 \\
\hline & $2 A$ & 2B & 2D & $2 \mathrm{E}$ & & $2 A$ & 2B & 2D & $2 \mathrm{E}$ \\
\hline & 4802364 & 5405267 & 5868720 & 1138910 & & 2806538 & 4277228 & 5369418 & 3074400 \\
\hline & $3 A$ & 3B & 3D & $3 E$ & & $3 A$ & 3B & 3D & $3 E$ \\
\hline & Injeção & 5482320 & 4449703 & 3120780 & & 6594000 & Injeção & 10829160 & 3291750 \\
\hline \multicolumn{10}{|c|}{7 a $10 \mu \mathrm{m}$} \\
\hline \multirow{6}{*}{ 3A } & $1 \mathrm{~A}$ & 1B & 1D & $1 \mathrm{E}$ & \multirow{6}{*}{ 3B } & $1 \mathrm{~A}$ & 1B & 1D & $1 \mathrm{E}$ \\
\hline & 687721 & 1203119 & 89744 & 553640 & & 1024333 & 653956 & 470876 & 469093 \\
\hline & $2 A$ & 2B & 2D & $2 \mathrm{E}$ & & $2 A$ & 2B & 2D & $2 \mathrm{E}$ \\
\hline & 2602928 & 1954737 & 3252800 & 700909 & & 606025 & 935247 & 1159605 & 925857 \\
\hline & $3 A$ & 3B & 3D & $3 \mathrm{E}$ & & $3 A$ & 3B & 3D & $3 \mathrm{E}$ \\
\hline & Injeção & 4975216 & 1892733 & 1354600 & & 2637890 & Injeção & 4033333 & 3266560 \\
\hline
\end{tabular}


Tabela E.3 - Valores de concentração de partículas para o sistema MV+PV2A em Partículas $/ \mathrm{m}^{3}$.

\begin{tabular}{|c|c|c|c|c|c|c|c|c|c|}
\hline \multicolumn{10}{|c|}{2 a $3 \mu \mathrm{m}$} \\
\hline \multirow{6}{*}{$3 \mathrm{~A}$} & $1 \mathrm{~A}$ & $1 \mathrm{~B}$ & 1D & $1 \mathrm{E}$ & \multirow{6}{*}{ 3B } & $1 \mathrm{~A}$ & 1B & 1D & $1 \mathrm{E}$ \\
\hline & 101931400 & 78225000 & 18541177 & 46332640 & & 135489328 & 106255682 & 88531675 & 72300499 \\
\hline & $2 A$ & 2B & 2D & $2 \mathrm{E}$ & & $2 A$ & 2B & 2D & $2 \mathrm{E}$ \\
\hline & 66722000 & 109026913 & 90598713 & 65833600 & & 63786250 & 95737355 & 135265593 & 130992598 \\
\hline & $3 A$ & 3B & 3D & $3 E$ & & $3 A$ & 3B & 3D & $3 \mathrm{E}$ \\
\hline & Injeção & 105461708 & 107115820 & 72057773 & & 146113677 & Injeção & 132880218 & 131762603 \\
\hline \multicolumn{10}{|c|}{3 a $5 \mu \mathrm{m}$} \\
\hline \multirow{6}{*}{ 3A } & $1 \mathrm{~A}$ & $1 B$ & 1D & $1 \mathrm{E}$ & \multirow{6}{*}{ 3B } & $1 \mathrm{~A}$ & $1 B$ & 1D & $1 \mathrm{E}$ \\
\hline & 60337667 & 66439467 & 15543605 & 39002480 & & 78376267 & 83941935 & 63939283 & 53976927 \\
\hline & $2 \mathrm{~A}$ & 2B & 2D & $2 \mathrm{E}$ & & $2 \mathrm{~A}$ & 2B & 2D & $2 \mathrm{E}$ \\
\hline & 53358867 & 83989600 & 77699280 & 58041083 & & 48607783 & 88856950 & 100792250 & 75712333 \\
\hline & $3 A$ & 3B & 3D & $3 E$ & & $3 A$ & 3B & 3D & $3 E$ \\
\hline & Injeção & 103377199 & 84486400 & 62165976 & & 128086505 & Injeção & 109385260 & 89314834 \\
\hline \multicolumn{10}{|c|}{5 a $7 \mu \mathrm{m}$} \\
\hline \multirow{6}{*}{$3 A$} & $1 \mathrm{~A}$ & 1B & 1D & $1 \mathrm{E}$ & \multirow{6}{*}{ 3B } & $1 \mathrm{~A}$ & 1B & 1D & $1 \mathrm{E}$ \\
\hline & 35277083 & 36143333 & 7504541 & 20350101 & & 41332433 & 38566096 & 28480990 & 26401541 \\
\hline & $2 \mathrm{~A}$ & 2B & 2D & $2 \mathrm{E}$ & & $2 A$ & 2B & 2D & $2 \mathrm{E}$ \\
\hline & 43750467 & 63835845 & 56303454 & 27748622 & & 25931750 & 49049000 & 61908700 & 37800000 \\
\hline & $3 A$ & 3B & 3D & $3 E$ & & $3 A$ & 3B & 3D & $3 E$ \\
\hline & Injeção & 58453274 & 48724941 & 39979944 & & 92482983 & Injeção & 116180737 & 48508066 \\
\hline \multicolumn{10}{|c|}{7 a $10 \mu \mathrm{m}$} \\
\hline \multirow{6}{*}{ 3A } & $1 \mathrm{~A}$ & 1B & 1D & $1 \mathrm{E}$ & \multirow{6}{*}{$3 B$} & $1 \mathrm{~A}$ & 1B & 1D & $1 \mathrm{E}$ \\
\hline & 8785000 & 13138805 & 1221453 & 6848185 & & 12606314 & 6895623 & 5520800 & 5172191 \\
\hline & $2 A$ & $2 B$ & 2D & $2 \mathrm{E}$ & & $2 A$ & 2B & 2D & $2 \mathrm{E}$ \\
\hline & 22743160 & 23500767 & 27106667 & 16517774 & & 4732767 & 9013688 & 10568820 & 10568745 \\
\hline & $3 A$ & 3B & 3D & $3 E$ & & $3 A$ & 3B & 3D & $3 E$ \\
\hline & Injeção & 59392667 & 22910580 & 16881507 & & 27511553 & Injeção & 35910000 & 36497754 \\
\hline
\end{tabular}


Tabela E.4 - Valores das incertezas calculadas das concentrações de partículas para o sistema MV+PV2A em Partículas $/ \mathrm{m}^{3}$.

\begin{tabular}{|c|c|c|c|c|c|c|c|c|c|}
\hline \multicolumn{10}{|c|}{2 a $3 \mu \mathrm{m}$} \\
\hline \multirow{6}{*}{$3 A$} & $1 \mathrm{~A}$ & $1 B$ & 1D & $1 \mathrm{E}$ & \multirow{6}{*}{$3 B$} & $1 \mathrm{~A}$ & 1B & 1D & $1 \mathrm{E}$ \\
\hline & 8214244 & 6899445 & 1301591 & 3669545 & & 17326641 & 9771450 & 6679325 & 6711698 \\
\hline & $2 A$ & 2B & 2D & $2 \mathrm{E}$ & & $2 \mathrm{~A}$ & $2 B$ & $2 \mathrm{D}$ & $2 \mathrm{E}$ \\
\hline & 5704731 & 10249075 & 8113115 & 5059970 & & 8339006 & 9705915 & 17371762 & 5766340 \\
\hline & $3 A$ & 3B & 3D & $3 E$ & & $3 A$ & 3В & 3D & $3 E$ \\
\hline & Injeção & 9482062 & 10700870 & 8011816 & & 5760009 & Injeção & 13176590 & 10781126 \\
\hline \multicolumn{10}{|c|}{3 a $5 \mu \mathrm{m}$} \\
\hline \multirow{6}{*}{ 3A } & $1 \mathrm{~A}$ & 1B & 1D & $1 \mathrm{E}$ & \multirow{6}{*}{$3 B$} & $1 \mathrm{~A}$ & 1B & 1D & $1 \mathrm{E}$ \\
\hline & 5686984 & 6543787 & 1228370 & 3391520 & & 7848270 & 5408802 & 3852936 & 3852421 \\
\hline & $2 A$ & 2B & 2D & $2 \mathrm{E}$ & & $2 A$ & 2B & 2D & $2 \mathrm{E}$ \\
\hline & 7139567 & 8356000 & 7491355 & 5195167 & & 5197884 & 7183982 & 8220554 & 4902746 \\
\hline & $3 A$ & 3B & 3D & $3 E$ & & $3 A$ & 3B & 3D & $3 E$ \\
\hline & Injeção & 9836820 & 9087200 & 8049455 & & 7641809 & Injeção & 9616294 & 5128200 \\
\hline \multicolumn{10}{|c|}{5 a $7 \mu \mathrm{m}$} \\
\hline \multirow{6}{*}{$3 A$} & $1 \mathrm{~A}$ & 1B & 1D & $1 \mathrm{E}$ & \multirow{6}{*}{ 3B } & $1 \mathrm{~A}$ & 1B & 1D & $1 \mathrm{E}$ \\
\hline & 2864591 & 3373830 & 541319 & 1663375 & & 3515179 & 2416746 & 1656813 & 1643774 \\
\hline & $2 A$ & $2 B$ & 2D & $2 E$ & & $2 A$ & 2B & 2D & $2 \mathrm{E}$ \\
\hline & 4898411 & 5513372 & 5986094 & 1161688 & & 2278908 & 3473109 & 4359967 & 2496413 \\
\hline & $3 A$ & 3B & 3D & $3 E$ & & $3 A$ & 3B & 3D & $3 E$ \\
\hline & Injeção & 5591967 & 4538697 & 3183196 & & 5354328 & Injeção & 8793278 & 2672901 \\
\hline \multicolumn{10}{|c|}{7 a $10 \mu \mathrm{m}$} \\
\hline \multirow{6}{*}{$3 A$} & $1 \mathrm{~A}$ & 1B & 1D & $1 \mathrm{E}$ & \multirow{6}{*}{ 3B } & $1 \mathrm{~A}$ & $1 \mathrm{~B}$ & 1D & $1 \mathrm{E}$ \\
\hline & 722107 & 1182019 & 87461 & 553224 & & 1447089 & 555790 & 394551 & 417830 \\
\hline & $2 A$ & 2B & 2D & $2 \mathrm{E}$ & & $2 A$ & 2B & 2D & $2 \mathrm{E}$ \\
\hline & 1983431 & 2091568 & 3090160 & 660311 & & 412745 & 802218 & 1204845 & 422494 \\
\hline & $3 A$ & 3B & 3D & $3 E$ & & 3A & 3В & 3D & $3 E$ \\
\hline & Injeção & 5472737 & 2039042 & 1316758 & & 1014373 & Injeção & 3195990 & 2846825 \\
\hline
\end{tabular}


Tabela E.5 - Valores de concentração de partículas para o sistema MV+PV2B em Partículas $/ \mathrm{m}^{3}$.

\begin{tabular}{|c|c|c|c|c|c|c|c|c|c|}
\hline \multicolumn{10}{|c|}{2 a $3 \mu \mathrm{m}$} \\
\hline \multirow{6}{*}{$3 A$} & $1 \mathrm{~A}$ & 1B & 1D & $1 E$ & \multirow{6}{*}{ 3B } & $1 \mathrm{~A}$ & 1B & 1D & $1 E$ \\
\hline & 114118850 & 65560005 & 20064600 & 49507848 & & 136489328 & 113652820 & 83959617 & 75478055 \\
\hline & $2 A$ & 2B & 2D & $2 \mathrm{E}$ & & $2 A$ & 2B & 2D & $2 E$ \\
\hline & 84088000 & 78928750 & 84967810 & 72965573 & & 86749300 & 70808783 & 141717139 & 120010261 \\
\hline & $3 A$ & 3B & 3D & $3 E$ & & 3A & 3B & 3D & $3 E$ \\
\hline & Injeção & 109436396 & 114495633 & 72095574 & & 145897500 & Injeção & 128333810 & 122845982 \\
\hline \multicolumn{10}{|c|}{3 a $5 \mu \mathrm{m}$} \\
\hline \multirow{6}{*}{ 3A } & $1 \mathrm{~A}$ & 1B & 1D & $1 E$ & \multirow{6}{*}{ 3B } & $1 \mathrm{~A}$ & $1 B$ & 1D & $1 E$ \\
\hline & 66053867 & 65437867 & 15716837 & 40852400 & & 85365733 & 78731214 & 63254851 & 57734607 \\
\hline & $2 A$ & 2B & 2D & $2 E$ & & $2 A$ & 2B & 2D & $2 E$ \\
\hline & 75904867 & 58832000 & 73407750 & 61441667 & & 64833198 & 62427924 & 97380820 & 70281733 \\
\hline & $3 A$ & 3B & 3D & $3 E$ & & $3 A$ & 3B & 3D & $3 E$ \\
\hline & Injeção & 96497333 & 81702933 & 69066067 & & 134690106 & Injeção & 110379474 & 95725676 \\
\hline \multicolumn{10}{|c|}{5 a $7 \mu \mathrm{m}$} \\
\hline \multirow{6}{*}{ 3A } & $1 \mathrm{~A}$ & 1B & 1D & $1 \mathrm{E}$ & \multirow{6}{*}{ 3B } & $1 \mathrm{~A}$ & 1B & 1D & $1 \mathrm{E}$ \\
\hline & 31535833 & 35843333 & 7984589 & 20371301 & & 40659047 & 40261050 & 31086202 & 23643000 \\
\hline & $2 A$ & 2B & 2D & $2 E$ & & $2 A$ & 2B & 2D & $2 E$ \\
\hline & 50534680 & 45436125 & 51916164 & 30237577 & & 35270463 & 36855000 & 61246004 & 42160000 \\
\hline & $3 A$ & 3B & 3D & $3 E$ & & $3 A$ & 3B & 3D & $3 E$ \\
\hline & Injeção & 58453274 & 48724941 & 39979944 & & 95488680 & Injeção & 117636584 & 44883481 \\
\hline \multicolumn{10}{|c|}{7 a $10 \mu \mathrm{m}$} \\
\hline \multirow{6}{*}{$3 A$} & $1 \mathrm{~A}$ & $1 B$ & 1D & $1 E$ & \multirow{6}{*}{ 3B } & $1 \mathrm{~A}$ & $1 B$ & 1D & $1 E$ \\
\hline & 8798017 & 13251490 & 1264725 & 7345252 & & 12471371 & 7375671 & 4877600 & 4772307 \\
\hline & $2 A$ & 2B & 2D & $2 \mathrm{E}$ & & $2 A$ & 2B & 2D & $2 E$ \\
\hline & 30480086 & 17329070 & 28129117 & 17905434 & & 5689884 & 6864200 & 11539923 & 9912687 \\
\hline & $3 A$ & 3B & 3D & $3 E$ & & $3 A$ & 3B & 3D & $3 E$ \\
\hline & Injeção & 57772867 & 20203333 & 16360761 & & 30700867 & Injeção & 36000000 & 36589227 \\
\hline
\end{tabular}


Tabela E.6 - Valores das incertezas calculadas das concentrações de partículas para o sistema MV+PV2B em Partículas/m³.

\begin{tabular}{|c|c|c|c|c|c|c|c|c|c|}
\hline \multicolumn{10}{|c|}{2 a $3 \mu \mathrm{m}$} \\
\hline \multirow{6}{*}{ 3A } & $1 \mathrm{~A}$ & 1B & 1D & $1 E$ & \multirow{6}{*}{ 3B } & $1 \mathrm{~A}$ & 1B & 1D & $1 \mathrm{E}$ \\
\hline & 9380309 & 5898040 & 1436706 & 3999442 & & 10618870 & 9978718 & 6536256 & 6642069 \\
\hline & $2 A$ & 2B & 2D & $2 E$ & & $2 A$ & 2B & 2D & $2 E$ \\
\hline & 7333314 & 7024659 & 9686330 & 2916856 & & 8241184 & 7395977 & 14100855 & 10248876 \\
\hline & $3 A$ & 3B & 3D & $3 E$ & & $3 A$ & 3B & 3D & $3 E$ \\
\hline & Injeção & 10084017 & 10190111 & 5623455 & & 11452954 & Injeção & 14245053 & 9459141 \\
\hline \multicolumn{10}{|c|}{3 a $5 \mu \mathrm{m}$} \\
\hline \multirow{6}{*}{ 3A } & $1 \mathrm{~A}$ & 1B & 1D & $1 \mathrm{E}$ & \multirow{6}{*}{$3 B$} & $1 \mathrm{~A}$ & 1B & 1D & $1 \mathrm{E}$ \\
\hline & 4862371 & 5859961 & 1091161 & 3088996 & & 6573161 & 7007078 & 7211053 & 2307986 \\
\hline & $2 \mathrm{~A}$ & 2B & 2D & $2 \mathrm{E}$ & & $2 \mathrm{~A}$ & 2B & 2D & $2 \mathrm{E}$ \\
\hline & 4562183 & 7895442 & 6957971 & 4461038 & & 2390451 & 5752421 & 8666893 & 5481975 \\
\hline & $3 A$ & 3B & 3D & $3 E$ & & 3A & 3B & 3D & $3 E$ \\
\hline & Injeção & 9294644 & 8440191 & 6911986 & & 15461185 & Injeção & 7888413 & 7733103 \\
\hline \multicolumn{10}{|c|}{5 a $7 \mu \mathrm{m}$} \\
\hline \multirow{6}{*}{ 3A } & $1 \mathrm{~A}$ & 1B & 1D & $1 \mathrm{E}$ & \multirow{6}{*}{ 3B } & $1 \mathrm{~A}$ & 1B & 1D & $1 \mathrm{E}$ \\
\hline & 2864591 & 3373830 & 541319 & 1663375 & & 3276550 & 3551025 & 2182251 & 1872526 \\
\hline & $2 A$ & 2B & 2D & $2 \mathrm{E}$ & & $2 A$ & 2B & 2D & $2 \mathrm{E}$ \\
\hline & 4800443 & 5403105 & 5866373 & 1138455 & & 3015625 & 3464554 & 5484580 & 3240418 \\
\hline & 3A & 3B & 3D & 3E & & 3A & 3B & 3D & 3E \\
\hline & Injeção & 5480127 & 4447923 & 3119532 & & 6746275 & Injeção & 11751895 & 4990415 \\
\hline \multicolumn{10}{|c|}{7 a $10 \mu \mathrm{m}$} \\
\hline \multirow{6}{*}{ 3A } & $1 \mathrm{~A}$ & 1B & 1D & $1 \mathrm{E}$ & \multirow{6}{*}{ 3B } & $1 \mathrm{~A}$ & 1B & 1D & $1 \mathrm{E}$ \\
\hline & 736549 & 1205660 & 89210 & 564288 & & 1094986 & 721341 & 428497 & 467686 \\
\hline & $2 A$ & 2B & 2D & $2 E$ & & $2 A$ & 2B & 2D & $2 E$ \\
\hline & 2023100 & 2133400 & 3151963 & 673517 & & 597438 & 785608 & 1263622 & 945670 \\
\hline & 3A & 3B & 3D & $3 E$ & & 3A & 3B & 3D & $3 \mathrm{E}$ \\
\hline & Injeção & 5582192 & 2079822 & 1343093 & & 2717027 & Injeção & 4356000 & 3183263 \\
\hline
\end{tabular}


Tabela E.7 - Valores de concentração de partículas para o sistema DV em Partículas $/ \mathrm{m}^{3}$.

\begin{tabular}{|c|c|c|c|c|c|c|c|c|c|}
\hline \multicolumn{10}{|c|}{2 a $3 \mu \mathrm{m}$} \\
\hline \multirow{6}{*}{$3 A$} & $1 \mathrm{~A}$ & 1B & 1D & $1 \mathrm{E}$ & \multirow{6}{*}{ 3B } & $1 \mathrm{~A}$ & 1B & 1D & $1 \mathrm{E}$ \\
\hline & 64545010 & 37210000 & 46050700 & 39163333 & & 88516667 & 71713323 & 52066667 & 63133601 \\
\hline & $2 \mathrm{~A}$ & 2B & $2 D$ & $2 \mathrm{E}$ & & $2 A$ & 2B & $2 D$ & $2 \mathrm{E}$ \\
\hline & 41548333 & 32416667 & 51803333 & 31470000 & & 59520100 & 90725000 & 71676667 & 108363232 \\
\hline & $3 A$ & 3B & 3D & $3 E$ & & $3 A$ & 3B & 3D & $3 \mathrm{E}$ \\
\hline & Injeção & 82461667 & 98960000 & 98960000 & & 105066667 & Injeção & 69466667 & 48516667 \\
\hline \multicolumn{10}{|c|}{3 a $5 \mu \mathrm{m}$} \\
\hline \multirow{6}{*}{ 3A } & $1 \mathrm{~A}$ & 1B & 1D & $1 \mathrm{E}$ & \multirow{6}{*}{ 3B } & $1 \mathrm{~A}$ & 1B & 1D & $1 \mathrm{E}$ \\
\hline & 48506667 & 45280000 & 33501001 & 28466667 & & 71850000 & 66663323 & 43017000 & 41846667 \\
\hline & $2 \mathrm{~A}$ & 2B & 2D & $2 \mathrm{E}$ & & $2 \mathrm{~A}$ & 2B & 2D & $2 \mathrm{E}$ \\
\hline & 64173333 & 59616667 & 71826667 & 38340000 & & 59466667 & 63343339 & 61880000 & 42846667 \\
\hline & $3 A$ & 3B & 3D & $3 E$ & & $3 A$ & 3B & 3D & $3 E$ \\
\hline & Injeção & 63314526 & 42526667 & 65066667 & & 86543333 & Injeção & 62960000 & 31960100 \\
\hline \multicolumn{10}{|c|}{5 a $7 \mu \mathrm{m}$} \\
\hline \multirow{6}{*}{ 3A } & $1 \mathrm{~A}$ & 1B & 1D & $1 \mathrm{E}$ & \multirow{6}{*}{ 3B } & $1 \mathrm{~A}$ & 1B & 1D & $1 \mathrm{E}$ \\
\hline & 26173333 & 36198333 & 45258333 & 16666667 & & 39766667 & 41700304 & 28466667 & 18034001 \\
\hline & $2 A$ & 2B & 2D & \begin{tabular}{|l|}
$2 \mathrm{E}$ \\
\end{tabular} & & $2 \mathrm{~A}$ & 2B & $2 D$ & $2 \mathrm{E}$ \\
\hline & 52740080 & 48513343 & 51630020 & 16663323 & & 53733333 & 56166667 & 88113311 & 64283213 \\
\hline & $3 A$ & 3B & 3D & $3 E$ & & $3 A$ & 3B & 3D & $3 E$ \\
\hline & Injeção & 48537333 & 31816667 & 45273332 & & 48968657 & Injeção & 46666667 & 30200011 \\
\hline \multicolumn{10}{|c|}{7 a $10 \mu \mathrm{m}$} \\
\hline \multirow{6}{*}{$3 A$} & $1 \mathrm{~A}$ & 1B & 1D & $1 \mathrm{E}$ & \multirow{6}{*}{ 3B } & $1 \mathrm{~A}$ & 1B & 1D & $1 \mathrm{E}$ \\
\hline & 3846667 & 6283333 & 6006667 & 3333339 & & 14000022 & 10033333 & 7012458 & 5333231 \\
\hline & $2 A$ & $2 B$ & $2 \mathrm{D}$ & $2 \mathrm{E}$ & & $2 A$ & $2 B$ & $2 \mathrm{D}$ & $2 \mathrm{E}$ \\
\hline & 21946667 & 9500123 & 20001090 & 27263333 & & 11033783 & 11030000 & 18066667 & 5501001 \\
\hline & $3 A$ & 3B & 3D & $3 \mathrm{E}$ & & $3 A$ & $3 B$ & 3D & $3 \mathrm{E}$ \\
\hline & Injeção & 21746667 & 14571667 & 16066667 & & 13446373 & Injeção & 13875010 & 1301088 \\
\hline
\end{tabular}


Tabela E.8 - Valores das incertezas calculadas das concentrações de partículas para o sistema DV em Partículas $/ \mathrm{m}^{3}$.

\begin{tabular}{|c|c|c|c|c|c|c|c|c|c|}
\hline \multicolumn{10}{|c|}{2 a $3 \mu \mathrm{m}$} \\
\hline \multirow{6}{*}{$3 A$} & $1 \mathrm{~A}$ & 1B & 1D & $1 \mathrm{E}$ & \multirow{6}{*}{$3 B$} & $1 \mathrm{~A}$ & 1B & 1D & $1 \mathrm{E}$ \\
\hline & 5201423 & 3281922 & 3232710 & 3101736 & & 6101100 & 5660047 & 3591350 & 4995488 \\
\hline & $2 A$ & $2 B$ & 2D & $2 \mathrm{E}$ & & $2 A$ & $2 B$ & 2D & $2 \mathrm{E}$ \\
\hline & 3552383 & 3047329 & \begin{tabular}{|l|}
4638989 \\
\end{tabular} & 2418784 & & 5124497 & 8671133 & 6495770 & 8292612 \\
\hline & $3 A$ & 3B & 3D & $3 E$ & & $3 A$ & $3 B$ & $3 D$ & $3 E$ \\
\hline & Injeção & 7414128 & 9886104 & 11002967 & & 7315372 & Injeção & 7094353 & 3305246 \\
\hline \multicolumn{10}{|c|}{3 a $5 \mu \mathrm{m}$} \\
\hline \multirow{6}{*}{ 3A } & $1 \mathrm{~A}$ & 1B & 1D & $1 \mathrm{E}$ & \multirow{6}{*}{$3 B$} & $1 \mathrm{~A}$ & 1B & 1D & $1 \mathrm{E}$ \\
\hline & 4343287 & 4437440 & 2613000 & 2505067 & & 4952333 & 5261470 & 2965968 & 3311159 \\
\hline & $2 A$ & $2 B$ & 2D & $2 \mathrm{E}$ & & $2 A$ & $2 B$ & 2D & $2 \mathrm{E}$ \\
\hline & 6096467 & 6226961 & 7146753 & 3274236 & & 5121626 & 6054102 & 5607937 & 3278884 \\
\hline & $3 A$ & 3B & 3D & $3 E$ & & $3 A$ & 3B & 3D & $3 \mathrm{E}$ \\
\hline & Injeção & 6327000 & 4720460 & 8038336 & & 6025666 & Injeção & 6429853 & 2177307 \\
\hline \multicolumn{10}{|c|}{5 a $7 \mu \mathrm{m}$} \\
\hline \multirow{6}{*}{ 3A } & $1 \mathrm{~A}$ & 1B & 1D & $1 \mathrm{E}$ & \multirow{6}{*}{ 3B } & $1 \mathrm{~A}$ & 1B & 1D & $1 \mathrm{E}$ \\
\hline & 2151388 & 3256547 & 3240678 & 1346400 & & 3560707 & 4086600 & 2220400 & 1584000 \\
\hline & $2 A$ & $2 B$ & 2D & $2 \mathrm{E}$ & & $2 \mathrm{~A}$ & $2 B$ & 2D & $2 \mathrm{E}$ \\
\hline & 4599455 & 4317687 & 5885820 & 666130 & & 5104667 & 5866608 & 8789167 & 5489797 \\
\hline & $3 A$ & 3B & $3 D$ & $3 E$ & & $3 A$ & 3B & 3D & $3 E$ \\
\hline & Injeção & 4472104 & 2831683 & 3531320 & & 3843883 & Injeção & 5180000 & 3706200 \\
\hline \multicolumn{10}{|c|}{7 a $10 \mu \mathrm{m}$} \\
\hline \multirow{6}{*}{ 3A } & $1 \mathrm{~A}$ & 1B & 1D & $1 \mathrm{E}$ & \multirow{6}{*}{ 3B } & $1 \mathrm{~A}$ & 1B & 1D & $1 \mathrm{E}$ \\
\hline & 316187 & 565274 & 430101 & 269280 & & 1229200 & 981260 & 614950 & 522667 \\
\hline & $2 A$ & 2B & 2D & $2 \mathrm{E}$ & & $2 A$ & 2B & $2 \mathrm{D}$ & $2 \mathrm{E}$ \\
\hline & 1913969 & 845500 & 2280000 & 1089873 & & 1158500 & 1262384 & 1978300 & 524700 \\
\hline & $3 A$ & 3B & 3D & 3E & & $3 A$ & 3B & 3D & $3 E$ \\
\hline & Injeção & 2003847 & 1296878 & 1253200 & & 1189735 & Injeção & 1678875 & 113100 \\
\hline
\end{tabular}


Tabela E.9 - Valores de concentração de partículas para o sistema DV+PV2A em Partículas $/ \mathrm{m}^{3}$.

\begin{tabular}{|c|c|c|c|c|c|c|c|c|c|}
\hline \multicolumn{10}{|c|}{2 a $3 \mu \mathrm{m}$} \\
\hline \multirow{6}{*}{$3 A$} & $1 \mathrm{~A}$ & 1B & 1D & $1 \mathrm{E}$ & \multirow{6}{*}{ 3B } & $1 \mathrm{~A}$ & 1B & 1D & $1 E$ \\
\hline & 66158625 & 38326300 & 47431500 & 38380067 & & 89578867 & 77306973 & 55451000 & 59345333 \\
\hline & $2 A$ & 2B & 2D & $2 E$ & & $2 A$ & 2B & 2D & $2 \mathrm{E}$ \\
\hline & 24098033 & 31120000 & 52839400 & 34617000 & & 36890000 & 93560156 & 70673193 & 107062973 \\
\hline & 3A & 3B & 3D & $3 E$ & & $3 A$ & 3B & 3D & $3 E$ \\
\hline & Injeção & 85430287 & 106678880 & 95001600 & & 102965333 & Injeção & 73634667 & 49001833 \\
\hline \multicolumn{10}{|c|}{3 a $5 \mu \mathrm{m}$} \\
\hline \multirow{6}{*}{$3 A$} & $1 \mathrm{~A}$ & 1B & 1D & $1 E$ & \multirow{6}{*}{$3 B$} & $1 \mathrm{~A}$ & 1B & 1D & $1 E$ \\
\hline & 50446933 & 47996800 & 33332500 & 29890000 & & 72640350 & 66516674 & 38141000 & 45600313 \\
\hline & $2 A$ & 2B & 2D & $2 \mathrm{E}$ & & $2 A$ & 2B & 2D & $2 E$ \\
\hline & 41712667 & 61405167 & 71108400 & 38378340 & & 39604800 & 59859450 & 57610280 & 42091193 \\
\hline & $3 A$ & 3B & 3D & $3 \mathrm{E}$ & & $3 A$ & 3B & 3D & $3 E$ \\
\hline & Injeção & 65613333 & 45843747 & 62464000 & & 89355992 & Injeção & 63748944 & 29571908 \\
\hline \multicolumn{10}{|c|}{5 a $7 \mu \mathrm{m}$} \\
\hline \multirow{6}{*}{$3 A$} & $1 \mathrm{~A}$ & 1B & 1D & $1 \mathrm{E}$ & \multirow{6}{*}{ 3B } & $1 \mathrm{~A}$ & 1B & 1D & $1 E$ \\
\hline & 27492469 & 38293493 & 46112811 & 17902500 & & 41132415 & 44449131 & 29977450 & 16730496 \\
\hline & $2 A$ & 2B & 2D & $2 \mathrm{E}$ & & $2 A$ & 2B & 2D & $2 \mathrm{E}$ \\
\hline & 36918000 & 47543067 & 50494140 & 15679197 & & 37076000 & 57273150 & 87610280 & 60799078 \\
\hline & $3 A$ & 3B & 3D & $3 E$ & & $3 A$ & 3B & 3D & $3 E$ \\
\hline & Injeção & 51035508 & 31526788 & 45684828 & & 48520537 & Injeção & 50016307 & 30636673 \\
\hline \multicolumn{10}{|c|}{7 a $10 \mu \mathrm{m}$} \\
\hline \multirow{6}{*}{$3 A$} & $1 \mathrm{~A}$ & 1B & 1D & $1 \mathrm{E}$ & \multirow{6}{*}{ 3B } & $1 \mathrm{~A}$ & 1B & 1D & $1 E$ \\
\hline & 3796660 & 6409000 & 6066733 & 3323333 & & 13995475 & 10041935 & 6139459 & 5746642 \\
\hline & $2 A$ & 2B & 2D & $2 \mathrm{E}$ & & $2 A$ & 2B & 2D & $2 E$ \\
\hline & 16679467 & 9522325 & 20300000 & 28135760 & & 7855733 & 10306608 & 16631682 & 5313317 \\
\hline & $3 A$ & 3B & 3D & $3 \mathrm{E}$ & & $3 A$ & 3B & 3D & $3 E$ \\
\hline & Injeção & 22867833 & 14438906 & 16212698 & & 13981067 & Injeção & 13847250 & 1378000 \\
\hline
\end{tabular}


Tabela E.10 - Valores das incertezas calculadas das concentrações de partículas para o sistema DV+PV2A em Partículas $/ \mathrm{m}^{3}$.

\begin{tabular}{|c|c|c|c|c|c|c|c|c|c|}
\hline \multicolumn{10}{|c|}{2 a $3 \mu \mathrm{m}$} \\
\hline \multirow{6}{*}{$3 A$} & $1 \mathrm{~A}$ & 1B & 1D & $1 \mathrm{E}$ & \multirow{6}{*}{$3 B$} & $1 \mathrm{~A}$ & 1B & 1D & $1 \mathrm{E}$ \\
\hline & 5721566 & 3610114 & 3555981 & 3411910 & & 10282830 & 6230973 & 3962878 & 4794153 \\
\hline & $2 A$ & $2 B$ & $2 D$ & $2 \mathrm{E}$ & & $2 A$ & $2 B$ & $2 D$ & $2 \mathrm{E}$ \\
\hline & 3907621 & 3352062 & 5102887 & 2660663 & & 3217177 & 8326854 & 8056744 & 4279926 \\
\hline & $3 A$ & 3B & 3D & $3 E$ & & $3 A$ & 3B & 3D & $3 E$ \\
\hline & Injeção & 8155541 & 10874714 & 12103263 & & 3796413 & Injeção & 6553485 & 3822143 \\
\hline \multicolumn{10}{|c|}{3 a $5 \mu \mathrm{m}$} \\
\hline \multirow{6}{*}{$3 A$} & $1 \mathrm{~A}$ & 1B & 1D & $1 E$ & \multirow{6}{*}{$3 B$} & $1 \mathrm{~A}$ & 1B & 1D & $1 \mathrm{E}$ \\
\hline & 4734183 & 4836810 & 2848170 & 2730523 & & 8174945 & 5256148 & 2672349 & 3611545 \\
\hline & $2 A$ & 2B & $2 \mathrm{D}$ & $2 \mathrm{E}$ & & $2 A$ & 2B & $2 \mathrm{D}$ & $2 \mathrm{E}$ \\
\hline & 6645149 & 6787387 & 7789961 & 3568917 & & 3386210 & 5627088 & 5159001 & 3235129 \\
\hline & $3 A$ & 3B & 3D & $3 E$ & & $3 A$ & 3B & $3 D$ & $3 E$ \\
\hline & Injeção & 6896430 & 5145301 & 8761786 & & 6313001 & Injeção & 6368520 & 2049333 \\
\hline \multicolumn{10}{|c|}{5 a $7 \mu \mathrm{m}$} \\
\hline \multirow{6}{*}{$3 A$} & $1 \mathrm{~A}$ & 1B & 1D & $1 \mathrm{E}$ & \multirow{6}{*}{ 3B } & $1 \mathrm{~A}$ & 1B & 1D & $1 \mathrm{E}$ \\
\hline & 2345013 & 3549636 & 3532339 & 1467576 & & 277023 & 358803 & 172858 & 139392 \\
\hline & $2 A$ & 2B & 2D & $2 \mathrm{E}$ & & $2 A$ & 2B & 2D & $2 \mathrm{E}$ \\
\hline & 5013406 & 4706278 & 6415544 & 726082 & & 484943 & 612767 & 874522 & 468829 \\
\hline & $3 A$ & 3B & 3D & $3 \mathrm{E}$ & & $3 A$ & $3 B$ & $3 D$ & $3 E$ \\
\hline & Injeção & 4874593 & 3086535 & 3849139 & & 301745 & Injeção & 574980 & 285377 \\
\hline \multicolumn{10}{|c|}{7 a $10 \mu \mathrm{m}$} \\
\hline \multirow{6}{*}{$3 A$} & $1 \mathrm{~A}$ & 1B & 1D & $1 \mathrm{E}$ & \multirow{6}{*}{$3 B$} & $1 \mathrm{~A}$ & 1B & 1D & 1E \\
\hline & 379425 & 678329 & 516122 & 323136 & & 1292572 & 972320 & 620539 & 560183 \\
\hline & $2 A$ & 2B & $2 D$ & $2 \mathrm{E}$ & & $2 A$ & 2B & $2 D$ & $2 \mathrm{E}$ \\
\hline & 2296763 & 1014600 & 2736000 & 1307848 & & 1183086 & 996021 & 1950275 & 535835 \\
\hline & $3 A$ & 3B & 3D & $3 \mathrm{E}$ & & $3 A$ & $3 B$ & 3D & $3 E$ \\
\hline & Injeção & 2404616 & 1556254 & 1503840 & & 14701872 & Injeção & 13973109 & 1476910 \\
\hline
\end{tabular}


Tabela E.11 - Valores de concentração de partículas para o sistema DV+PV2B em Partículas $/ \mathrm{m}^{3}$.

\begin{tabular}{|c|c|c|c|c|c|c|c|c|c|}
\hline \multicolumn{10}{|c|}{2 a $3 \mu \mathrm{m}$} \\
\hline \multirow{6}{*}{$3 A$} & $1 \mathrm{~A}$ & 1B & 1D & $1 \mathrm{E}$ & \multirow{6}{*}{ 3B } & $1 \mathrm{~A}$ & 1B & 1D & $1 \mathrm{E}$ \\
\hline & 65497039 & 38709563 & 45059925 & 38763867 & & 87720017 & 70924487 & 53732800 & 55999267 \\
\hline & $2 A$ & $2 B$ & $2 D$ & $2 \mathrm{E}$ & & $2 \mathrm{~A}$ & $2 B$ & 2D & $2 \mathrm{E}$ \\
\hline & 48196067 & 16493600 & 53896188 & 30996062 & & 73506300 & 61511550 & 71584204 & 103909600 \\
\hline & $3 A$ & 3B & $3 D$ & $3 E$ & & $3 A$ & $3 B$ & 3D & $3 E$ \\
\hline & Injeção & 83721681 & 106465522 & 100701696 & & 92458667 & Injeção & 67695267 & 44635333 \\
\hline \multicolumn{10}{|c|}{3 a $5 \mu \mathrm{m}$} \\
\hline \multirow{6}{*}{ 3A } & $1 \mathrm{~A}$ & 1B & 1D & $1 \mathrm{E}$ & \multirow{6}{*}{ 3B } & $1 \mathrm{~A}$ & 1B & 1D & $1 \mathrm{E}$ \\
\hline & 50951403 & 47900806 & 34132480 & 30577470 & & 71124315 & 68196590 & 42871000 & 39503253 \\
\hline & $2 A$ & 2B & 2D & $2 \mathrm{E}$ & & $2 A$ & 2B & 2D & $2 \mathrm{E}$ \\
\hline & 75499927 & 30404500 & 71819484 & 36075640 & & 78496000 & 37309223 & 63111412 & 44071173 \\
\hline & $3 A$ & 3B & $3 D$ & $3 \mathrm{E}$ & & \begin{tabular}{|l|}
$\mathbf{B A}$ \\
\end{tabular} & 3B & $3 D$ & $3 E$ \\
\hline & Injeção & 64301067 & 45752059 & 66211840 & & 82475580 & Injeção & 68676738 & 28745780 \\
\hline \multicolumn{10}{|c|}{5 a $7 \mu \mathrm{m}$} \\
\hline \multirow{6}{*}{ 3A } & $1 \mathrm{~A}$ & 1B & 1D & $1 \mathrm{E}$ & \multirow{6}{*}{ 3B } & $1 \mathrm{~A}$ & 1B & 1D & $1 \mathrm{E}$ \\
\hline & 26984707 & 38676428 & 43807170 & 18081525 & & 39075794 & 40779397 & 29048571 & 15787181 \\
\hline & $2 A$ & 2B & 2D & $2 \mathrm{E}$ & & $2 A$ & 2B & 2D & $2 \mathrm{E}$ \\
\hline & 65925000 & 25197825 & 51504023 & 14039153 & & 65638680 & 37654493 & 88610280 & 61799078 \\
\hline & $3 A$ & 3B & $3 D$ & $3 E$ & & $3 A$ & 3B & 3D & $3 E$ \\
\hline & Injeção & 44911247 & 34048931 & 44519865 & & 53372590 & Injeção & 48619039 & 28115275 \\
\hline \multicolumn{10}{|c|}{7 a $10 \mu \mathrm{m}$} \\
\hline \multirow{6}{*}{ 3A } & $1 \mathrm{~A}$ & 1B & 1D & $1 \mathrm{E}$ & \multirow{6}{*}{ 3B } & $1 \mathrm{~A}$ & 1B & 1D & $1 \mathrm{E}$ \\
\hline & 3892827 & 6346167 & 5994653 & 33811254 & & 13304256 & 11042935 & 6699840 & 4833280 \\
\hline & $2 A$ & 2B & 2D & $2 \mathrm{E}$ & & $2 A$ & 2B & 2D & $2 \mathrm{E}$ \\
\hline & 26994400 & 6650120 & 19720070 & 27917653 & & 13981440 & 7941600 & 17689146 & 5438458 \\
\hline & $3 A$ & 3B & 3D & $3 \mathrm{E}$ & & $3 A$ & 3B & 3D & $3 \mathrm{E}$ \\
\hline & Injeção & 24635517 & 14035537 & 14878393 & & 14435451 & Injeção & 14020768 & 1275034 \\
\hline
\end{tabular}


Tabela E.12 - Valores das incertezas calculadas das concentrações de partículas para o sistema DV+PV2B em Partículas $/ \mathrm{m}^{3}$.

\begin{tabular}{|c|c|c|c|c|c|c|c|c|c|}
\hline \multicolumn{10}{|c|}{2 a $3 \mu \mathrm{m}$} \\
\hline \multirow{6}{*}{ 3A } & $1 \mathrm{~A}$ & 1B & 1D & $1 \mathrm{E}$ & \multirow{6}{*}{$3 B$} & $1 \mathrm{~A}$ & 1B & 1D & $1 \mathrm{E}$ \\
\hline & 5435487 & 3429608 & 3378182 & 3241314 & & 6824617 & 6227170 & 4183098 & 4927935 \\
\hline & $2 A$ & 2B & 2D & $2 \mathrm{E}$ & & $2 \mathrm{~A}$ & 2B & 2D & $2 \mathrm{E}$ \\
\hline & 3712240 & 3184459 & 4847743 & 2527629 & & 6983099 & 6424881 & 7122628 & 8873880 \\
\hline & $3 A$ & 3B & 3D & $3 E$ & & $3 A$ & 3B & 3D & $3 E$ \\
\hline & Injeção & 7747764 & 10330979 & 11498100 & & 7258005 & Injeção & 7514175 & 3436921 \\
\hline \multicolumn{10}{|c|}{3 a $5 \mu \mathrm{m}$} \\
\hline \multirow{6}{*}{$3 A$} & $1 \mathrm{~A}$ & 1B & 1D & $1 \mathrm{E}$ & \multirow{6}{*}{ 3B } & $1 \mathrm{~A}$ & 1B & 1D & $1 \mathrm{E}$ \\
\hline & 4562189 & 4694279 & 2662333 & 2690817 & & 6244715 & 6669627 & 3766217 & 3871319 \\
\hline & $2 A$ & $2 \mathrm{~B}$ & 2D & $2 \mathrm{E}$ & & $2 A$ & \begin{tabular}{|l|}
$2 B$ \\
\end{tabular} & $2 \mathrm{D}$ & $2 \mathrm{E}$ \\
\hline & 7172493 & 3175750 & 7146039 & 3080860 & & 8242080 & 4270041 & 6910700 & 4204390 \\
\hline & $3 A$ & $3 B$ & $3 D$ & $3 E$ & & $3 A$ & 3B & $3 D$ & $3 E$ \\
\hline & Injeção & 6423677 & 5078479 & 8179811 & & 7299089 & Injeção & 8309885 & 2500883 \\
\hline \multicolumn{10}{|c|}{5 a $7 \mu \mathrm{m}$} \\
\hline \multirow{6}{*}{ 3A } & $1 \mathrm{~A}$ & $1 \mathrm{~B}$ & 1D & $1 \mathrm{E}$ & \multirow{6}{*}{ 3B } & $1 \mathrm{~A}$ & 1B & 1D & $1 \mathrm{E}$ \\
\hline & 2416211 & 3790290 & 3416959 & 1591174 & & 3430855 & 3988225 & 2551917 & 1547144 \\
\hline & $2 A$ & 2B & 2D & $2 \mathrm{E}$ & & $2 A$ & 2B & 2D & $2 \mathrm{E}$ \\
\hline & 6262875 & 2631913 & 5124650 & 1198944 & & 6892061 & 4309557 & 9702826 & 5895632 \\
\hline & $3 A$ & 3B & 3D & $3 E$ & & $3 A$ & 3B & 3D & $3 E$ \\
\hline & Injeção & 4486634 & 3779431 & 5499984 & & 4723474 & Injeção & 5882904 & 2446029 \\
\hline \multicolumn{10}{|c|}{7 a $10 \mu \mathrm{m}$} \\
\hline \multirow{6}{*}{$3 A$} & $1 \mathrm{~A}$ & 1B & 1D & $1 \mathrm{E}$ & & $1 \mathrm{~A}$ & 1B & 1D & $1 \mathrm{E}$ \\
\hline & 303540 & 542663 & 412897 & 258509 & & 1193044 & 1069552 & 668507 & 544533 \\
\hline & $2 A$ & $2 B$ & 2D & $2 \mathrm{E}$ & & $2 A$ & $2 B$ & $2 \mathrm{D}$ & $2 \mathrm{E}$ \\
\hline & 1837410 & 811680 & 2188800 & 1046278 & & 1085718 & 745148 & 1966798 & 568704 \\
\hline & $3 A$ & $3 B$ & 3D & $3 E$ & & $3 A$ & $3 B$ & 3D & $3 E$ \\
\hline & Injeção & 1923693 & 1245003 & 1203072 & & 1624566 & Injeção & 982365 & 100983 \\
\hline
\end{tabular}

